\title{
New Design Guidelines for Mobile Learning Application: A Transactional Distance Perspective
}

\author{
by \\ Pakapan Limtrairut
}

\author{
A thesis \\ submitted to the Victoria University of Wellington \\ in fulfilment of the \\ requirements for the degree of \\ Doctor of Philosophy \\ in Computer Engineering. \\ Victoria University of Wellington \\ 2018
}





\begin{abstract}
M-learning is the approach of using mobile device such as mobile phones to help users engage with learning content. M-learning software exists, but does not have high uptake especially compared to e-learning. One reason for this could be the lack of a model to combine learning theories with best practice in user interface design. One such learning theory relevant to mobile learning is Transactional Distance Theory (TDT). TDT identifies a number of key aspects and the concept of transactional distance. The thesis contributed an analysis of how TDT can be combined with both general and mobile specific usability guidelines. This thesis also contributes a multi-stage evaluation using both test subjects and experts to access both the model and proof-of-concept prototypes. Based on the results of our analysis and experience with designing, developing, and evaluating prototypes, we proposed a set of design guidelines that could be used to develop engaging m-learning applications that may improve uptake.
\end{abstract}





\section{Contents}

1 Introduction 1

1.1 Problem context . . . . . . . . . . . . . . . 3

1.2 Methodology ................... 4

1.3 Contributions .................. 7

1.4 Scope and Limitations . . . . . . . . . . . . . . . . . . . . . . . . . . . .

1.5 Thesis Structure Outline . . . . . . . . . . . . . . . . . . . 9

1.6 Publications ..................... 11

2 Literature Review $\quad 13$

2.1 Mobile Learning . . . . . . . . . . . . . . . . . . 13

2.1.1 M-learning and other forms of learning . . . . . . . 14

2.1.2 Potentials of Mobile Learning . . . . . . . . . . . . . 18

2.1.3 Challenges of Mobile Learning \& Proposed Solutions 23

2.1.4 M-learning Design Guidelines . . . . . . . . . . . 34

2.2 Transactional Distance Theory . . . . . . . . . . . . . . 36

2.2.1 Development of Transactional Distance Theory . . . 37

2.2.2 Elements of Transaction Distance Theory . . . . . . . 42

2.2.3 Applications of Transactional Distance Theory . . . . 47

2.3 Learner Autonomy \& Measurement . . . . . . . . . . . . . 52

2.3.1 Components of learner autonomy . . . . . . . . . . . . 52

2.3.2 Measuring learner autonomy . . . . . . . . . . 55

2.4 Other Learning Theories . . . . . . . . . . . . . . . . . 57

2.4.1 Cognitive Load Theory . . . . . . . . . . . 57 
2.4.2 Self Determination Theory . . . . . . . . . . . 59

2.4.3 Media Richness Theory . . . . . . . . . . . . . 61

2.4.4 Learning Theory of Andragogy . . . . . . . . . . . . 62

2.4.5 Activity \& Cultural-Historical Activity Theory . . . . 65

2.5 Student Engagement \& Measurement . . . . . . . . . . 68

2.5.1 Definition of Engagement . . . . . . . . . . . . . . . . . 69

2.5.2 Measuring Engagement . . . . . . . . . . 70

2.6 Usability Design . . . . . . . . . . . . . . . . 71

2.6.1 Basic Design Checklist . . . . . . . . . . . . 72

2.6.2 Eight Golden Rules of Interface Design . . . . . . . . 74

2.6.3 Heuristic Evaluation . . . . . . . . . . . . . . 77

2.7 Learner Persona \& Scenario . . . . . . . . . . . . . . . . 82

3 User Study \& Persona $\quad 87$

3.1 Methodology . . . . . . . . . . . . . . . 88

3.2 Quantitative Results . . . . . . . . . . . . . . . . 91

3.2.1 Graphical Clustering Technique . . . . . . . . . . . . 91

3.2.2 K-means Clustering Technique . . . . . . . . . . . 94

3.3 Qualitative Findings . . . . . . . . . . . . . . . . . . . . . . . 98

3.3.1 Mobile Phones Usages . . . . . . . . . . . . . . . 98

3.3.2 Mobile Learning Goals . . . . . . . . . . . . . . . . 99

3.4 Personas . . . . . . . . . . . . . . . . . . . 100

3.5 Discussion . . . . . . . . . . . . . . . 106

3.6 Feasibility Analysis . . . . . . . . . . . . . . . . . . 108

3.7 Summary . . . . . . . . . . . . . . . . . . 110

4 First Design guidelines \& Prototype Development 111

4.1 Adapting TDT to M-learning . . . . . . . . . . . . . . 112

4.2 Contributions of other learning theories . . . . . . . . . 118

4.3 Usability Design of M-learning . . . . . . . . . . . . . . 121

4.4 First M-learning Design Guidelines . . . . . . . . . . . . . 123

4.5 First Prototype Design . . . . . . . . . . . . . . . . . 125 
4.6 Guidelines and prototype analysis . . . . . . . . . . . 136

4.7 Summary . . . . . . . . . . . . . . . . 138

5 First Prototype Evaluation $\quad 139$

5.1 Hypotheses . . . . . . . . . . . . . . . . . . . 139

5.2 Evaluation Process . . . . . . . . . . . . . . . . . 140

5.2.1 Participant Recruitment . . . . . . . . . . . . . 140

5.2.2 Participant Observation and Data Collection . . . . . 141

5.3 Quantitative Results . . . . . . . . . . . . . . . . 147

5.3.1 Learner Autonomy . . . . . . . . . . . . . . . . 147

5.3 .2 Student Engagement . . . . . . . . . . . . . . . 149

5.3.3 Six concepts of student engagement . . . . . . . . . 154

5.3.4 Correlation between Autonomy and Engagement . . 156

5.4 Qualitative Findings . . . . . . . . . . . . . . . . . 160

5.4.1 Hierarchical learning content design . . . . . . . . . 160

5.4 .2 Media Presentation . . . . . . . . . . . . . 162

5.4 .3 Learning support functions . . . . . . . . . . . . 163

5.5 Limitations . . . . . . . . . . . . . . . . . . . . . . . 168

5.6 Results and Findings Analysis . . . . . . . . . . . . . . . 171

5.7 Summary . . . . . . . . . . . . . . . . . . 174

6 Heuristic Evaluation $\quad 175$

6.1 M-learning Heuristics Development . . . . . . . . . . . . . 175

6.2 Applicability of the M-learning Heuristics . . . . . . . . . . . 183

6.2.1 Methodology . . . . . . . . . . . . 183

6.2.2 Heuristic evaluation findings . . . . . . . . . . . 186

6.2 .3 Analysis . . . . . . . . . . . . . . . . 192

6.3 Summary .......................... 195

7 Second Design Guidelines \& Prototype Development 197

7.1 Second M-learning Design Guidelines . . . . . . . . . . . . . 198

7.2 Second Prototype Design . . . . . . . . . . . . . . 206 
7.3 Summary . . . . . . . . . . . . . . . . . 222

8 Second Prototype Evaluation 223

8.1 Hypotheses . . . . . . . . . . . . . . . . . . 224

8.2 Evaluation Process . . . . . . . . . . . . . . . . . 225

8.2.1 Participant recruitment . . . . . . . . . . . 225

8.2.2 Participant Observation and Data Collection . . . . . 226

8.3 Quantitative Results . . . . . . . . . . . . . . . . . . 229

8.3.1 Learner Autonomy . . . . . . . . . . . . . . . . . . 229

8.3.2 Student engagement . . . . . . . . . . . . 231

8.3.3 Six concepts of student engagements . . . . . . . 238

8.3.4 Correlation between Learner Autonomy and Student Engagement . . . . . . . . . . . . . . 240

8.3.5 Average usability . . . . . . . . . . . . . . 243

8.4 Qualitative Findings . . . . . . . . . . . . . . . . 247

8.4.1 Menus and learning content interface design . . . . . 247

8.4.2 Media Presentation . . . . . . . . . . . . . . 252

8.4.3 Learning-support features . . . . . . . . . . . . 255

8.4.4 Variants in the average engagement level value . . . 260

8.5 Limitations . . . . . . . . . . . . . . . . . . . . . . . . 261

8.6 Results and Findings Analysis . . . . . . . . . . . . . 263

8.7 Summary . . . . . . . . . . . . . . . . 266

9 Conclusion $\quad 269$

9.1 Contributions . . . . . . . . . . . . . . . . . 269

9.1.1 Critique towards TDT . . . . . . . . . . 270

9.1.2 M-learning design guidelines . . . . . . . . . . 270

9.1.3 Proof-of-concept prototype design . . . . . . . . . 273

9.2 Response to research questions . . . . . . . . . . . . 276

9.3 Comparison with related works . . . . . . . . . . . . 277

9.4 Future Work . . . . . . . . . . . . . . . . . . . 278

9.4.1 M-learning design guidelines . . . . . . . . . 278 
9.4 .2 Mobility . . . . . . . . . . . . . . . 280

9.4 .3 Guidelines improvement . . . . . . . . . . . . . 280

9.5 Summary . . . . . . . . . . . . . . . . . . . . . 281 



\section{List of Figures}

1.1 Research process cycle . . . . . . . . . . . . . . . . 5

$2.1 \quad$ M-learning as a part of other learning $\ldots \ldots \ldots \ldots$

2.2 Picca's educational activities in research study by Fernández-López et al. (2013) [42] . . . . . . . . . . . . 20

2.3 EasyLexia's activities created in a research study by Skiada et al. (2014) [128] . . . . . . . . . . . . . . . . . . . . 21

2.4 Desktop and mobile versions of e-learning platform Udemy. The screen shots were taken from https://www.udemy.com/ and Udemy application downloaded from Apple App store . . . . . . . . . . . . . 28

2.5 Desktop and mobile versions of e-learning platform edX. The screen shots were taken from https://www.edx.org/ and edX application downloaded from Apple App store . . 29

2.6 Comparison of early mobile phones and recent smart phones' keyboard and communication features . . . . . . . . 30

2.7 Apple's iPhone screen size and its ability to zoom with twofingers gestures for reading small text . . . . . . . . . . 31

2.8 Security Agent (SA) strategy in SEMS by Kaiiali et al. (2016)[62] . . . . . . . . . . . . . . . . . . . . 32

2.9 Teaching-learning relationship of distance education programs defined by Moore (1983) [89]. "A" represented a teacher while "B", "C", "D", and "E" represented learners. . . 39 
2.10 Moore's (2013) [94, pp. 73] Three-dimension autonomy classification of distance program . . . . . . . . . . . 41

2.11 Moore's (1980) [89, pp. 73] Typology of educational program classification ... . . . . . . . . . 42

2.12 Two dimension of relationship between transactional distance, dialogue and structure by Moore (2013) [94, pp. 71] 45

2.13 Moore's (1993) [93] illustration of relationship between transactional distance and learner autonomy . . . . . . . 46

2.14 Littlewood's (1996) [78] components of autonomy[78] . . . . 53

2.15 E-learning course designs by Sun \& Cheng (2007) [133] . . . 63

2.16 Example of a personal-mobile knowledge and learning organisation system [139] . . . . . . . . . . . . 66

2.17 Screenshots of "iLearn Geography" a m-learning application downloaded from Apple's app store . . . . . . . . . 73

3.1 Graphical clustering process . . . . . . . . . . . . . 93

3.2 Silhouette plots to find the appropriate number for cluster (K) 95

3.3 The most appropriate participant to represent the rest of the participants in its cluster . . . . . . . . . . . . 97

3.4 John persona created with graphical clustering technique . . 102

3.5 Annie persona (secondary) created with K-means clustering technique . . . . . . . . . . . . . . 103

3.6 Stephen persona (secondary) created with K-means clustering technique . . . . . . . . . . . . . . 104

3.7 Clara persona (primary) created with K-means clustering technique .................... 105

4.1 Software architecture of the prototype . . . . . . . . . 126

4.2 iPhone $6 \mathrm{~s}^{\prime}$ hardware specifications ${ }^{1} \ldots$. . . . . . . . . . 127

4.3 Examples of how the learning content was presented . . . . 129

4.4 Chat function design . . . . . . . . . . . . . . . . 131

4.5 Game-based learning design . . . . . . . . . . . . . . 132 
4.6 Assignment (compulsory) design . . . . . . . . . . . . . 132

4.7 Text media . . . . . . . . . . . . . . . . . . . 133

4.8 Examples of available recorded-audio media . . . . . . . . . 134

4.9 Examples of animation video media . . . . . . . . . . . . . 134

4.10 Feedback given in quiz game . . . . . . . . . . . . 135

5.1 Participant observation and data collection process . . . . . 142

5.2 Comparison of P1_1 and P1_2 prototypes . . . . . . . . . . 146

5.3 Average engagement levels of P1_1 and P1_2 . . . . . . . . . 150

5.4 Average learner autonomy level value of P1_1 and P1_2 . . . 153

5.5 Average engagement level for each engagement concept measured against prototype P1_1 and P1_2 . . . . . . . 155

5.6 Graphical illustration of learner autonomy and student engagement for participants who used prototypes P1_1 and P1_2 . . . . . . . . . . . . . . . . . . 159

5.7 Pop-up buttons and labels . . . . . . . . . . . . . . 161

5.8 Chat conversations between the participants and the researcher . . . . . . . . . . . . . . . 164

5.9 Examples of the assignment answers sent from the participants to the researcher's email . . . . . . . . . . 167

5.10 Screen captures of moments when the mobile phone's screen were blocked or out of frame . . . . . . . . . 170

6.1 Visual presentation on how the guideline was constructed from Nielson [97], Reeves et al. [113] and Yanez et al.[143] 178

6.2 Storytelling format of the persona profile adapted from the primary persona, Clara, presented in chapter 3 . . . . . . 184

7.1 Adjustment and incorporation of the 16 developed heuristics into the first design guidelines . . . . . . . . 200

7.2 Learning content presentation of the second prototype . . . 208

7.3 The second prototype chat room design . . . . . . . . . . . 210 
7.4 Chat feature interface design improvements . . . . . . . . . 211

7.5 The second prototype game design . . . . . . . . . . . . 212

7.6 Compulsory assignments in the second prototype . . . . . . 214

7.7 The second prototype's media presentation . . . . . . . . . 215

7.8 The second prototype visual design . . . . . . . . . . 217

7.9 Navigation control . . . . . . . . . . . . . . . . . 217

7.10 Provided links to resources from inside the prototype . . . . 221

8.1 Comparison of P2_1 and P2_2 prototypes . . . . . . . . . . 227

8.2 Average engagement levels of prototypes P2_1 and P2_2 . . 232

8.3 Silhouette plots to find the appropriate number of cluster (K) for prototype P2_1 . . . . . . . . . . . . . 235

8.4 Silhouette plots to find the appropriate number of cluster (K) for prototype P2_2 . . . . . . . . . . . . . 235

8.5 Average learner autonomy level values of prototypes P2_1

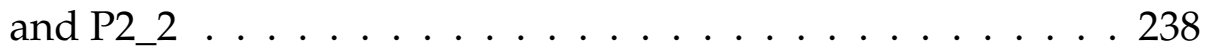

8.6 Average engagement level for each engagement concept measured against prototypes P2_1 and P2_2 . . . . . . . 239

8.7 Graphical illustration of learner autonomy and student engagement for participants who used prototype P2_1 and P2_2 . . . . . . . . . . . . . . . . . . 242

8.8 Average usability level of prototypes P2_1 and P1_1 . . . . 245

8.9 Average usability level of prototypes P2_2 and P1_2 . . . . 246

8.10 Learning content presentation . . . . . . . . . . . . . 251

8.11 Chat conversations between the participants and the researcher ...................... 256

8.12 Assignment 1 and some example answers . . . . . . . . . . 258

8.13 assignment 2 and some example answers . . . . . . . . . 259 


\section{List of Tables}

4.1 Transformation of TDT definitions and applicability from original distance education to m-learning context . . . . . . 113

4.2 Applying Moore's (1993) [93] instructional processes using mobile devices in m-learning environment . . . . . . . . 117

4.3 The first iteration of m-learning design guidelines developed based on the principles of transactional distance and other learning theories . . . . . . . . . . . . . 123

5.1 Average level of motivation and confidence level of each participant . . . . . . . . . . . . . . 148

5.2 Average engagement level and standard deviation of P1_1

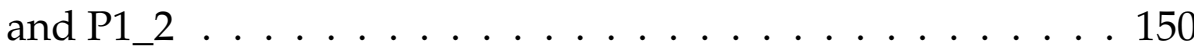

5.3 Average learner autonomy level value and standard deviation of prototype P1_1 and P1_2 . . . . . . . . . . 153

5.4 Average engagement level for each engagement concept measured against prototypes P1_1 and P1_2 . . . . . . . . 155

5.5 Autonomy and engagement level for each participant who used prototype P1_1 . . . . . . . . . . . . . . . . . 158

5.6 Autonomy and engagement level for each participant who used prototype P1_2 . . . . . . . . . . . . . . . . 159

6.1 Newly developed heuristics to evaluate interface design of m-learning application . . . . . . . . . . . . . . 179 
7.1 The second m-learning design guidelines . . . . . . . . . 201

8.1 Average level of motivation and confidence for each participant . . . . . . . . . . . . . 230

8.2 Average engagement level and standard deviation of prototypes P2_1 and P2_2 . . . . . . . . . . . . . . 231

8.3 Average engagement level value for the 3 clusters of prototype P2_1 . . . . . . . . . . . . . 236

8.4 Average engagement level value for the 2 clusters of prototype P2_2 . . . . . . . . . . . . . 236

8.5 Average learner autonomy level value and standard deviation of prototypes P2_1 and P2_2 . . . . . . . . . 237

8.6 Average engagement level value and standard deviation for each engagement concept measured against prototypes P2_1 and P2_2 . . . . . . . . . . . . . . . . . . 239

8.7 Average autonomy and average engagement level for each participant who used prototype P2_1 . . . . . . . . . 241

8.8 Average autonomy and average engagement level for each participant who used prototype P2_2 . . . . . . . . . . 242

8.9 Average usability level and standard deviation of prototypes P2_1 and P1_1 . . . . . . . . . . . . . . 245

8.10 Average usability level and standard deviation of prototypes P2_2 and P1_2 . . . . . . . . . . . . 246 


\section{Chapter 1}

\section{Introduction}

Soon upon waking up in the morning, university student Stephen grabs his mobile phone and checks for incoming e-mails, unread-messages, and social media network updates. He gets ready to head to university. Last minute before departing, he uses a mobile application on his mobile phone to check his class schedules and confirm the bus schedule. On his way to the bus station, he listens to music on his mobile phone. He also texts his classmates about meeting up for lunch and replies to a discussion board thread about assignments that are due the next day. Using another mobile application, Stephen creates a list of assignments and sets submission notifications for each assignment. After class, he gets together with his classmates and work on a group assignment together. They discuss their response to the assignment topic, and each person record notes on their own laptop. On the way back from university, Stephen posts on a closed group chat-room reminding his classmates about the assignment's due date. With his study and course work organised for the day, he relaxes and watches live streaming music videos.

The advance of mobile technology along with the wide-spread popularity of mobile devices have transformed our societies and altered many facets of our lives. In response to this transformation, more educational 
institutions are extending their education platforms to encompass mobile-based learning and teaching. For example, in 2014, the University of South Australia piloted a location-based mobile learning game in a core undergraduate business course [114] and the Florida International University [43] and Stanford University [131] leveraged smart phones to provide students with access to learning resources such as recorded-video lectures and digital library, and created collaborative learning. This allows students to obtain knowledge regardless of their geographic locations.

The importance of distance learning is highlighted by its potential to reach a large audience, especially people who suffered from various barriers inhibiting their access to education such as locations of available schools, cost of studying, language barrier, and gender inequality. Mobile devices have the potential to reduce some of these barriers by assisting students at any level in accessing learning materials, promote distance teaching and learning globally.

Although mobile devices have the potential to promote distance learning and teaching, they are not purposefully designed to be educational tools. Owing to the need to ensure mobility when using these devices, the entailing hardware and software limitations present unique challenges when mobile devices are being used in educational context. Compare to traditional desktop computers or laptops, it is more difficult for mobile devices to deliver large quantities of learning content and provide advanced application functionalities or features to support such content. These limitations serve as a reminder that shifting educational platforms to mobile learning requires deliberate planning and considerations.

This thesis aims to establish a set of design guidelines grounded in learning principles to drive effective design and evaluation for mobile learning applications, and address some of the limitations of using mobile devices as educational tools for distance learning and teaching. 


\subsection{Problem context}

Mobile learning or m-learning is a subset of e-learning. Owing to the advances and rapid development of mobile technologies and devices such as mobile phones, tablets, and Personal Digital Assistants (PDAs) to support the process of learning and teaching, m-learning has remarkable potentials as a mode of education, such as facilitating personalised learning, supporting a cooperative learning environment where many students and their instructors are physically remote from each other, and providing flexibility around learning time and locations for students.

Despite these promises, m-learning faces some important challenges, and more so than e-learning due to software and hardware limitations associated with mobile devices (e.g., small screen size, low screen resolution, lack of efficient data entry capability, small storage, slow processing speed, and short battery life). Furthermore, same as e-learning, m-learning has pedagogical complexity. It is difficult to track students' learning efficiency and engagement because m-learning enables their learning process to occur without instructors' supervision. Although there are various researches focus on developing m-learning applications, only a few established design guidelines based upon learning principles to address this complexity.

Transactional Distance Theory (TDT) is a long-standing theory primarily applied in the field of distance education. According to the theory, students feel disconnected and isolated when they were physically separated from their instructors and other students. It introduced three contributing factors, namely dialogue, course structure, and learner autonomy.

This thesis formed a set of design guidelines based on the principles of TDT. It also evaluated TDT's actual applicability to guide the design of m-learning application by creating an m-learning application prototype based on these developed design guidelines tailored to match the learner 
autonomy of the target learners. This process aimed to observe:

1. "Can TDT principles be used to construct design guidelines that will

affect student engagement on m-learning education application?"

While the TDT provides distance learning principles, it does not deal with interface design techniques that are crucial to the success of any application. As a result, the thesis drew upon heuristic evaluation and a new m-learning heuristics developed based on other heuristics created for evaluating general software, e-learning application, and general mobile devices. The heuristic evaluation formed the interface design and usability aspects of this thesis' theoretical guidelines, from which the following observation is considered:

2. "Can m-learning heuristics usability be used to complement TDT-based design guidelines and affect student engagement?"

Lastly, TDT also emphasises the importance of "Learner Autonomy" on students' learning effectiveness. At the application's evaluation stage, the thesis observed:

3. "Is there any correlation between learner autonomy and student engagement?"

\subsection{Methodology}

The m-learning application design guidelines are developed based on outputs from three phases. In order to validate the completeness and efficacy of the developed guidelines, all three phases were repeated once in the second iteration. Figure 1.1 illustrates the research process.

Guidelines Development: the first phase focused on establishing the design guidelines. In addition to ensuring the quality of the m-learning 


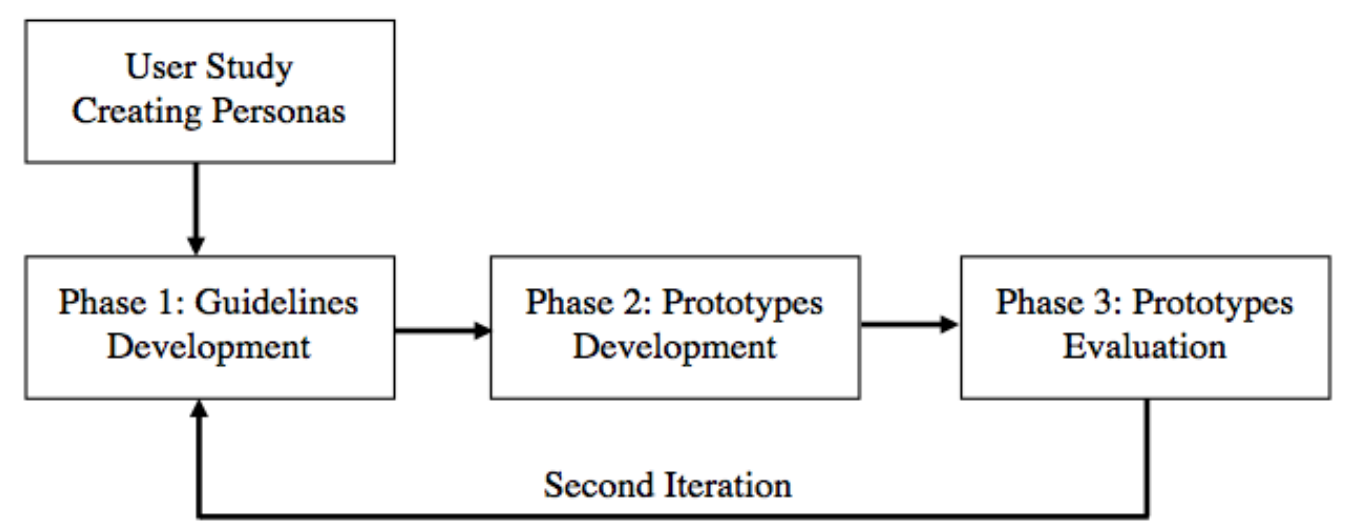

Figure 1.1: Research process cycle

application, identifying and understanding target users is also critical to the success of the design, particularly at the early stage of the application development process. It facilitates the selection of appropriate and meaningful learning content that can be delivered on mobile technology with limited resources, while highlighting the necessary adjustments required to match students' preferences and abilities. As a result, a User Study was launched in an effort to understand our target m-learning application users and their learner autonomy characteristics. This study was carried out via an online survey targeted at first year computer science and engineering students at Victoria University of Wellington, New Zealand.

In the first iteration, theoretical guidelines were developed based on the principles of TDT and the findings from the user study. TDT was published in the general context of distance education. During this phase, the research process examined how the theory could be adjusted to guide the design of modern m-learning application. Other learning theories that could complement TDT were also reviewed and analysed on their applicability in an m-learning context.

The second iteration of the guidelines were developed by refining learner autonomy based on observations from the first iteration, and 
incorporating interface design techniques (i.e., heuristic evaluation) into the theoretical design guidelines developed in the first iteration.

Prototypes Development: the second phase of the research process was focused on designing m-learning application prototypes using the design guidelines and user study findings developed in the first phase.

In order to compare if the guidelines developed based on TDT could engage students during their learning process, two prototypes were created. One prototype followed the TDT guidelines and provided learning support mechanisms as suggested by TDT, whereas the other prototype did not incorporate any of such mechanism. Both prototypes used the same interface design and presented the same learning content, with the purpose of eliminating usability as a variable that could influence the comparison process.

Prototypes Evaluation: the last phase of the research process focused on evaluating learner autonomy and the prototypes. A combination of the researcher's observation and a pre-questionnaire were used to measure learner autonomy before participants began learning using the prototype. A post-questionnaire was used to measure student engagement after they finished their study using the prototype.

As a part of learner autonomy observation, a researcher observed if the participants had knowledge and skills to perform some m-learning related tasks such as connecting a smart phone to an available WiFi network, sending a text message, and managing notifications received from the mobile phone's calendar application. These tasks were listed in various literature as required tasks for m-learning. The pre- and post-questionnaires were developed based on learner autonomy and student engagement measuring scales offered by various literature. This formed the quantitative measurement of students' self-evaluation of their motivation and confidence towards m-learning (as another part of the learner autonomy measurement) and how well they engaged with the prototypes. 
Additionally, video recordings of students interacting with the prototypes were captured as part of the interface design evaluation, and formed the qualitative findings of this thesis. An online analytics tool (i.e., Google Analytics for mobile devices) was used to track and report on the students' tasks performance statistically as a backup evaluation tool.

The quantitative results and qualitative findings from each prototype were compared and analysed. These results helped determine the practicality, possibility, and appropriateness of the theoretically-based design guidelines, and whether the prototype developed based on these guidelines could engage students better than the other prototype where such implementation was absent. Furthermore, the results act as an assessment mechanism to determine the efficacy of the application's interface design, and to gage any potential relationship between learning autonomy and student engagement.

\subsection{Contributions}

This thesis makes three contributions to m-learning:

1. Draws on TDT to contribute to new design knowledge with emphasis on the concept of dialogue, course structure, and learner autonomy, which can be incorporated into the design and evaluation process of m-learning applications.

2. Develops new proof-of-concept prototypes for m-learning application based on learning principles and empirical studies to ensure learning engagement.

3. Presents a critique towards the appropriateness, ability, and possibility of TDT in guiding the design of modern education platform such as m-learning. 


\subsection{Scope and Limitations}

To evaluate the guidelines, an m-learning application was designed for a specific smart phone. Its specifications formed a defined scope for measuring participants' performance, developing suitable interface design and incorporating proposed design suggestions.

Learning content presented in the application are based on curriculum for undergraduate degree programs within the field of Computer Science and Computing-based Engineering. These subjects were chosen based on their relevance to students but not already taught. There was no prior assessment of participants' interests in these subjects, which might have an effect on their level of attention and engagement to learning the subjects via the application.

A reward strategy (i.e., grocery voucher) was employed to recruit student participants, encourage them to be motivated and be willing to interact with the m-learning application in ways that would be comparable to a real-life application user. This strategy may have some influence on the outcome of the "learner autonomy" evaluation. Results collected from the Prototype Evaluation phase indicated the absence of any participant with low autonomy level.

In the first evaluation iteration, an erroneous function within the application required participants to reset the application in order to continue with their learning process. The potential effect of this defect on participants' engagement with the first iteration application prototype have been documented in the relevant analysis and results sections. This defect was resolved in the second iteration prototypes. 


\subsection{Thesis Structure Outline}

Chapter 2 - Background and Related Work defines m-learning and presents its potentials and challenges. This chapter introduces TDT and its relevant elements: dialogue, course structure, and learner autonomy, upon which the m-learning guidelines proposed by this thesis would be developed. It further defines the concepts of learner autonomy and student engagement, which are the key evaluation criteria for m-learning applications. It also investigates relevant literature to form learner autonomy and student engagement's evaluation scales.

This chapter explores existing studies on teaching and learning involving TDT, and other learning theories with the potential to complement the TDT in the guidelines development process. It discusses existing interface and heuristic design guidelines, and examines current m-learning interface design best practices, all of which will shape the usability aspect of the ensuing m-learning guidelines and prototypes in this thesis.

Additionally, the concept of learner persona aimed to understand and represent target learners is considered. Finally, this chapter reflects on existing design and evaluation strategies for m-learning application which are used in this thesis.

Chapter 3 - User study \& Persona presents a user study aimed to understand the target m-learning application users and describes their experience and attitude towards using such applications, as well as their learner autonomy characteristics. A primary user persona is selected based on this user study and is used in subsequent phases of the thesis. The proposed persona development technique can be used as a model for other researches.

Chapter 4 - First Design Guidelines \& Prototype Development explains 
how the original concept of TDT proposed in general distance education context is translated to the modern education context of m-learning. Other learning theories and interface design guidelines are analysed for their applicability to the m-learning environment. The ensuing design guidelines produced are then combined with the primary persona and its learner autonomy characteristics created in Chapter 3 to develop the first iteration m-learning application prototype.

Chapter 5 - First Prototype Evaluation explains the prototype evaluation process. It presents quantitative results on learner autonomy and student engagement and uses statistical analysis methods to investigate potential correlation between these two elements. Furthermore, it details interesting qualitative findings from observing the participants' interaction with the m-learning prototype design. These results and findings are analysed and used to critique and evaluate the first iteration theoretical design guidelines.

Chapter 6 - Heuristic Evaluation presents the development process of heuristics evaluation guidelines for the thesis' m-learning application. The heuristics guidelines is first proposed based on the literature presented in chapter 2 . They are then used by user experience experts to evaluate the first iteration prototype in chapter 4 . The result of the evaluation is used to verify the applicability of the proposed heuristics guidelines.

Chapter 7 - Second Design Guidelines \& Prototype Development details how the proposed heuristic evaluation guidelines are incorporated into the m-learning design guidelines proposed in chapter 4 to form the second iteration design guidelines. As per the first iteration design guidelines and prototypes from chapter 4, the second iteration design guidelines are used for developing the second iteration 
m-learning application prototype.

Chapter 8 - Second Prototype Evaluation repeats the same evaluation techniques used in chapter 5 against the newly developed second iteration m-learning application prototype and presents the quantitative results, qualitative findings, and critique of the second design guidelines. It further compares and analyses the interface design and usability of the first and second iteration m-learning prototypes to understand the potentials and applicability of heuristic evaluation technique, which has been incorporated into the first iteration design guidelines to form the second iteration design guidelines.

Chapter 9 - Conclusion summarises the thesis, answers the three research questions posed in chapter 1, and describes the thesis' three major contributions to the field of m-learning. By placing these contributions into the context of related works discussed in chapter 2, this chapter further presents considerations and possible future approaches for m-learning application design guidelines.

\subsection{Publications}

Some of the work presented in the thesis had been published elsewhere prior to thesis write-up. These publications are the primary works of the author of this thesis, with the co-author providing some supervisions and advice.

Chapter 1 - research motivations, problem context, goals, methodology, and expected contributions were briefly described in "Mobile Learning Application for Computer Science Students: A Transactional Distance Perspective", published in the Proceedings of the 2016 ACM Conference on International Computing Education Research [76].

Chapter 3 - primary user study, user persona, and initial prototype 
design were discussed in "Know the Mobile Learning Application Users Transactional Distance Perspective", published in the Proceedings of the $8^{\text {th }}$ International Conference on Computer Supported Education [75]. 


\section{Chapter 2}

\section{Literature Review}

\subsection{Mobile Learning}

Since the Global System of Mobile communications (GSM) was introduced as an international protocol of digital cellular network for mobile devices and mobile telephones, mobile telephony has gained immense popularity. Jones \& Marsden (2006) [61] claimed that in 1993, less than 10 million people subscribed to mobile services worldwide. By 2003 , ten times this number of people subscribed to mobile services in just China alone. Similarly, Liu et al. (2010) [80] claimed that in 2010, nearly half of the world's population were mobile phone owners and this number was forecasted to expand to $75 \%$ within a year. A report on a survey of New Zealanders' use of smart-phones and other mobile communication devices in 2015 [116] also provided evidence supporting that in 2013, New Zealand mobile phone owners increased dramatically from $48 \%$ to $70 \%$.

Supported by the rapid growth of technology and swift uptake of mobile device ownership, communication not only grew faster, easier and brought people closer together, it also contributed to considerable expansion to education channels. Education platforms have expanded to include mobile-based teaching and learning. According to Adkins (2013) 
[1] "The worldwide market for Mobile Learning products and services reached $\$ 5.3$ billion in 2012. The five-year compound annual growth rate (CAGR) is $18.2 \%$ and revenues will more than double to $\$ 12.2$ billion by 2017" [1, pp. 13].

\subsubsection{M-learning and other forms of learning}

Following the rapid growth of mobile technology and highly increased popularity of mobile devices, mobile learning (m-learning) attracted more attention from both education providers and learners. To introduce mlearning, this section first identifies scope of m-learning and differentiates it from other modes of learning.

Georgiev et al. (2004) [46] claimed that m-learning was a modern learning platform resulting from the natural progression of distance learning (d-learning) and electronic learning (e-learning). They illustrated m-learning as a part of these two forms of learning (See figure 2.1a). Georgiev et al. further discussed that unlike traditional classroom setting, d-learning had the characteristics of distance and time separation between teachers and learners. Computers and Internet technologies introduced e-learning as a new form of d-learning. With mobile devices coming into existence and coupled with substantial development of mobile communication technologies, e-learning had been extended to m-learning and provided learners the capability to learn anywhere, anytime. Similarly, Brown (2005) [17] claimed that mobile learning (m-learning) was a subset of electronic learning (e-learning) which in turn was a subset of distance learning (d-learning).

On the other hand, Low \& O'Connell (2006) [83] developed a model of m-learning and e-learning in the context of flexible learning based on Peters' (2005) [107] model of flexibility learning which introduced m-learning as a concept of learning being "just enough, just in time, just for me" [83, pp.2], and Sharples, Taylor, \& Vavoula' s (2005) [125] 
statement on m-learning in that "it is the learner that is mobile, not the technology" [83, pp.2]. Based on these definitions, m-learning offered more flexibility and could support a more personalised style of learning when compared to e-learning, although some overlaps existed between m-learning and e-learning (See figure 2.1b).

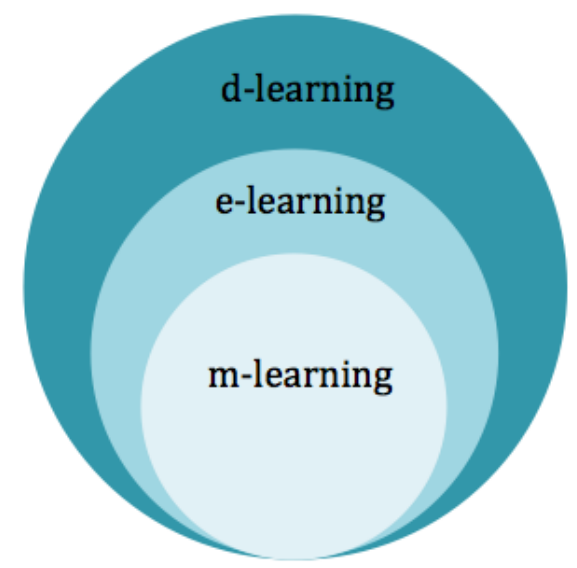

(a) M-learning as a part of e-learning and d-learning by Georgiev et al. (2004) [46]

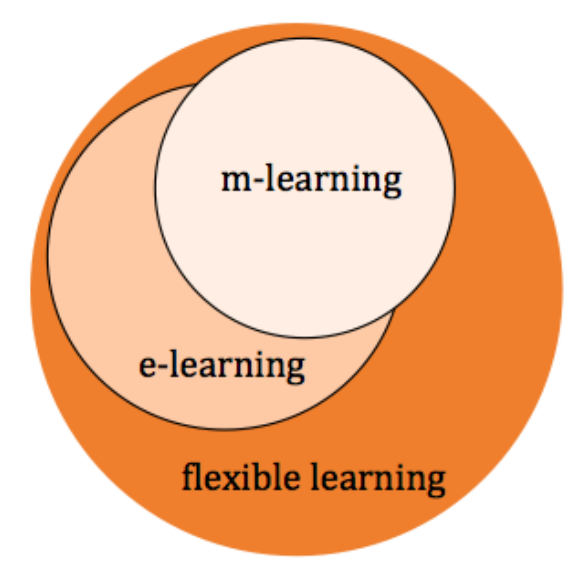

(b) M-learning as a part of e-learning and flexible learning by Low \& O'Connell (2006) [83]

Figure 2.1: M-learning as a part of other learning

Much research had confined the scope of m-learning and defined it based on its relationship with e-learning only. For example, Hoppe et al. (2003) [54] defined e-learning as the learning supported by electronic devices and digital media while m-learning was the delivery of e-learning content via mobile devices and mobile technologies.

Similarly, Petrova (2005) [108] claimed that e-learning and m-learning had the same learning context of physical separation between teachers and learners and the learning process was facilitated by communication technologies. However, Petrova (2005) pointed out that the mobility attribute of m-learning which enabled learning anywhere and anytime differentiated it from e-learning. 
These literature found e-learning and m-learning to be closely related. E-learning had been widely defined from various perspectives depending on researchers' interests and their approaches. Much research (e.g. $[7,2,38])$ defined e-learning in an educational context as a new learning platform that used multimedia and communication technologies to facilitate learners in both synchronous and asynchronous learning, such as offering interactive content through multimedia presentation and providing collaborative learning through online communication channels. On the other hand, much research (e.g., [50,40]) defined it from a technological-driven viewpoint as the use of technology and electronic media to deliver learning.

Much research used special characteristics such as "mobility" and "ubiquity" to distinguish mobile learning (m-learning) from e-learning. For example, Shudong \& Higgins (2005) [127] defined m-learning as learning ubiquitously and movable using mobile devices such as mobile phones, Personal Digital assistance (PDA), and iPod. Lui et al. (2010) [80] also agreed that mobile devices and mobile technologies in m-learning allowed people to gain knowledge and skills in ubiquitous manners.

Focusing on the mobility characteristics of m-learning, Vavoula \& Sharples (2002) [139] provided further clarification on its definition that learning could be considered as "mobile" if it was mobile in terms of: location where learning could happen - anywhere at workplace or at home; between different aspects in daily life such as learning for self improvement, self entertainment, or as demanded from work; time when learning could happen anytime during the day, on weekdays or weekends. Sharples \& Spikol (2017) [124] concurred that m-learning had mobility in physical space and could be merged into the learners' daily activities.

It could be argued that some of these elements were not specifically applicable only to m-learning. E-learning platform such as Massive Open Online Course (MOOC) which offered numerous courses via open access 
websites also exhibited the mobility characteristic of m-learning. According to Hoy (2014) [55], MOOC allowed learners to learn anywhere, anytime, and other than lecture videos, learners could participate in discussion forums. This indicated that e-learning could also exhibit mobility characteristics.

Pozzi (2007) [110] refined the definition of mobility by pointing out that learning with devices that were too large to be held comfortably such as laptops, netbooks and some tablets could not be considered as m-learning because of its size and weight. Such learning do not adhere to the anywhere concept of the mobility characteristics.

Aside from the technological aspect, Berge et al. (2013) [15] included pedagogical, context, and social interaction facets to defining m-learning. They stated that m-learning was "learning across multiple context, through social and content interactions, using personal electronic devices." [15, pp. 4]. They further explained that the learning could be either self-directed learning or directed by others; happen either inside or outside a classroom; be a planned or an unplanned spontaneous learning experience.

However, O'Malley (2003) [102] argued that m-learning should be defined from a learner's point of view. For instance, m-learning should enable a learner's knowledge acquiring process to happen everywhere, such as a university student viewing class lectures on a bus, doctors read medical journals on their mobile phones en-route to their workplaces, or a language student listening and practising conversations when travelling on a plane. These informal learning activities happened when people were on the move without any use of advanced technologies. Hence, the definition of m-learning was recommended to be broadened to "any sort of learning that happens when the learners is not at a fixed, predetermined location, or learning that happens when the learner take advantage of the learning opportunities offered by mobile technologies" [102, pp.7]. Likewise, Lohnari (2016) [81] also defined m-learning from 
the learner's aspect as the times when learners took advantages of mobile devices to support their learning processes on the move.

Based on this literature, m-learning was a subset of e-learning which in turn was a sub-set of d-learning. These modes of learning had the same characteristic of physical separation between teachers and learners. However, m-learning offered more flexibility owing to its mobility and ubiquitous characteristics. M-learning could be defined as the process of teaching and learning across multiple contexts via mobile devices supported by communication technology to enable learning anywhere and anytime when learners were not at fixed locations.

\subsubsection{Potentials of Mobile Learning}

Owing to the popularity of mobile devices and its mobility characteristic, m-learning has immense potential to help advance and enhance teaching and learning processes. This potential has been widely recognised and highlighted in various researches and initiatives.

M-learning could assist specific groups of children who struggled to participate in typical schooling systems or those who encountered difficulties during their learning process. For example, the United Nations (UN) developed a set of eight Millennium Development Goals (MDG). One of the goals identified a target towards achieving universal primary education. UN wanted to "ensure that, by 2015, children everywhere, boys and girls alike, will be able to complete a full course of primary schooling" [138, pp. 24]. In 2015, the UN drew new agenda under this MDG to focus attention on primary schooling for specific groups of children such as those from minorities and nomadic communities, children with disabilities, involved in child labour, or those who lived in urban slums. Through the use of mobile devices, M-learning has the potential to help UN achieve this goal.

Based on a survey of mobile phone ownership conducted among 169 
homeless youths in Los Angeles, California, United states of America, $62 \%$ of them owned a mobile phone [117]. In Australia, a research observation on mobile phone ownership amongst 95 families and young people experiencing homelessness found that $95 \%$ of the participants had a mobile phone [57]. These evidences supported the notion that m-learning had the potentials to reach to these groups of audiences.

Additionally, a learner research study by Attewell \& Webster (2005) [10] was evidential of m-learning's potential to help accomplish this goal. Their study explored learners and mentor's experience towards using smartphones and PDA/phone to seek learning support. They found that m-learning developed learning confidence in a homeless learner who left school and inspired him/her to seek further assistance to improve his/her skills.

Research studies by Fernández-López et al. (2013) [42] and Skiada et al. (2014) [128] both demonstrated the potential of m-learning. Fernández-López et al. (2013) [42] developed an m-learning application on iOS devices to support students with special education needs with the aim to develop their cognitive abilities, help them learn new knowledge, improve their behaviour, communication, and relationship with their surrounding environment. The application was called "Picca" and had four educational activities: exploration, association, puzzle and sorting, and could be personalized by teachers to suit each individual learners. Figure 2.2 shows the four activities design on iPad and iPod Touch devices. Picca was used by 39 learners with special education needs from Spain. Observation results showed that the learners' basic skills in language, mathematics, environment awareness, learner autonomy, and social skills have been improved.

Similarly, Skiada et al. (2014) [128] developed an m-learning application called "EasyLexia". The goal of the application was to help children with learning difficulties improve their reading comprehension, orthographic coding, short-term memory, and mathematical problem 

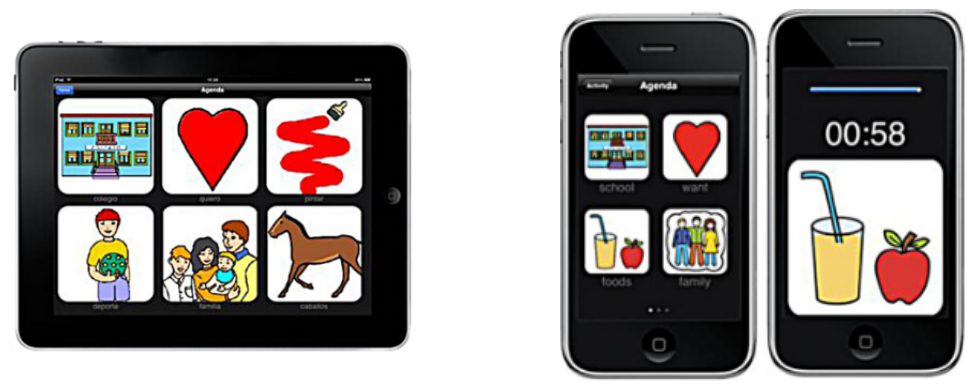

(a) Exploration on iPad

(b) Exploring on iPod

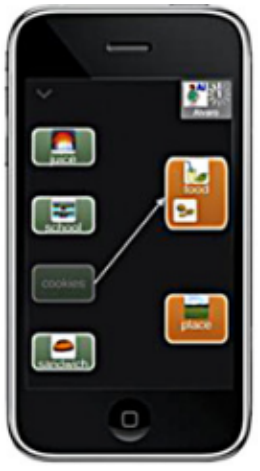

(c) Association

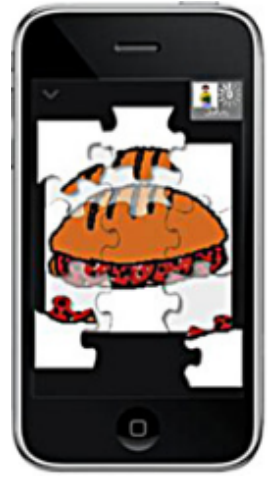

(d) Puzzle

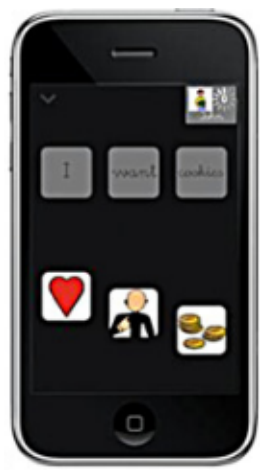

(e) Sorting

Figure 2.2: Picca's educational activities in research study by FernándezLópez et al. (2013) [42]

solving. Figure 2.3 provides examples of learning activities available in EasyLexia. EasyLexia was used by learners in a speech therapy center in Greece. Although the impact of EasyLexia was only assessed using its first iteration design, the researchers' initial observation was promising. Their initial assessment indicated that learners made progress in over game performance and achieved skills improvement.

Not only could m-learning facilitate education for specific groups of learners, for general users in tertiary education, a recent study by Hinze et al. (2017) [52] claimed that mobile applications (mobile apps) had huge potential to change teaching and research practices. Based on findings from an online, self-administered survey about the use of mobile app for 


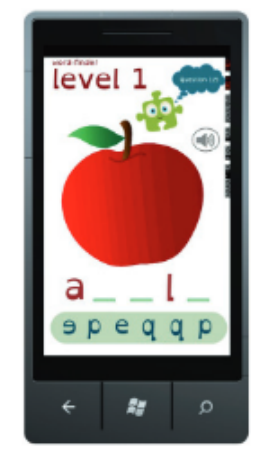

(a) Word Finding

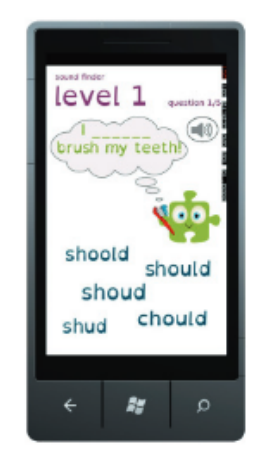

(b) Choosing It

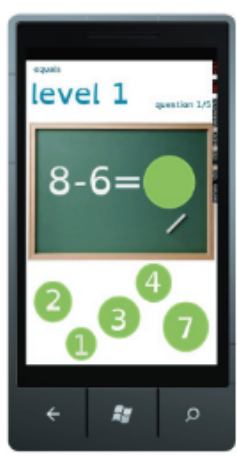

(c) Number

Figure 2.3: EasyLexia's activities created in a research study by Skiada et al. (2014) [128]

teaching and research by Higher Degree Research students and staff at the University of Waikato, nearly two thirds of the total 138 participants who completed the survey reported using mobile apps. Its abilities to share document, communicate with peers and support academic collaboration were found to be the primary motivating factors behind users' adoption of mobile apps in this context.

Additionally, Klopfer et al. (2002) [65] found that running a simulation on PDAs were more cost effective and could provide easier access compared to desktop computers in their land areas investigation. According to their research, PDAs offered the following benefit during field studies:

- Portability - learners could roam around areas with simulation available on the PDAs

- Social interactivity - learners could share and exchange portable data from their PDAs

- Context sensitivity - learners could collect real time data at their current location 
- Connectivity - learners could easily connect their PDAs to any desktop computer and computer network

- Individuality - learners could set their individual observation paths

Traxler (2007) [136] also agreed that m-learning had remarkable potentials to support authentic learning and provide flexible learning environment when learners approached real work problems in their field studies.

Other research studies also discovered m-learning's capability to enhance learning engagement and improve learners' satisfaction. For example, Attewell (2005) [9] observed a large-scale m-learning project across three Europe countries (Italy, UK, and Sweden). In the project, teachers created learning materials on desktop computers and learners accessed these materials from their mobile phones. The observation findings suggested that mobile phones could encourage computer-resistant learners to learn, while presenting formal learning content in an attractive and entertainment manner could engage young learners for a longer period of time.

Evans (2008) [41] and Manuguerra \& Petocz (2011) [86] also discovered that $\mathrm{m}$-learning using Podcasting had potential to engage and satisfy learners. The study adopted Podcasting to pre-record learning content into an audio or video format to teach first year undergraduate learners at the University of London, United Kingdom and allowed the learners to download and play these pre-recorded files on their mobile devices. The observation findings suggested that learners were satisfied and preferred learning via Podcasting over attending lectures.

Manuguerra \& Petocz (2011) [86] observed the adoption of Apple's iPad both within the university and in distance learning. Within the university, the iPad was used by lecturer to present lecture slides. In the distance learning setting, iPad was used to deliver lecture videos and handle learners' enquiries. The iPad adoption received positive 
acceptance in both settings as it could deliver livelier learning content and introduce a more convenient communication platform.

Finally, m-learning on smart phones were found to have the potential to encourage communication and collaborations. Corbeil \& Valdes-Corbeil (2007) [33] claimed that smart phones were more adaptable as a m-learning tool when compared to other hand-held devices such as iPod, MP3 players, and Personal Digital Assistant (PDA) owing to its unique combination of communication and computing features in a single device. Jacob \& Issac (2014) [60] agreed that the features on smart phones such as camera, MP3 player, and its accessibility to the Internet supported collaborative learning and enabled situated learning discussed in other studies.

The development of mobile devices and communication technology introduced m-learning as a new dimension to education platforms. M-learning brought many potentials to both traditional and distance learning, from enabling learners to gain education opportunities where otherwise denied, to supporting a wide spectrum of learners. As with e-learning, it facilitated learning content dissemination and enabled learning content to be enhanced with digital media to help engage learners. M-learning, particularly via smart phones, also had the potential to foster and support collaborative learning.

\subsubsection{Challenges of Mobile Learning \& Proposed Solutions}

Notwithstanding its immerse potentials, m-learning still faced challenges. Although people own mobile devices with the latest communication technologies, it was not a guarantee that they would utilise m-learning. Much research recognised this challenge and attempted to find the reasons inhibiting people from adopting m-learning. 
Firstly, health concerns might affect m-learning adoption as many people felt apprehensive towards undesirable health risks associated with mobile usage.

There was a wide range of different opinions regarding the effect of radio frequency and human health. For example, World Health Organization (WHO) [115] reported in 2000 that there was no correlation found between exposure to mobile phones' radio frequency and adverse health risk. Lönn et al. (2004) [82] found no increased risk of acoustic neuroma associated with short-term mobile phone usage. However, Thomée (2011) [135] argued that long-term mobile phone usage could have indirect effects such as sleep disturbances and depression.

Suhang et al. (2016) [132] conducted a quantitative study on the impact of mobile phone usage and human physical structure. Based on the observations gathered by 150 doctors from three different hospitals, his study found that the doctors believed the wireless devices were accountable for the development of brain tumour diseases, male infertility, and hearing impairment.

A recent study by Fowler \& Noyes (2017) [45] which surveyed 163 teenage participants aged between 14-18 years reported that these mobile phone users faced some health risks from radio frequency such as musculoskeletal problems, impaired performance, anti-social behaviour, and sleep disturbance.

Due to conflicting opinions from existing reports, such health concerns could not be dismissed as a factor that might influence m-learning adoption.

Secondly, learners might not adopt m-learning because they lacked motivation to learn on mobile devices. Shudong \& Higgins (2005) [127] found that people only preferred to use m-learning when they were on the move. However, when they were at home they preferred to learn using a computer loaded with an e-learning program rather than on their mobile devices. This might be due to the various constraints posed by 
mobile devices such as smaller screen sizes and lower quality of the multimedia that could be played on mobile devices when compared to a computer.

Similarly, Liu et al. (2010) [80] claimed that hardware and software limitations such as small keyboard and incompatibility between multiple operating systems had some negative effects on the quality of m-learning.

Furthermore, in a language study by Godwin-Jones (2011) [47], it was found that learners who needed to practice extensive writing faced difficulties performing such task on the T9 keyboard of some early mobile phones.

Cochrane \& Bateman (2010) [30] concurred that the hardware constraints of mobile devices had critical a critical impact on its acceptance and use. They discussed that in order to facilitate social collaboration, smart phones should be able to, for example: capture image and video; stream video; and provide touch screen function, good mobile web experience, and ease of user interface experience.

Chae \& Kim (2004) [23] argued that screen size actually had no impact on mobile internet users' perception and navigation behaviour when they were carrying out easy tasks such as checking e-mails. However, when the tasks involved relatively complex search operations such as buying a gift on a website, the smaller screen size led to more scrolling behaviour and the website layout and display also changed more extensively. These caused difficulties in users maintaining their focus throughout the whole activity process.

Similar to Chae \& Kim (2004) [23], Alghamdi et al. (2013) [5] argued that the screen size had no effect on readability. They observed patients with normal vision reading health information on smart phones with various screen sizes. Samsung Note 10, Note 2 and Galaxy 3 Mini were used to represent large, medium, and small screen sizes respectively. They found that the screen size of smart phones did not affect readability. Rather, it had impact on users' reading concentration and readability was 
actually affected by the size of the text.

To advance learners' motivation and m-learning adoption, much research suggested methods such as presenting enjoyable learning tasks, rewarding knowledge and providing quality functions in m-learning. For example, Liaw \& Huang (2012) [74] claimed that learners' were incentivized to adopt m-learning if they enjoyed the learning tasks and could perceive long-term rewards of acquiring knowledge.

In addition, Liew et al. (2010) [73] observed learners' willingness to use an individual knowledge management system implemented on mobile phones. The system provided features to assist learners in managing the knowledge they retrieved from online websites. They suggested that learners would adopt m-learning system if the learners could perceive: m-learning application's quality of activities and functionalities; that the m-learning system could enhance their learning satisfaction; that the m-learning could promote learners' autonomy.

There were many available programs and techniques that could help improve the quality of learning content presentation on the small screens of mobile devices. For example, Cascading Style Sheets 3 (CSS3) could automatically re-format content on the websites to be appropriately displayed on mobile devices based on individual devices' screen size.

Alternatively, other tools such as Mobify ${ }^{2}$ and Wirenode ${ }^{3}$ offered a ready to be installed code block that would automatically re-direct learners to mobile friendly version of a website if the learners browsed the websites using a mobile browser.

Many e-learning had adopted this technique to deliver their courses on mobile devices. Figure 2.4 and 2.5 present a comparison of desktop and mobile versions of e-learning websites called Udemy and edX respectively.

Additionally, there were many proposed techniques to ensure the quality of visual content presented on the small screen of mobile devices.

\footnotetext{
${ }^{2}$ https: //www.mobify.com/

${ }^{3}$ http: //www.wirenode.com/
} 
For example, Lui et al. (2003) [79] adopted an image attention model to automate the scrolling and navigation of a large picture with minimal amount of user interaction on mobile devices.

Chittaro (2006) [27] explained that rendering 3-dimensional model on mobile devices could suffer from short battery life and low resolution. The study suggested using "teleporting" technique to render the 3-dimensional model on a powerful desktop computer and transmit the results to a mobile device wirelessly as a video sequence.

Finally, the observed hardware constraints had become less material to m-learning adoption as the recent rapid growth in communication technology resulted in a much wider range of smart phone choices that were rich in features (Figure 2.6a) and later generation smart phones introduced larger virtual keyboards and touch screens to aid easier text entry (Figure 2.6b), larger screen sizes (Figure 2.7a), and ability to zoom in and out (Figure $2.7 \mathrm{~b}$ ). 


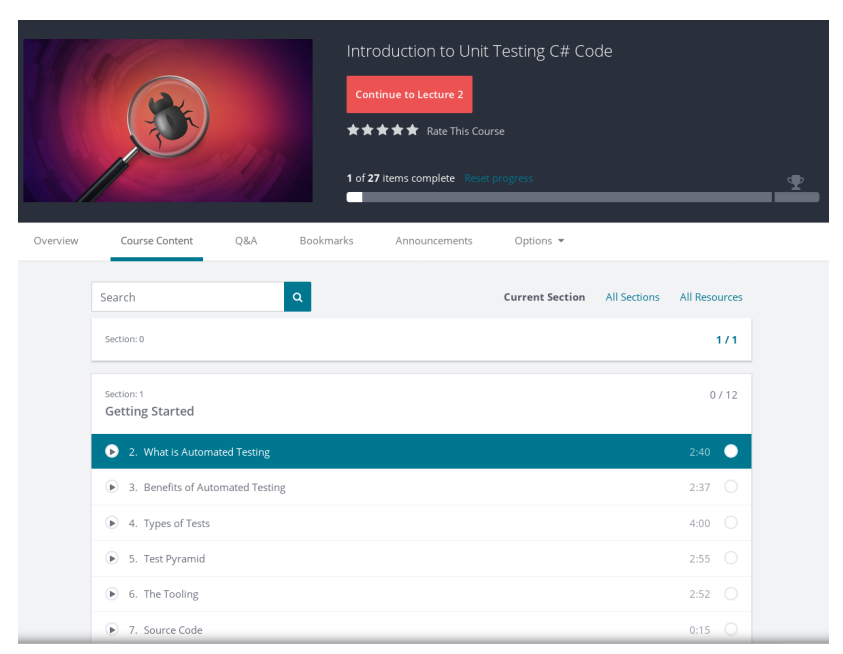

(a) Desktop version

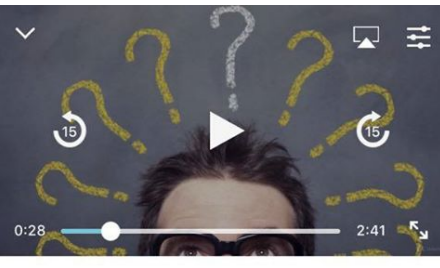

Introduction to Unit Testing C\# Code Mosh Hamedani

Lectures Mor

(4)

1 Welcome

Section 1 - Getting Started

What is Automated Testing

Video - 02:10 mins remaining

Benefits of Automated Testing

Video - 02:37 mins

Types of Tests
Video - 04:00 mins

5 Test Pyramid

(b) Mobile application

Figure 2.4: Desktop and mobile versions of e-learning platform Udemy. The screen shots were taken from https://www.udemy.com/ and Udemy application downloaded from Apple App store 


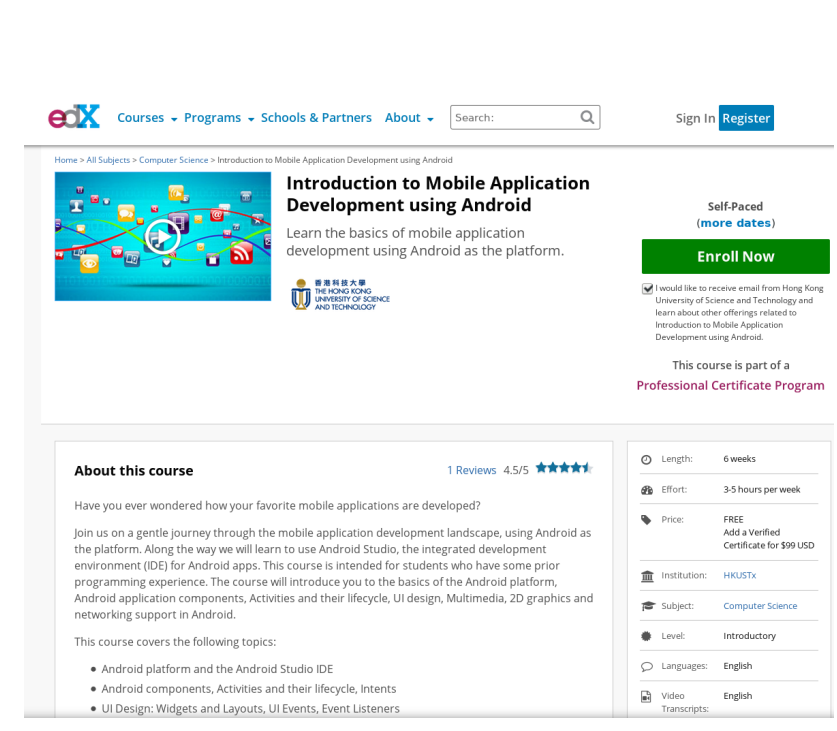

(a) Desktop version

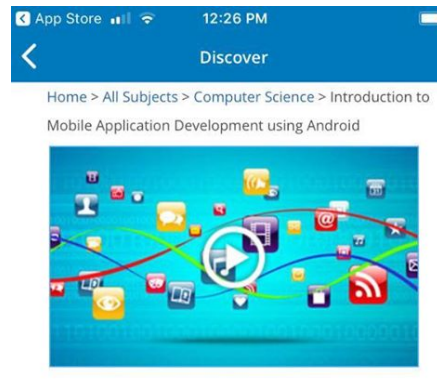

Introduction to Mobile Application Development using Android

Learn the basics of mobile application development using Android as the platform.

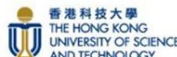

Register

Sign In

(b) Mobile application

Figure 2.5: Desktop and mobile versions of e-learning platform edX. The screen shots were taken from https:/ /www.edx.org/ and edX application downloaded from Apple App store 


\begin{tabular}{|l|l|l|}
\hline & & \\
\hline
\end{tabular}

(a) Early text messaging on mobile phone and recent communication technology advances

\begin{tabular}{|c|c|}
\hline 2015 & 2016 \\
\hline 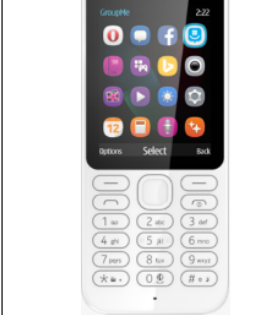 & 6 \\
\hline https://www.nokia.com & https://www.androidiospack.com \\
\hline $\begin{array}{l}\text { Nokia } 222 \\
\text { Physical T9 Keyboard }\end{array}$ & $\begin{array}{l}\text { Samsung S7 } \\
\text { Virtual Qwerty Keyboard }\end{array}$ \\
\hline
\end{tabular}

(b) Physical T9 and virtual qwerty keyboards

Figure 2.6: Comparison of early mobile phones and recent smart phones' keyboard and communication features 


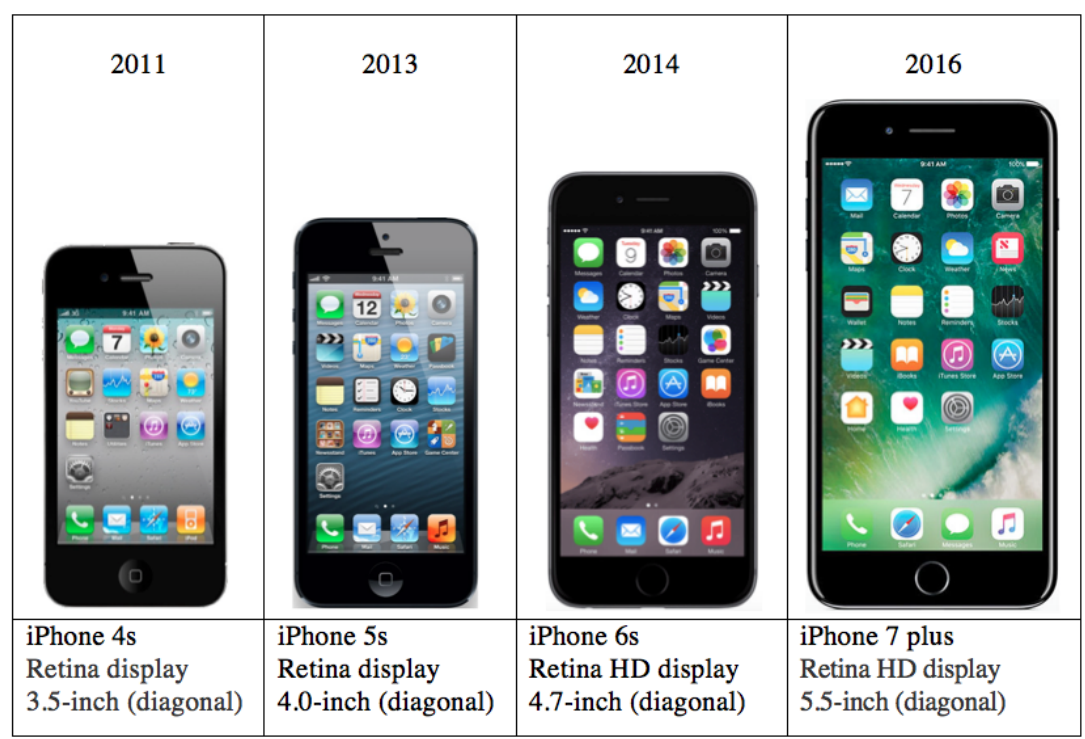

(a) Revolution of Apple's iPhone

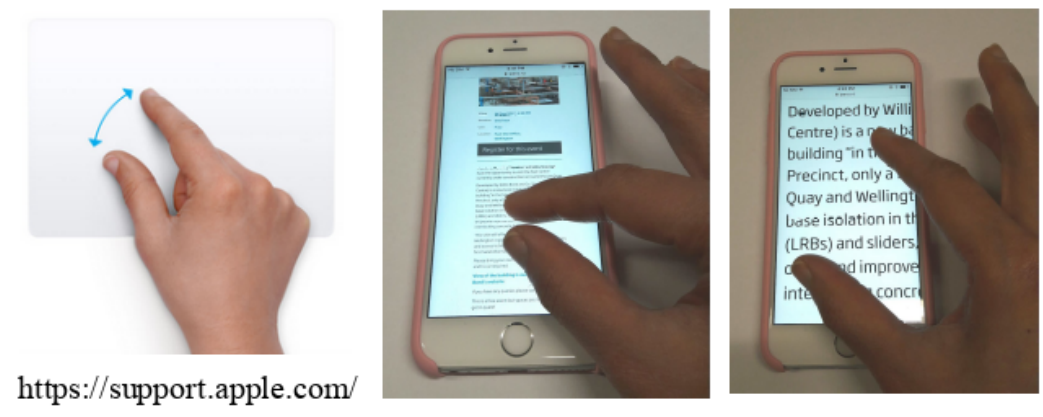

(b) Apple's two-fingers gestures to zoom in and out

Figure 2.7: Apple's iPhone screen size and its ability to zoom with twofingers gestures for reading small text

Besides technical challenges posed by the hardware and software limitations of mobile devices, m-learning also faced pedagogical challenges

First of all, Shudong \& Higgins (2005) [127] discussed that m-learning introduced difficulties validating learners' learning progress and achievement. As learning activities could be carried out anywhere and anytime without instructor's supervision, it would be difficult to 
ascertain any assessment or examination was truly completed by the registered learners themselves.

However, this challenge could be diminished by some advance computer algorithms. For example, Kaiiali et al. (2016) [62] proposed a Secure Exam Management System (SEMS) for secured mobile examinations. The system provided m-learning security services such as biometric-based authentication service for anti-impersonation and limited internet access during the exam period. They adopted face recognition technology as the biometric-based authentication of choice, and was used in conjunction with username and password pre-authentication. After a learner had successfully processed his/her login, the system would capture his/her face and would ask the learner to present his/her face to the camera on a random basis. Meanwhile, the system control learners' access to some online resources using a Security Agent (SA) that was pre-installed onto the learner's device. The SA controlled some access policies such as blocking all Bluetooth, Wi-Fi, and cellular communications except for any connection to an exam server. In order to prevent the learner to manually disable the SA, the application periodically sent heartbeat to the exam server to ensure its active status (Figure 2.8).

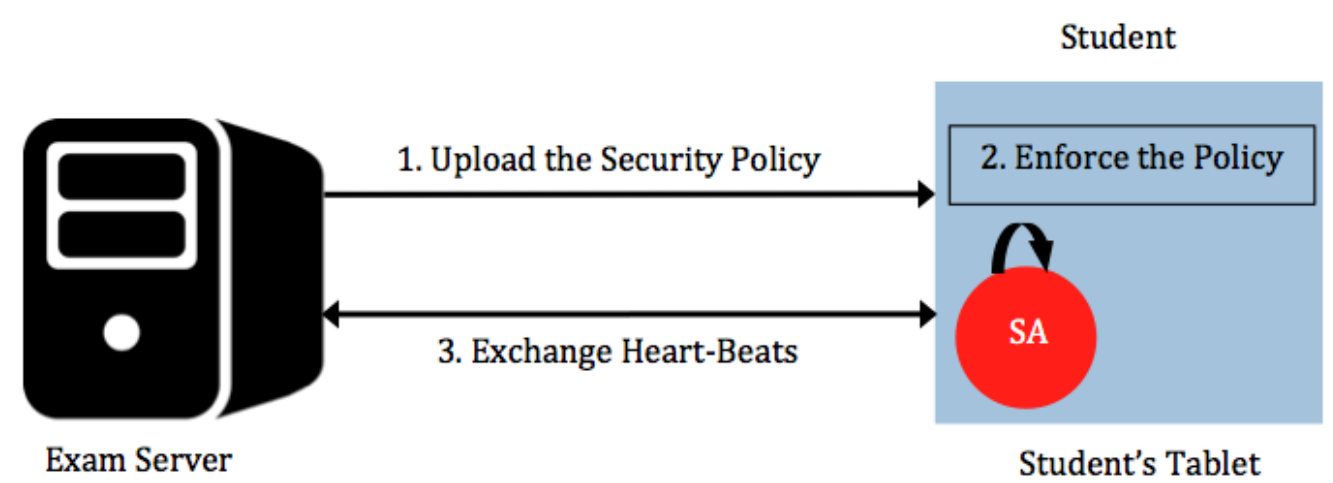

Figure 2.8: Security Agent (SA) strategy in SEMS by Kaiiali et al. (2016)[62] 
Secondly, Corbeil \& Valdes-Corbeil (2007) [33] further pointed out that m-learning might cause inequality as computer-literate learners would benefit more from the learning process whilst triggering isolation for learners who were less proficient in using mobile technologies. However, advancement in communication technologies such as FaceTime communication could ease such inequality by allowing easy communication between the learners and their teachers. The learners could ask questions and the teachers could track the learners' progress, encourage any learners who were falling behind in their learning process, and provide individual feedback to them.

Lastly, Pozzi (2007) [110], Corbeil \& Valdes-Corbeil (2007) [33], and Cochrane \& Bateman (2010)[30] expressed concerns towards teachers who might need to spend extra efforts on adapting existing teaching material for presentation on smaller screen sizes and prepare the materials in multiple versions to cater to different mobile devices' operating systems. If the teachers were not familiar with mobile technologies, they would require further training at the initial stage of m-learning implementation in order to become accustomed to their roles.

The adoption of m-learning might be inhibited by various factors such as concerns with health risks, lack of psychological motivation and perceived benefits of m-learning, hardware and software limitations, and pedagogical challenges. Although some of these challenges had been diminished by recent mobile devices and communication technologies advances, some fundamental difficulties still exist, particularly in the areas of learners' motivation and learning content presentation. A successful m-learning course still requires an effective design guidelines that will lead developers through concrete steps to ensure quality application design that can engage learners and maximise the impact of the learning content. 


\subsubsection{M-learning Design Guidelines}

According to O'Malley et al. (2003) [102], design guideline was defined as "Rules or principles of action, encapsulating some combination of practitioner-determined best practices in a domain and research-based insights into factors relevant in that domain" [102, pp. 7]. Based on this definition, developing a m-learning design guideline could potentially be problematic as m-learning was a new education platform that had very little best practice to draw upon.

However, they attempted to gather all available m-learning design guidelines from case studies and relevant literature. They found a total of twenty-seven categories of m-learning design guidelines. For example, for the guidelines on how to provide m-learning usability, they found the study of Lehner \& Nosekabel (2002) [72]. For the guidelines on designing learner general control (i.e., input and output), they cited the study of Alessi \& Trollip (2000) [3]. For the guidelines on choosing m-learning technology, they found the study of Alexander (2003) [4], Perry (2003) [106], and Smith (2003) [129]. Despite their research, little guidelines or best practices were available to guide m-learning design and development.

There were also many guidelines proposed within other learning context (e.g., actual classroom and e-learning) that might be able to contribute to the development of m-learning design guidelines.

However, many of them might not be applicable due to the unique characteristics of m-learning, or their scope might be too narrow for holistic m-learning guidelines development. For example, some existing instructional guidelines for traditional classroom settings such as Perkins (2008) [105]'s smart school concept suggested three characteristics of working together systematically, providing positive energy, and treating each other mindfully, had little bearing on the development of m-learning design guideline as it was not applicable due to the mobility characteristics of m-learning. 
Other domain specific guidelines such as Wright (1985) [142]'s text editing guidelines were too narrow in scope to be applicable to the m-learning design guidelines development as it only focused on guiding one particular domain (i.e., text). As a result, developing a design guideline for the entire m-learning system might require a combination of many domain specific guidelines.

In addition, the mobile and communication technology that underpinned m-learning changed rapidly and once the technology context had changed, such guidelines might lose their relevance.

As much research linked m-learning to e-learning (See section 2.1), and e-learning had already reached its mature stage in terms of best practices and guidelines development, there might be an opportunity to draw upon and adapt e-learning guidelines for m-learning.

Clark and Mayer (2016) [28] proposed research-based design guidelines for e-learning suggesting how text, graphics, and audio could be best presented and under what conditions they could be effectively applied. Some examples of the guidelines were: do not provide text in narrated video (i.e., concurrent on-screen text and graphics) as too many visual presentations could cause heavy working memory load; build conversational style of writing or speaking for e-learning environment; provide polite wording feedback; and use friendly human voice in audio media. These guidelines were recently published in 2016 and included a new media format (i.e., animation), as well as using a modern pedagogical approach (i.e., game design). Therefore, guidelines for e-learning could potentially become a foundation for the development of modern m-learning design guidelines.

Despite the promises, it could be argued that e-learning design guidelines did not cater for the mobility aspect of m-learning and might need to be used in conjunction with other designs guidelines to ensure its inclusion in the developed m-learning guidelines.

For example the design guidelines for mobile devices offered by Gong 
\& Tarasewich (2004) [48] took into account the aspect of mobility within $\mathrm{m}$-learning and suggested designs should cater for multiple and dynamic contexts, as mobile devices were generally used in various environmental conditions such a brightness, noise, weather and in different locations such as home, office, or on the street.

M-learning was still a modern education platform and there was insufficient best practices to draw upon for its design guidelines development. Guidelines for traditional classroom settings and those for other learning context might not be satisfactory as they could not cater for multiple aspects of m-learning, such as its mobility and rich media characteristics. Although the design guidelines for e-learning showed more promises, its lack of consideration towards m-learning's mobility aspect meant that the e-learning design guidelines would need to be complemented by other design guidelines such as those for mobile devices to produce a comprehensive set of design guidelines for m-learning.

\subsection{Transactional Distance Theory}

Psychological theories described various reasons behind individual learners' behaviour and enabled teachers, instructors or institutions to predict learning outcomes (e.g., Bandura (1969) [12], Astin (1984) [8], and Ally (2004) [6]). Therefore, they could contribute to the pedagogical aspect of m-learning guidelines development. This section introduces Transactional Distance Theory (TDT), one of the learning theories.

TDT was a theory in distance education that highlighted the special characteristic of physical separation between learners and their teachers in that learning context. Due to the separation, learners might perceive isolation, encounter communication barriers, and found difficulties in managing their own learning.

TDT further identified the elements that caused these issues with the 
aim to promote a better understanding of distance education. This section discussed how the theory was developed, defined the elements presented within TDT and explained how they affected quality of distance teaching and learning, and introduced applications of TDT to e-learning and $\mathrm{m}$ learning.

\subsubsection{Development of Transactional Distance Theory}

Transactional Distance Theory (TDT) was a long-standing, prominent theory in distance education. It came into being in 1973.

The beginning of e-learning could be traced back to the first development of network communication in 1969s and the invention of e-mail and computer conference over packet-switched network in 1971 when people could communicate despite locating at different places [51].

However, Michael G. Moore (1972) [90] found no systematic theory that could explain this non-traditional education platform when learners learned physically apart from their teachers.

He raised this concern at the World Conference of the International Council for Correspondence Education (ICCE). Soon after, this approach to teaching and learning was acknowledged as "distance education". This marked the beginning of TDT. The following year, Moore defined distance education based on relevant scholars analysis as

"An educational system in which the learner is autonomous, and separated from his teacher by space and time, so that communication is by print, electronic, or other non-human medium" [91, pp. 663].

Distance education had since been formally recognised and from the 1980s and 1990s, e-learning was expanded to reach public schools and tertiary institutions [51]. M-learning became recognised in 2005 [34].

Due to physical separation, learners and teachers might never speak or 
personally know each other at all. Learning material would be used upon learners' decision outside of the teachers' control, and the learners would need to manage their own learning process, such as those participated in the Massive Open Online Course (MOOC), which provided "self-directed learning on open online networks" [67, pp.19].

Based on these specific natures of distance education, Moore (1973) [91] discovered three elements: dialogue, course structure, and learner autonomy that affected distance education.

In the next decade, Moore [89] introduced "transactional distance" to describe the psychological perception of physical separation in distance education. He claimed that transactional distance was a special characteristic of such education.

Although learners in traditional classroom might separate from their teachers at some stage, the transactional distance within this educational setting was narrow because learners had many channels and opportunities to have verbal communications with their teachers. On the other hand, the transactional distance within distance education was much wider because learners and teachers would only communicate through printed or electronic media.

As TDT and transactional distance emerged and became better defined over time, the definitions of dialogue, structure and learner autonomy, i.e. the three elements of transactional distance, also became more precise. Moore (1983) [89] defined:

The dialogue - two-way communication between learners and teachers

The structure - an educational program's responsiveness to identify learning objectives, implement learning program, and evaluate learning outcomes to meet learners' individual needs

The autonomous learner - a learner who could identify required skills and 
information that helped them to approach their learning problems, able to set their own learning goals and achievement criteria, effectively carry out their own learning process, and able to value their learning experience and knowledge.

Additionally, Moore (1980; 1983) [92, 89] proposed four types of distance education programs that were generated from the interplay of dialogue (D) and structure (S). Figure 2.9a - d illustrate the teaching-learning relationship of the four types of distance education programs.

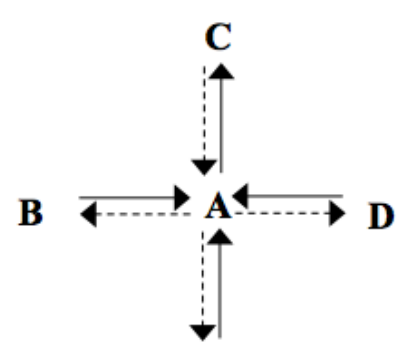

$\mathbf{E}$

(a) -D-S

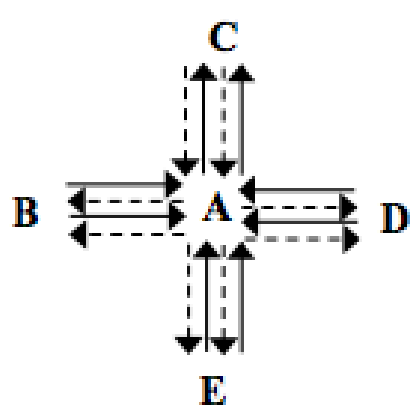

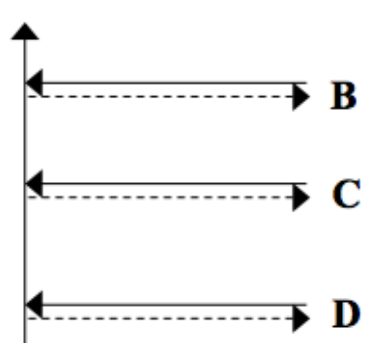

$\mathbf{A}$

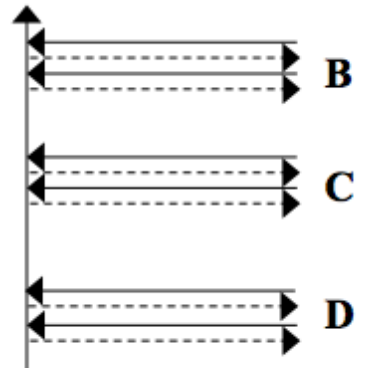

$\mathbf{A}$

(b) $-\mathrm{D}+\mathrm{S}$

(c) $+\mathrm{D}+\mathrm{S}$

s.--ד refers to one-way communication refers to two-way communication

Figure 2.9: Teaching-learning relationship of distance education programs defined by Moore (1983) [89]. "A" represented a teacher while "B", "C", "D", and "E" represented learners. 
- -D-S in Figure 2.9a represents a program with no dialogue (i.e., oneway communication) and had no mandated structure (i.e., a flexible course structure) such as self-directed study

- $-\mathrm{D}+\mathrm{S}$ in Figure $2.9 \mathrm{~b}$ represents a program with no dialogue (i.e., one-way communication) and had a mandated structure (i.e., an inflexible course structure) such as radio and television

- +D+S in Figure 2.9c represents a program with dialogue (i.e, two-way communication) and had a mandated structure (i.e., an inflexible course structure) such as correspondence program

- +D-S in Figure 2.9d represents a program with dialogue (i.e., twoway communication) and had no mandated structure (i.e., a flexible course structure) such as tutorial program

The distance in this context was qualitative and was based on psychological perceptions. Based on the principles of TDT [89], the -D-S relationship within the four programmes caused the most distance because it was a self-study where learners needed to plan, implement, and evaluate their own learning.

On the opposite spectrum, the $+\mathrm{D}-\mathrm{S}$ had the least distance because it allowed the learners to communicate with teachers. However, this type of distance course did not allow learners to exercise much of their autonomy because the teachers might lead most of the teaching-learning process.

Besides examining the relationship between distance (D) and structure (S), Moore (1980; 1983) [92, 89] also employed learner autonomy to classify distance education. He identified three activities: goal setting, implementation, and evaluation which could be governed by learners or teachers.

In his classifications, "A" represented autonomous which referred to learners having control over one of the three defined activities, while "N" 
represented non-autonomous which referred to teachers having control over one of the three defined activities.

The classification ranged from a program that allowed learners to completely control all three processes (AAA) to one which only allowed little autonomy (NNN). The most common type of learning would most probably align to NAN, where learners took control over their learning processes and the teachers set learning objectives and controlled the evaluation process. The least common type of learning were NAA and NNA, as teachers rarely set learning goals but allowed learners to evaluate themselves.

This learner autonomy classification could be plotted in a three-dimension diagram (Figure 2.10), and placed against distance in a two-dimension diagram (Figure 2.11).

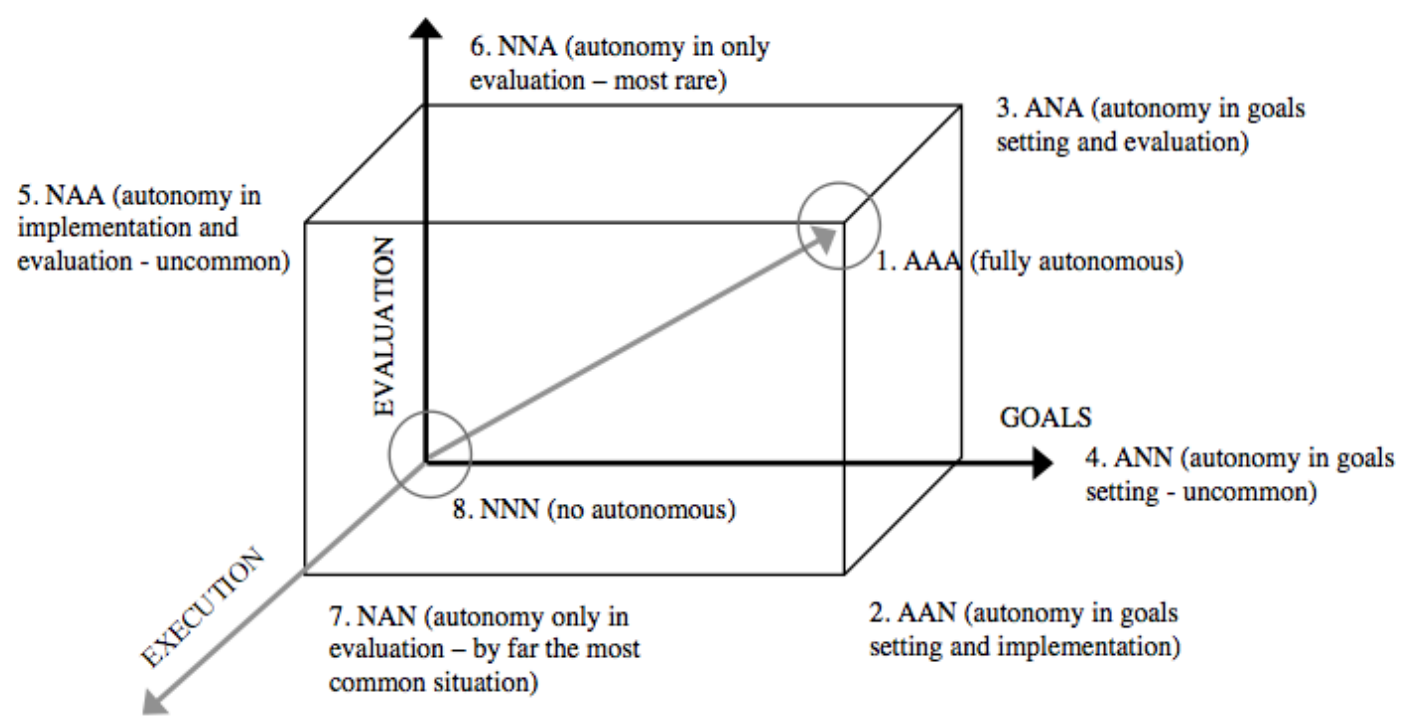

Figure 2.10: Moore's (2013) [94, pp. 73] Three-dimension autonomy classification of distance program

In 1993, Moore [93] formed Transactional Distance Theory (TDT) to explain the special characteristic of separation between teachers and 


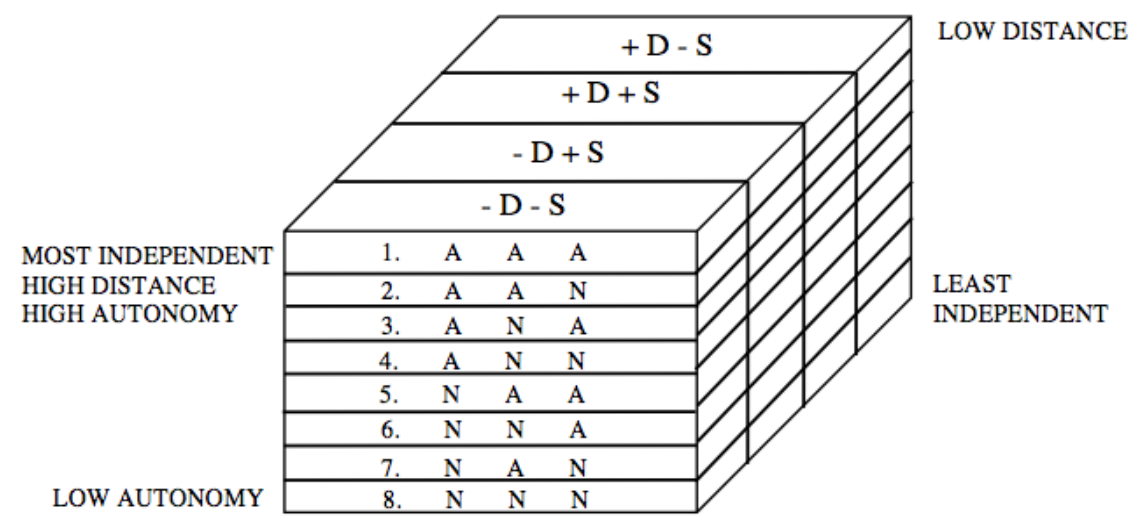

Figure 2.11: Moore's (1980) [89, pp. 73] Typology of educational program classification

learners in distance education. Due to the physical separation, both parties might never meet or hardly have any conversation, the learners needed to take control over their own learning and would potentially perceive transactional distance which could decrease learning quality. There were three elements that varied the transactional distance: dialogue between teachers and learners, course structure, and learner autonomy.

\subsubsection{Elements of Transaction Distance Theory}

\section{Dialogue}

According to Moore (2013) [94],

Dialogue was a subset of interactions including words and actions that had positive qualities, were purposeful and constructive.

The amount and quality of dialogue were controlled by three factors: philosophy of the course, personality of teachers and learners, and the 
learning environment including number of learners, language, and communication media. For example, a single learner was found having more dialogue with teachers compared to a group study of many learners; a learner who shared the same native language with teachers was found to have more dialogue than learners who used foreign languages; and a course delivered via video conferencing had more and quicker dialogue than the course that was delivered via course material sent through the post.

\section{Course Structure}

Similar to the dialogue, course structure was a qualitative and dependent variable. According to Moore (2013) [94],

Structure referred to the structural plan of the course which dictated how learning content would be delivered through communication media.

In 1993, Moore [93] suggested launching a pilot-study to observe if learners were comfortable with either a highly-structured or a flexible course.

Later in 2011, Moore (2011) [95] provided further clarification on these two structures. In a highly-structured course, learners might be instructed to learn according to a planned schedule. They would not be able to explore other parts of learning content without permission. Media such as audio or video could be used by learners only when allowed, and they could communicate with their teachers within a pre-determined time table. In a flexible course, on the other hand, teachers should allow learners to learn in their desired speed, submit the assignment when they were ready, and enable them to access and explore all course materials. In addition, teachers should also provide communication channels such as electronic mail or help-desk. 
According to Moore (1993) [93], media presentation and course structure had significant effects on the quality of distance education courses. He further suggested that teaching processes should be delivered via numerous media. For example, presenting learning content through video recording, evaluating learners' knowledge using correspondence, and providing feedback through video conference. In addition, Moore (1993) [93] suggested six-instructional processes that should be constructed in every distance education course:

1. Presentation - use either text, audio, or video to present learning content. If the learning content needed frequent updating, consider use computer media over printed media.

2. Motivation - use film, text, feedback, or personal dialogues to motivate learners to learn and maintain their interest

3. Stimulation of Analysis and Criticism - arrange discussion sessions with experts or teachers for learners, or allow them to hear pre-recorded audio or video of the experts' discussions. These processes would help the learners develop their cognitive skills

4. Advice and Consolation - either within learning materials or through personal contact such as e-mails, provide some instructions on how to use learning materials, offer suggestions on learning techniques, and include references to external learning resources

5. Practice and Evaluation - allow learners to practice what they had learned such as providing a written assignment, evaluate their performances, reward their performance especially if they were able to apply some new knowledge, and provide some feedback through an e-mail or discussing session

6. Creation of Knowledge - allow learners to discuss and share their ideas with teachers though video-conferencing, e-mail, or text 
Relationships between Dialogue, Structure, and Transactional Distance

Moore (2013) [94] claimed that "transactional distance is a function of dialogue and structure" [94, pp. 71].

- A course that had a high degree of structure and allowed little to no dialogue had high transactional distance

- A course with flexible structure and allowed dialogue through an appropriate medium had less transactional distance

The relationship between dialogue, structure, and transactional distance could be presented in a two-dimension graph (See figure 2.12).

As structure increases, transactional distance decreases

As dialogue decreases, transactional distance increases

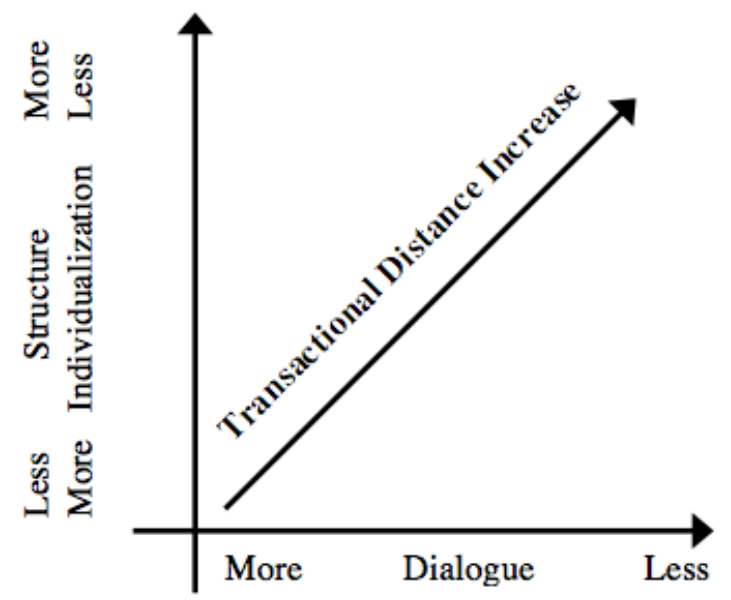

Figure 2.12: Two dimension of relationship between transactional distance, dialogue and structure by Moore (2013) [94, pp. 71]

\section{Learner Autonomy}

According to Moore (1993) [93], 
Learner autonomy is learners' ability to determine learning goals, make decision on their learning process, and evaluate learning outcomes and new knowledge they acquired from their learning experience.

The relationship between learner autonomy and transactional distance was that the greater the transactional distance, the more responsibilities learners would have had to exercise (See figure 2.13).

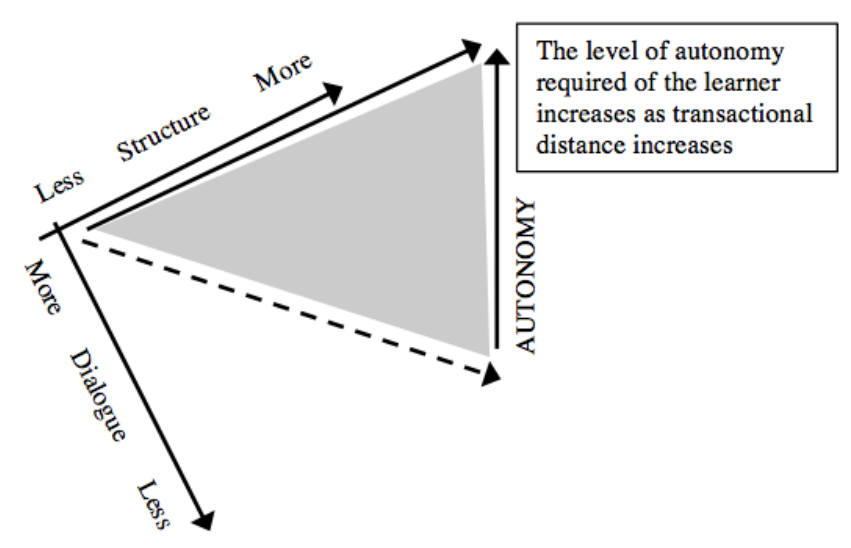

Figure 2.13: Moore's (1993) [93] illustration of relationship between transactional distance and learner autonomy

Based on an empirical study, Moore (1993) [93] found patterns among learners' personalities, dialogue, and course structure:

1. Autonomous learners were comfortable with less dialogue and less structural course. Without much dialogue with the teachers, these learners were still able to and prefer to learn on using flexible course structure

2. Non-autonomous learners, on the other hand, were more comfortable with having more dialogue with their teachers and an inflexible course structure. These learners were more heavily reliant on teachers guidance, encouragement and motivation. They needed 
the teachers to manage goal setting, manage their learning processes, and evaluate if they had successfully accomplished the learning goals.

\subsubsection{Applications of Transactional Distance Theory}

Since TDT was introduced in 1993, it contributed to a better understanding of other new platforms for distance education, such as e-learning and $\mathrm{m}$ learning.

For example, Benson et al. (2009) [14] adopted TDT as a heuristic tool to observe the six e-learning courses offered at two Australian universities. First, they divided the courses into three groups based on its transactional distance (TD) (i.e., low, medium, or high transactional distance). Next, they analysed how much dialogue the courses provided (D), how the courses were constructed (S), and the autonomy of learners (A). The following list presented their analysis of the three (out of six) e-learning courses and their proposed contributions.

1. An on-campus and classroom enhanced course - it was placed in the low transactional distance group due to the fact that learners had opportunities to meet their teacher face-to-face. Based on their observations, this course did not provide any dialogue in its e-learning platform (-D). It offered unstructured online material $(-S)$, and despite the findings showing that the learners were autonomous learners, they disregarded the learner autonomy element, as the teachers had complete control over the learner autonomy process within a classroom setting.

2. An off-campus and partially online course - it was placed in the high transactional distance group. Based on their observations, this course provided online discussion within a pre-arranged schedule $(+D)$, offered printed materials, DVD of relevant case studies, and a 
course website with the learning content $(+S)$, and the learners were autonomous learners $(+\mathrm{A})$.

3. Work-place based and blended learning courses - they were placed in the medium transactional distance group. Based on their observations, despite unknown learner autonomy, these courses provided dialogue and course structure $(+D-S)$ or $(-D+S)$. In other words, these courses provided some dialogue opportunities with a flexible course structure. Meanwhile, the course that provided no dialogue opportunity had an inflexible course structure.

Based on their observations and findings, they concluded that for the low transactional distance course (i.e., number 1 in the above list), e-learning design could provide a flexible learning course structure but disregard learner autonomy and provide no dialogue. For the high transactional distance course (i.e., number 2 in the above list), if learners were autonomous learners, e-learning should provide dialogue opportunities with an inflexible course structure. Ultimately, for the medium transactional distance course (i.e., number 3 in the above list), dialogue and course structure should be provided according to learner autonomy.

Similarly, Park (2011) [103] adopted TDT to classify some existing m-learning courses. However, they claimed that mobile technologies allowed learners to communicate not only with their teachers but also among themselves and TDT did not cover this particular aspect of social interactions. Therefore, in order to complete the classification criteria, they added Activity Theory (AT) which included social collaboration into the learning process (See section 2.3.5 for further explanation of AT) as another classification dimension.

Under the principles of TDT, a m-learning course would be placed in a high transactional distance group if the course did not provide any dialogue opportunity and its teaching and learning activities and 
material were all pre-determined and managed by the teachers (i.e., inflexible course structure). In contrast, a m-learning course would be placed into a low transactional distance group if the course provided some dialogue opportunities and had a flexible course structure.

However, using the principles of AT, a m-learning course would be classified as an individualised type if the course allowed the learners to have direct contact with the teachers and if they could maintain their independent learning processes. Meanwhile, a m-learning course would be classified as a socialised type under AT if a group of learners were allowed to work together and engage in social collaboration.

Using both of these theories, there were four types of m-learning course:

1. Type 1 - High Transactional Distance and Socialised Mobile Learning Activity (HS)

2. Type 2 - High Transactional Distance and Individualised Mobile Learning Activity (HI)

3. Type 3 - Low Transactional Distance and Socialised Mobile Learning Activity (LS)

4. Type 4 - Low Transactional Distance and Individualised Mobile Learning Activity (LI)

Aside from proposing the m-learning classification criterion, Park (2011) [103] also provided some design recommendations for each of the classification groups.

For classification type 1, the m-learning interface design should encourage social participation and observation for software and hardware compatibility across all mobile devices involved in this m-learning activity might be required.

For classification type 2, the m-learning design should ensure that learning materials were well organized and could be accessed remotely. 
For classification type 3, the m-learning design should promote social participation and provide many collaborative learning tasks, such as arranging an online discussion session.

Finally, for classification type 4, the m-learning course should provide suitable learning supports (e.g., an instruction sheet) based on the type of learning environment (e.g., in a classroom setting or a field study).

Besides functioning as a heuristic tool to classify e-learning and m-learning, much research adopted TDT principles as a key evaluation mechanism. For example, Zhang (2003) [144] proposed a survey to measure transactional distance for a web-based learning environment.

The study claimed that transactional distance was "cognitive, emotional, social, cultural, and/or physical distance between learners and other elements of their learning environments that prohibit active student engagement with learning" [144, pp.148]. This referred to the idea that the transactional distance between student and student, student and teacher, student and learning content, student and web-based interface design might prohibit students to engage with learning. In order to provide an effective web-based program, the transactional distance should be measured. They utilised questionnaire to measure the transactional distance and the results were validated using confirmatory factor and exploratory analyses. Through their process, questionnaire had been proven as a statistically reliable measurement tool for measuring transactional distance.

Despite these contributions, there were some concerns towards the applicability of TDT to m-learning. As mentioned earlier in Park (2011)'s [103] study, TDT lacked considerations towards the social collaboration aspect of m-learning and would need another learning theory (in this study they adopted AT) to fulfill this gap.

Kang \& Gyorke (2008) [63] agreed with that observation and further pointed out that TDT also lacked a social-cultural aspect which was critical in today's practice. In their comments, they compared TDT with 
the Cultural-Historical Theory of Activity (CHAT) and stated that "CHAT's tool-mediated and sign-mediated nature of all aspects of human interaction makes more sense with regards to the concept of social learning interaction" [63, pp.211] (See section 2.3.5 for further explanation of CHAT), while "TDT isolates learners from their multi-society context" [63, pp.212].

Furthermore, TDT faced challenges towards the interpretation of its original concepts. Gorsky \& Caspi (2005) [49] raised this concern in their study. It investigated published empirical studies of TDT including those from Saba \& Shearer [121], Bunker et al. (1996) [19], Bischoff (1996) [16], Chen (2001) [25, 24], and Chen \& Willits [26].

They found that these researchers constructed their empirical studies based on their personal interpretation of TDT, which were different from the original proposition. For example, Chen \& Willis (2007) [26]'s study measured frequency of communication as an extension of the dialogue element. This was in conflict with the original definition of dialogue given in TDT where it was defined as the communication that provide positive quality such as improving learners' understanding.

TDT was a long-standing theory related to distance education. It defined distance education and explained its special characteristic of physical separation between learners and teachers. Its fundamental concept, "transactional distance", referred to the isolation perception of learners when they need to take control of their own learning within such educational setting.

In addition, it introduced three elements that varied transaction distance: dialogue, course structure, and learner autonomy. As TDT developed, it proposed the existence of relationships between transactional distance and these elements, and further hypothesised interplay among them.

Since TDT was formed, it had contributed to a better understanding of distance education, and was used as a heuristic tool to observe 
e-learning and m-leaning which consequently helped develop design guidelines and recommendation. Furthermore, transactional distance was used as a key evaluation mechanism to observe the quality of teaching and learning courses. However, in the modern context, TDT was observed to lack considerations towards social collaboration and the definitions of its core concepts suffered from ambiguous interpretations in some research studies.

\subsection{Learner Autonomy \& Measurement}

TDT defined learner autonomy as learners' ability to set their own learning goals, implement learning process, and evaluate their acquired knowledge. It should be observed at the initial stage of designing a distance learning course in order to provide the learners with suitable proportion of dialogue and course structure. This section explores some factors that may help learners develop such abilities, then discusses different methodologies to measure learner autonomy.

\subsubsection{Components of learner autonomy}

The term learner autonomy had been a centrepiece in the language teaching and learning area in Europe since 1979. Holec (1979) [53] defined the term as learners' ability to take charge of their own learning.

In order to become an autonomous learner, Holec (1979) [53] and later studies such as Moore (1993) [93] and Little (2003) [77] shared the same opinion and explained that the learners should understand the purpose of their learning, take part in setting their learning goals, initiate their own learning processes, execute their own learning activities, have abilities to review their learning process and evaluate their learning effectiveness.

Much research examined crucial characteristics in learners that would help them in their autonomous learning. For example, Littlewood (1996) 
[78] claimed that the autonomy was the learners' abilities and willingness to carry out the learning independently and further explained that their abilities and willingness each had two sub-components.

Learners' abilities were dependent on their knowledge on how to use available tools and learn, which would help them make their decisions on various learning activities, such as knowing which application or feature of a smart phone could be used to access some online references.

In addition, learners needed skills to execute their decisions. For example, the learner knew the Google Chrome browser could help them access some online references. They would need some skills to be able to actually use the browser and identify which references were meaningful to their learning.

Learners' willingness would be dependant on their motivation and their confidence to act on their decisions. Figure 2.14 illustrates Littlewood's (1996) [78] components of autonomy.

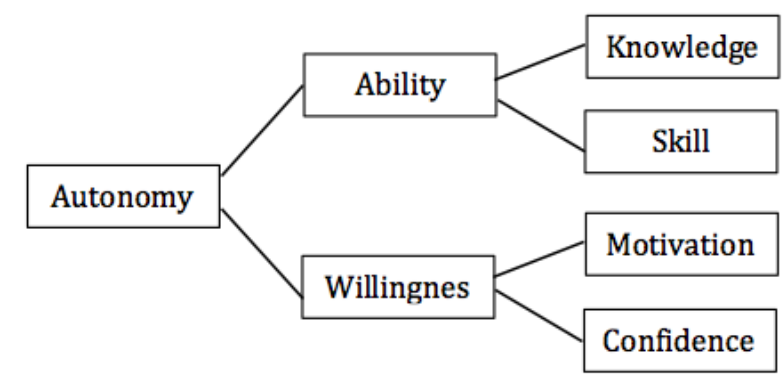

Figure 2.14: Littlewood's (1996) [78] components of autonomy[78]

Littlewood (1996) [78] further explained that a learner would successfully learn autonomously if $\mathrm{s} / \mathrm{he}$ presented these four components together. For example, a learner who had the ability to use mobile devices and communication technology but did not want to use it for m-learning, would not be considered can autonomous learner. Similarly, a learner who was willing to adopt m-learning but did not have enough ability to process the learning content would not be an 
autonomous learner either.

In an observation whether an asynchronous online interaction using e-mail communications could aid online learners to develop their autonomy, Kuar \& Sidhu (2010) [64] also observed learner's confidence and computer skills to determine whether these factors could influence learner autonomy. They suggested equipping learners with knowledge and skills on how to plan, organise, monitor and evaluate their own learning before introducing them to online learning would also help them develop their autonomy.

An autonomous learner was defined as a learner who had the ability to perform three learning processes: set their own learning goal, implement their own learning process, and evaluate their own learning outcomes. To determine if a learner was an autonomous learner, their ability to perform these processes should be measured. However, carrying out such measurement was not an easy task as this involved many factors. For example, to measure learners' abilities to implement their learning process would involve gauging learners' prior experience with learning tools (e.g., computer or mobile devices) and the learning topic, planning their learning schedule, and communicating with teachers and peers.

Littlewood (1996) [78] presented components of autonomy that were more specific and easier to be measured. Much research also claimed that these components were closely related to the autonomy of learners. Although this thesis defined learner autonomy based on the original definition given by Moore (1993) [93], the four learner autonomy components: knowledge, skills, motivation, and confident would be measured and observed to attain the overall learner autonomy. 


\subsubsection{Measuring learner autonomy}

Based on the studies by Littlewood (1996) [78] and Kuar \& Sidhu (2010) [64], the components of autonomy were motivation, confidence, skills, and knowledge and an autonomous learner would be a learner who demonstrated that $\mathrm{s} /$ he had all of these components. Hence, measuring these components in a learner could identify if a learner was autonomous or non-autonomous.

There were many proposed measurement scales to gauge learners' motivation. For example, Tuan et al. (2005) [137] proposed using a questionnaire to measure students' motivation towards science learning (SMTSL). They divided questions related to motivation into six scales for measurement (i.e., self-efficacy, active learning strategies, science learning value, performance goal, achievement goal, and learning environment simulation). In order to prove the questionnaire's applicability and reliability, the scales were used to measure junior high school students' motivation to learn science.

Dermitzaki et al. (2013) [36] also adopted this questionnaire to measure motivation of the learners at two Greek universities. The study proved that the questionnaire could be used to measure learners' motivation effectively regardless of the difference in learners' culture and age.

Despite its potential to measure learners' motivation, the existing questionnaire from SMTSL could not be directly applied to m-learning as SMTSL was primarily designed to measure motivation in an actual classroom. Therefore, some amendments would be needed for the questionnaire to be applicable in a m-learning context. For example, in the SMTSL, they asked if learners had active learning strategies. This could be adjusted in a m-learning context to ask if learners actively used a variety of strategies to learn individually and remotely.

Similar to the motivation aspect of learner autonomy, there were many existing measurement scales for measuring confidence. For 
example, Compeau \& Higgins (1995) [31] proposed a measurement scale of computing self-efficacy that measured how much users believed in their capabilities to use computers, while Hsu \& Chiu (2004) [56] presented a questionnaire which measured the Internet self-efficacy. However, their questions were more likely to use a task-oriented approach.

Roca \& Chiu (2006) [118] adopted these two measurement scales in their e-learning service acceptance study. These scales could also be used in a manner similar to Roca \& Chiu's (2006) study to measure learners' self-confidence in using m-learning applications and carrying out m-learning related tasks such as using various media (text, audio, animation video) and other learning support functions such as quiz game, chat, and assignment.

For the knowledge and skills aspects of learners autonomy, one possible measurement methodology was direct questioning. Developers could ask learners if they know how to perform a learning task (i.e., to observe knowledge) and if they had performed the task previously (i.e., to observe skills).

However, m-learning was a practical based learning, therefore the learners could gain knowledge and develop their skills required in m-learning by, for example, asking their teachers, searching from online resources, and practicing until they had enough skills to perform the tasks on their own. Therefore, it would be more appropriate to allow the learners to discover and practice m-learning tasks on their own, but provide some support mechanisms such as allowing them to contact their teachers or give them access to the Internet and observe if they could perform these tasks.

Smura et al. (2009) [130] presented some tasks essential for general m-learning including calling, messaging, using multimedia presentation, sharing and receiving files. These tasks could form an observation checklist for measuring learners' knowledge and skills in m-learning. 
Based on the literature review, an autonomous learner was a learner who was willing - motivated and confident, and had the abilities knowledge and skills, to perform the required tasks. To be able to learn autonomously, a learner must possess all of these components. In order to determine if a learner was an autonomous learner, developers could measure each of these components via questionnaires and observations. Additionally, once learners were determined to be autonomous, this would imply that they had the ability to carry out all three activities (i.e., setting learning goal, implementing learning process, and evaluating their learning effectiveness and acquired knowledge) defined in the learner autonomy element of TDT.

\subsection{Other Learning Theories}

As discussed in the previous sections, TDT could potentially guide the design of m-learning application. However, its lack of consideration towards social participation, which was a common practice in modern day m-learning, raised some concerns that TDT might need to be complemented by other learning theories to develop an effective design guidelines for m-learning. Among many exciting learning theories, this section introduces only a few learning theories that have the potentials to contribute to the development of m-learning design guidelines alongside TDT.

\subsubsection{Cognitive Load Theory}

In the principles of TDT, the concept of course structure was not expanded to clarify how the learning tasks should be presented in a manner suitable to the learners. However, the Cognitive Load Theory (CLT) could address this gap.

In 1998, Sweller et al. (1998) [134] introduced CLT as a theory that "... 
has been designed to provide guidelines intended to assist in the presentation of information in a manner that encourages learner activities and optimize intellectual performance" [134, pp. 251]. According to Sweller et al., there were three types of cognitive load:

- Intrinsic cognitive load that deal with complexity inherited in learning tasks

- Extraneous cognitive load that deal with non-relevant elements such as decorating pictures and animation that required extra mental processing and did not promote learning

- Germane cognitive load that provided actual benefits to learning and deal with information processing resulting in schema construction and automation

The three additive cognitive load types together formed a working memory load that learners needed to invest in their learning process. Building on CLT, many studies proposed various instructional designs to decrease the working memory load. For example, Clarke (2005) [29] claimed that presenting learning tasks with a progressive method (i.e., presenting a simple task first and add more complexity to the task later) would decrease intrinsic cognitive load. In their experiment, they used spreadsheets to assist mathematics learning. One group was trained to use spreadsheet first and learned about mathematics skills later (i.e., sequencing learning method). Meanwhile, the other group learned both skills concurrently. They found that learners who had no prior knowledge working with spreadsheets performed better using the sequencing learning method compared to the concurrent learning method. Meanwhile, for learners who had prior knowledge of spreadsheets, the opposite result occurred. Based on these outcomes, carrying out tasks via the sequencing learning method from simple to complex bear implications to the cognitive load, but this was only 
applicable to learners who had low level of prior knowledge on the learning topic.

Similarly, Schnotz \& Rasch (2005) [122] used animation to increase learners' motivation and germane cognitive load. They claimed that comparing to static image, animation had enabling function that would encourage more interactions and facilitating function that would help learners understand learning content and ease their cognitive process. Although these functions could potentially reduced cognitive load, they found that using animation did not improve the overall learning performance in learners who had little prior knowledge of the learning topic because the facilitating function of animation reduced their germane cognitive load. Therefore, Schnotz \& Rasch suggested that animation was only beneficial in some circumstances and might otherwise have negative effects to the overall learning performance.

\subsubsection{Self Determination Theory}

In Moore's (1993) [93] six instructional processes related to TDT and distance education (See the course structure elements of TDT in section 2.2.2), motivation was one of the proposed processes. It encouraged teachers to motivate learners to learn using rich media presentation and dialogue features. The Self Determination Theory could provide some insights on how learners could be motivated in the context of m-learning.

According to Ryan \& Deci (2000) [120], "To be motivated means to be moved to do something. A person who feels no impetus or inspiration to act is thus characterised as unmotivated, whereas someone who is energised or actively working towards an end is considered motivated." [120, pp. 54]. According to the study, there were two types of motivation: intrinsic and extrinsic motivation. Intrinsic motivation was defined as "the doing of an activity for its inherent satisfactions rather than for some separable consequence." [120, pp. 56]. 
Malone \& Lepper (1987) [85] further explained the relationship between learning and intrinsic motivations and that intrinsic motivation could be triggered by providing learners with perceptions of challenge, curiosity, control, fantasy, cooperation, competition, and recognition.

Extrinsic motivation was defined as "a construct that pertains whenever an activity is done in order to attain some separable outcome.âĂİ [120, pp. 60]. This was in contrast with intrinsic motivation as learners were motivated by external validation or rewards such as good grades and scholarships rather than personal rewards.

Schwabe \& Göth (2005) [123] designed a mobile game prototype based on the relationship between learning and intrinsic motivations. It was used on orientation day to introduce learners to their surroundings at the university. It displayed the position of each learner on the digital map on the their own hand-held devices. The learners would be asked to perform activities such as answering questions before moving to other locations. Based on their evaluation, the game had potential to enhance learning, as most of the participants enjoyed the game and would like to play it again.

Muntean (2011) [96] claimed that both types of motivations could work together within gamification to raise engagement levels in e-learning. According to their research, gamification was "the use of game play elements for non-game applications, particularly consumer-oriented web and mobile sites, in order to encourage people to adopt the applications." [96, pp.325]. Gamification could motivate learners intrinsically by triggering their sense of competition and cooperation, and motivate them extrinsically using rewards such as level progression, points, and badges. They claimed that gamification could improve learning performance.

Nevertheless, Rosenfield (1980) [119] expressed concerns that using rewards to extrinsically motivate learners might unintentionally decreased their intrinsic motivation, known as "overjustification effects". Therefore, they suggested that if learners had already found that the 
learning was intrinsically rewarding, extrinsic rewards should not be applied.

\subsubsection{Media Richness Theory}

One of the six Moore's (1993) [93] proposed instructional processes related to TDT and distance education was presentation. TDT proposed that using a variety of media to present learning content could potentially motivate learners to learn, engage them during their learning process, and decrease their perception of transactional distance.

The rapid development of software and hardware on computers and hand-held devices vastly improved multimedia presentation on these devices. Sun \& Cheng (2007) [133] claimed that integrating multimedia into e-learning could increase learners' willingness to read and attract their attention. However, they argued this might be costly to implement and there were no solid evidence to confirm its effectiveness towards learners' genuine understanding of learning content. Hence, developer might need a deliberate plan on how to integrate multimedia into a m-learning application.

In 1983, Daft \& Lengel (1983) [35] introduced Media Richness Theory and the term "media richness", which was defined as the ability of various media in facilitating a shared understanding among a group of people and eliminating any ambiguous communication within an organization. Despite recognising these potentials of multimedia presentation, Media Richness Theory also raised awareness that too much multimedia could distract the learners and worsen their learning performance.

According to Sun \& Cheng (2007) [133], media richness had four characteristics: able to provide immediate feedback, transmit multiple cues (e.g., body gesture and voice inflections), provide variation, and adapt to each individual. Within this framework, face-to-face communication which had all these characteristics was considered as a 
rich media. On the other hand, a numerical report would be placed at the lowest rank in rich media classification. Sun \& Cheng (2007) further examined how instructional media affected learners' performance and satisfaction. They designed two e-learning courses: one course which explained the meaning of a Chinese poem to represent highly abstruse learning content, and another course which demonstrated a number system transformation scheme to represent non-abstruse learning content, and delivered these courses with high and low media richness. For high richness media, they chose a Macromedia Flash animation which included sound, images, and music. For low richness media, they chose text and numbers to present the learning content. Figure 2.15 presented their designs.

Sun \& Cheng (2007) [133] evaluated both learning scores and learners' satisfaction. They found that for the e-learning course with highly abstruse content, high media richness had positive effects on the learning scores and satisfaction. On the other hand, they found no significant difference in the learning scores and satisfaction for the e-learning course with non-abstruse content delivered using either high and low media richness. Therefore, for highly ambiguous and abstruse learning content, rich media such as animation would be appropriate for its delivery. Meanwhile, for unambiguous and non-abstruse learning content, rich media was not necessary.

\subsubsection{Learning Theory of Andragogy}

In regards to learner autonomy, TDT defined it as learners' ability to set their own learning goal, implement learning process, and evaluate learning outcome. It also hypothesised that autonomous and non-autonomous learners preferred different course structures and varying extent of dialogue. The Learning Theory of Andragogy indirectly supported these proposition. It proposed that maturity had significant 


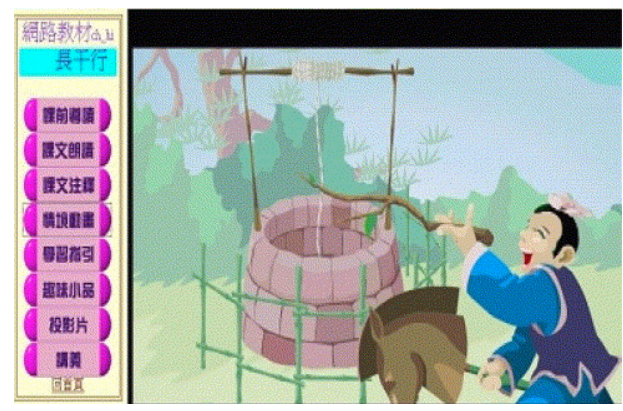

(a) Poem - High richness media

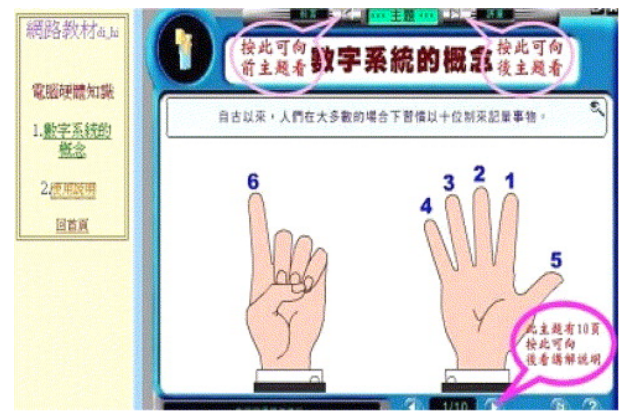

(c) Number - High richness media

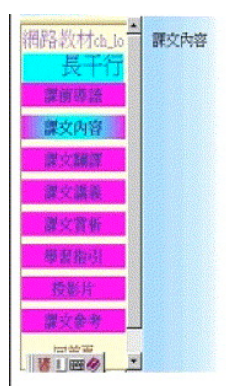

長种

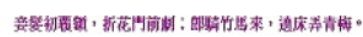

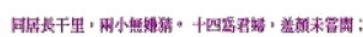

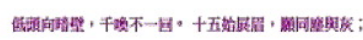

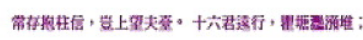

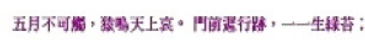

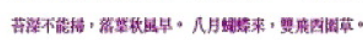

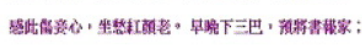

(b) Poem - Low richness media

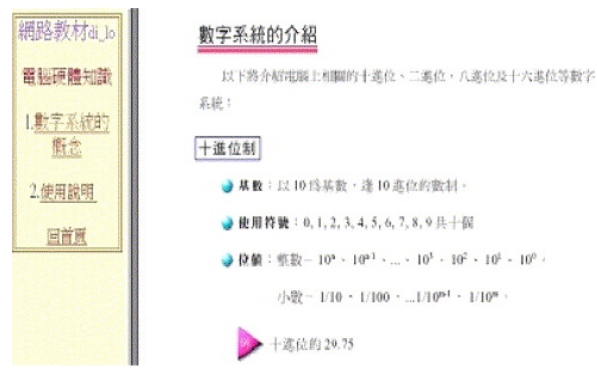

(d) Number - Low richness media

Figure 2.15: E-learning course designs by Sun \& Cheng (2007) [133]

effects on how learners learned. That is to say, adult learners would have different cognitive process and should be motivated differently when compared to children learners.

Cercone (2008) [22] predicted characteristics of adult learners that could have implications for the instructional design of online learning. Such prediction was mainly grounded on Knowles et al.'s (1970) [66] Learning Theory of Andragogy and was complemented by multiple other theories, such as Lowry's (1989) [84] Self-directed Learning, Merriam's (1991) [87] Knowledge of Experienced Learning, and Mezirow's (1997) [88] Transformative Learning Theory. According to Cercone (2008), adult learners had thirteen characteristics:

1. Adult learners have some limitations - Teachers should consider, for example, providing large enough and easy to read fonts, using some 
visual presentations such as images, charts, and tables, providing clear menu structure, and ensuring that culture bias is not included within the course

2. They have their individual learning experience and preference, therefore they should be allowed to learn at their own pace Teachers, in addition, should provide enough online learning resources

3. They like to be involved in their own learning process. Therefore, they should be allowed to learn autonomously - Teachers, in addition, should arrange regular communication sessions with individual and group learners

4. They need teachers to provide foundation material such as coaching audio file, resources, examples, or scenarios to assist them in completing their learning tasks

5. They have their own pre-existing learning history and might need some time to adjust themselves to a learner-centered paradigm Teachers should encourage learner participation and collaboration

6. They need teachers to be facilitators who arrange appropriate course environment for them and summarise learning lessons for closure.

7. They have their own prior experience - Teachers should include some learning activities that allow learners to use their prior knowledge, provide clear explanations on how new learning topics can be linked to learners' prior experience

8. They want to see the connection between their learning content to their real lives - Therefore teachers should provide learning activities related to real life situations and encourage learners to apply their own experience in this learning process 
9. They need to feel that their learning focused on topics that would directly concern them (i.e., they wanted to know why they should learn things and what benefits they will get from learning those particular subjects) - Teachers should provide clear explanations on how the knowledge learned could be applied practically

10. They need self-evaluations to challenge themselves - Teachers should reward them for success

11. They prefer collaborative and mutually respectful learning environment - Teachers should allow them to freely express their opinions and arrange a comfortable learning environment

12. They need opportunities for self-reflection - Teachers should provide periodic opportunities for learners to discuss how they managed their online course

13. They need dialogue and social interactions - Teachers should provide collaborative learning activities between peers

\subsubsection{Activity \& Cultural-Historical Activity Theory}

As pointed out previously, TDT did not allow for social participation which was a common practice in m-learning. Activity Theory (AT) and Cultural-Historical Activity Theory could both fulfill this gap.

According to Kuutti (1996) [70], Activity Theory (AT) was first developed around 1920s by Lev Semyonovich Vygotsky within Soviet psychology. They defined AT as "a philosophical and cross-disciplinary framework for studying different forms of human practices as development processes, at both individual and social levels interlinked at the same time" [70, pp. 23]. Based on the definition, it was a framework or descriptive theory rather than a predictive theory. AT looked beyond just the core concept of learners carrying out activities to achieve desired 
learning goals. It accounted for other factors such as environment, culture, motivation, mediated tool, and more as elements of an activity system.

Engeström (1987) [39] presented the activity triangle model (See figure 2.16) which helped explain how this wide range of elements worked together. The subjects were socio-culturally embedded actors that interacted with objects within the community through the use of instruments, rules, and division of labour.

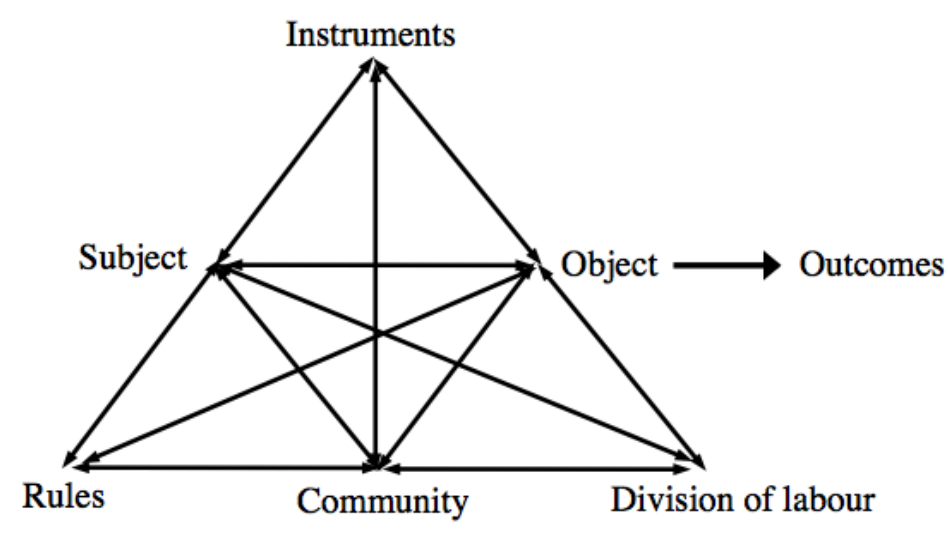

Figure 2.16: Example of a personal-mobile knowledge and learning organisation system [139]

Cultural-Historical Activity Theory (CHAT) had three significant components: cultural theory, historical theory, and activity theory. According to Foot (2014) [44], "Cultural points to the premise that humans are enculturated, and everything people do is shaped by and draws upon their cultural values and resources" [44, pp. 3]. Since cultures were gradually developed over time, to analyse peoples' behaviour, the historical path of the behaviour should also be considered. CHAT, same with $\mathrm{AT}$, was also a framework or descriptive theory that explained and provided understanding of human activity. However, CHAT included not only the interrelationship between the six elements presented in Engeström's (1987) [39] activity triangle model (See figure 2.16), but also 
cultural and historical dimensions.

For teaching and learning activity, AT could contribute to a better understanding of how an instrument-mediated learning activity could be used as a framework to evaluate its applicability within a particular learning context. For example, Waycott et al. (2005) [140] adopted AT to analyse the applicability of PDAs (i.e., as an instrument) to support life-long learning within three particular learning contexts: distance learners using e-book on PDAs; industrial workers using PDAs to access information when they were away from their offices; and learners using PDAs in an art gallery. The first two contexts were similar in the sense that the learners owned the PDAs and they used it in a stationary fashion, such as sitting at a desk or travelling on a train. Meanwhile in the third context, PDAs were loaned to the learners and they used it when they were roaming around the art gallery.

Waycott et al.'s observation results indicated that the learners who were the subject of the learning system integrated their past experiences, personal preference, motivation, and daily schedule into their PDA adoption. They reported that PDA could support life-long learning. However, some of learners who were new to using PDAs faced difficulties typing on them and preferred to use a computer keyboard instead. The PDAs, which were the instrument within the learning system could not completely replace other tools such as laptops and / or desktop computers because PDAs could not support every required activity. For example, it did not allow the learners to take personal notes when they were roaming around the art gallery. Thus, the role of the PDAs was a complementary instrument within these particular learning contexts.

TDT had the potentials to guide the pedagogical design of m-learning. However, it could not provide a comprehensive foundation for developing m-learning design guidelines, and would require other complementary learning theories, such as those discussed in this section, 
in order to address any gaps within TDT and ensure quality of the TDT theoretically-based design guidelines. These complementary theories proposed strategies for motivating learners, presenting learning tasks appropriately and using the right amount of media, as well as understanding learner autonomy and adding social participation to TDT.

\subsection{Student Engagement \& Measurement}

Much research claimed that engagement could be used to predict system success. For example Hwang \& Thorn (1999) [58] performed a meta-analysis on 25 studies in an attempt to find if engagement (in which they defined as involvement) had any effect on system success. Their findings found positive correlation between the two. Likewise, Carini (2006) [21] also found positive linkage between student engagement and learning performance.

Attfield et al. (2011) [11] referred to engagement as the positive interaction that could captivate users in web-application design. They further explained that the application would be considered successful if it was used by users as well as being able to engage them.

Within the realm of learning, many studies claimed that engagement could be used as a key evaluation criterion for an institution's quality. For example, Kuh (2001) [69] claimed that high quality institutions were those that could engage students using a variety of activities and contribute to value outcomes.

Similarly, Pontius \& Harper (2006) [109] claimed that "Student engagement represents a critical benchmark of educational effectiveness for graduate as well as under-graduate students" [109, p.47].

Finally, Robinson \& Hullinger (2008) explained that even though measuring students' knowledge was an important practice in evaluating quality of teaching and learning, in an online learning context, quality of learning experience and student engagement were also the other key 
evaluation criterion.

These studies provided evidence that student engagement could be used as an evaluation tool to observed the quality of learning design. The following sections define the concept of engagement and identify its characteristics and measurement methodology.

\subsubsection{Definition of Engagement}

Much research linked engagement to the term involvement and participation. For example, Barki \& Hartwick (1998) [13] defined engagement as involvement of users at a psychological level and further claimed that it could be observed through users' participation.

Likewise, Hwang \& Thorn (1999) [58], found that engagement referred to either involvement, participation, or both through their literature study. According to their study, involvement referred to users' mental reaction to the system design, while participation referred to users' behaviour towards that design. Furthermore, their study pointed out that involvement led to participation.

Similarly, Attfield et al. (2011) [11] defined engagement as the connection between users' emotion and cognitive process which could influence their behaviour when they interacted with the system.

Within the realm of learning, engagement was defined in a similar fashion. For example, Krause (2005) [68] defined it as the effort students spent to devote to learning in order to reach their learning outcomes.

On the other hand, Coates (2007) argued that engagement was not a single element of a student's effort to his/her own learning process. It also involved other participatory activities (e.g., communication among students and collaborative learning).

Within the realm of teaching and learning, engagement was defined as learners' psychological process which drove their behaviour in their learning process. In this m-learning study, student engagement was 
involvement, participation, and effort that a learner invested in learning on a mobile device. Although the student engagement could not genuinely inform whether the learner gained any knowledge from the learning (e.g., an engaged learner might not get a good grade in an exam), the study used student engagement to measure learning quality based on an assumption that if a learner was willing to spend the time and effort to be involved and participate in an m-learning design process, there was a possibility that the learner would succeed in learning.

\subsubsection{Measuring Engagement}

This thesis' literature review process uncovered many available engagement models. For example, Bulger (2008) [18] proposed Classroom Behavioural Analysis System (CBAS) that measured student engagement in college writing class.

Additionally, Lehmann (2012) [71] proposed a model for measuring user engagement for an online services.

Furthermore, O'Brien \& Toms' (2008) [100] carried out a critical multidisciplinary literature review and an exploratory study of users carrying out web searching, online shopping, Webcasting, and using gaming applications. They proposed a conceptual framework for defining user engagement with technology. In their later research, O'Brien \& Toms (2010) [101] identified six attributes of engagement (i.e., perceived usability, aesthetics, novelty, felt involvement, focused attention, and endurability). Based on reliability analysis and exploratory factor analysis, they further claimed that these six attributes were interconnected and should be considered together in an engagement observation. The following list defined each of the six attributes of engagement and presented questionnaire items that could be used to measure engagement for software application.

- Focused attention - user's concentration on only one stimulus 
activity and ignored the others [141, 100]

- Aesthetic - visual beauty that attracted user, stimulated user, and promoted user's attention [100]

- Novelty - provided features that user found surprising, new, and unfamiliar [101]

- Repeatability - overall evaluation of users' experience (e.g. perception of usefulness, enjoyment, and accomplishment) that encouraged users' willingness to repeat the tasks and recommend it to others [100]

- Involvement - user's feeling of being encouraged to participate and be involved with the provided activities

- Perceived usability - users' emotional experience while they were performing provided activities, (i.e., "annoyed", "frustrated", "stimulated", "discouraged", and "confused") [101]

This study adopted O'Brien \& Toms' (2008) [100] six attributes of engagement to measure student engagement due to its credible approach and applicability to m-learning. Measuring the six attributes would inform how much a learner felt engaged to the m-learning prototype design.

\subsection{Usability Design}

In previous sections, the Transactional Distance Theory (TDT) and other learning theories and their capabilities to contribute to building functional and pedagogical design guidelines of m-learning were discussed. However, the TDT-based theoretical design guidelines still lacked consideration towards interface design, an element critical to 
ensure the resulting application design would be usable, easy, and enjoyable to learners.

Unfortunately, according to Dix (2009) [37], designing the usability aspect for a new application such as m-learning could take a lot of time and required many skills. The study further suggested adopting existing best practices commonly incorporated in usability design guidelines, design principles, or heuristics.

There were three long-standing design guidelines for global interactive systems that influenced many ensuing interface design guidelines for general mobile devices and modern education platform such as e-learning and m-learning.

\subsubsection{Basic Design Checklist}

In 1988, Norman [99] proposed a basic design checklist highlighting the importance of users and providing ease-of-use:

1. Provide visibility - make all available options to be easily visible to users

2. Provide feedback - give clear explanations for the consequence of a user's action

3. Provide good conceptual model - make the overall design of the system easy for users to draw a conceptual map, so they can comprehend the relationships between different parts of the system and navigate themselves easily

4. Provide clear mapping between goals and required actions, the actions and results, and the results and achievements

Figure 2.17 presents an evaluation of a mobile learning application based on Norman's (1988) [99] checklist. The application called "iLearn Geography", downloaded from Apple's app store on September $5^{\text {th }}, 2017$. 


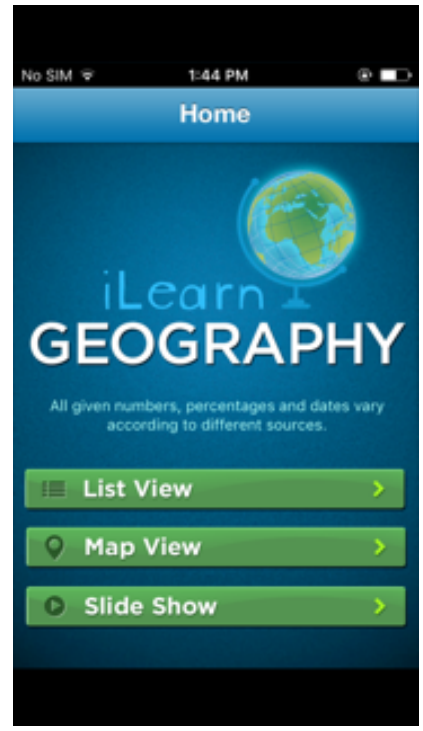

(a) Main menu

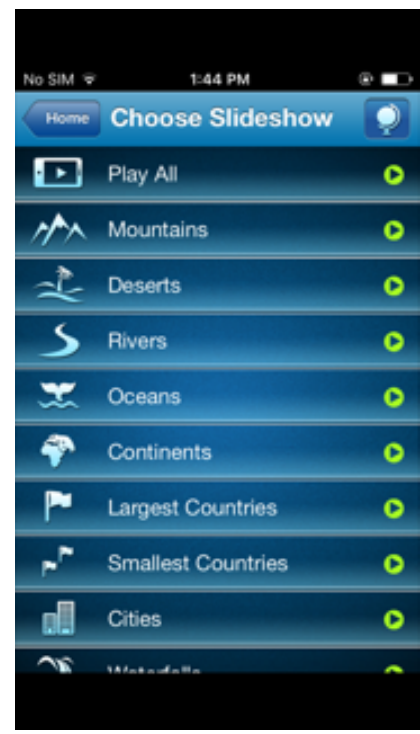

(b) Sub-menu

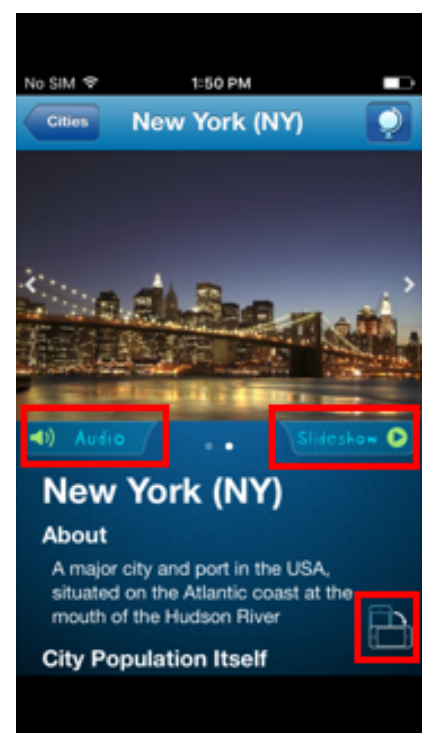

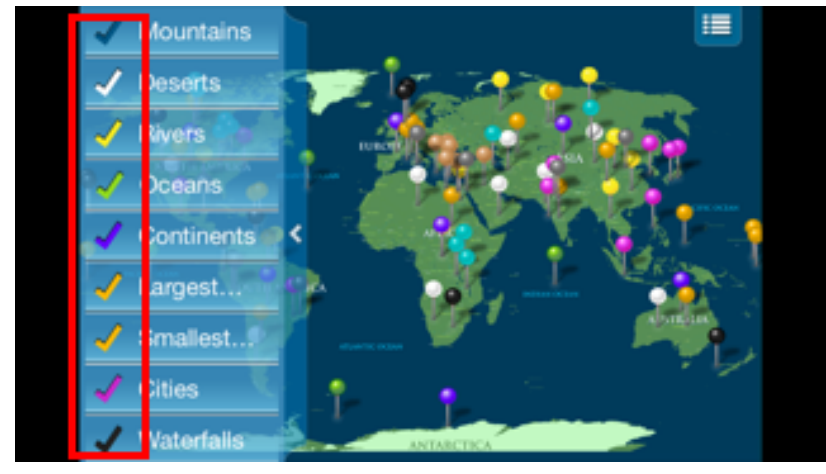

(d) Graphical content

(c) Text content

Figure 2.17: Screenshots of "iLearn Geography" a m-learning application downloaded from Apple's app store

Overall, the application provided visibility: it used menu interface design to present available options (See figure 2.17a and 2.17b); it used 
icons that represented the actions. For example, a speaker and rotational icons were used to inform learners of available audio files and rotational ability respectively (See figure $2.17 \mathrm{c}$ ).

The application provided a good conceptual model by presenting a hierarchical menu interface design which helped learners depict the flow of information and navigate through the application smoothly.

Although the application used colours and tick signs (See figure 7.12d) to inform users that there were some hidden information on the map, it did not provide any clear instruction on how the users could open the hidden information on the screen. Without the instructions, users might miss some important information.

\subsubsection{Eight Golden Rules of Interface Design}

In 1988, Shneiderman (1988) [126] proposed the "Eight Golden Rules of Interface Design". Similar to Norman's [99] guidelines, the eight golden rules of interface design had a user-centered concept and aimed to ensure interface design effectiveness and usability.

The eight golden rules were:

1. Strive for consistency - provide language consistency and ensure that in similar situations, users are required to act in consistent sequences

2. Enable frequent users to use shortcuts - reduce operations for any regular performance

3. Offer informative feedback

4. Design dialogue to yield closure - inform users clearly where they are, what they are doing, and provide them with closure when they have accomplished any task

5. Offer simple error handling - provide a design in which users cannot make a serious error. If they make an error, provide them with a 
simple and comprehensible solution

6. Permit easy reversal of actions - if users make any input mistake, allow them to undo their actions

7. Support internal focus of control - allow users to feel in control of the system and that they are the one who initiate actions

8. Reduce short-term memory load - do not burden users with any complicated sequence, code, numbers, or other information that they need to process using their short-term memory

The eight golden rules of interface design influenced many other interface design guidelines for mobile devices that followed. For example, Gong \& Tarasewich (2004) [48] proposed guidelines for the interface design of hand-held mobile devices in which four of the eight golden rules remained unchanged (i.e., enable frequency users to use shortcuts, offer informative feedback, design dialogue to yield closure, and support internal locus of control). The other four rules were modified:

1. Consistency - aside from language consistency, provide media display consistency (e.g., text, audio, and visual presentation) across all mobile operating system platforms

2. Reversal of actions - as mobile devices had less memory storage to store the past action events, allow users to undo any accidental actions as soon as possible to reduce excessive storage requirement

3. Error prevention and simple error handling - small buttons of mobile devices could increase the potentials of accidental actions, users should not be allowed to perform a simple action (e.g., one press power on/off) that could result in harmful consequences (e.g., lose all stored-data) 
4. Reduce short-term memory load - as mobile devices users had more possibility to get distracted by their surroundings (e.g., when they used the device on their move), provide alternative interactions such as using a voice control instead of a button press to activate some features

They added seven further guidelines:

1. Design for multiple and dynamic contexts - allow users to adjust display output such as brightness and volume to suit immediate context

2. Design for small devices - provide alternative interactions. For example, a speech input could be used as an alternative to small virtual buttons and and audio output could be used instead of text and graphics

3. Design for limited and split attention - provide interface designs that require as little attention as possible. For example, an audio or a tactile output could be used instead of a visual display

4. Design for speed and recovery - as mobile devices users would easily lose their interest if they needed to wait for few seconds, provide a quick access and a functionality that saves and restores users' progress

5. Design for top-down interaction - present information using hierarchical mechanism

6. Allow personalisation - as mobile devices were considered to be more personal when compared to other stationary computers, allow users to self configure the application

7. Design for enjoyment - mobile interface design should be useful, fun, and visually pleasing 
Similarly, Jones \& Marsden (2006) [61] presented some guidelines based on the Schneiderman's eight golden rules, but focused on mobile devices' hardware constraints. They suggested using menu interface design and arranging it either in concave or wide-shallow tree hierarchical order. They further proposed using: an icon in a menu title to provide visual cue; providing an on-screen manual or a link to an online manual if mobile devices' screen was small; presenting content concisely; and using bold or italics to help users with their skim reading.

\subsubsection{Heuristic Evaluation}

In addition to the two usability and interface design guidelines discussed previously, Nielsen \& Molish (1990) [98] proposed heuristic evaluation as an inspection method for investigating software usability in general.

In 1990, Nielsen \& Molich (1990) [98] tried to reduce the complexity of investigating software usability by specifying nine usability heuristics as a usability checklist for user interface evaluation, including: provide simple and natural dialogue; speak the user's language; minimize user memory load; be consistent; provide feedback; provide clearly marked exits; provide shortcuts; provide good error messages; and prevent errors.

They further suggested that the heuristic evaluation could be done at the early stage of the development process by a small group between three to five evaluators who were independent from each other. The evaluators would inspect and judge an interface design according to the heuristics and report positive and negative aspects of the interface. Therefore, this evaluation technique was cost effective and required minimal advance planning.

In 1995, Nielsen (1995) [97] published an improved list which included ten concrete usability heuristics:

1. Visibility of system status - inform users about current status using an appropriate feedback and within a reasonable time 
2. Matching system and the real world - avoid using system-oriented terms. Instead, use language that users are familiar with and present them in logical order

3. User control and freedom - provide "undo" and "redo" options for users so they could exit out of or retrieve their actions

4. Consistency and standards - follow platform convention and make sure all words and actions are consistent throughout the system

5. Error prevention - provide clear indications to avoid error. If there is an error, provide a clear error message

6. Recognition rather than recall - make all objects, actions, and options visible to users. They should not need to remember any information or instruction from screen to screen.

7. Flexibility and efficiency of use - design for both experienced and inexperienced users by allowing users to configure their application to suit their competency and preference

8. Aesthetic and minimalist design - only present relevant dialogue

9. Help users recognise, diagnose, and recover from errors - inform users about errors in understandable language and provide them with constructive solution

10. Help and documentation - provide help and documentation that could easily be found by users, and clearly list what they should do in concrete steps

Much research extended Nielsen's (1995) [97] heuristic checklist to suit specific domains. For example, Reeves et al. (2002) [113] adopted some of Nielsen \& Molich's (1990) [97] original heuristic work, applied them to e-learning context, and added more heuristics to cover all aspects 
of e-learning. The following was Reeves et al. (2002)'s extended checklist and sample questions that evaluators could ask themselves when they evaluate an e-learning system [113, pp.4-6].

1. Navigation support

- Does the interface of the e-learning program speak for itself so that extensive consultation of a manual or other documentation is kept at a minimum and does not interfere with learning?

- Does the e-learning program provide user-friendly hints and/or clear directions when a learner requests assistance?

- Does the e-learning program include a map or table of content that allow the learner to see what has been seen and not yet seen?

2. Interactivity

- Does the e-learning program provide meaningful interactions for a learner, rather than simply presenting long sections of text?

- Does the e-learning program engage a learner in completing content-specific tasks and problems to solve that take advantage of the state-of-the-art e-learning capabilities?

3. Message design

- Is the most important information placed in areas on the screen that are most likely to attract attention?

- Does the e-learning program follow good information presentation guidelines for organisation and layout?

4. Learning design

- Does the e-learning program follow an appropriate learning design to achieve its stated objectives? 
- Does the e-learning program engage a learner in tasks that are closely aligned with the learning goals and objectives?

5. Media integration

- Is included media obviously superfluous, i.e., lacking a strong connection to the objectives and design of the program?

- Is the most appropriate media selected to match message design guidelines or to support instructional design principles?

- If appropriate to the content, are various forms of media included for re-mediation and/or enrichment?

6. Instructional Assessment

- If appropriate to the content, does the e-learning program provide opportunities for self-assessments that advance learner achievement?

- If appropriate to the content, do assessments provide sufficient feedback to a learner to provide remedial directions?

- Wherever appropriate, are higher order assessments (e.g., analysis, synthesis, and evaluation) provided rather than lower order assessments (e.g., recall and recognition)?

\section{Resources}

- Does the e-learning program provide access to a range of resources (e.g., examples or real data archives) appropriate to the learning context?

- If the e-learning program includes links to external World Wide Web or Intranet resources, are the links kept up-to-date?

- Are resources provided in a manner that replicates as closely as possible their availability and use in the real world? 
8. Feedback

- Is the feedback given at any specific time tailored to the content being studied, problem being solved, or task being completed by the learner?

- Does feedback provide the learner with information concerning his/her current level of achievement within the program?

- Does the e-learning program provide learners with opportunities to access extended feedback from instructors, experts, peers, or others through e-mail or other Internet communications?

Similarly, Yanez et al. (2004) [143] also applied the same method when building their heuristic evaluation checklist for mobile devices. They adapted Nielsen \& Molich's (1990) [97] original heuristic checklist to a mobile-devices' context and added some new criteria from mobile device interface design best practice and recommendations. The following list represented Yanez et al.'s (2004) additional criteria and example questions that evaluators could asked themselves when they evaluate a mobile device's design [143, pp. 10].

1. Skills

- If the system supports both novice and expert users, are multiple levels of error massage details available?

- Do the selected input device(s) match user capability?

2. Pleasure and respectful interaction

- Protect users' work, and for data entry screens with many fields or where source documents may be incomplete, can users save a partially filled screen?

- Are typing requirements minimal for question and answer interface? 


\section{Privacy}

- Can protected areas be completely inaccessible?

- Can protected or confidential areas be accessed with certain passwords?

All three usability guidelines presented in this section (i.e., Norman' s basic design checklist (1988) [99], Shneiderman's eight golden rules of interface design (1988) [126], and Nielsen \& Molish's heuristic evaluation (1990) [98]) could potentially guide the usability design of m-learning applications. This thesis proposed adding them to the TDT theoretical design guidelines developed in this thesis to form a comprehensive set of guidelines that would encompass pedagogical and usability aspects of m-learning application design and ensure the design's effectiveness to m-learning users.

\subsection{Learner Persona \& Scenario}

In menu-based voice interfaces for telephone system, if developers did not consider limitations of human working memory, which was limited in capacity and decay rapidly, they might overload users' memory with too many choices (e.g., press 1 to ..., press 2 to ..., press 3 to ..., and so on), the users might forget these choices quickly and eventually made mistakes with their selection.

Although the principles of TDT, other learning theories and available usability design guidelines could be drawn upon as the basis for the pedagogical and interface design aspects of this thesis' m-learning application design guidelines, and that the ensuring design guidelines should provide some degree of confidence that the developed application would be effective and could enhance learning quality, the application would only be used by specific group of learners within a specific 
domain. As a result, the design process would still need an initial user study to understand the target group of learners.

According to Jones \& Marsden (2006) [61], understanding user was an important activity in mobile interaction design process that helped developers to select better design choices.

Parsons et al. (2006) [104] added that identifying m-learning users would help developers create a better and more personalised learning experience.

As an example suggested by Jones \& Marsden (2006) [61], the user study could be carried out by performing a field study, through direct questioning in an interview, or gather user's data from a questionnaire. The gathered information from the user study had to be transcribed, organised and presented in a proper format in order to capture some key elements and design issues that could guide the development team and inform a usable and effective design.

According to Dix (2009) [37] the information from the user study could be presented in many ways. For example, a persona which was a descriptive fictional character representing real users; a story-based scenario to inform how a design was used; hierarchical task analysis to arrange users' performance hierarchically to provide understanding on how users managed to achieve their goals; and dialogue specification which focused on the interaction of users' input and system's response.

However, Pruitt \& Adlin (2010) [111] claimed that these were challenging tasks. A development team might face challenges in identifying which specific portion from the huge collection of users' information would be useful for the design, and each member of the team could interpret the information in different ways. Even after all team members shared the same understanding about the users, they might face another challenge on how this understanding could translate to an appropriate design decision to ensure the design effectiveness.

In 1999, Cooper et al. (1999) [32] introduced persona to explain 
customers' behavior in marketing research. They defined persona as a character which was created by gathering behavioural data from real users. It presented a lot of users' information and helped developers make decisions in a product development process.

Other studies defined it slightly different. For example, Idoughi et al. (2012) [59] defined it as "a descriptive model of the user, encompassing information such as user characteristics, goals, and needs". Similarly, Pruitt \& Adlin (2010) [111] defined it as a fictitious character representing target users and raised focus towards them in the development process.

According to Pruitt \& Adlin (2010) [111], the benefits of persona were:

- Clarifying assumptions about users - a design team might have many conflicting hypotheses about their users. Persona could assist them in making a concrete design decision and focus on the same explicit definition of users

- Identifying specific groups of users - in general, products were created to target as many customers as possible. However, there were also many specific users who were not recognised by a design team. Persona helps the design team identify these users, hence the design could be expanded to a much wider audience

- Helping a design team to make the most from limited resources - at the beginning of the development process, there were many proposed design ideas and one would have to be selected based on its possibility and effectiveness. As pointed out by Pruitt \& Adlin (2010) [111], "Personas offer a consistent target-audience vision" [111, p.18], hence there was a higher possibility that many people would be partial to the design

- Engaging a development team - Pruitt \& Adlin (2010) [111] claimed that personas were different from other user centred design techniques because they could be presented as cartoon characters, 
which would be more fun and enjoyable and could inspire imagination, provide compelling, intense, and memorable information about users

Much research placed importance on users and including personas in their design processes. For example, Rahim et al. (2014) [112] created personas representing users' background and their behaviour when they purchased food products. These personas were created with the aim to investigate users' requirements and contribute to their Halal-Checker Mobile Application (I-scan) design.

Calvo et al. (2014) [20] also created personas in their study to improve the performance of the synchronous chat function in an m-learning application for students and teachers with disabilities.

Similar to the concept of persona, Jones \& Marsden (2006) [61] pointed out that scenario could also be used to represent users' characters. However, it would be more focused on the actions carried out by these users.

In this thesis, personas were created at the initial stage of m-learning application development. They represented the profiles and experience of a group of learners who had the same m-learning goals and showed similar behaviour and attitude when they made their decisions within a m-learning environment. These behaviour and attitude were impartial to learners' age, gender, and education. The personas helped decide which functions were meaningful and should be included in the m-learning application presented by this thesis. At a later stage, a scenario was combined with a persona to better refine the prototype development process. 



\section{Chapter 3}

\section{User Study \& Persona}

To produce a usable and effective application, it is paramount to employ user-centered design practices starting from the early stage of an application design process. Such practices can facilitate a better understanding of the target user population and consequently help guide the application's design and development. At this stage, the only known information about the target users for this m-learning prototype was that they were first year engineering and computer science students at the School of Engineering and Computer Science, Victoria University of Wellington. This information provided an opportunity to form some rudimentary assumptions about their ability to use various communication technologies offered by smart phones. However, it did not offer any detailed insights about their preferences and abilities in the context of using m-learning applications. To address this lack of understanding about the target learners, this chapter proposed a methodology to develop a user persona, which is a descriptive character created to represent these learners. The persona contains certain information about the learners such as their goals, experience, needs and attitude critical to the research process. Parts of the persona development process have been documented and published within the paper "Know the Mobile Learning Application Users - Transactional Distance 
Perspective" [75]

\subsection{Methodology}

The process of carrying out a user study to create a representative persona was divided into four main stages: identify behavioural variables and m-learning media and activities; recruit participants and collect quantitative and qualitative responses of the participants' experience and attitude towards m-learning using a questionnaire; perform statistical clustering on the quantitative results and collate notable qualitative findings from participants' responses; complete the personas using statistically transformed quantitative results and collated qualitative findings.

In the first stage, this study observed learners' experience and attitude towards m-learning media and activities. Additionally, to observe the applicability of TDT, the m-learning media and activities used in the study were selected specifically based on their relevance to the dialogue and course structure elements of TDT and the six instructional processes proposed by Moore [93]. The following list identified the m-learning media and activities that would help provide a focus for the subsequent user study questionnaire.

- Communication channels - current smart phones have many communication capabilities, such as text messaging, e-mail, voice and video calling. However, text messaging within a chat application was selected as a more appropriate communication channel in an education context, as it could accommodate more flexible and inclusive conversation arrangements (i.e., flexible communication schedule for teachers and allow many-to-many communication).

- Presentation media - smart phones could deliver learning content 
to target users via text, recorded audio and video, as well as links to other media on the Internet. For the purpose of this m-learning research, all of the above media formats were selected.

- Learning supported activities - smart phones could provide gamebased learning to encourage learners to practice what they learnt, and electronic assignments for evaluating their knowledge on the learning topics.

In the second stage, first year computer science, software, network, and computer system engineering students from the School of Engineering and Computer Science at the Victoria University of Wellington in New Zealand were recruited as the target learners of the m-learning application in this research to participate in the online-based, anonymous questionnaire (see Appendix). The questionnaire consisted of:

- 24 quantitative questions asking the learners to rank their experience and rate their attitude towards the communication tools, presentation media and learning supported activities selected in the first stage.

- 4 text fields to collect free-form, text-based responses to the types of activities other than calling and text messaging learners perform using their mobile phones, how they used their mobile phones to support learning, and their m-learning goals.

The questionnaire was conducted in October 2015 during the second trimester. From a pool of approximately 150 students, 41 of them had started the questionnaire and 30 of them completed it. These participants were students enrolled in either the Engineering Modelling and Design (ENGR110) or the Introduction to Data Structures and Algorithm (COMP103) class. They had prior experience in tertiary level learning 
from their entry-level courses in the first trimester. These entry-level courses covered a range of fundamental technical engineering concepts (electronics, mechatronic, networked, and software systems) or programming.

Thirdly, the five point Likert scale was used in the questionnaire to rank the target learners' experience and measure their attitude towards m-learning. The scale was chosen because it was easier for participants to rank their responses compared to the seven-point Likert scale. Additionally, Victoria University also used the same scale in their online questionnaires. Therefore, participants might be more familiar with it. The results gathered from the questionnaire were further manipulated using two separate and independent statistical techniques - graphical clustering and K-means clustering. Graphical cluster is an experimental clustering technique proposed in this study whilst the K-means clustering is a well-known and reliable clustering algorithm. By comparing the clustering results collected from each clustering technique, this study critiqued the validity of the proposed graphical clustering.

The results from graphical clustering were then combined with a random selection process to identify representative learner from each cluster (i.e., randomly selected a representative learner from within a group of learners belonged to the same cluster). The random selection method was chosen based on an assumption that the participants belonged in the same cluster had similar behaviour. On the other hand, the results from K-means clustering were combined with Euclidean Distance calculation to select the most appropriate representatives among the learners. Additionally, notable qualitative findings from the participants' responses to the free-form text-based questions were collated (Section 3.3).

Lastly, the quantitative results from the statistical clustering manipulation and the qualitative findings from the text-based questions of these selected representatives were unified to create potential learner 
personas. These initial personas were further analysed based on their reliability in accurately reflecting the characteristics of the target learners. As a result of the analysis, one primary and three secondary personas were chosen to be used in subsequent stages of the m-learning application development.

\subsection{Quantitative Results}

Two separate and independent statistical techniques were used to transform the quantitative results as part of the persona creation process: graphical clustering and K-means clustering.

\subsubsection{Graphical Clustering Technique}

Graphical clustering was a trial clustering technique carried out in an attempt to find a behaviour pattern from the participants' responses. This was achieved by plotting the 24 quantitative questionnaire results on the same graph (Figure 3.1a). The initial graph was highly distributed and was deemed not effective for establishing a definitive behaviour pattern. As a result, three rounds of clustering were carried out:

- First Round (Attribute Clustering) - the questions were divided into seven clusters based on participants' level of experience in, and attitude towards different aspects of mobile phone usage (i.e., everyday use, for educational purposes, using assorted digital media formats, using various mobile phone functions, attitude towards m-learning, attitude towards mobile phone functions, and learning preferences). For the clusters with more than one question, the graph was plotted based on their average values (Figure 3.1b).

- Second Round (Elimination) - an allowed interval was set based on the average value of each cluster. If a participant provided two or 
more responses outside of the allowed interval, the participant will be removed from the considered group because s/ he was considered to be too different from the majority of the remaining participants. There were 17 participants excluded as a result (Figure 3.1c). Despite being excluded from the considered group, these participants were deemed to belong to other minor groups. As each minor group had a small number of participants and would provide little contribution to the next stage of this research, they were not considered in the next stage.

- Third Round (Elimination due to Extreme Value) - there were three participants who qualified in the second round of clustering, but were excluded in this round due to their responses to a particular question varied greatly from other participants in the same cluster (Figure 3.1d).

In figure 3.1d, the graph shows a general trend (i.e. these ten participants showed a similar behaviour pattern). From a total of 30 participants, only these ten participants were grouped together. The remaining 20 participants were excluded from the final persona creation process.

Next, the K-means clustering technique was used to statistically cluster the quantitative analysis results and select a representative from each cluster. 


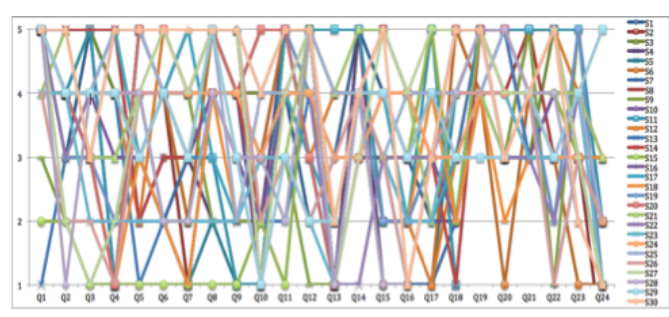

(a) The 30 participants' responses $(X$-axis represents 24 quantitative questions)

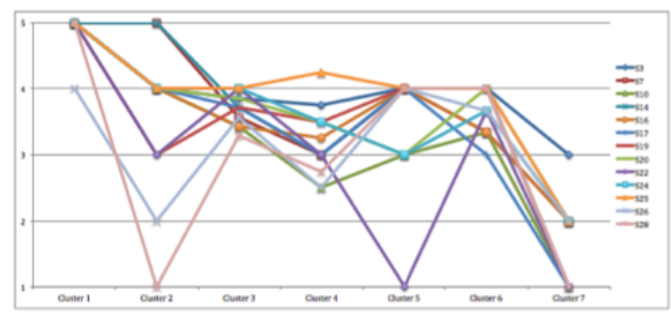

(c) The graph after second round elimination

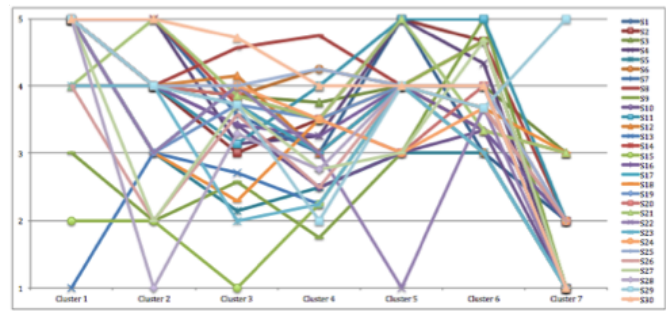

(b) The graph after first round attribute clustering ( $\mathrm{X}$ axis presents the seven clusters

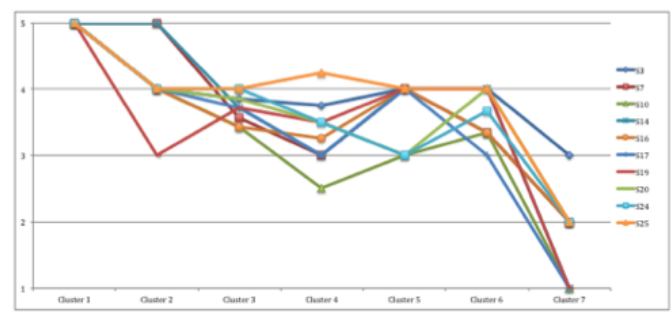

(d) The graph after third round elimination due to extreme values

Figure 3.1: Graphical clustering process 


\subsubsection{K-means Clustering Technique}

$\mathrm{K}$-means clustering is a clustering algorithm which partitions all the data $(\mathrm{N})$ into $(\mathrm{K})$ clusters (where $\mathrm{K}$ is the number of cluster, chosen before the algorithm starts). The partitioning minimises the sum of squared distances between items and the corresponding centroid (where the centroid is the mean vectors).

MATLAB was used to perform this clustering. This clustering process was divided into three parts:

1. Found an appropriate number of cluster (K) using a silhouette plot. The plot illustrated how close each point in one cluster is to the points in the neighbouring clusters. A trial commenced with the number of cluster $(K)=2$ and increasing the $K$ to $3,4,5,6$, and 7 (Figure 3.2). The plots range from +1 to -1 .

- The closer a cluster is to +1 , this means it is more distant from its neighbouring clusters. That is to say, the cluster is appropriated partitioned.

- The closer a cluster is to -1 , this means the data is probably partitioned into the wrong cluster. 


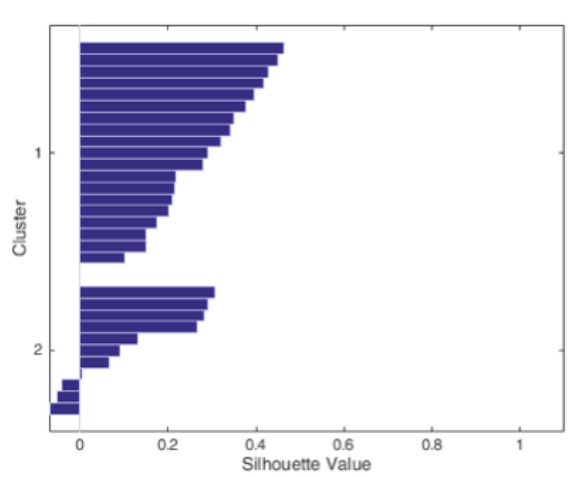

(a) Silhouette Value when $\mathrm{K}=2$

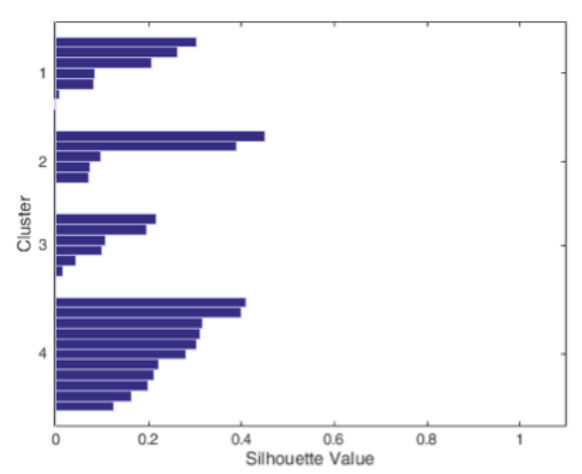

(c) Silhouette Value when $K=4$

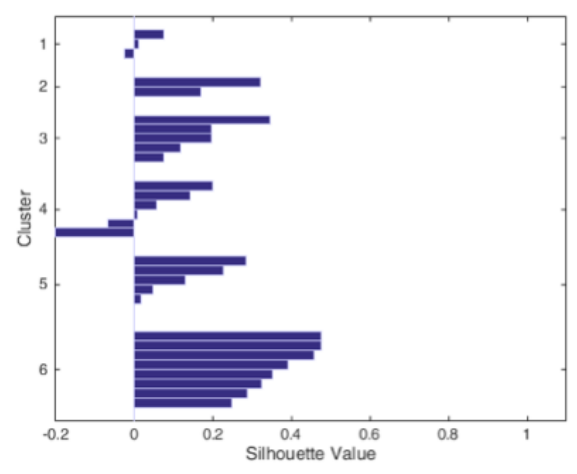

(e) Silhouette Value when $\mathrm{K}=6$

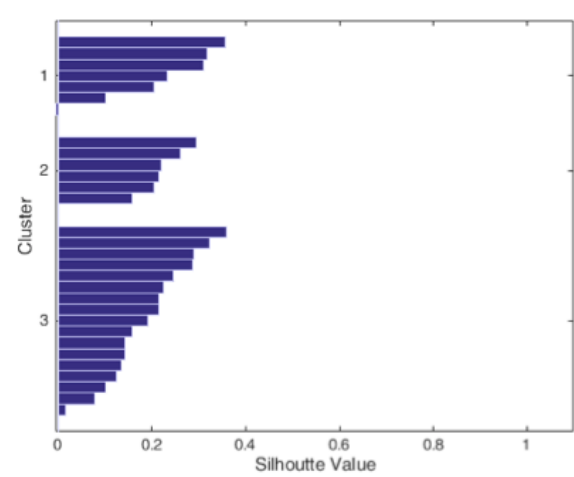

(b) Silhouette Value when $K=3$

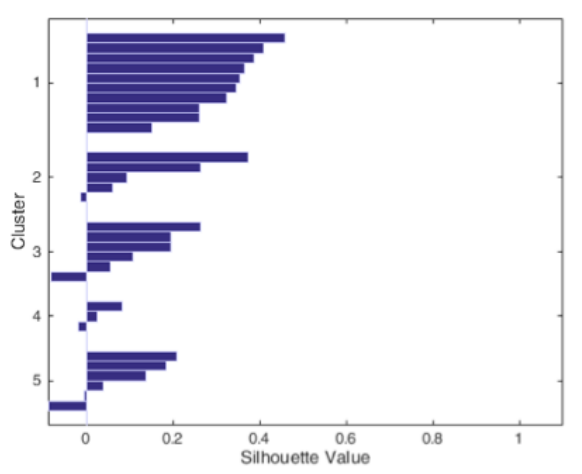

(d) Silhouette Value when $K=5$

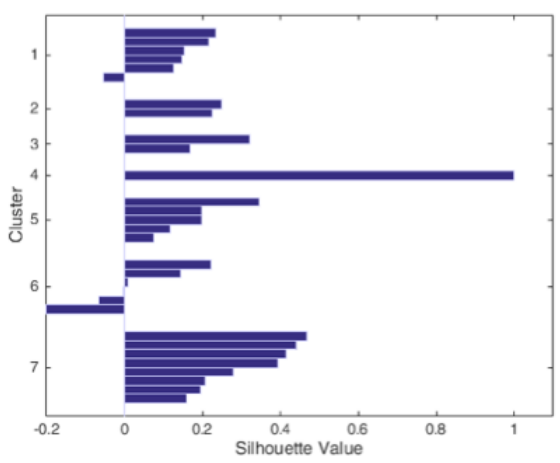

(f) Silhouette Value when $\mathrm{K}=7$

Figure 3.2: Silhouette plots to find the appropriate number for cluster (K) 
In figure 3.2, only two plots show non-negative value where $\mathrm{K}=3$ and 4 (Figure 3.2b and 3.2c). Therefore, at this point, either 3 or 4 was the appropriate number of clusters. However, when the number of cluster $K=3$, most of its points had larger silhouette value in comparison to cluster $\mathrm{K}=4$. Ultimately, the data was divided into 3 clusters.

2. Arranged the participants $(\mathrm{N}=30)$ into 3 clusters $(\mathrm{K}=3)$ using means clustering function in MATLAB. The results were:

- Cluster 1 consisted of seven participants: P4, P5, P13, P15, P18, P23 and P28.

- Cluster 2 consisted of six participants: P9, P19, P20, P22, P26 and P27.

- Cluster 3 consisted of 17 participants: P1, P2, P3, P6, P7, P8, P10, P11, P12, P14, P16, P17, P21, P24, P25, P29 and P30.

3. Sought the most appropriate participant from each cluster to represent the rest of the participants in the same cluster by calculating Euclidean distance using MATLAB. Euclidean distance is a distance between each participant's answers and the average answers of all the participants in the same cluster. The participant who had the lowest Euclidean distance would be chosen as the representative. Figure 3.3 presented Euclidean distance of participants of each cluster and illustrated the representative's answer value of each question in the questionnaire (i.e. orange, green, and red lines were the representative of cluster 1, 2, and 3 respectively) against the average answers of all participants in the cluster (i.e., blue line). 


\begin{tabular}{|l|l|}
\hline Participant & $\begin{array}{l}\text { Euclidean } \\
\text { Distance }\end{array}$ \\
\hline P4 & 5.5915 \\
\hline P5 & 4.2738 \\
\hline P13 & 4.3401 \\
\hline P15 & 5.9744 \\
\hline P18 & 4.7337 \\
\hline P23 & 3.5828 \\
\hline P28 & 4.4538 \\
\hline
\end{tabular}

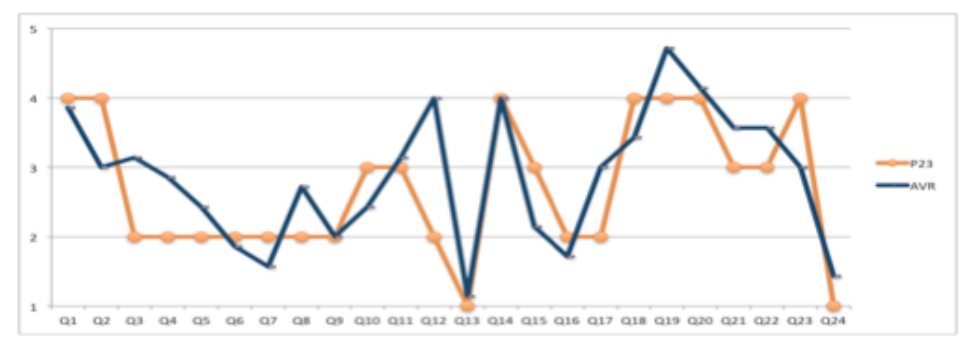

(a) P23 was chosen as the representative for cluster 1

\begin{tabular}{|l|l|}
\hline Participant & $\begin{array}{l}\text { Euclidean } \\
\text { Distance }\end{array}$ \\
\hline P9 & 5.4442 \\
\hline P19 & 3.5551 \\
\hline P20 & 3.8694 \\
\hline P22 & 3.9122 \\
\hline P26 & 4.1600 \\
\hline P27 & 5.0305 \\
\hline
\end{tabular}

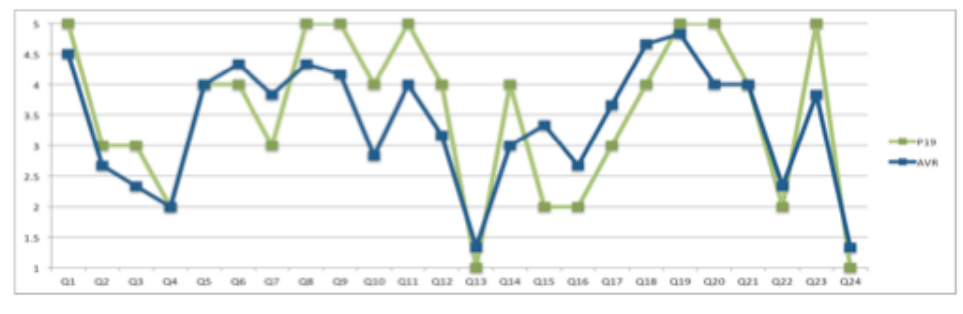

(b) P19 was chosen as the representative for cluster 2

\begin{tabular}{|l|l|}
\hline Participant & $\begin{array}{l}\text { Euclidean } \\
\text { Distance }\end{array}$ \\
\hline P1 & 3.8389 \\
\hline P2 & 5.6231 \\
\hline P3 & 3.6904 \\
\hline P6 & 6.0173 \\
\hline P7 & 6.5103 \\
\hline P8 & 4.7187 \\
\hline P10 & 4.5084 \\
\hline P11 & 6.8579 \\
\hline P12 & 4.6306 \\
\hline P14 & 4.6749 \\
\hline P16 & 2.9855 \\
\hline P17 & 4.0695 \\
\hline P21 & 4.3557 \\
\hline P24 & 2.4558 \\
\hline P25 & 4.3625 \\
\hline P29 & 5.0149 \\
\hline P30 & 5.5068 \\
\hline
\end{tabular}

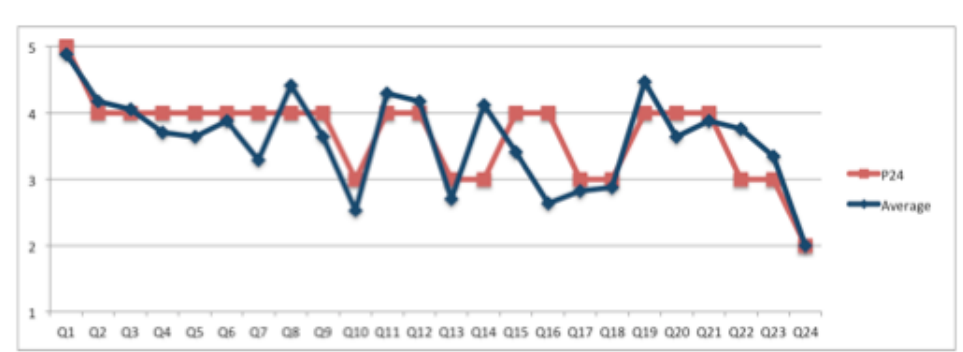

(c) P24 was chosen as the representative for cluster 3

Figure 3.3: The most appropriate participant to represent the rest of the participants in its cluster 


\subsection{Qualitative Findings}

Participants' responses in the 4 text fields within the questionnaire were gathered. Analysis of the gathered information revealed some interesting qualitative findings.

\subsubsection{Mobile Phones Usages}

Participants were asked to list the activities they performed on their mobile phones other than calling and text messaging. The following list shows the usage categories:

1. Communication - Accessed social media websites (e.g., Facebook ${ }^{4}$, Reddit ${ }^{5}$ and sending and receiving e-mails

2. Entertainment - Watched videos online from video-sharing websites (e.g., YouTube), listened to music, and played games

3. Research - Accessed Google to find information. Participants also mentioned they read news and participated in online-forums using their mobile phones

4. Personal Management - Used many basic functions available on mobile phones to manage daily life. For example, participants used note function to list activities to be completed, calendar to receive notifications for when these tasks were due, alarm clock to wake up in the morning and managed their bank accounts online

5. Other - Regularly utilised many others basic supplementary functions and out of the box applications on mobile phones (e.g., flash light, map, camera)

\footnotetext{
${ }^{4}$ https://www.facebook.com

${ }^{5}$ https://www.reddit.com
} 
When they were asked about their usage of mobile phones specifically for "educational purposes", some note-worthy findings were:

1. They used their mobile phones to access social media websites, then contact their classmates to discuss lessons and assignments

2. They also downloaded lecture notes, slides, and videos and used these downloaded materials on their mobile phones when they were away from university

3. For research purposes, they read academic articles on their mobile phones and used online search engines (i.e., Google) when they had questions and wanted to find more information

4. They visited the school's website to keep themselves updated, and accessed learning resources via the University's Blackboard system

5. They used mobile phones' basic functions such as clock, calendar, and note to help them manage their learning schedule. They also used their camera to capture their lecture notes

\subsubsection{Mobile Learning Goals}

Learning goal was another notable focus area, as it could inspire and motivate learners to learn. Firstly, the participants were asked to explain the term "mobile learning" in order to observe their initial understanding and by inference determine whether they could set their m-learning goal. Most of them showed that they understood the term and could differentiate m-learning from other types of learning. For example a student answered that

"Mobile learning to me is being able to gain and apply knowledge anywhere at anytime including when an internet connection is unavailable" 
Other learners also mentioned learning on the go, learning anywhere, and at a time convenient to them even when they were not stationary.

When the participants were asked to identify their goals of learning on mobile phone, most of them considered mobile phones as tools to help them learn outside of their classrooms when they were not in front of their laptops or computers. Examples of some of their answers were:

"I do not consider myself a person who learns from a mobile phone, only one who uses it for time management and organising my learning, which comes from other sources unless it is an extreme scenario (i.e. there are absolutely no computers available to me)"

"I just want to be able to find out what I need to know very quickly..."

These qualitative findings were subsequently used in conjunction with quantitative results (Section 3.2) to form personas.

\subsection{Personas}

From the graphical clustering technique in section 3.2, ten participants remained as a result of the elimination process. To present these ten participants, a persona with pseudonym "John" was created (Figure 3.4). In order to complete persona John, one of the ten final participants was randomly selected and his/her qualitative responses were used in persona John's profile.

From the K-means clustering technique also presented in section 3.2, three personas with the pseudonyms "Annie" (Figure 3.5), "Stephen" (Figure 3.6), and "Clara" (Figure 3.7) were created to represent participants from cluster 1, 2, and 3 respectively. Based on the results of the K-means clustering, cluster 3 had the highest number of participants, 
therefore Clara was chosen as the primary persona. Clusters 1 and 2 had less number of participants, therefore Annie and Stephen were considered as secondary personas. In step 3 of the K-means clustering technique (Section 3.2.2), one participant was chosen from each of the three clusters as the representative of participants within that cluster. To complete the personas' profiles, the qualitative responses from these three participants were used to populate the corresponding persona profiles.

Permissions were granted for all profile images used in the four personas' profiles. 


\begin{tabular}{|c|c|}
\hline \multicolumn{2}{|c|}{$\begin{array}{l}\text { John } \\
\text { First Year Engineering Student } \\
\text { Mobile learning is "utilising our mobile devices for learning such as }\end{array}$} \\
\hline \multicolumn{2}{|c|}{$\begin{array}{l}\text { Mobile Phone Usage } \\
\text { John explained that his mobile learning goal is "To learn on the go when I am not in } \\
\text { front of my laptop or PC". He uses his mobile phone all the time and often uses it for } \\
\text { educational purposes. He uses it to contact his family and friends through Facebook. } \\
\text { When he has free time, he watches online videos on YouTube. He listens to pre- } \\
\text { downloaded music when he is travelling. He also uses his mobile phone to search for } \\
\text { information from Google website and enjoys using it to capture some photos. }\end{array}$} \\
\hline $\begin{array}{l}\text { Mobile Phone Experience } \\
\text { * John sometimes watches movies or } \\
\text { online videos on his mobile phone } \\
\text { and he knows how to use play, pause, } \\
\text { fast forward, reply buttons } \\
\text { * He often listens to music on his } \\
\text { mobile phone and he knows how to } \\
\text { use the control buttons very well } \\
\text { * He sometimes sends and receives e- } \\
\text { mail on his mobile phone } \\
\text { * He rarely plays games or works on } \\
\text { assignments on his mobile phone } \\
\text { He mostly uses laptop to work on } \\
\text { assignments }\end{array}$ & $\begin{array}{l}\text { Attitude } \\
\text { * John thinks mobile phones are tools that } \\
\text { he can use to learn. However, he prefers } \\
\text { to learn course material and do } \\
\text { assignments on a PC or a laptop rather } \\
\text { than a mobile phone because it is more } \\
\text { convenient } \\
\text { * He likes watching movies and prefers } \\
\text { watching learning videos to listening } \\
\text { recorded lectures, or reading text by } \\
\text { himself } \\
\text { * He wants to try playing games created as } \\
\text { part of course material (game-based } \\
\text { learning) } \\
\text { * He rarely contacts instructors, but he } \\
\text { realises that keeping in touch with them } \\
\text { regardless of any communication } \\
\text { channels (e.g., chat, e-mail, face to face, } \\
\text { synchronous, asynchronous) may help } \\
\text { him learn better }\end{array}$ \\
\hline
\end{tabular}

Figure 3.4: John persona created with graphical clustering technique 


\begin{tabular}{|c|c|}
\hline \multicolumn{2}{|c|}{$\begin{array}{l}\text { Annie } \\
\text { First Year Engineering Student } \\
\text { Mobile learning is "learning using technology that is not tied to a single } \\
\text { location" }\end{array}$} \\
\hline \multicolumn{2}{|c|}{$\begin{array}{l}\text { Mobile Phone Usage } \\
\text { Annie expressed that she didn't have a clear goal towards mobile leaning. She said "I don't } \\
\text { have a goal of learning. I'm using it only to support my daily life to make other learning } \\
\text { easier". However, she often uses her mobile phone for things other than calling and text } \\
\text { messaging and often uses it for education purpose. She uses her mobile phone to play games, } \\
\text { browse the Internet and visit websites (including university's website), send/receive e-mails, } \\
\text { and uses many build-in features of smart phone such as calculator, flashlight, compass/metal } \\
\text { detector, GPS, and accelerometer. }\end{array}$} \\
\hline $\begin{array}{l}\text { Mobile Phone Experience } \\
\text { * Annie rarely reads long text on a } \\
\text { mobile phone, uses a scroll bar to } \\
\text { go through text or zoom function } \\
\text { to read text } \\
\text { * She rarely plays video on a } \\
\text { mobile phone or uses play, } \\
\text { pause, rewind, fast forward and } \\
\text { repeat function for the video } \\
\text { * She rarely listens to recorded } \\
\text { voices or music on a mobile } \\
\text { phone, nor uses play, pause, } \\
\text { rewind, fast forward and repeat } \\
\text { function of music player } \\
\text { * She rarely chats (by text } \\
\text { messaging) on her mobile phone } \\
\text { * She sometimes plays games and } \\
\text { sends and receives an e-mail on } \\
\text { her mobile phone he her } \\
\text { * She has never done her her a } \\
\text { homework or assignment on a } \\
\text { mobile phone }\end{array}$ & $\begin{array}{l}\text { Attitude } \\
\text { * Annie prefers to learn by reading text rather than } \\
\text { watching a video or listening to a recorded voice } \\
\text { on a mobile phone } \\
\text { * She has a positive attitude towards using a } \\
\text { mobile phone to help her learning process } \\
\text { * She doesn't like game-based learning activities } \\
\text { * She thinks assignments have helped her to } \\
\text { improve her learning and prefers to do them on a } \\
\text { computer rather than on actual paper } \\
\text { She expresses a neutral attitude towards having } \\
\text { a conversation with her instructors and whether } \\
\text { that has encouraged her to learn } \\
\text { * She expresses a neutral attitude between having } \\
\text { a face-to-face conversation versus e- } \\
\text { mail/message exchanges } \\
\text { * She prefers to have synchronous to } \\
\text { asynchronous communication } \\
\text { The small keyboard of her mobile phone seems } \\
\text { to bother her } \\
\text { - She strongly prefers to learn on a desktop or } \\
\text { laptop computer to a mobile phone }\end{array}$ \\
\hline
\end{tabular}

Figure 3.5: Annie persona (secondary) created with K-means clustering technique 


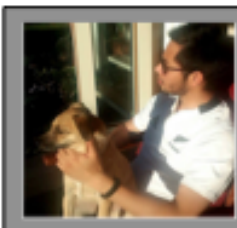

Stephen

First year engineering student

Mobile learning is "Viewing lecture notes and assignments. Setting important dates. Communicating with staffs or other students"

Mobile Phone Usage

Stephen explained his mobile learning goal is "to gain a brief understanding of what I need to study at a more in depth level". He uses his mobile phone all the time for things other than calling and texting and sometimes uses it for educational purposes. He uses his mobile phone to send e-mails, plan daily activities, take pictures with phone camera, play games, view lecture notes and assignments, set courses' important dates on the phone's calendar, and communicate with staff and other students.

Mobile Phone Experience

* Stephen sometimes reads long text on his mobile phone and often used the zoom function. However, he rarely uses a scroll bar to go through text

* He often plays video on his mobile phone, and knows how to use play, pause, rewind, fast forward and repeat functions for the video player

* He very frequently listens to recorded voices or music on his mobile phone and knows how to use the control functions very well

* He regularly sends and receives e-mails on his mobile phone

* He often chats (by text messaging) and plays games on his mobile phone. However he rarely does his homework and assignment on his mobile phone

\section{Attitude}

* Stephen prefers to learn by reading text to watching a video or listening to a recorded voice on a mobile phone

* He has a positive attitude towards using a mobile phone to help his learning process

* He has a neutral attitude towards game based learning activity

* He thinks assignments have helped him improve his learning and prefers to complete his assignments on a computer than on actual paper

* He thinks that having a conversation with his instructors has encouraged him to learn and prefers a face-to-face discussion rather than an e-mail/message conversation

* He prefers synchronous to asynchronous communication

* The small keyboard of his mobile phone seems to bother him

* He strongly prefers to learn on a desktop or laptop computer rather than a mobile phone

Figure 3.6: Stephen persona (secondary) created with K-means clustering technique 


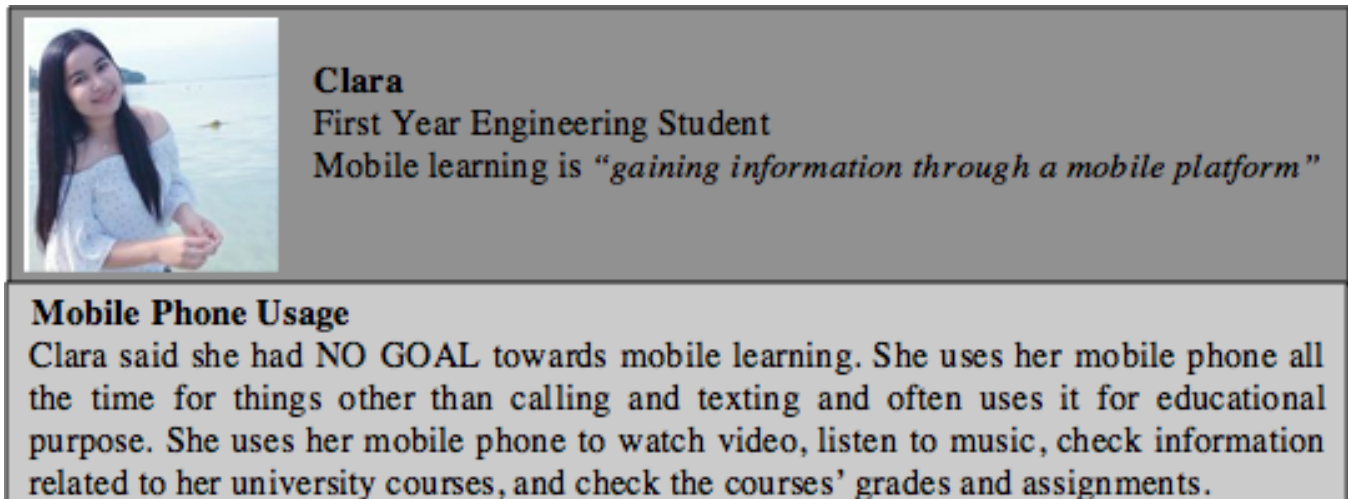

\begin{tabular}{|c|c|}
\hline $\begin{array}{l}\text { Mobile Phone Experience } \\
\text { Clara often reads long text on } \\
\text { her mobile phone and she often } \\
\text { uses a scroll bar to go through } \\
\text { text and zoom function to read } \\
\text { them } \\
\text { She often plays video on her } \\
\text { mobile phone and knows how } \\
\text { to use play, pause, rewind, fast } \\
\text { forward and repeat buttons } \\
\text { She often listens to recorded- } \\
\text { voices or music on her mobile } \\
\text { phone and knows how to use } \\
\text { the control functions very well } \\
\text { She often sends and receives an } \\
\text { e-mail and chats (by text } \\
\text { messaging) on her mobile } \\
\text { phone } \\
\text { She sometime plays game and } \\
\text { does her homework or } \\
\text { assignment on a mobile phone }\end{array}$ & $\begin{array}{l}\text { Attitude } \\
\text { * Clara prefers to leam by watching a video and } \\
\text { listening to a recorded voice to reading a long } \\
\text { text on a mobile phone } \\
\text { * She has a neutral attitude towards using a } \\
\text { mobile phone to help her learning process } \\
\text { * She has a neutral attitude towards game based } \\
\text { learning activity } \\
\text { * She thinks assignments help her improve her } \\
\text { learning and prefers to do the assignment on a } \\
\text { computer rather than on actual paper } \\
\text { * She thinks that having a conversation with her } \\
\text { instructors has encouraged her to learn and } \\
\text { expresses a neutral attitude between having a } \\
\text { face-to-face conversation versus } \\
\text { mail/message exchanges } \\
\text { * She expresses a neutral attitude between } \\
\text { having synchronous and asynchronous } \\
\text { communication } \\
\text { * The small keyboard of her mobile phone } \\
\text { doesn't seem to bother her } \\
\text { * She prefers to learn on a desktop or laptop } \\
\text { computer to a mobile phone }\end{array}$ \\
\hline
\end{tabular}

Figure 3.7: Clara persona (primary) created with K-means clustering technique 


\subsection{Discussion}

This study created four personas from a total of 30 participants. Although the number of participants was the minimum dataset size for the statistical technique (i.e., clustering) used during the persona development process, when the clustering results were combined with qualitative findings, the resulting information was sufficient to create personas: it confirmed the viability of the media and learning-supported activities that we planned to present in the first prototype; it helped developers to assume the learner autonomy level of the participants in the first prototype development process before that was actually measured. Albeit the personas created in this chapter specifically represented first year engineering students at the Victoria University of Wellington, the persona development process, and in particular the clustering techniques used, could be adopted as a model for persona development for other studies.

The graphical clustering technique was used as a trial for proposing new approach to persona formation. As the persona John was created based on 10 participants out of a pool of 30 participants, there were concerns that the graphical clustering technique eliminated and neglected more than half of the participants. Despite such concern, it was strongly believed that the 20 participants excluded would have belonged to many minor groups, with each group containing only a small number of participants and therefore immaterial to the overall design. Too many personas might also distract the design teams and reduce their focus on the primary persona. As a result, they were excluded.

Additionally, in figure 3.1a for the graphical clustering technique, the graph was too highly distributed and no specific trend could be drawn from it. Although the graphs were re-plotted during the first round of clustering based on the average value (See figure 3.1b), this process might have introduced some deviation to the results. For example, the extreme 
outlying responses of 2 and -2 could have contained significantly meaningful results, but were neutralised to 0 after using the average value for re-plotting. The graphical clustering approach would be better suited for analysing results from a questionnaire that had lesser number of questions. It might also be necessary to pair this approach with other statistical techniques instead of using an average value to cluster the results and select a representative.

Ultimately, the single person chosen from the remaining 10 participants using random selection may not actually be the most appropriate and representative reflection of the entire participant pool.

On the other hand, the K-means clustering approach was deemed to be more effective because it covered more participants. Using K-means clustering, all responses from the 24 questions could be divided into three clusters, with each cluster comprising an acceptable number of participants for the results to be considered meaningful to the next phase of research while ensuring the process of cluster representative selection was well-founded on statistical analysis technique.

Despite using two separate and independent statistical techniques, almost every participants ( 8 out of 10 ) used to form persona John were also among the 17 participants that formed primary person Clara. In addition, persona John and primary persona Clara shared some similarities in their profiles. For example, they both preferred to learn by watching video rather than listening to audio or reading text, and both personas were more partial to completing assignment using a desktop or laptop computer than using a mobile phone. Additionally, they had the same learning attitude with both personas believe that the opportunity to communicate and converse with their instructors would encourage them to learn. 


\subsection{Feasibility Analysis}

The primary persona Clara's profile was used to analyse whether the communication channels, presentation media and learning supported activities previously identified for testing the applicability of TDT to m-learning (Section 3.1) were practicably feasible.

Based on Clara's profile, she had prior experiences in using text, recorded audio and video on her mobile phone. She also knew how to use the standard control functions of audio or video players (i.e., play, pause, rewind and fast forward). Therefore, these presentation media were deemed to be viable for inclusion in the application design.

Among the learning support activities, the chat function seemed to be the most appropriate communication channel for the m-learning application design as Clara was already familiar with text messaging and emailing on a mobile device, and recognised that communication with her teachers would help improve her learning.

On the other hand, despite her acknowledgement that assignments had helped improve her learning, Clara preferred to complete her assignments using a desktop computer or laptop rather than on mobile phone. This demonstrated that the target participants did not consider m-learning as a primary mode of learning. In addition, Clara had neutral attitude towards game-based learning. Consequently, strategies such as rewarding techniques and notification reminders may be required to encourage target learners to complete electronic assignments and participate in game-based learning.

Overall, the selected communication channels, presentation media and learning supported activities were all deemed to be feasible, with some adjustments, to be incorporated into the application design that would be useful and effective for evaluating the applicability of TDT to m-learning.

Notwithstanding the aforementioned feasibility, the mobility aspect of m-learning required context awareness to be considered when utilising 
these presentation media and learning-supported activities within an m-learning application. Text media might be more suitable as the primary media for m-learning application because it demanded less user attention compared to video media and would be less easily influenced by surrounding noise compared to audio media. However, text media might not be suitable for presenting every type of learning content. For example, a page with multiple long paragraphs on English literature could be presented using text media in an m-learning application, but it would not be suitable as a primary choice of media for learning because learners could feel worn out by reading from the small screen of mobile devices for a long time and their learning might be interrupted by surroundings, leading them to lose track of their learning progress. Text media would also be unsuitable for presenting computer programming and mathematics equations on mobile devices. Equations would be better suited to be displayed on a big screen for learners to see the overall picture and help them develop their creativity. For these content, m-learning should be considered as a secondary mode of learning to supplement classroom-based learning or e-learning.

Similarly, despite their potential to assist with learning using mobile devices, the proposed learning-supported activities might only help learners to learn at a basic level (e.g., remember, understand, and apply). Mobile devices might limit the quality of the activities and therefore unable to help the learners learn at a higher level (e.g., analyse, evaluate, and create). For example, the chat feature that allowed dialogue between learners and teachers might be unable to cater for a long discussion and debate between learners and many experts. The assignment which required learners to type a long answer might not be suitable for m-learning either because the learners could experience difficulties in typing the assignment answer on a small virtual keyboard. 


\subsection{Summary}

User-centered design is critical not only for informing the m-learning application design presented in this thesis, but also for the successful evaluation of the applicability of TDT principles to m-learning education applications design guidelines.

Although the first year computer engineering and computer science students at the Victoria University of Wellington in New Zealand were selected to help provide a definitive scope for the design, development and testing of the m-learning application, Persona creation became the user-centered design practice of choice to help uncover and synthesise these students' mobile phones usage patterns, their m-learning goal and their attitudes towards m-learning in an educational context.

Four personas were created through the combination of quantitative and qualitative responses received from 30 students within the original target user group. These personas provided focus and guidance for the next $\mathrm{m}$-learning application design and development process.

While the two separate and independent statistical clustering techniques and the ensuing quantitative results assisted in identifying the representative participants for the personas, the qualitative findings from the questionnaire reinforced the idea that mobile phone is a powerful tool for supporting ubiquitous learning.

The use of mobile phones as an educational tool is now very much an established part of the target users' daily lives and within their learning environment. However, the absence of their m-learning goals in contrast to their phone usage for education-related activities raised awareness about the target users' acceptance and recognition of m-learning as a formal education channel, and further encouragement and promotions of m-learning may be required to ensure its future growth. 


\section{Chapter 4}

\section{First Design guidelines \& Prototype Development}

In chapter 2, the pedagogical theory of Transactional Distance (TDT) and its three variables: dialogue, course structure, and learner autonomy were explored. Additionally, the six instructional processes of distance education proposed by Moore (1993) [93] to describe the potential correlations between those three variables and the consequences of their interactions on the resulting transactional distance were considered. Furthermore, some design guidelines proposed within e-learning context and other learning theories that could complement TDT were outlined and discussed.

However, TDT was originally proposed within the context of distance education and would require modification for the theory to be applicable to the modern m-learning environment. In order to form new m-learning application design guidelines based on TDT, its original concept and utilisation are transformed in this chapter. Other relevant learning theories that could address the deficiencies of TDT within the realms of m-learning are also analysed. Furthermore, possible contributions of the existing e-learning guidelines to m-learning application design are identified. The transformation and analysis results are subsequently used 
to produce the first iteration m-learning application design guidelines. Thus, based on these guidelines, the first version of m-learning application prototype is designed, developed and presented in this chapter.

\subsection{Adapting TDT to M-learning}

As pointed out in chapter 2, although m-learning is a subset of distance education that uses mobile devices and communication technologies, it has some differentiating characteristics and specific limitations compared to other forms of distance education. To effectively adapt the original concept and principles of TDT and guide m-learning application design, the definitions of TDT and its related terms in the original distance education context required appropriate adjustments to be utilised in a m-learning context (See table 4.1). Furthermore, various approaches to retain the six instructional processes (i.e., presentation, motivation, stimulation of analysis and criticism, advice and consolation, practice and evaluation, and creation of knowledge) of distance education proposed by Moore (1993) [93] in the m-learning environment were examined (See table 4.2).

Table 4.1 shows the definitions of TDT terms and variables in the original distance education context and their transformation and applicability in the m-learning context. 
Table 4.1: Transformation of TDT definitions and applicability from original distance education to m-learning context

\begin{tabular}{|c|c|c|}
\hline Term & Original Concept [93] & M-learning Context \\
\hline $\begin{array}{l}\text { Transactional } \\
\text { Distance }\end{array}$ & $\begin{array}{l}\text { Perceptions of } \\
\text { isolation due to } \\
\text { certain hardships } \\
\text { in communication } \\
\text { and the need to take } \\
\text { control over one's own } \\
\text { learning process when } \\
\text { physically separated } \\
\text { from teachers }\end{array}$ & $\begin{array}{l}\text { The definition of transactional } \\
\text { distance remain unchanged. } \\
\text { However, owing to recent } \\
\text { advances in communication } \\
\text { technologies for m-learning, } \\
\text { this isolation is likely to be } \\
\text { lessened as mobile devices } \\
\text { are capable of providing } \\
\text { both synchronous (e.g., } \\
\text { voice and video calling) and } \\
\text { asynchronous communication } \\
\text { (e.g., email) among learners } \\
\text { and teachers alike }\end{array}$ \\
\hline & & Continue to the next page \\
\hline
\end{tabular}




\begin{tabular}{|c|c|c|}
\hline Term & Original Concept [93] & M-learning Context \\
\hline Dialogue & $\begin{array}{l}\text { Interactions include } \\
\text { words and actions that } \\
\text { have positive qualities, } \\
\text { that are purposeful } \\
\text { and constructive in } \\
\text { promoting learners' } \\
\text { understanding }\end{array}$ & $\begin{array}{l}\text { The definition of dialogue } \\
\text { remain unchanged. While } \\
\text { mobile devices enable quicker } \\
\text { and easier communication } \\
\text { and allow multiple } \\
\text { interactions of words and } \\
\text { actions simultaneously, the } \\
\text { resulting dialogue needs } \\
\text { specific adjustments and } \\
\text { design to achieve the same } \\
\text { level of purposefulness, } \\
\text { constructiveness and positive } \\
\text { qualities as described in the } \\
\text { original TDT context }\end{array}$ \\
\hline $\begin{array}{l}\text { Course } \\
\text { Structure }\end{array}$ & $\begin{array}{l}\text { Structural plan of the } \\
\text { course to inform how } \\
\text { learning content would } \\
\text { be delivered through } \\
\text { communication media }\end{array}$ & $\begin{array}{l}\text { The definition of course } \\
\text { structure remain unchanged. } \\
\text { However, mobile devices } \\
\text { could potentially present } \\
\text { more flexible course structures } \\
\text { or utilise more varieties of } \\
\text { multimedia such as audio, } \\
\text { video, and animation }\end{array}$ \\
\hline
\end{tabular}




\begin{tabular}{|c|c|c|}
\hline Term & Original Concept [93] & M-learning Context \\
\hline $\begin{array}{l}\text { Learner } \\
\text { Autonomy }\end{array}$ & $\begin{array}{l}\text { Learners' ability to } \\
\text { determine their own } \\
\text { learning goals, manage } \\
\text { their own learning } \\
\text { processes, and can } \\
\text { evaluate their own } \\
\text { learning outcomes }\end{array}$ & $\begin{array}{l}\text { The definition of learner } \\
\text { autonomy remain unchanged. } \\
\text { However, as m-learning } \\
\text { involve mobile devices in the } \\
\text { learning process, this research } \\
\text { used Littlewood's (1996) [78] } \\
\text { learner autonomy components } \\
\text { (i.e., ability and willingness) } \\
\text { towards m-learning and } \\
\text { mobile technology to measure } \\
\text { the learner autonomy }\end{array}$ \\
\hline
\end{tabular}

Following the above transformation, the list below explores how Moore's (1993) [93] original proposed relationship between TDT's three variables can be maintained in a m-learning context.

1. Distance education course with a high degree of course structure (i.e., inflexible course structure) and allowed little to no dialogue had high transactional distance

To implement this scenario in an m-learning context, teachers would control all three learning processes: setting learning goal, implementing learning and evaluating learning outcomes.

During the implementing process, teachers could, for example, allow learners to explore only parts of learning content and disable their access to the remaining parts, or allow learners to access the content only in a prearranged and scheduled manner. Such an 
inflexible course would allow the teachers to completely control learners' learning pace and schedule.

Additionally, if the inflexible m-learning course structure did not incorporate elements of dialogue, then in an m-learning context, high transactional distance could be further perceived by learners if there was a lack of feedback from teachers when such communication was sought actively by learners, thus reducing overall m-learning quality.

2. Distance education course with a flexible course structure and allowed dialogue opportunities had less transactional distance

To enable a flexible course structure in the m-learning context, learners would be allowed to control all three learning process, from setting learning goals, implementing learning, to evaluating learning outcomes. Concurrently, teachers would assume the role of facilitators and support learners throughout the entire learning processes.

During the implementation process, a learner could, for example, be given access to all learning materials, allowing him/her to learn at his/her own pace and manage his/her own learning schedule.

To incorporate the element of dialogue within this flexible m-learning course structure, learners would need to engage in quality, purposeful and constructive communication exchange with their teachers. For example, a learner who received a reply from his/her teacher that helped him/her better understand the learning topic would not perceive transactional distance, thus increasing overall m-learning quality. 
3. Autonomous learners seemed to be comfortable with less dialogue and less structural programme, while non-autonomous learners seemed to prefer more dialogue and more structural programme

As shown in number 1 and 2 above, m-learning had the potential to provide learners with varying levels of dialogue and course structure flexibility. Therefore, observing learner autonomy at the early stage of m-learning application design process would be necessary to develop a suitable m-learning course for learners.

Ultimately, Moore (1993) [93] suggested six instructional process applicable for every distance education course. Table 4.2 presents mobile devices' capabilities to accommodate these instructional processes within an m-learning environment.

Table 4.2: Applying Moore's (1993) [93] instructional processes using mobile devices in m-learning environment

\begin{tabular}{|l|l|}
\hline $\begin{array}{l}\text { Instructional } \\
\text { Process [93] }\end{array}$ & Mobile Devices Capabilities \\
\hline Presentation & $\begin{array}{l}\text { Mobile devices could present multiple media such } \\
\text { as text on screen, recorded-audio file, and animation } \\
\text { video }\end{array}$ \\
\hline Motivation & $\begin{array}{l}\text { Teachers could use the many communication features } \\
\text { available on mobile devices, such as text service, e- } \\
\text { mail, voice and video call to send learners feedback } \\
\text { and encourage them to learn. Furthermore, rich } \\
\text { multimedia available on mobile devices could pique } \\
\text { learners' interest and motivate them to learn }\end{array}$ \\
\hline
\end{tabular}




\begin{tabular}{|c|c|}
\hline $\begin{array}{l}\text { Instructional } \\
\text { Process [93] }\end{array}$ & Mobile Devices Capabilities \\
\hline $\begin{array}{l}\text { Stimulation } \\
\text { of Analysis } \\
\text { and Criticism }\end{array}$ & $\begin{array}{l}\text { Teachers could arrange an on-line discussion with a } \\
\text { group of learners, send them pre-recorded videos of } \\
\text { experts' discussions, or provide them links to further } \\
\text { online multimedia resources related to the course }\end{array}$ \\
\hline $\begin{array}{l}\text { Advice and } \\
\text { Consolation }\end{array}$ & $\begin{array}{l}\text { Similar to motivation process, teachers could use all } \\
\text { available communication features on mobile devices } \\
\text { to provide advice and personal consultation to } \\
\text { learners }\end{array}$ \\
\hline $\begin{array}{l}\text { Practice and } \\
\text { Evaluation }\end{array}$ & $\begin{array}{l}\text { Learners could practice what they had learned } \\
\text { through discussion with their teachers using mobile } \\
\text { devices' communication features, challenging } \\
\text { themselves through game-based learning, or } \\
\text { completing assignments. Teachers' feedback via } \\
\text { various communication features could be used as an } \\
\text { evaluation mechanism for learners }\end{array}$ \\
\hline $\begin{array}{l}\text { Creation of } \\
\text { Knowledge }\end{array}$ & $\begin{array}{l}\text { Mobile devices could provide learners with various } \\
\text { communication platforms to engage in dialogue } \\
\text { among themselves and with teachers to discuss and } \\
\text { share their ideas as part of the knowledge creation } \\
\text { process }\end{array}$ \\
\hline
\end{tabular}

\subsection{Contributions of other learning theories}

Chapter 2 introduced other learning theories that could help form a better set of design guidelines for m-learning. The following list identified these theories and explained their potential contributions in improving Moore's 
(1993) six instructional processes for TDT [93].

1. Presentation - Moore (1993) [93] suggested that distance education course should employ several media formats. For this instructional process, Media richness theory raised the awareness that providing too much multimedia presentation in m-learning could be distracting and affect effectiveness.

Despite mobile devices' capabilities to facilitate knowledge sharing and clarify difficult concepts, too much multimedia presentation could become a distraction during the learning process. For highly abstract ideas and subjective learning content that could be open to interpretation, rich media such as animation would be an appropriate tool for content delivery. On the other hand, for learning content that are concrete and objective in nature, rich media would be unnecessary and could be detrimental to the learning process.

2. Motivation - Moore (1993) [93] suggested that distance education course should use various media to motivate learners to learn. For this instructional process, Self-determination theory, a motivational theory describing learners' cognitive process and factors affecting their self-learning determination, could help identify better motivational strategies.

Based on the Self-determination theory, in order to motivate learners to learn, teachers could provide rich multimedia learning content or create challenges as learning tasks to trigger learners' curiosity and competitiveness, allow them to take some control and participate. Such approaches could intrinsically motivate learners and should be chosen as initial motivational techniques. However, if learners could not be intrinsically motivated, teachers should 
proceed to use extrinsic motivations such as rewarding learners by giving them extra points or scholarship.

3. Practice and Evaluation - Moore (1993) [93] suggested that distance education course should provide some learning tasks that would challenge learners and allow them to practice what they had learned. For this instructional process, Cognitive load theory introduced strategies for presenting learning tasks that could reduce working memory load and improve learning tasks presentation.

If learners had little prior knowledge of the learning topic, then learning tasks should be arranged in a progressive manner (e.g., presenting easier tasks first and add more complexity to the tasks later). Furthermore, despite mobile devices' capability to provide multimedia presentation, developers should take caution when using video animation to present learning content to this group of learners. Video animation could decrease germane cognitive load, and subsequently affect the learning process and reduce learner's ability to permanently store the learned knowledge cognitively.

4. Learner autonomy - an element that affect transactional distance and learning quality. For this element, the Learning theory of andragogy which recognised the significant effects of maturity on learners' approach to learning contributed to a better understanding of learner autonomy. It explained that adult learners had their own cognitive process, and therefore would be motivated differently when compared to children learners. Additionally, it strengthened the proposition that learner autonomy should be observed before designing an m-learning course.

Furthermore, Activity theory and cultural-historical activity theory highlighted that enculturation could affect learners' learning 
processes at both individual and social levels. These contributed to learner autonomy observation.

TDT primarily defined learner autonomy based on learners' ability to set their own learning goals, carry out their own learning process and self-evaluate their learning outcomes. In the context of m-learning, Activity theory and Cultural-historical activity theory augment the definition by recognising that learners' experience in m-learning and their familiarity to mobile devices and communication technology might also affect learner autonomy. Moreover, m-learning not only supports individual learning but also enables social participation. Therefore, teachers should consider providing both individual and collaborative social tasks in an m-learning course.

\subsection{Usability Design of M-learning}

By this point, the proposed m-learning design guidelines were mainly grounded on the principles of TDT and complemented with knowledge from other learning theories. However, these guidelines were still insufficient and lacked elements of interface design which developers would need to draw upon. In response to this, the eight golden rules of interface design for global interactive system [126] were adopted to complete the m-learning design guidelines.

Based on the eight golden rules of interface design, m-learning application design should:

1. Provide language and interaction consistency

2. Allow learners to use shortcut

3. Offer informative feedback 
4. Provide dialogue that informs learners where they are in the learning process, what they are doing, and when they accomplish any task

5. Provide simple error handling mechanism

6. Permit easy reversal of action if learners make any input mistake

7. Allow learners to feel in control over the application

8. Reduce the use of learners' short term memory load

Additionally, to address the limitation of small screen display on mobile devices and adapt to their mobility features, some design guidelines proposed by Gong \& Tarasewich (2004) [48] and Jones \& Marsden (2006) [61] were included. Based on their suggestions, m-learning application design should:

1. Provide alternative interactions - as mobile devices were commonly used in a dynamic context such as during a train ride, at home, or at a library, users should be given some interaction options. For example, allowing users to choose using text rather than audio notifications when they were at a library.

2. Provide interface design that require as little attention as possible as users might use the mobile devices when they were on the move, it might contribute to potential accidents if users became distracted and were not aware of their surroundings.

3. Present learning content in hierarchical order - as mobile devices had smaller display compared to laptop and desktop computers, a hierarchical learning content order would help group related content together, provide easy navigation, and assist learners to draw connections between each learning section.

4. Be useful, fun, and visual pleasing - engage users when they were using the mobile devices. 


\subsection{First M-learning Design Guidelines}

Using the transformed principles of TDT, the eight golden rules of interface design and knowledge from other relevant learning and design theories presented in previous sections of this chapter, the first iteration of m-learning application design guidelines were developed. Table 4.3 shows the developed guidelines. Note that in order to use these proposed design guidelines, developers should first observe target learners' autonomy. Learner autonomy could be observed through a user study such as that discussed in chapter 3 , a questionnaire or direct observation.

Table 4.3: The first iteration of m-learning design guidelines developed based on the principles of transactional distance and other learning theories

1. Despite learner autonomy, it is essential to provide positive quality dialogue opportunities among learners and teachers, and ensure that the resulting dialogues are constructive, encourage learners to collaborate, and promote learners' understanding of course content 
2. Provide flexible course structure that caters to learner autonomy 2.1 Autonomous learners - Learners should receive a flexible course structure where they can take part in setting their own learning goals, manage their own learning schedule and learn at their own pace, set their own evaluation criteria to evaluate their knowledge. Teachers take on the role of facilitators to provide feedback, consultations, advice and other learning support as required by the learners.

2.2 Non autonomous learners - provide an inflexible course structure. Teacher should set learning goals, track learning progress, provide constructive encouragement and feedback, arrange advice and consultation schedule, and provide constructive learning material and evaluate learners' knowledge to ensure learning quality.

3. Choose appropriate presentation media suitable for learners' capabilities and learning content - rich multimedia should only be used to deliver abstract or ambiguous content to avoid introducing distraction to learners' learning process. To ensure the application's usability, language and interactions should be consistent throughout the design, learning content should be presented in a hierarchical order and the interface design should be visually pleasing 
4. Motivate Learners by providing learning tasks that are challenging and trigger learners' curiosity and competitiveness. If learners lacked motivation towards learning topics or learning tasks, use rewarding techniques to increase their participation

5. Allow learners to practice what they have learned and ensure that they receive feedback on their performance. Ensure the feedback is informative to maintain the application's usability

6. Design for usability that considers the unique aspects of mobile devices.

6.1 For general usability: allow learners to use shortcuts, provide dialogue that informs learners where they are in the learning process, what they are doing, and when they accomplish any task. Provide simple error handling mechanism and permit easy reversal of action if learners make any input mistakes. Allow learners to feel in control over the application and reduce the use of learners' short term memory load.

6.2 For mobile device usability: provide alternative interactions and use interface design that is enjoyable and require as little attention as possible.

\subsection{First Prototype Design}

An m-learning application prototype was developed to observe and evaluate the actual applicability of the first iteration design guidelines created in section 4.4 . 
Note that the first design guidelines were generally applicable to any m-learning application, but the first prototype was developed specifically for first year engineering and computer science students at the Victoria University of Wellington. The prototype used the specific topic of "Engineering Ethics". Some features within the prototype such as the quiz game, the case study assignment and the types of media (i.e., text, recording audio, and animation video) used in the prototype were all chosen to match the learners' learner autonomy. As a result, the prototype could only be used as a design example.

To anchor the design of the application prototype and ensure the correct guidelines were incorporated, the learner autonomy characteristics from the primary persona developed in Chapter 3 was used. Figure 4.1 presents the software structure of the prototype.

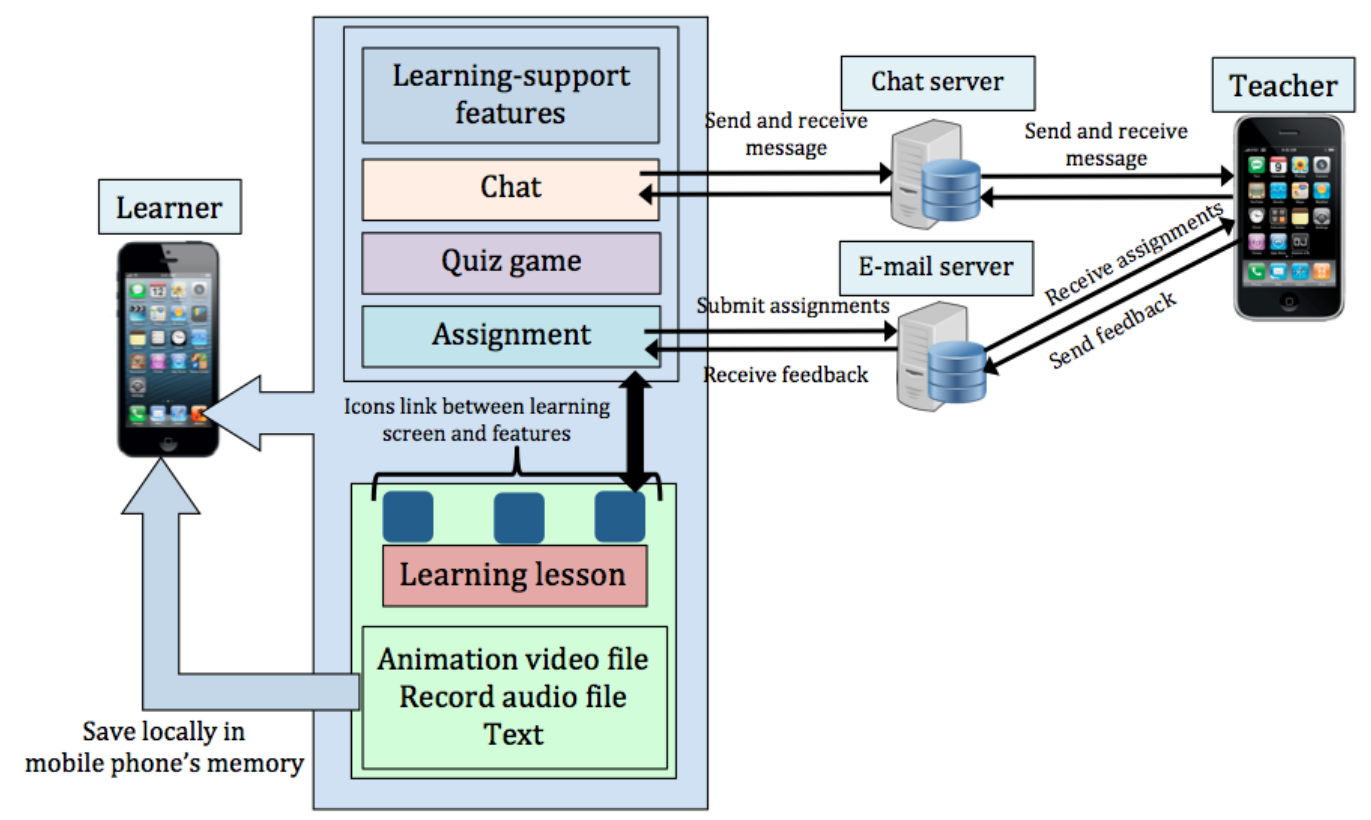

Figure 4.1: Software architecture of the prototype

Additionally, iPhone 6s was chosen as the mobile device for the prototype (See figure 4.2 for its hardware specification). The mobile 
phone used the iOS 10.2.1. operating system and the application prototype was developed using an integrated development environment Xcode 7.0.1 available on macOS.

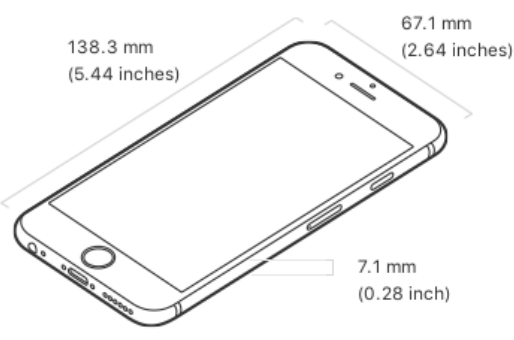

(a) Size

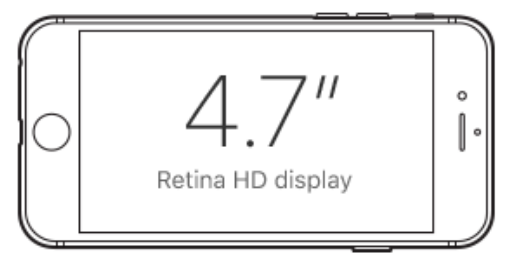

(b) Display

Figure 4.2: iPhone $6 \mathrm{~s}^{\prime}$ hardware specifications ${ }^{6}$

${ }^{6}$ Figure taken from https://www.apple.com/nz/iphone-6s/specs/ on September, 2017 
"Engineering ethics" was chosen as the learning topic to be presented in the first m-learning application prototype in accordance to the course curriculum of first year engineering and computer science students (i.e., the target group of learners). This topic could potentially benefit target learners academically and was deemed relevant to their future professional life.

The quality of the learning topic content had been approved by the Institution of Professional Engineers New Zealand (IPENZ). The learning content "IPENZ code of ethics" was taken from IPENZ website in $2014 .^{7}$ The first m-learning application was used for research purpose within the Victoria University of Wellington laboratory only and was not released for public downloading. Figure 4.3 presents overall designs of learning content.

As noted in the previous section, learners autonomy should be observed before implementing the developed guidelines. Therefore, learners autonomy was analysed based on the primary persona, Clara, created in Chapter 3. Despite having no clear m-learning goals, Clara showed that she could implement m-learning process on her own based on her experience in using various text and multimedia functionalities, as well as media player control functions on the mobile phone. Therefore, she was assumed to be a partially autonomous learner.

\footnotetext{
${ }^{7}$ https://www.engineeringnz.org/. IPENZ had since published new code of ethics which came into force on 1 July 2016.
} 


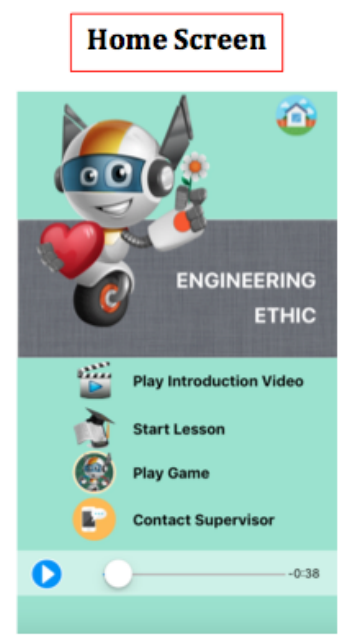

(a) Home screen

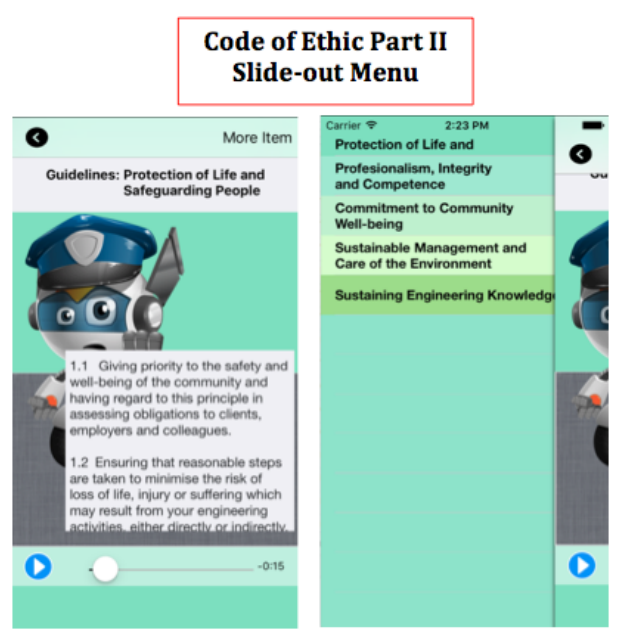

(c) Code of ethics part II

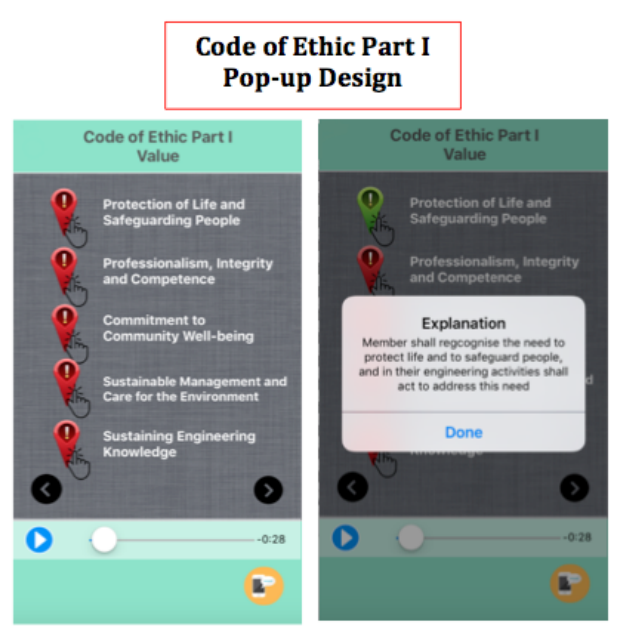

(b) Code of ethics part I

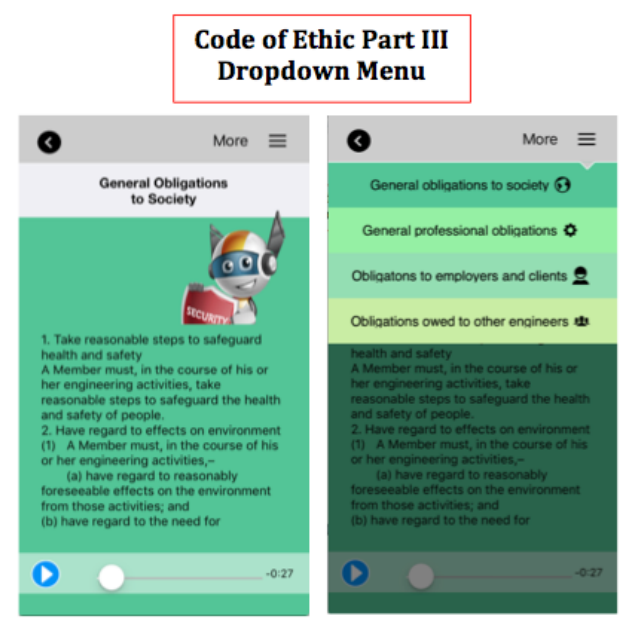

(d) Code of ethics part III

Figure 4.3: Examples of how the learning content was presented

According to the first iteration of design guidelines:

1. dialogue opportunities were provided via a many-to-many chat function. To ensure course structure remained flexible while enabling dialogue opportunities, Clara would have the ability to initiate a chat session with her fellow learners and teachers if she 
chose to do so. Figure 4.4 presents designs of chat function within the application.

The chat icon was available from other areas within the application, so learners could use that functionality at any point during their learning process. Furthermore, as Clara pointed out that communication with her teachers would help improve her learning and she was already familiar with using text media on the mobile devices, the chat function was selected as the dialogue tool of choice. It was expected that she would use it without any specific encouragement from teachers.

2. a flexible course structure was utilised to match Clara's learner autonomy. As she was assumed to be a partially autonomous learner, pre-learning guidance was provided to assist her in setting her learning goal by defining what knowledge she would gain from the selected learning topic.

Since Clara had previous experience with the various multimedia features used within the application, she would be able to control her own learning implementation process. Teachers would instead act as the facilitators and provide her with assistance via the chat function upon her request.

During the evaluation process, self-evaluation through game-based learning was provided (See figure 4.5 for the game-based learning design), along with a compulsory assignment evaluation to gage her understanding of the learning topic (See figure 4.6 for the compulsory assignment)

Furthermore, Clara reported that she had neutral attitude towards game-based learning despite her appreciation of learning improvement via assignments. She also preferred to complete her assignments using a desktop computer or laptop rather than a mobile phone. To accommodate her lack of intrinsic motivation 
towards the chosen evaluation techniques, rewarding technique (a grocery voucher) was used to extrinsically motivate her.

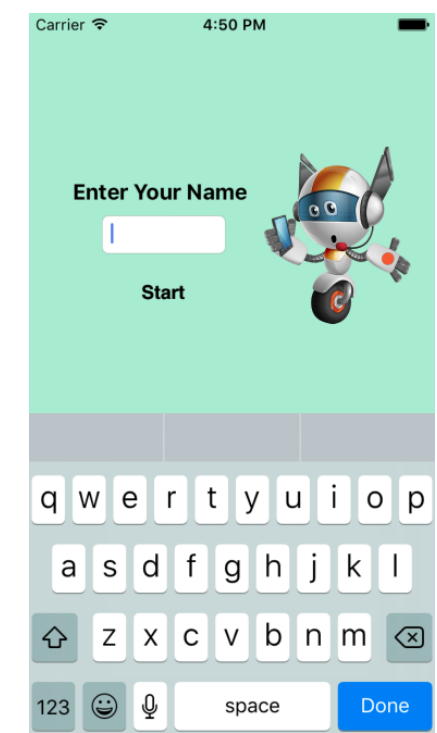

(a) Login Screen

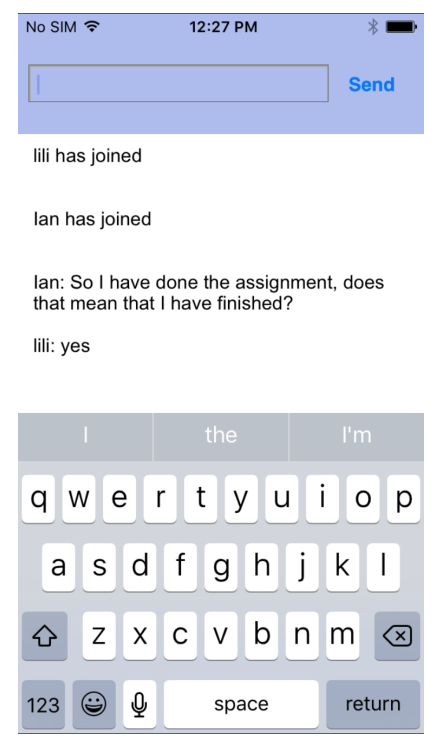

(b) Example of Chat
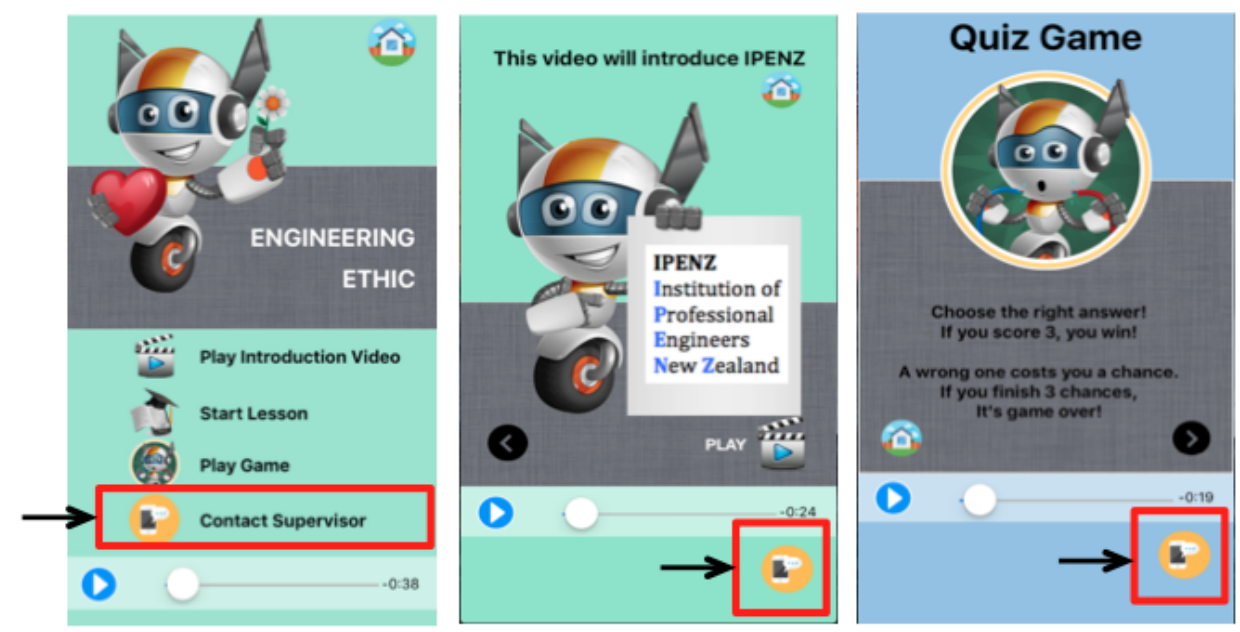

(c) Chat icon available along application design

Figure 4.4: Chat function design 


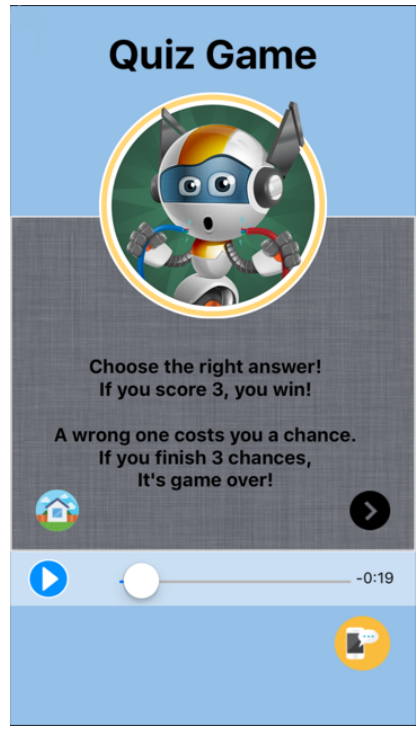

(a) Introduction

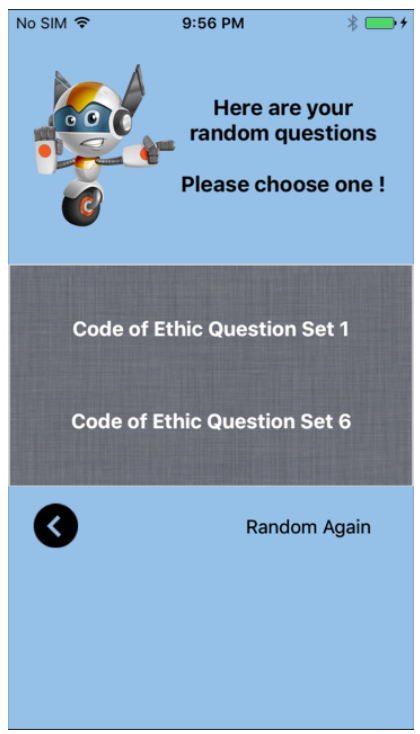

(b) Categories

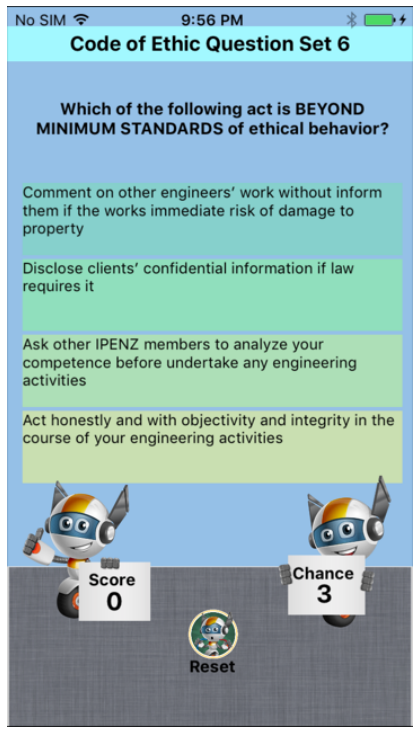

(c) Multiple-choices

Figure 4.5: Game-based learning design

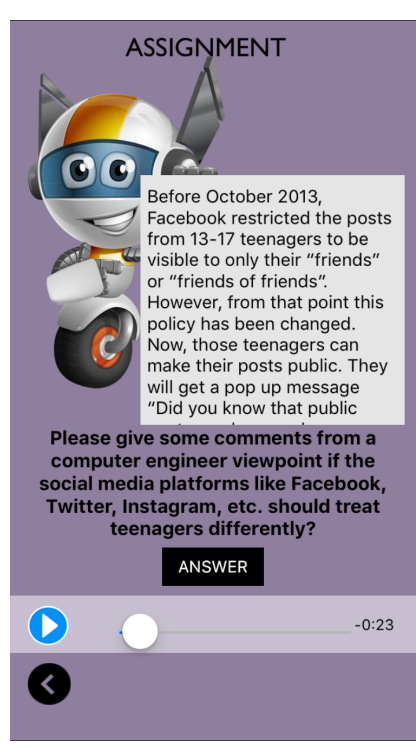

(a) Assignment

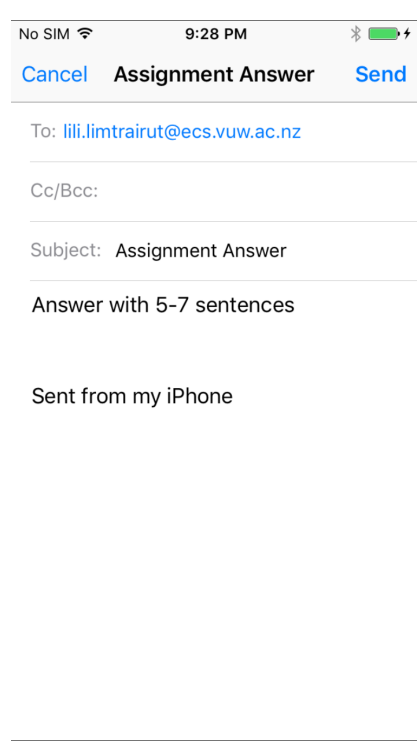

(b) Answer

Figure 4.6: Assignment (compulsory) design 
3. the various media formats where the primary persona, Clara, had claimed prior experience with, were chosen to present various learning content. For example, text media was used to deliver the main learning content (See Figure 4.7); recorded audio was used to introduce learner to each part of the learning content (See Figure $4.8 \mathrm{a}$ ), how to use the video media (See Figure $4.8 \mathrm{~b}$ ), and guide her on how to use the learning support functions such as chat, learning game and assignment (See Figure 4.8c); animation video was designed to introduce each learning topic in a more entertaining manner to encourage and motivate her to learn (See figure 4.9). Additionally, application icons, labels and interactions were applied consistently, and learning content was arranged in hierarchical order to ensure the application's usability was maintained.

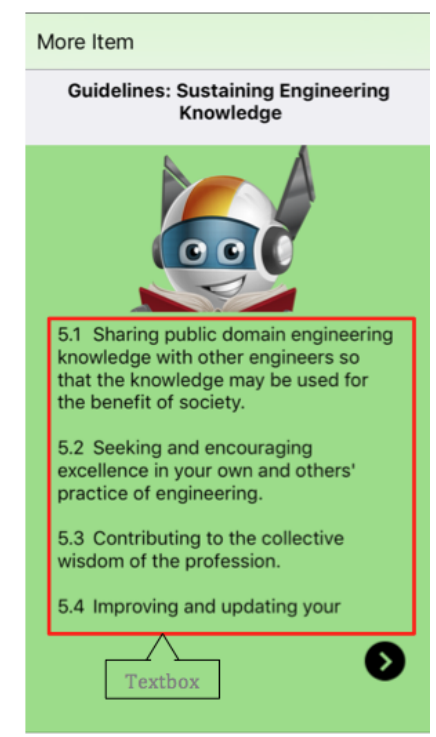

(a) Text in textbox

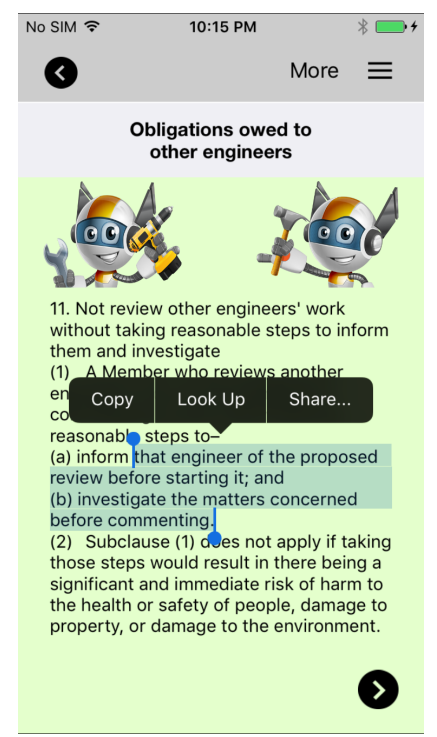

(b) Copy and highlight

Figure 4.7: Text media 


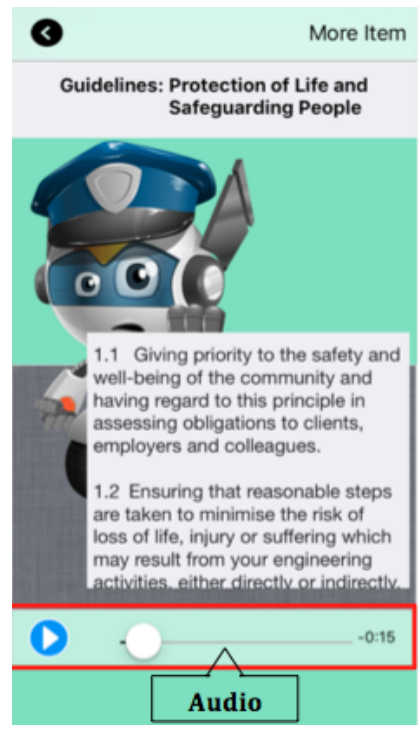

(a)

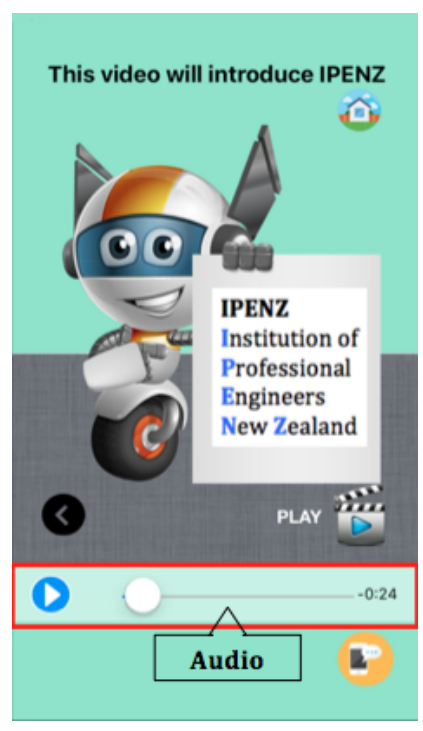

(b)

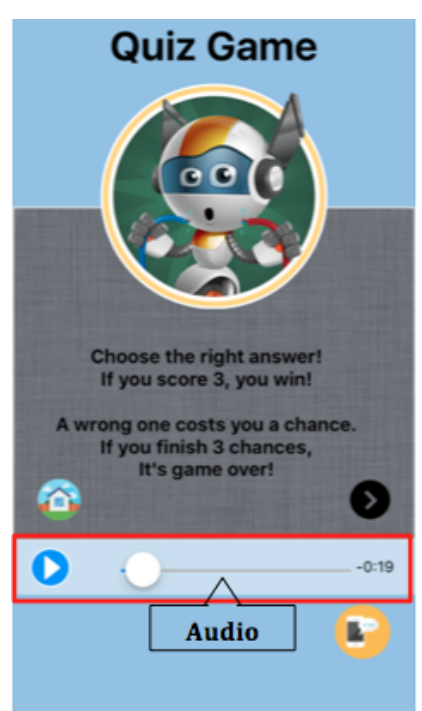

(c)

Figure 4.8: Examples of available recorded-audio media
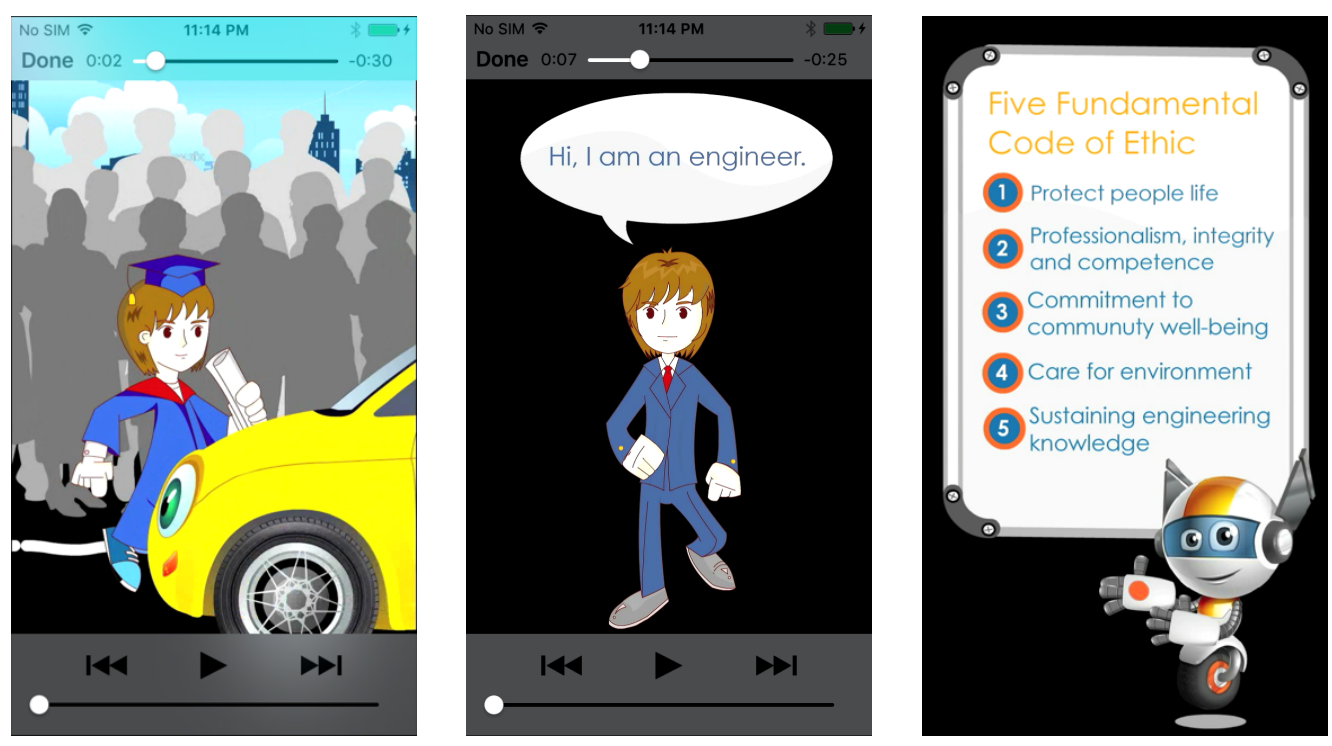

Figure 4.9: Examples of animation video media 
4. extrinsic motivation (a grocery voucher) was used to motivate Clara (i.e., she would receive the voucher if she successfully submitted the assignment and played the quiz game). The animation video was also used for this purpose, although passively triggered based on her preference.

5. a quiz game was provided for Clara to practice what she had learned. A scoring system within the game acted as a feedback channel to Clara (See figure 4.10). Moreover, chat icons were made available for her throughout the application to contact the teachers for further discussions.
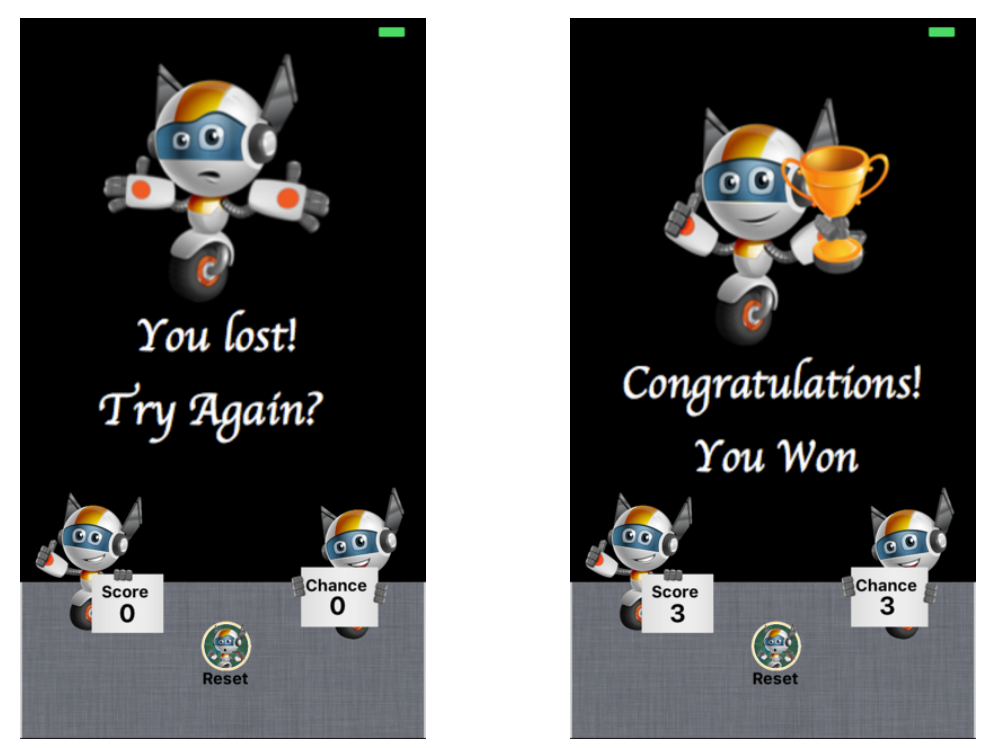

Figure 4.10: Feedback given in quiz game

6. relevant usability elements were incorporated into the application design:

- Informative and visual feedback were provided (e.g., in figure $4.3 \mathrm{~b}$ the information button would change from red to green after it had been clicked and the information window popped up on the screen). 
- Navigation controls and menu were provided to enable Clara to feel in control over the application.

- The use of Clara's short term memory load was reduced by providing relevant heading in every learning content screen to inform her of her location within the learning application.

- Multimedia that required less visual attention were used, such as recorded audio rather than text media.

- A learning topic that would contribute to Clara's academic improvement was used.

- A cartoon character was incorporated into the application to hopefully provide enjoyable and visual entertainment to her.

\subsection{Guidelines and prototype analysis}

Transactional Distance Theory (TDT) contributed to the development of the first iteration design guidelines for m-learning. However, as m-learning was a subset of e-learning and e-learning in turn was a sub-set of distance education [46], some parts of these newly developed design guidelines overlapped with existing e-learning design guidelines. For example, Clark \& Mayer's (2016) [28] e-learning design guidelines suggesting how media (i.e., text, audio, and animation) would be best presented were similar to the this thesis' first iteration design guidelines number 3. Furthermore, as e-learning had already reached its maturity, their detailed guidelines were built upon best practices. On the other hand, as m-learning had less best practices to draw upon, the first iteration design guidelines were established based on the principles of TDT complemented by other well known learning theories. These guidelines were applicable to m-learning generally, but lacked context-awareness necessary for individual m-learning applications. For example, in guideline number 6, it suggested that alternative interactions 
should be provided as m-learning application could be used in a dynamic environment generally. However, it did not specifically identify which media or interaction would be most suited to present the learning content in a particular environment (e.g., noisy area or dim light).

As mentioned in chapter 2, the existing design guidelines of e-learning could guide m-learning application design. Conversely, TDT had been modified to be applicable in the m-learning context during the guidelines development process, and as e-learning and m-learning were pedagogically similar, the functional design guidelines (i.e., guidelines number 1. to 5.) and part of the usability design guidelines (i.e, guideline number 6) from the first iteration design guidelines would also be applicable to e-learning.

The first iteration design guidelines could be differentiated from the existing e-learning design guidelines as they were developed based on principles of learning theories and included interface design guidelines that took into account hardware limitations of mobile devices and the mobility of m-learning.

Ultimately, the learner autonomy must be observed before selecting the course structure. To measure the learner autonomy, this research suggests assessing target learners' ability and willingness towards m-learning and mobile technologies. However, the result might differ from the original learner autonomy defined by Moore's (1993) [93]. In light of this, learners' previous experience and ability to set their own learning goal, implement their own learning process, and evaluate their learning outcome should also be measured.

In section 4.5, the first iteration prototype was developed for target learners to learn a specific topic. Thus, it could only be used as an example of how the first iteration design guidelines could be applied. Alternatives to the learning-support features and presentation media choices implemented in the first iteration prototype could be used in other m-learning application designs. For example, for part-time students 
who worked during day time and were unable to actively participate in the chat-room conversations, providing dialogue through e-mail communication channel would be more suitable to them than the chat feature.

\subsection{Summary}

In this chapter, the principles and the three variables of the TDT were transformed from their original distance education context to be used in an m-learning environment. Other complementary learning theories and the eight golden rules of interface design were also analysed to determine how they could be applied in the m-learning context. From these transformation and analysis, the first iteration of m-learning application design guidelines were developed.

The resulting design guidelines emphasised the need to provide sufficient dialogue opportunities and suitable course structure based on the characteristics of learner autonomy. Consequently, the role of teachers and their control over the learning development, implementation and evaluation process would also change.

A first iteration m-learning application prototype were designed and developed based on the design guidelines generated from this chapter and the learner autonomy drawn from the primary persona created in Chapter 3. Furthermore, Moore's (1993) [93] six instructional processes also formed the foundation for the chosen range of multimedia and functionalities incorporated within the m-learning application.

In the next chapter, the applicability and suitability of these design guidelines would be assessed by observing target learners' interactions with the developed prototype and analysing their evaluation of the application. 


\section{Chapter 5}

\section{First Prototype Evaluation}

In chapter 4, an m-learning prototype was developed based on the first design guidelines. In this chapter, an evaluation process is used to evaluate the prototype and collect information about participants' learner autonomy and engagement levels using a variety of tools and techniques. The quantitative results and qualitative findings are then analysed to determine how the first design guidelines and the prototype design can be further improved. Additionally, the prototype's ability and effectiveness to engage students is analysed to provide some indications towards TDT's suitability and ability to guide the design of modern education application. Furthermore, the evaluation results are explored to seek any potential correlation between learner autonomy and student engagement.

\subsection{Hypotheses}

This evaluation is designed to observe if an m-learning prototype developed based on the guidelines proposed in chapter 4 can improve learning quality as measured by student engagement in comparison to another prototype developed partially based on the guidelines, specifically for autonomous learners. Therefore, it can be hypothesised 
that:

1. An m-learning prototype designed to decrease transactional distance can engage autonomous learners better than a prototype providing the same learning flexibility but has no other mechanisms in place to decrease transactional distance

To test this hypothesis, participants' learner autonomy is observed.

Additionally, this evaluation is conducted in an attempt to uncover possibilities of correlation between learner autonomy and student engagement. Therefore, another hypothesis is:

2. There is a correlation between learner autonomy and student engagement

\subsection{Evaluation Process}

The first iteration m-learning application prototype evaluation was conducted to observe evaluation participants' interaction with the prototype, gather information about their learner autonomy and gage their student engagement levels. The results of this evaluation would be used to validate the two hypotheses stated in the previous section. This evaluation process was divided into three stages: participant recruitment, participant observation and data collection, and data analysis.

\subsubsection{Participant Recruitment}

To ensure consistency in the selection of target learners throughout this research, participants for the first round of prototype evaluation were selected from first year engineering students at the School of Engineering and Computer Science, Victoria University of Wellington.

These students were either enrolled in the Engineering Technology 
(ENGR101) or the Introduction to Computer Program Design (COMP102) course. ENGR101 introduced fundamental technical concepts of engineering electronics, mechatronics, networked, and software systems, while COMP102 focused on the fundamentals of programming using high-level programming languages such as Java.

The participants were recruited via a closed-group email sent to all students enrolled in the two courses during the second trimester in 2016. To encourage their participation, a grocery voucher was offered to each participant as a reward upon their completion of the prototype evaluation. From a pool of approximately 150 students, 21 of them expressed interests in participating in the prototype evaluation. Of the 21 participants who took part in this study, 18 were male and 3 were female, aged between 18 to 22 years old.

The prototype evaluation was conducted between August $10^{\text {th }}$ and $26^{\text {th }}$ 2016 , week $5^{\text {th }}$ to $6^{\text {th }}$ of the second trimester. A laboratory room at the Victoria University of Wellington was used to carry out this evaluation. The time participants spent in the laboratory to complete this evaluation ranged from 20 to 80 minutes.

\subsubsection{Participant Observation and Data Collection}

The second stage of the prototype evaluation process was further divided into 4 steps. Figure 5.1 illustrates the overall observation and data collection part of this process.

1. To evaluate the prototype, each participant attended the evaluation individually at the laboratory at different times. S/he was first asked to complete a pre-questionnaire (See appendix). The pre-questionnaire was designed to capture information about each participant's learner autonomy, in particular his/her motivation and confidence in using m-learning. The pre-questionnaire had three sections: 


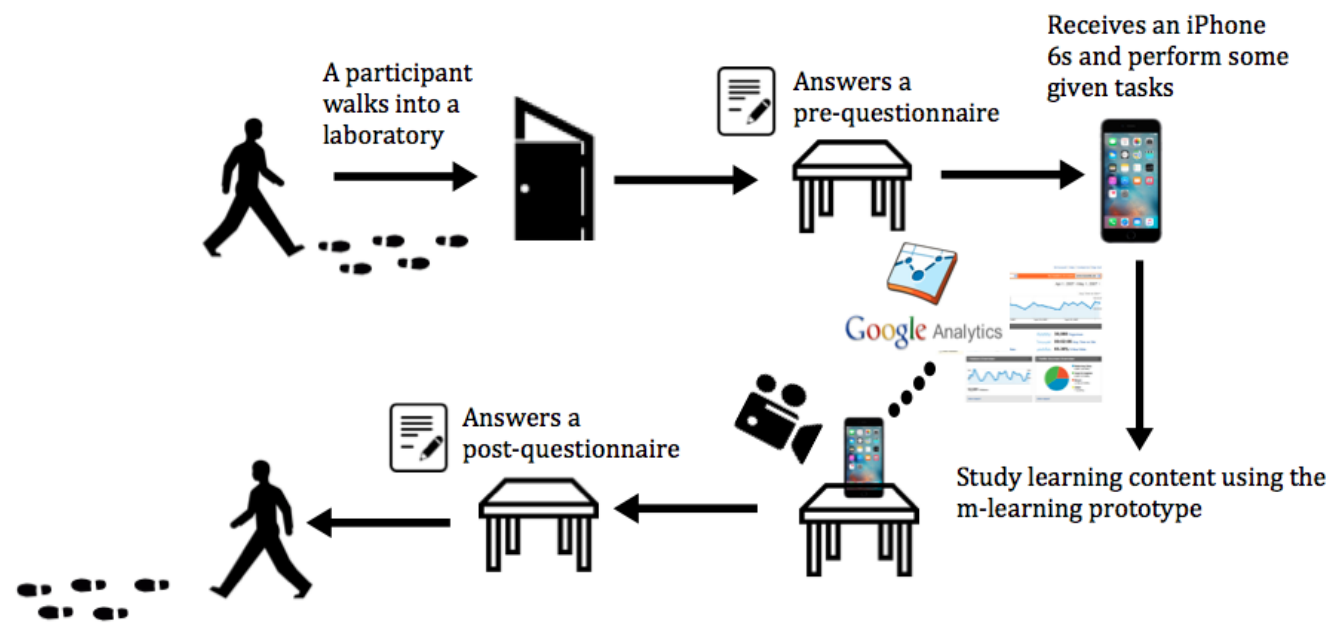

Figure 5.1: Participant observation and data collection process

- student information (i.e., gender and age),

- motivation (11 questions), and

- confidence (9 questions).

For questions related to their motivation and confidence in m-learning, participants were asked to rank their responses using the five point Likert Scale (from strongly disagree to strongly agree). This scale was used in both the pre- and post-questionnaire. Although the five point Likert Scale produced less granular results when compared to the seven point Likert scale, it provided sufficient results for the developers to make judgement regarding ways to improve the prototype. Additionally, the five point Likert scale was easier for participants to rank their opinions. The Victoria University of Wellington had previously used the same scale for their online questionnaires, hence the participants might feel more familiar with using the scale.

2. Next, each participants was provided with a smart phone (i.e., iPhone 6s) and was observed individually while they performed 
eight tasks on the mobile phone that were relevant to m-learning [130] (See appendix). These tasks were:

- Connect the given mobile phone to an available WiFi network

- Open a web browser

- Send an email

- Send a text message

- Play an audio recording

- Play a video recording

- Use the in-built camera to capture a photo

- Create an event in the calendar

All participants were informed that some guidance of how the tasks could be completed would be available to them upon their requests. The results would indicate the level of participants' knowledge and skills in perform tasks commonly used in m-learning activities.

Since the user interface of the prototype would be consistent on any smart phone operating system and there was no specific interactions within the prototype that would be unique to the phone used by participants for evaluation, this research did not observe participants' experience towards mobile phone operating systems.

3. After completing the above general mobile phone skills test, the participants were then asked to use the m-learning prototype. To observe and document this process, the participants' usages of the prototype were video-recorded, and their interactions with the application were captured using Google Analytics ${ }^{8}$. Furthermore, their chat conversations were kept on a research server at the university for analysis purpose.

\footnotetext{
${ }^{8}$ https://developers.google.com/analytics/solutions/mobile
} 
All participants had been informed of the above recording and tracking activities during the participant recruitment process, and again via an information sheet (See appendix) given to them at the beginning of this observation process. All participants had given their consent to participate in this research through a consent form (See appendix).

To test the first hypothesis, the prototype developed in chapter 4 was loaded onto the mobile phone using two different design versions:

- $\mathrm{P}_{1}{ }_{1}$ - an m-learning prototype designed to decrease transactional distance. It included a chat room feature that allowed learners to have dialogue with their teachers, multimedia presentation (i.e., text, recorded-audio, and an animation video), and learning-support features (i.e., a quiz game and a compulsory assignment).

- $\mathrm{P} 1 \_2$ - a prototype providing the same learning flexibility but had no other mechanisms to decrease transactional distance. It had almost none of the media presentation and learning-support features implemented. The chat function was not present, so participants had no dialogue opportunity with their teachers or peers. Learning content was presented using text media only, with no recorded audio or animation video media to motivate and encourage participants to learn. Furthermore, it contained no mechanism such as game-based learning or compulsory assignment for participants to evaluate their own learning, nor receive any feedback from teachers.

To control usability variable, both prototype versions had similar interface design (e.g., learning content were arranged hierarchically in menu) and a similar flexible course structure which allowed participants to access all learning content and set their own learning goals, implement their own learning processes and learn at their 
own pace. Figure 5.2 provides an example of the difference between the two versions. Eleven of the twenty-one participants were randomly selected to use prototype P1_1, whilst the remaining ten used prototype P1_2.

4. Lastly, each participant completed a post-questionnaire (See appendix) for measuring their level of student engagement. The five point Likert scale was once again used by participants to rank their responses. Participants were informed that they could seek clarifications if they did not understand the questions in the questionnaire. However, there was no face-to-face debriefing with the participants to elucidate their individual questionnaire results.

Results gathered from this evaluation process were analysed both quantitatively and qualitatively to test the hypotheses and explore factors that might have influenced the results.

Additionally, the results could help identify potential improvements on the proposed design guidelines and the prototype design, and provide initial indication towards TDT's validity and its ability to guide the design of modern education applications. 


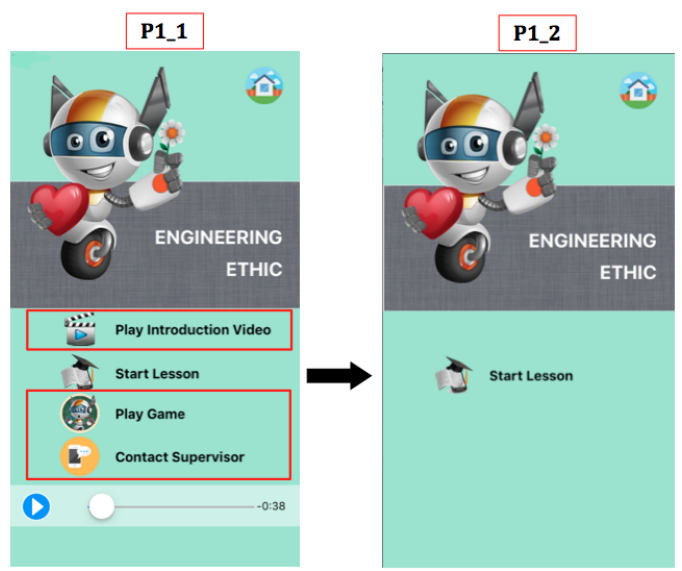

(a) Home Screen

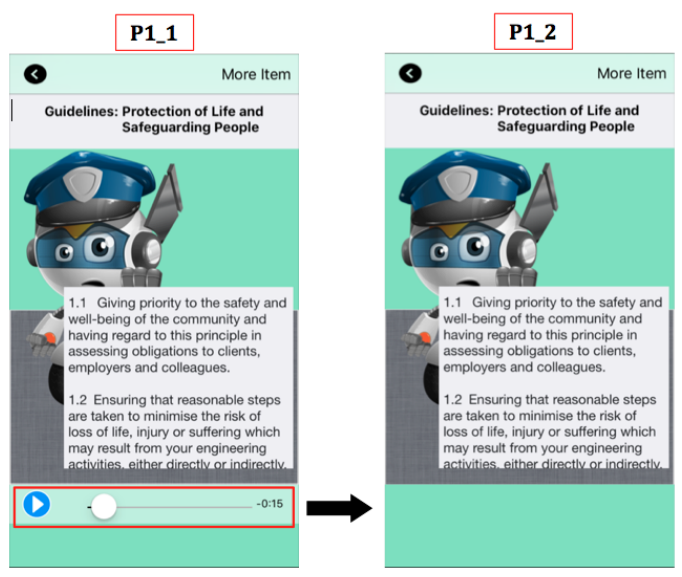

(b) Text media presentation
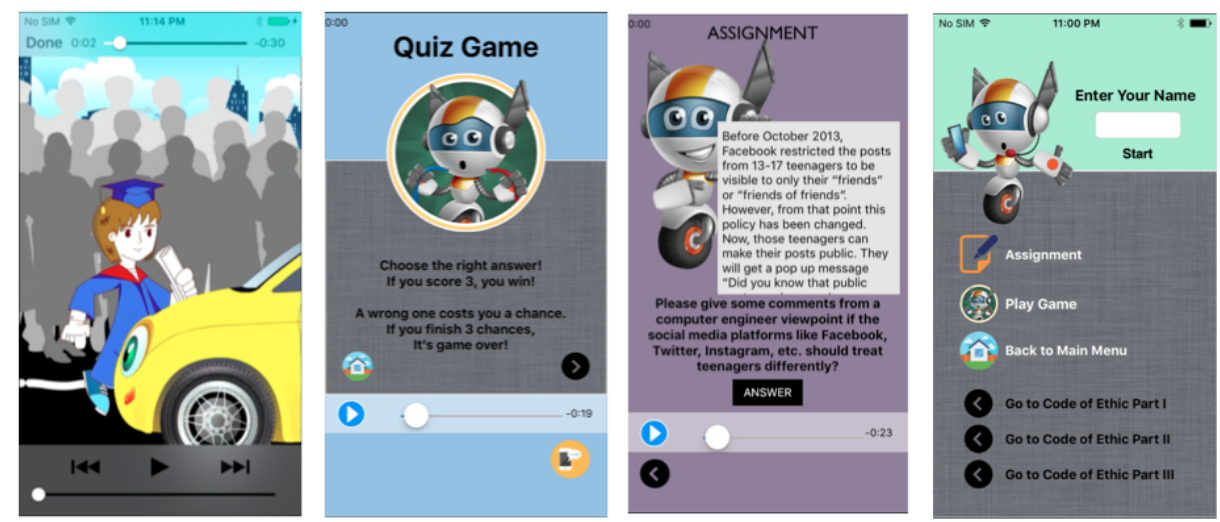

(c) Animation video media, quiz game, assignment, and chat learning supported features that were available only in prototype P1_1

Figure 5.2: Comparison of P1_1 and P1_2 prototypes 


\subsection{Quantitative Results}

\subsubsection{Learner Autonomy}

The pre-questionnaire and the eight tasks completed by participants on the mobile phone during their prototype evaluation process was intended to observe the four components of learner autonomy: their motivation and confidence in using m-learning, and their knowledge and skills in performing common tasks related to m-learning. The observation results would verify if the recruited participants were autonomous learners.

In the pre-questionnaire results, each level in the Likert Scale was assigned a value from -2 to 2 (i.e., strongly disagree $=-2$, disagree $=-1$, no opinion $=0$, agree $=1$, and strongly agree $=2$ ). Next, participants' responses in the pre-questionnaire were translated into the assigned values, and an average for each sets of motivation and confidence questions for each participant were calculated.

The results collected showed that every participant had a positive level of motivation and average confidence towards m-learning (See table 5.1):

- The highest motivation level was 1.73 and the lowest was 0.45 .

- The highest confidence level was 1.78 and the lowest was 0.33 .

- The average of motivation level was 1.09 and the average of confidence level was 1.04 .

After completing the pre-questionnaire, the participants were asked to perform eight tasks commonly related to m-learning. During this process, the thesis' researcher observed how each participant performed the given tasks. From the observation, 19 of the 21 total participants could complete all eight tasks in their first attempt. No participants requested for assistance from the researcher. Although two participants had problem connecting the given phone to an available WiFi network, they managed to complete the task in their second attempt by themselves. These 
Table 5.1: Average level of motivation and confidence level of each participant

\begin{tabular}{|c|c|c|c|}
\hline Participant (P) & Prototype & Motivation Level & Confidence Level \\
\hline P1 & P1_1 & 0.64 & 0.33 \\
\hline P2 & P1_2 & 0.82 & 1.11 \\
\hline P3 & P1_1 & 1.82 & 1.44 \\
\hline P4 & P1_2 & 1.09 & 0.89 \\
\hline P5 & P1_1 & 1.55 & 1.00 \\
\hline P6 & P1_1 & 1.18 & 1.56 \\
\hline P7 & P1_2 & 1.27 & 1.11 \\
\hline P8 & P1_2 & 1.55 & 1.33 \\
\hline P9 & P1_1 & 0.64 & 1.00 \\
\hline P10 & P1_1 & 1.27 & 1.11 \\
\hline P11 & P1_2 & 0.82 & 0.89 \\
\hline P12 & P1_2 & 1.27 & 1.67 \\
\hline P13 & P1_2 & 1.73 & 1.78 \\
\hline P14 & P1_1 & 1.36 & 0.67 \\
\hline P15 & P1_1 & 0.91 & 0.67 \\
\hline P16 & P1_2 & 0.91 & 0.78 \\
\hline P17 & P1_2 & 1.18 & 1.00 \\
\hline P18 & P1_1 & 0.45 & 1.11 \\
\hline P19 & P1_1 & 0.82 & 0.67 \\
\hline P20 & P1_2 & 0.36 & 1.00 \\
\hline P21 & P1_1 & 1.27 & 0.67 \\
\hline Average & & $\mathbf{1 . 0 9} \mathbf{( S D ~ 0 . 4 ) ~}$ & $\mathbf{1 . 0 4}$ (SD 0.36) \\
\hline & & & \\
\hline
\end{tabular}

participants claimed that they used a different mobile operating system on their personal phone (i.e., Android).

Consequently, it was concluded that all participants had the knowledge to perform all given tasks. Whilst some of them had the skills 
and experience in using mobile devices with the same operating system as the given phone (i.e., Apple's iOS), the other group who generally used mobile devices with a different operating system could develop the required skills on their own.

As discussed in section 2.3, an autonomous learner had all four components of learner autonomy, namely motivation, confidence, knowledge, and skills. Based on the results gathered from the pre-questionnaire and the observation of the participants' performance in completing the eight tasks related to m-learning, it can be concluded that:

"All of the participants were autonomous learners"

\subsubsection{Student Engagement}

During the evaluation process, eleven participants were presented with learning content using various multimedia and learning-support functions in the $\mathrm{P} 1_{-} 1$ prototype. However, none of these media or functionalities were compulsory, except for the course assignment. Therefore, these participants could choose to use all, some, or none of these media and functions. In either of the prototype, all participants could choose to study, skim, or skip any or all of the learning content.

A post-questionnaire was used to collect the results of the participants' feedback about using the prototypes and measure their feedback against the six concepts of student engagement (i.e., focused attention, perceived usability, aesthetic, endurability, novelty, and felt involvement). Similar to the pre-questionnaire, each level in the Likert Scale was assigned a value from -2 to 2 (i.e., strongly disagree $=-2$, disagree $=-1$, no opinion $=0$, agree $=1$, and strongly agree $=2$ ). If the questions were seeking negative responses, the values collected for those questions were inverted. Table 5.2 and Figure 5.3 present the average engagement level of prototypes $\mathrm{P} 1{ }^{1} 1$ and P1_2. 
Table 5.2: Average engagement level and standard deviation of P1_1 and P1_2

\begin{tabular}{|c|c|c|}
\hline Prototype & Avg. Engagement & SD \\
\hline P1_1 & 0.68 & 0.46 \\
\hline P1_2 & 0.01 & 0.59 \\
\hline
\end{tabular}

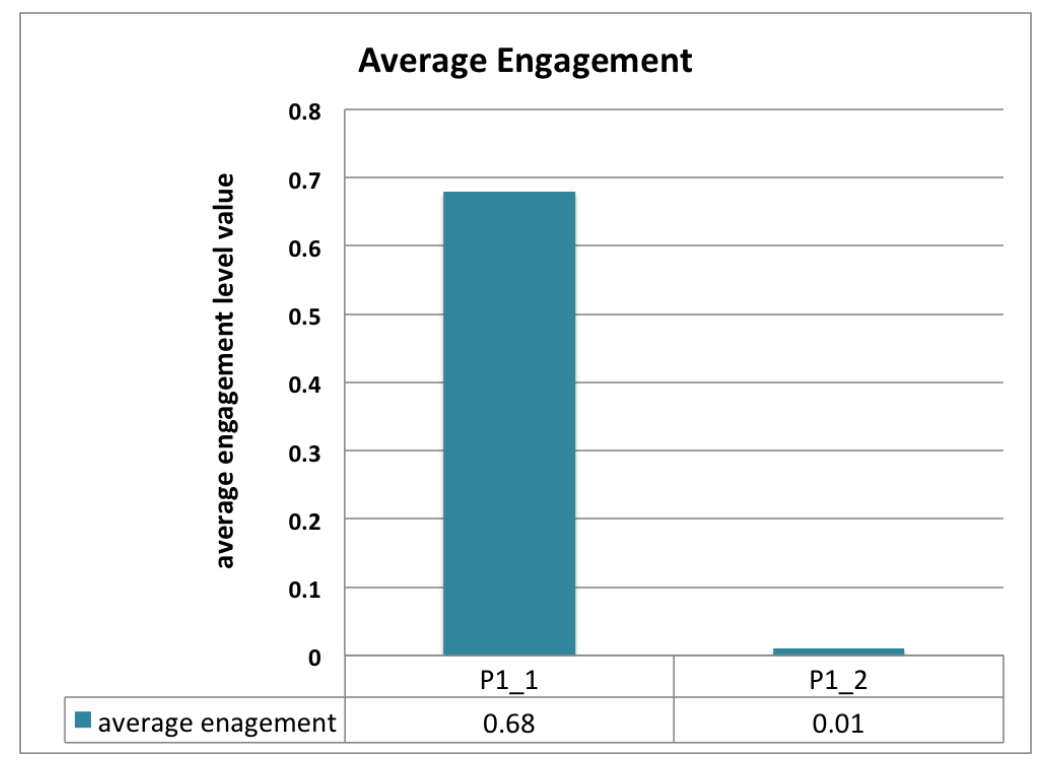

Figure 5.3: Average engagement levels of P1_1 and P1_2

\section{Hypothesis testing}

Although the results from the post-questionnaire indicated that one prototype had a higher engagement level value, due to the high standard deviation, the hypothesis testing was necessary to test if the results presented in table 5.2 (i.e., the average student engagement level value of prototype $\mathrm{P} 1 \_1$ was higher than the same value for prototype P1_2) were statistically significant. The following list presents the hypothesis testing process and its results. 
- Hypotheses:

$$
\begin{aligned}
& H_{1} \text { : average student engagement of prototype } P 1 \_1>P 1 \_2 \\
& H_{0} \text { : average student engagement of prototype } P 1 \_1 \leq P 1 \_2
\end{aligned}
$$

- The hypotheses would be tested using the test statistic for examining a hypothesis of two population means (t-test):

$$
t=\frac{\bar{x}_{1}-\bar{x}_{2}}{\sqrt{\frac{S_{1}^{2}}{n_{1}}+\frac{S_{2}^{2}}{n_{2}}}}
$$

where $\bar{x}_{1}$ and $\bar{x}_{2}$ are the average values of samples 1 and 2

$S_{1}$ and $S_{2}$ are standard deviation of samples 1 and 2

and $n_{1}$ and $n_{2}$ are the numbers of data points in samples 1 and 2

Calculation results : $t=2.882$

- Analysis plan: this research chose a significant level equal to 0.05. When the degree of freedom equals to 19 (i.e., number of participants - 2), the critical value of $t$ found in the $t-t^{2} b l e^{9}$ was 1.729 . Therefore,

$$
H_{0} \text { is rejected if } t>1.729
$$

- Result interpretation:

$$
\begin{aligned}
& \text { Because the calculated } t-\text { value }>\text { the critical } t-\text { value } \\
& H_{0} \text { is rejected }
\end{aligned}
$$

- Calculate p-value form the $t$-value

$$
p-\text { value }=0.0048
$$

The result is statistical significant when $p<0.05$

\footnotetext{
${ }^{9}$ http://www.ttable.org/
} 
Therefore, it had been statistical tested that the average student engagement level value of $\mathrm{P}{ }_{1}{ }^{1}$ was higher that the value of $\mathrm{P} 1{ }^{2}$.

At this stage, the first hypothesis was tested and the results indicated that

"The m-learning prototype designed to decrease transactional distance could engage autonomous learners better than the prototype providing the same learning flexibility but had no other mechanisms to decrease transactional distance"

\section{Average learner autonomy}

According to TDT, learner autonomy affects transactional distance. Although the participants had been observed as autonomous learners, if there was a significant difference in the learner autonomy level value for participants who used prototype $\mathrm{P}_{1}{ }_{1}$ compared that of participants who used prototype $\mathrm{P} 1$ _2 (i.e., highly autonomous versus low autonomous), this could affect the overall evaluation of the participants engagement ability of prototypes $\mathrm{P} 1 \_1$ and $\mathrm{P} 1{ }^{2}$.

In order to determine the average learner autonomy level value, only the quantitative results of the participants' motivation and confidence level values were used. Table 5.3 and figure 5.4 present the comparison of average learner autonomy of participants who used prototype P1_1 against the participants who used prototype $\mathrm{P} 1 \_2$. 
Table 5.3: Average learner autonomy level value and standard deviation of prototype P1_1 and P1_2

\begin{tabular}{|c|c|c|}
\hline Prototype & Avg. Autonomy & SD \\
\hline $\mathrm{P} 1 \_1$ & 1.01 & 0.33 \\
\hline $\mathrm{P} 1 \_2$ & 1.13 & 0.34 \\
\hline
\end{tabular}

In order to observe if the difference in average autonomy between the participants using the two prototypes presented in table 5.3 was statistical significant, we calculated the p-value. The p-value was 0.422 which indicated that the difference was not statistical significant at $\mathrm{p}<0.05$.

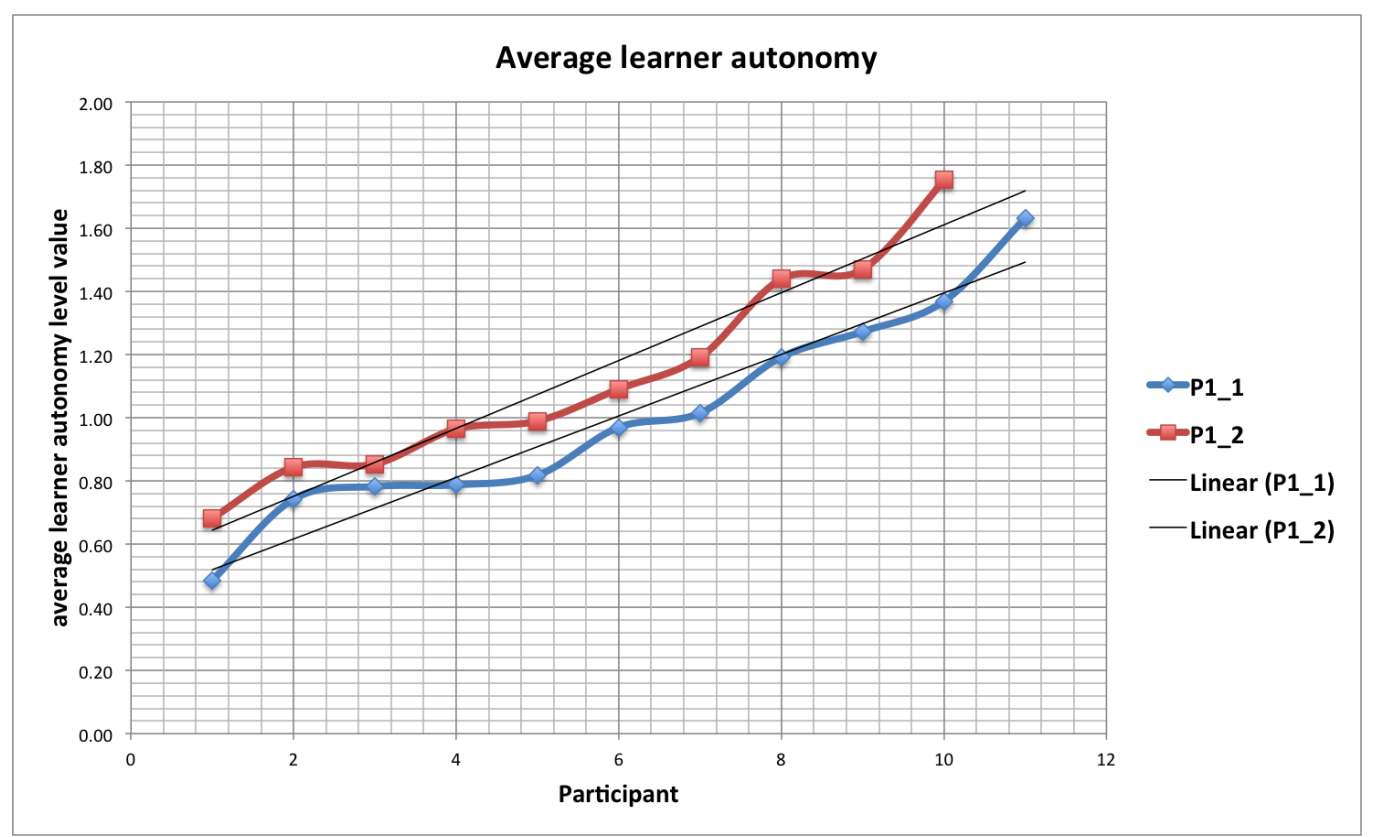

Figure 5.4: Average learner autonomy level value of P1_1 and P1_2

Based on table 5.3 and figure 5.4, the average learner autonomy of prototype $P 1 \_1$ was less than the value of prototype P1_2. However, the difference was small (i.e., it was not statistical significant at $p<0.05$ ). Consequently, the difference in average autonomy of participants who 
used the two different prototypes was assumed to have no significant effect on the first hypothesis test result.

\subsubsection{Six concepts of student engagement}

To closely analyse the factors behind the overall student engagement level value captured in section 5.3.2, the results were further divided according to each of the six concepts of student engagement (the definition of each concept can be found in section 2.7). Table 5.4 and Figure 5.5 present the engagement levels for each engagement concept measured against prototype $\mathrm{P} 1 \_1$ and $\mathrm{P} 1 \_2$.

Based on the results, perceived usability was the student engagement concept that received the best overall response amongst the participants. On the other hand, focused attention was the student engagement concept that the participants responded most negatively using either of the P1_1 and $\mathrm{P} 1 \_2$ prototype designs. For participants who used the prototype P1_2, it was clear that they found it difficult to focus and feel engaged based on their severely negative responses to the focused attention and felt involvement facets of engagement concepts.

However, endurability was found to be the most influential engagement concept critical to the overall engagement levels for prototypes $\mathrm{P} 1 \_1$ and $\mathrm{P} 1 \_2$, calculated based on the difference between the engagement values for each of the prototypes and the observed p-value, followed by felt involvement. 
Table 5.4: Average engagement level for each engagement concept measured against prototypes P1_1 and P1_2

\begin{tabular}{|c|c|c|c|}
\hline Engagement Concept & P1_1 & P1_2 & p-value \\
\hline Focused Attention & $0.40($ SD 0.61) & -0.30 (SD 0.52) & 0.005 \\
\hline Perceived Usability & 0.84 (SD 0.52) & 0.64 (SD 0.79) & 0.253 \\
\hline Aesthetic & 0.64 (SD 0.99) & 0.10 (SD 1.24) & 0.143 \\
\hline Endurability & 0.89 (SD 0.56) & 0.06 (SD 0.68) & 0.003 \\
\hline Novelty & 0.60 (SD 0.61) & 0.00 (SD 0.67) & 0.023 \\
\hline Felt Involvement & 0.70 (SD 0.41) & -0.23 (SD 0.90) & 0.003 \\
\hline
\end{tabular}

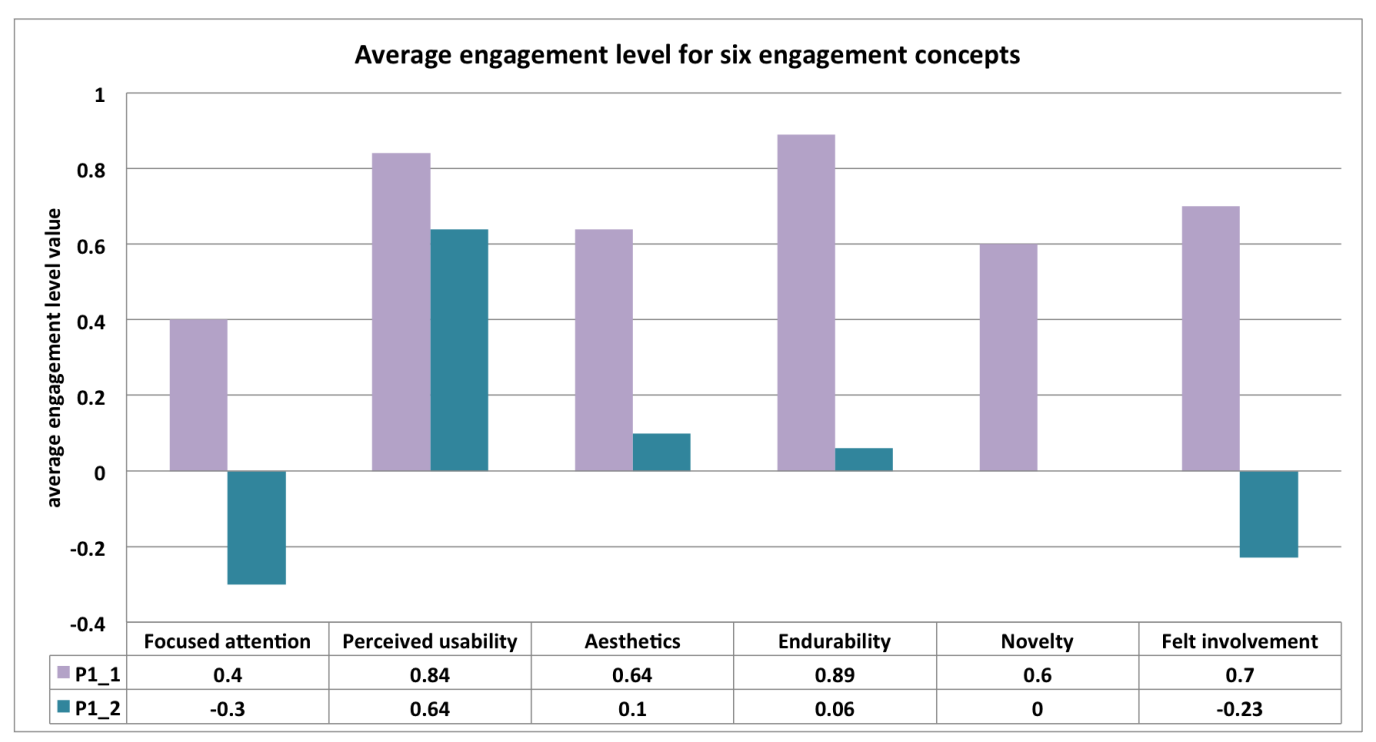

Figure 5.5: Average engagement level for each engagement concept measured against prototype P1_1 and P1_2

The p-values presented in table 5.3 indicated that focus attention, endurability, novelty, and felt involvement were the engagement concepts that had statistical significance in the different average engagement levels (when $p<0.05$ ) between the two prototypes. On the other hand, due to the high standard deviation and the low number of 
participants, the difference in average engagement of the other two engagement concepts (i.e., perceived usability and aesthetic) was not statistically confirmed.

\subsubsection{Correlation between Autonomy and Engagement}

In order to determine whether there was correlation between learner autonomy and student engagement, the statistical technique of correlation coefficient was used. The correlation coefficient could be presented as:

$$
\begin{aligned}
& \hat{p}=\frac{\text { Sxy }}{\sqrt{S_{x x} S_{y y}}} \text { where } S_{x x}=\sum x^{2}-\frac{\left(\sum x\right)^{2}}{n} \\
& S_{y y}=\sum y^{2}-\frac{\left(\sum y\right)^{2}}{n} \\
& S_{x y}=\sum x y-\frac{\left(\sum x\right)\left(\sum y\right)}{n} \\
& \text { and } n \text { is number of data points }
\end{aligned}
$$

To perform the statistical calculation, the built-in function of "CORREL" within Microsoft EXCEL was used. The formula of the CORREL function was defined as:

$$
=\operatorname{CORREL}(R A N G E 1, R A N G E 2)
$$

Calculating correlation coefficient required two variables, ' $x$ ' and ' $y$ '. In this thesis, learner autonomy was assigned as variable ' $x$ ' and student engagement level as variable ' $y$ '.

To determine the value for the learner autonomy variable ' $x$ ', only the quantitative results of the participants' motivation and confidence levels from section 5.3.1 were used. The knowledge and skills elements of learner autonomy in the evaluation process were only observation findings and could not be included. 
Additionally, the different application prototype designs P1_1 and P1_2 were shown to have an effect on participants' engagement levels. As a result, the correlation between learner autonomy and engagement levels had to be calculated twice, one for each engagement level value derived from each prototype design.

A correlation coefficient value between -1.0 and 1.0 indicates how strongly the two variables relate to each other. A correlation coefficient that is:

- close to +1.0 indicates that there is a strong positive linear relationship between $\mathrm{x}$ and $\mathrm{y}$ (i.e., as variable $\mathrm{x}$ increases, variable $\mathrm{y}$ increases or as variable $x$ decreases, variable $y$ decreases)

- close to -1.0 indicates that there is a strong negative linear relationship between $\mathrm{x}$ and $\mathrm{y}$ (i.e., as variable $\mathrm{x}$ increases, variable $\mathrm{y}$ decrease or as variable $x$ decreases, variable $y$ increases)

- close to 0 indicates that there is close to no linear relationship between $\mathrm{x}$ and $\mathrm{y}$.

The calculation indicated that there was a weak correlation between learner autonomy and student engagement:

\section{The correlation coefficient between learner autonomy and student engagement of P1_1 and P1_2 was 0.21 and -0.31 respectively}

The correlation coefficient further indicated that:

- For prototype $\mathrm{P} 1 \_1$, the positive correlation coefficient indicated a positive linear relationship between the two variables. That is to say, the better the participants could learn autonomously, the more they would engage with this prototype. 
- For prototype $\mathrm{P} 1 \_2$, the negative correlation coefficient indicated a negative linear relationship between the two variables. That is to say, the better the participants could learn autonomously, the less they would engage this prototype.

To better illustrate the correlation between autonomy and engagement, the results were arranged based on the average learning autonomy level value from low to high. These results were then plotted as scatter plots. Table 5.5 and 5.6 show the average autonomy and average engagement level value for each participant who used prototype P1_1 and P1_2 respectively and figure 5.6 illustrates the correlation between learner autonomy and student engagement of the two prototypes.

Table 5.5: Autonomy and engagement level for each participant who used prototype P1_1

\begin{tabular}{|c|c|c|}
\hline Participant & Autonomy & Engagement \\
\hline P1 & 0.48 & 0.69 \\
\hline P19 & 0.74 & 0.54 \\
\hline P18 & 0.78 & 0.43 \\
\hline P15 & 0.79 & 0.17 \\
\hline P9 & 0.82 & 0.81 \\
\hline P21 & 0.97 & 0.64 \\
\hline P14 & 1.02 & 1.19 \\
\hline P10 & 1.19 & -0.05 \\
\hline P5 & 1.27 & 1.66 \\
\hline P6 & 1.37 & 0.66 \\
\hline P3 & 1.63 & 0.72 \\
\hline
\end{tabular}


Table 5.6: Autonomy and engagement level for each participant who used prototype P1_2

\begin{tabular}{|c|c|c|}
\hline Participant & Autonomy & Engagement \\
\hline P20 & 0.68 & 0.72 \\
\hline P16 & 0.84 & 0.72 \\
\hline P11 & 0.85 & -0.61 \\
\hline P2 & 0.96 & 0.23 \\
\hline P4 & 0.99 & -0.41 \\
\hline P17 & 1.09 & -0.74 \\
\hline P7 & 1.19 & 0.28 \\
\hline P8 & 1.44 & 0.32 \\
\hline P12 & 1.47 & 0.39 \\
\hline P13 & 1.75 & -0.79 \\
\hline
\end{tabular}

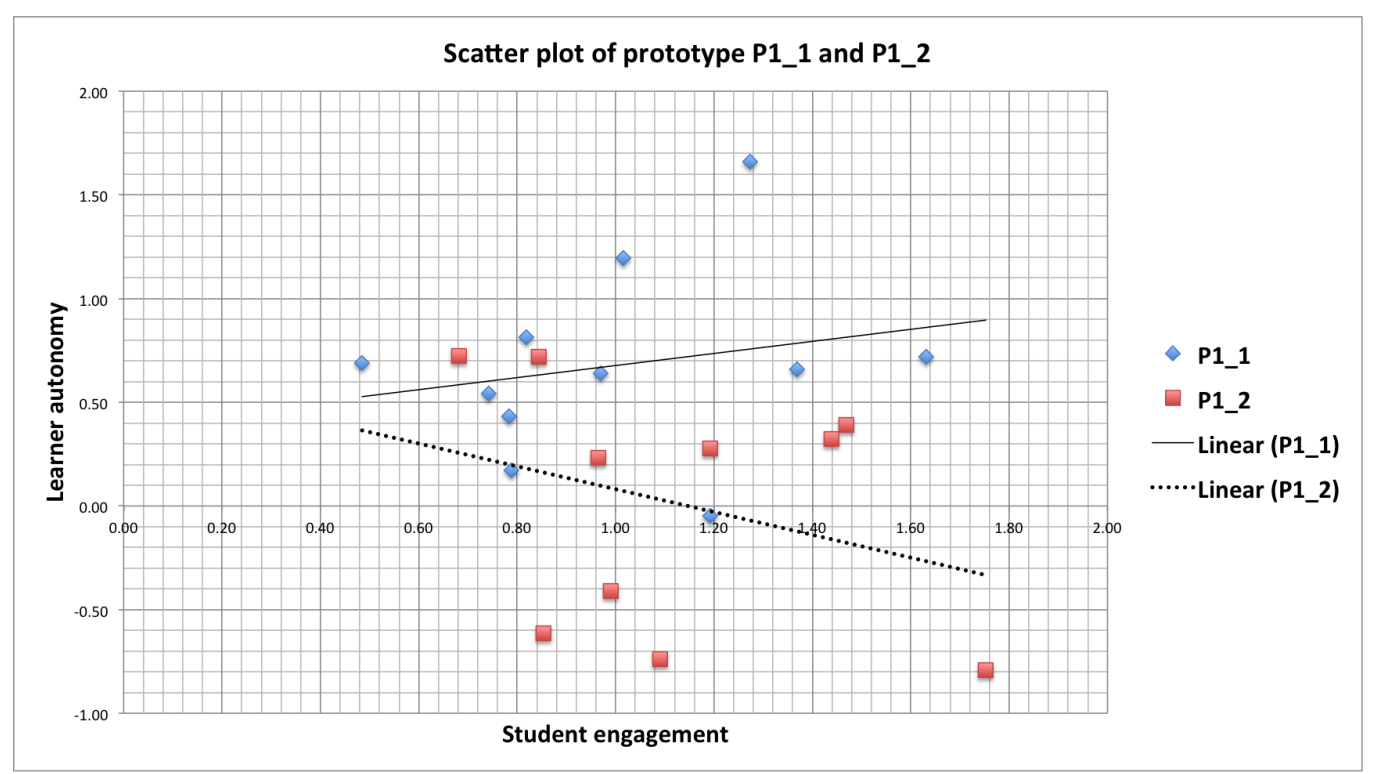

Figure 5.6: Graphical illustration of learner autonomy and student engagement for participants who used prototypes P1_1 and P1_2 


\subsection{Qualitative Findings}

Qualitative findings were gathered from the video-recordings of participants using the prototypes to assess the usability factor of the design guidelines and the prototype design. It specifically focused on how the participants interacted with the hierarchical learning content design (i.e., popup, slide-out, and dropdown menus), how they used the provided multimedia (i.e., text, audio recordings, and an animation video) and learning-support features (i.e., chat, quiz game, assignment).

\subsubsection{Hierarchical learning content design}

Hierarchical learning content designs were available in both P1_1 and $\mathrm{P} 1 \_2$ prototypes. As a result, qualitative findings from all 21 participants were considered.

\section{Pop-up interface design}

From a total of 21 participants, 18 of them successfully used the pop-up menu to study the information given in the pop-up windows. Among these 18 participants, less than half of them (7 participants) could find the provided buttons immediately. The remaining 11 participants tapped on the labels (not the pop-up buttons) several times (See figure 5.7) before they located the correct pop-up buttons, either by listening to the audio recorded instructions guiding them to tap on the icons or made the discovery themselves.

The remaining 3 participants were unable to use the pop up menu in this learning content screen. Despite listening to the guidelines given in the audio recording, one participant still could not open the pop up information. The other two participants tapped on the wrong places several times, navigated away from this menu, and subsequently forwent studying all the learning content in this section. 


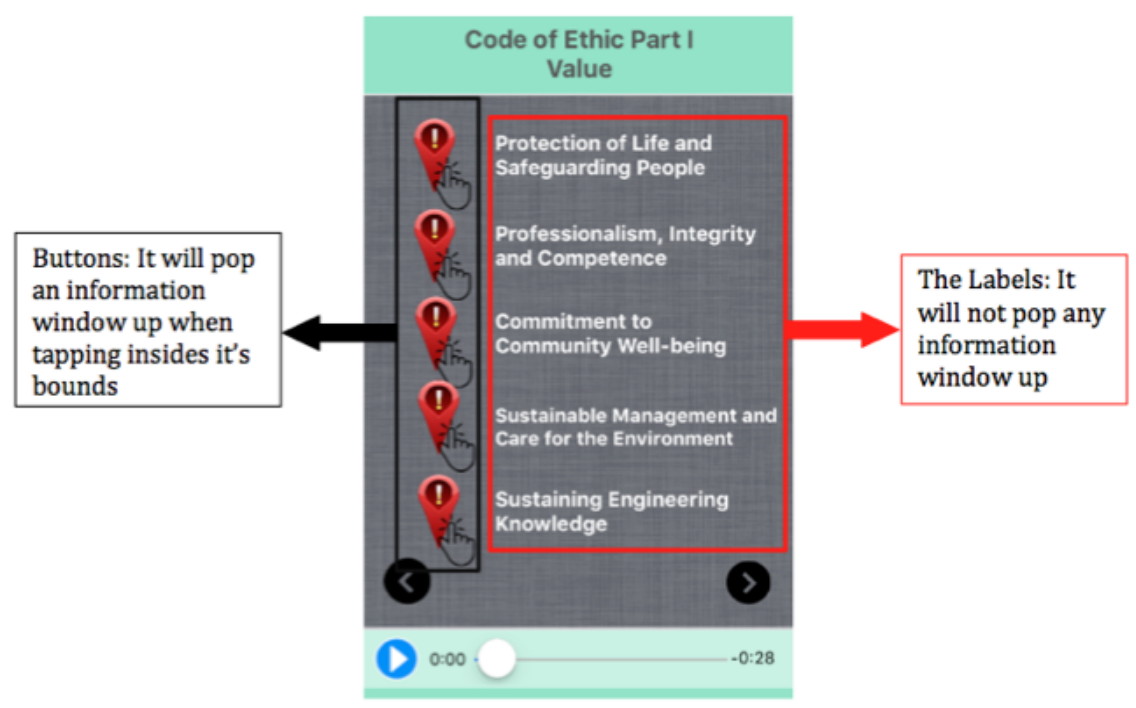

Figure 5.7: Pop-up buttons and labels

\section{Slide-out menu interface design}

All 21 participants visited this screen and located the button to reveal the slide-out menu. They were able to navigate through and studied all learning content hidden in this menu. 11 of the 21 participants successfully completed this during their first attempt. The remaining 10 participants could not locate the menu initially. They either tapped on the wrong places or went back and forth between this and other screens several times before locating the menu button and tapped on it.

\section{Dropdown menu interface design}

All but one participant were able to locate and open the dropdown menu to reveal and study the learning content hidden within the menu. The remaining one participant did not visit this part of the application. 15 of the 20 participants successfully found and used the dropdown menu on their first attempt. The remaining 5 participants could not find the dropdown menu immediately. Instead, they tapped on the wrong places 
or went back and forth between various screens several times before locating the menu button and tapped on it.

\subsubsection{Media Presentation}

Audio recordings and animation video were only available in prototype $\mathrm{P} 1$ 1. Therefore, qualitative findings relating to media presentation were collected from the prototype evaluation results of the 11 participants assigned to use this prototype.

\section{Text Media}

Text media was used in either pop up information window or in text boxes. The size of the provided text was equal throughout the application. During the evaluation process, none of the participants made zooming gesture to view, copy or highlight the text. They seemed to encounter no difficulty or require guidance in reading the provided text as it was. All participants could scroll up and down each screen to read all text content. Instead, the video recordings showed some participants skimmed-read the learning content, spent very little time on or even completely skipped certain screens.

\section{Animation video}

The animation video introduced the learning topic (i.e., engineering ethics) and briefly explained the learning content. The main purpose of this media was to engage and motivate learners at the beginning of the course. Hence, it was expected that the participants would watch the video before they began studying the learning content. From a total 11 participants who used prototype $\mathrm{P} 1_{-} 1$, all of them visited the animation video screen before they started the course. However, only 5 of them watched the entire video and only 1 participant among them watched the video more than once. This participant was also the only one who used 
the fast forward button in the video player. Despite visiting the animation video screen and listening to the audio recording which encouraged them to play the animation video, the remaining 6 participants exited this video screen without playing the animation video.

\section{Audio recordings}

There were seven audio recordings in the P1_1 prototype design. Most of the participants chose to listen to this media before reading the learning content in text. All 11 participants listened to at less one of the audio recordings provided within the application. 6 participants listened to every audio recordings in their entireties.

\subsubsection{Learning support functions}

All learning support functions proposed in chapter 4 were only made available in the $\mathrm{P} 1 \_1$ prototype. As a result, qualitative findings relating to learning support functions were collected from the prototype evaluation results of the 11 participants assigned to use this prototype.

\section{Chat}

The chat function was designed as a many-to-many communication channel between participants, their teachers and their peers. The participants were informed that they could ask any questions using this function and there might be other participants online in the chatroom at the same time. All users using the chatroom could view the content of the conversations.

This thesis' researcher took on the role as the instructor in this part of the evaluation process. This function was not a compulsory task for the participants. 8 of the 11 participants used the chat function. Figure 5.8 shows some examples of the chat conversations between the participants and the instructor. 


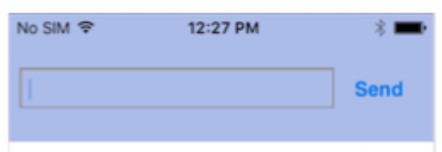

liil has joined

lan has joined

lan: So I have done the assignment, does that mean that I have finished?

lifi: yes

q w e r t y u i o p

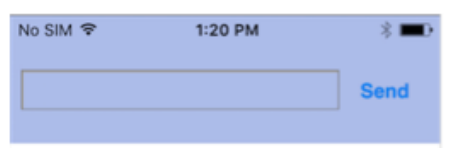

lili has joined

isaac has joined

isaac: is there only one part to the assignment?

lili: yes

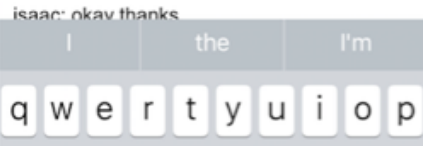

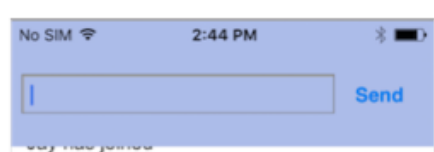

Jay: hello?

Fili : yes

Jay: I've sent in my assignment, did you receive it?

fili : yes I did thank you

q w e r t y u i o p

Figure 5.8: Chat conversations between the participants and the researcher

3 of the 8 participants used the chat function to ask about the given assignment (See conversation of participants 1 to 3). 3 participants asked if they had completed their assignments correctly or whether the assignments were received (See conversation of participants 4 to 6 ). The remaining 2 participants used the chat function to inform the instructor that they have completed their learning process. Examples of chat conversation were:

"...Participant_1: hi

Participant_1: I have a question

Instructor: Hi, please ask

Participant_1: do I need to answer the question now?

Instructor: Yes, you can click on the answer button

and answer a short one.

Participant_1: what do I have to describe about?

Instructor: Do you think Facebook should treat

teenager differently ..."

"... Participant_2: is there only one part of the 


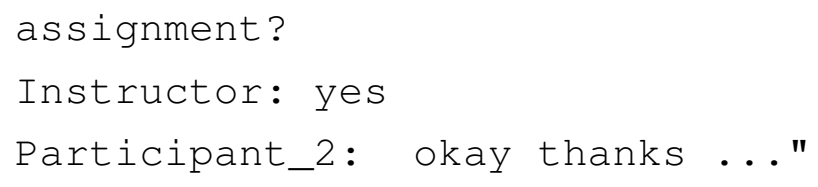

The observation process also uncovered a fault whereby the participants could not exit the chat function to return to the learning content. As a result, they must reset the application to exit the chat before restarting the application and continue with their learning process. This fault could affect the overall participants' engagement level. The participants who used the chat room and needed to reset the application were found to have lower average engagement level values compared to 
those who did not use this feature.

\section{Quiz Game}

Similar to the chat function, the quiz game was not compulsory for the participants to complete. 10 of the 11 participants played the quiz game after they finished studying their learning content. Among the 10 participants, 5 of them played the game only once, while 3 played the game more than once.

\section{Assignment}

The assignment was the only compulsory function in prototype $\mathrm{P} 1 \_1$. The participants were informed at the start of their learning process that they had to finish the assignment and sent it to the instructor via a given e-mail platform (as a condition to receive the grocery voucher). The assignment involved reading a case study and the participants had to express their opinions using 5-7 sentences.

All participants successfully submitted their assignment via e-mail. All assignments were received by the researcher and thus provided evidence that the participants had understood the case study. Figure 5.9 shows two of the answers submitted by the participants via the e-mail platform.

As the participants were asked to type in their answers, they were observed typing using the small keyboard of the iPhone6s. The participants seemed to have no problem with the small keyboard and rarely made a mistake while typing. 
Pakapan Limtrairut <pakapalimt@gmail.com>

Wed 17/08/2016 2:29 p.m.

¿ \& Reply all

To: Olili.limtrairut@ecs.vuw.ac.nz a

Inbox

Please give a short answer 5-7 sentences

Yes from an engineering perspective tech companies such as Facebook and Instagram should treat teenagers differently not in a way that changes the platform from them but added warnings are a good start as this is more ethical.

Sent from my iPhone

(a) Assignment answer example 1

Assignment Answer

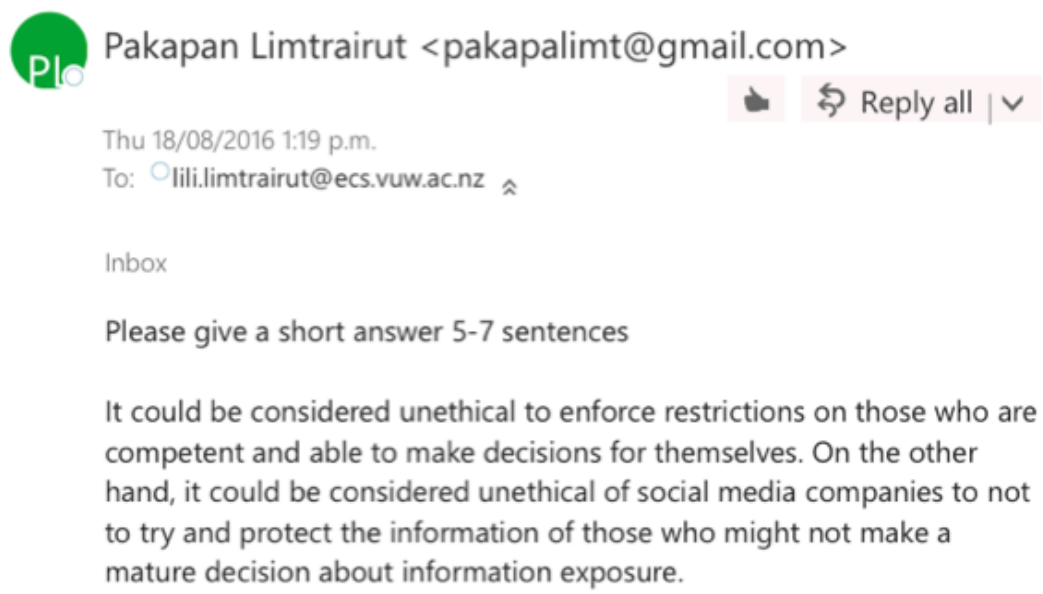

Sent from my iPhone

(b) Assignment answer example 2

Figure 5.9: Examples of the assignment answers sent from the participants to the researcher's email 


\subsection{Limitations}

There were various limitations to this research, particularly in the aspects of recruitment and evaluation procedures. The following list presented these limitations.

1. All participants were autonomous learners. Therefore, the results and findings from this research were not able to test the principles of TDT where non-autonomous learner would benefit from learning via an m-learning application if dialogue opportunities were provided and the course structure was inflexible. This portion of the TDT principles remained unproven and unresolved by this thesis.

This could be the result of unintentional screening for autonomous learners during the participant recruitment process. All participants volunteered to take part in this research, and had been informed about the learning topic and evaluation tasks prior to the evaluation. Therefore they could potentially feel motivated to learn already.

Additionally, they were tertiary level students in various fields of technology and would have used mobile devices frequently in their daily lives, including for educational purposes. Therefore, it was possible that they already had a certain level of knowledge and skills in using mobile phones and could have helped them develop confidence towards m-learning.

2. From a total 21 participants, 18 were male and 3 were female. The unequal number of participants between the two genders might be a factor that could influence the results and findings of this research.

3. The evaluation was conducted in a laboratory setting. Although the participants were allowed to spend as much time as they wanted to use the m-learning prototype, this observation environment might 
inadvertently introduced time pressure to the participants and affected their student engagement levels.

Additionally, the participants sat stationary in a control environment during the evaluation process. This setting would be different from an actual m-learning scenario when the learning happened in a mobile and dynamic environment where learning could be interrupted by surroundings such as noise and weather.

4. Both $\mathrm{P} 1{ }_{1} 1$ and $\mathrm{P} 1 \_2$ prototypes were designed to provide participants with a flexible course structure. Other than the compulsory assignment, all provided media and other learning-support features were used and controlled completely based on the participants' desire. For example, despite being assigned to learn using prototype $\mathrm{P}_{1}{ }_{1}$ and being informed about the types of presentation media and learning-supported features that were available prior to the evaluation, some participants did not watch the provided animation video, nor use the chat room to contact their teachers.

The first hypothesis of the first iteration evaluation was tested on the assumption that all participants who learnt using the $\mathrm{P}{ }_{1}{ }^{1}$ prototype used a variety of media presentations and had some (i.e, either directly through the chat or in-directly via the quiz game feature) dialogue with their teachers.

5. There was no face-to-face debriefing to elucidate the results from the post-questionnaire. The engagement level results were based entirely upon the participants' self evaluation. Hence, there was likelihood of participants providing inaccurate results due to misunderstanding questions within the post-questionnaire or selecting an incorrect ranking on the measurement scale.

6. The camera used to record participants' performance was placed 
statically and there were several moments of unintentional obstruction, resulting in the camera not being able to capture the participants' mobile phone screens during those times. This occurred mainly due to participants lifting their arms up, switching between hands, positioning his/her hand over the mobile phone, or positioning the mobile phone screen slightly out of the video-recording frame. Figure 5.10 shows the moments the mobile phone's screen could not be captured clearly.

In these cases, Google Analytics' statistical results helped report the number of times each participant clicked on buttons within the application. If the number did not match a participant's behaviour recorded in the video, it concluded that the participant had tapped on buttons while the mobile phone screen could not be captured on video. This evaluation encountered no mismatches.
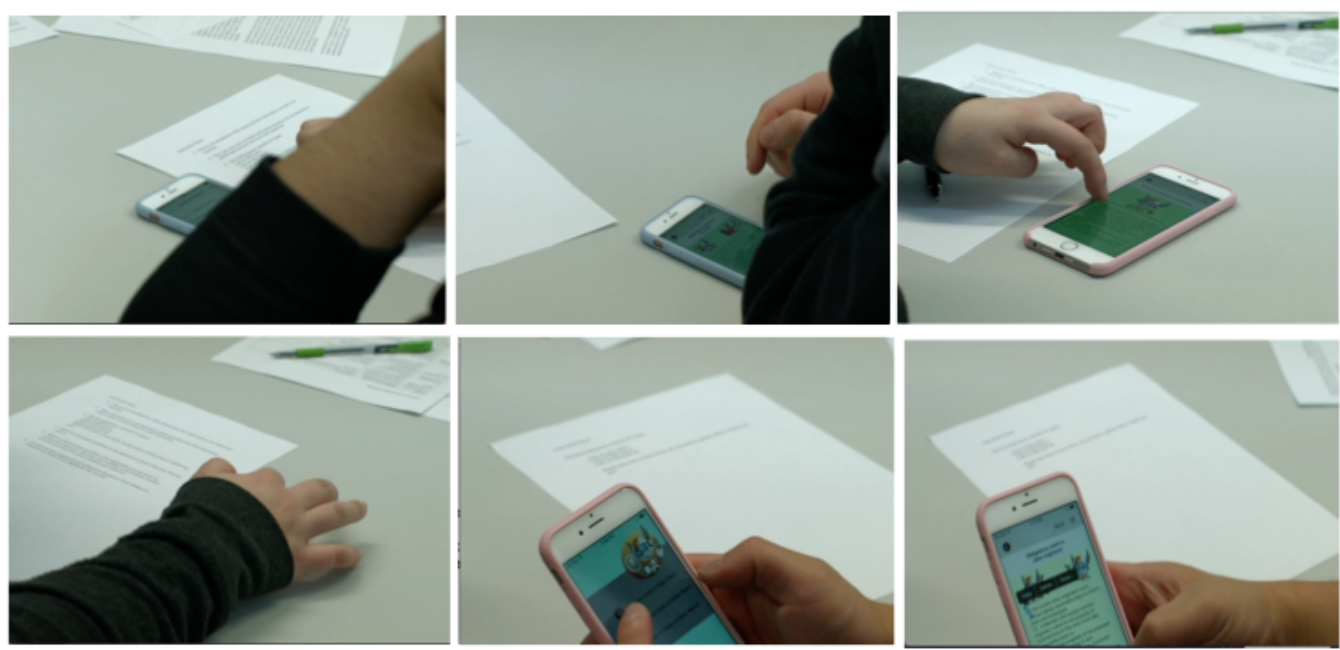

Figure 5.10: Screen captures of moments when the mobile phone's screen were blocked or out of frame 


\subsection{Results and Findings Analysis}

Results from the post-questionnaire and hypotheses testing indicated that autonomous learners felt more engaged to prototype $\mathrm{P} 1{ }_{1} 1$ than prototype $\mathrm{P} 1 \_2$. This suggested that the design guidelines that were constructed in chapter 4 were applicable to guide the design of modern education platform such as m-learning and could provide some positive influence on student engagement.

Additionally, the average learner autonomy level value of participants who used prototype P1_1 was less than that of participants who used prototype $\mathrm{P} 1$ 2. Although this difference in the average learner autonomy level value was not statistical significant, prototype $P 1 \_1$ was designed to decreased transactional distance and could help the less autonomous learners to engage better than the more autonomous learners who had the ability to learn on their own when they used prototype P1_2.

When the results of the evaluation were further divided into the six concepts of student engagement, participants of both prototypes reported that they perceived usability. This indicated that they were satisfied with the interface design of the prototypes. However, the video-recorded findings showed otherwise. The following list identified the usability problems.

1. Some participants could not locate the slide-out and dropdown menu and pop-up buttons. These led them to skip some of the learning screens.

2. Some participants who used prototype $\mathrm{P}{ }_{1}{ }_{1}$ could not find the play button of the animation video and skipped this presentation media.

3. Every participant who used the chat feature needed to reset the application before they could continue their learning.

In order to increase the overall engagement, these usability problems and shortcomings in the focused attention area of engagement would be 
highlighted as the concepts that would require some improvement in the next development iteration. On the other hand, participants reported that they were unsatisfied with the focused attention concept. Several factors could cause this dissatisfaction. For example, the participants might have learnt or had prior knowledge about the learning topic. Hence, they lost their interests and could not stay focused on the m-learning prototype.

Unsurprisingly, involvement and endurability were the engagement concepts that caused the difference in student engagement level values between prototype $\mathrm{P}^{1}{ }^{1}$ and $\mathrm{P}{ }^{1}{ }^{2}$. The prototype $\mathrm{P}^{1}{ }^{1}$ provided several learning-support features that allowed participants to practice and evaluate their knowledge and these might stimulate the participants to feel involved and rewarded in the learning process.

Furthermore, the qualitative findings from the prototype evaluation process provided some indication towards the appropriateness and applicability of various features included in the prototype. These findings also identified some potential areas of improvement for the usability design aspect of the presentation media and learning-support functions.

Chat feature was used by many participants to communicate with the instructor and seek confirmation. The participants indicated satisfaction in the answers provided by the instructors through responses such as "Thank you" and "Awesome". However, it only served its motivation, advisement and consultation purposes in a minor capacity. It was not used by the participants to help create further knowledge at all. Furthermore, its functionality must be reliable, as any functional encounter failure might decrease overall student engagement.

$90 \%$ of the learners played the quiz game upon completing their learning. This feature was deemed to be a practical tool for self-evaluation and a useful mechanism for learning by giving learners the opportunity to practice.

The assignment component of this research prototype was found to be a practical feature for evaluating learners' knowledge and observing their 
learning progress. Additionally, the participants reported that they were comfortable with the smart phone's touch screen and its small keyboard. Based on the qualitative findings, they could type on the keyboard smoothly and effectively. Hence, a short essay similar to the assignment feature in this research prototype could be used as an assessment tool in m-learning applications.

Although the pop-up interface design had the potential to help arrange learning content into related groups and improve the overall cleanliness of the application, and the slide-out and dropdown menus could present learning content hierarchically, learners struggled to find the menu buttons and overlooked the entire learning content section as a result. Therefore, it was paramount for these menu buttons to be made more visually attractive and distinctive, while other designs such as labels and images should be tempered to avoid distracting learners. Furthermore, these menus should be accompanied by other medium to guide learners (e.g., audio guide, guiding text, or a pointer).

Although various media formats were used to present learning content, motivate and encourage participants to learn, the qualitative findings uncovered some potential user preferences and enhancements needed to increase participants' usage. For example, text media was found to be suitable for presenting learning content, while audio recordings seemed to be a powerful media particularly for introducing learning topics or providing guidance to learners.

The video player controls should be made more visually attractive, distinctive from the background, and located in an obvious area on the screen. An audio recording can be used to accompany the video to guide the learners, but it must provide accurate directives.

Based on these qualitative findings, the functional design (i.e., chat, quiz game, and assignment) and presentation media (i.e., text, audio, and animation video) inherited from the TDT-based design guidelines were deemed to be practical and applicable for m-learning. However, these 
learning-support features and presentation media would need some interface re-design to improve their usability.

\subsection{Summary}

In this chapter, learner autonomy was observed using pre-questionnaire and via researchers' observation. Student engagement was measured using post-questionnaire and the participants' interaction with the first m-learning prototype design was captured with video recording and Google Analytics.

The evaluation results and hypotheses testing verified that all the participants were autonomous learners and engaged better with the m-learning prototype designed to decreased transactional distance developed based on the proposed design guidelines from chapter 4 . These findings implied that the principles of TDT proposed in its original distance education context stayed true when applied to the modern education platform such as m-learning applications. Additionally, results indicated that there was a weak correlation between learner autonomy and student engagement.

Usability was identified as an area of improvement to encourage learners to access all available learning content that might otherwise be hidden by various menus. Suitable media with clear directives should be employed to motivate and help guide learners through their learning process. Learning support functions were found to be effective tools in engaging participants during their learning process and could assist instructors in evaluating participants' learning outcomes in an actual m-learning context.

Finally, the results and findings from the evaluation process and the identified areas of improvement would be used to inform and refine the development of the second iteration design guidelines in the next chapter. 


\section{Chapter 6}

\section{Heuristic Evaluation}

In chapter 5, target learners evaluated the first m-learning application prototype developed based on the first iteration design guidelines. Although the results indicated that the prototype was engaging, the qualitative findings suggested that there were some usability issues not previously predicted by the guidelines. Consequently, this chapter seeks to improve the usability of the first design guidelines by incorporating heuristic evaluation. A new set of heuristics for m-learning application is developed from relevant heuristics proposed for general interactive devices, e-learning, and mobile devices. In order to observe the new heuristics' applicability, they are used to evaluate the first prototype.

\subsection{M-learning Heuristics Development}

Chapter 2 presented some usability design guidelines and heuristic evaluation with the capability to guide an m-learning application's interface design. They included Shneiderman's (1988) [126] eight golden rules of interface design and Nielsen \& Molish's (1990) [98] heuristic evaluation for identifying software usability issues. Each of them was a set of user interface design standards developed based on Norman's (1988) [99] four basic design checklist to ensure functional quality of 
product design.

The first design guidelines were focused on TDT's principles. To address the aspect of interface design usability, the design guidelines incorporated elements from the eight golden rules of interface design. The first guidelines were then utilised to develop the first prototype. Although elements of interface design usability were introduced in the first prototype, the evaluation findings for the first prototype indicated some further usability issues that ought to be addressed. This implied that the eight golden rules were not suitable for heuristics in heuristic evaluation.

Compared to the eight golden rules of interface design, the heuristic evaluations presented in chapter 2 (i.e., [97, 113, 143]) offered more heuristics and were deemed able to improve the ability to predict usability issues ahead of target learners' prototype evaluations.

Nielsen's (1995) [97] heuristics, updated from the original heuristics proposed by Nielsen \& Molish's (1990) [98], was only applicable to general interactive devices. Other works had since adopted this heuristics to comparable learning platforms (i.e., e-learning). Examples included Reeves et al.'s (2002) [113] usability and instructional design heuristic evaluation for e-learning, and Yanez et al.'s (2004) [143] heuristic evaluation on mobile interface devices. Although both works applied the original comprehensive heuristics from Nielsen's (1995) [97] heuristics, they did not offer heuristics in an m-learning context. Therefore in this chapter, a new set of m-learning heuristics is created from a combination of usability heuristics from Nielsen (1995) [97], the usability heuristics for e-learning from Reeves et al. (2002) [113], and mobile interface heuristics from Yanez et al. (2004) [143]. Figure 6.1 illustrates how the m-learning heuristics were built and table 6.1 presents the newly developed heuristics.

Note that this new set of heuristics for m-learning are used for heuristic evaluation to enhance the interface design usability of the 
design guidelines only. The role of TDT in guiding the functional design in the design guidelines remains unchanged.

In Figure 6.1, the purple highlights are Nielsen's (1995) [97] heuristics, the blue highlights are Reeves et al.'s (2002) [113] e-learning heuristics, and the orange highlights are Yanez et al.'s (2004) [143] mobile interface heuristics. The new set of heuristics for m-learning used Nielsen's (1995) [97] heuristics as a starting point and Reeves et al.'s (2002)[97] and Yanez et al.'s (2004) heuristics were incorporated into the newly developed heuristics to enrich the pedagogical and mobility aspects respectively. In the figure, Yanez et al.'s (2004) heuristics (i.e., the orange highlights) were only used to improve the descriptions of the heuristics and provide some examples, since their heuristics were already represented by those in Nielsen (1995) and Reeves et al. (2002). 


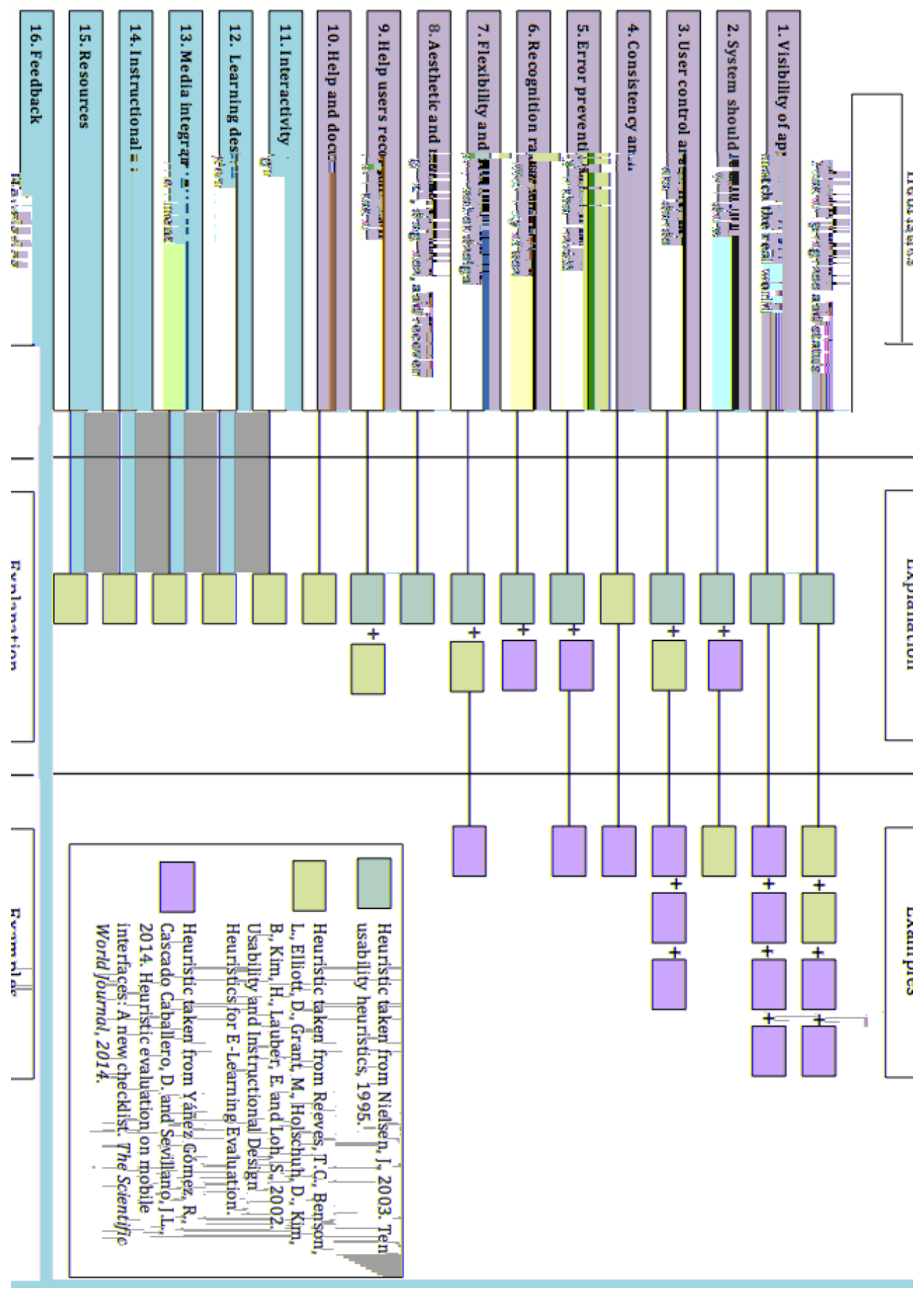

Figure 6.1: Visual presentation on how the guideline was constructed from Nielson [97], Reeves et al. [113] and Yanez et al.[143] 
Table 6.1: Newly developed heuristics to evaluate interface design of mlearning application

1. Provide visible application progress and status through appropriate and timely notification

For example, use a status bar to indicate downloading progress; provide visual feedback for every task that requires learners' action; sort learning content hierarchically; and use visual feedback on buttons and menu items to inform learners which item is selectable and when it has been selected.

\section{Match the system design with real world convention}

Use words and phrases that are familiar to the learners and appropriate to their knowledge level, and arrange the learning content in a natural and logical order. For example, use icons and colours that suitably represent the learning content; categorise menus, ensure their titles are parallel grammatically, and their navigation are controlled to avoid memory overloading.

3. Allow users to take control of the system and provide them with navigational freedom

Provide functions allowing the learners to reveal all available options and explore all available learning content. Permit learners to choose their learning order themselves. Ensure the interface is "forgiving" by enabling them to exit from the application and return to the closest point of their learning progress after a mistake has been made with minimum penalty and seek their confirmation when their actions can lead to drastic consequences. For example, use "undo", "redo", "forward", "backward", and "exit" buttons when appropriate.

Continue to the next page 
4. Use consistent language and maintain software interaction standards

- Typographical standards - avoid heavy use of upper-case fonts, present the available menu vertically and its title should be positioned either in center or left-justified, and use the same heading for multiple learning screens that belong to the same category.

- Language and tone of voice - use a soft vocal tone when giving learners positive feedback and adjust it to a harsher tone when the feedback is increasingly negative. Apply consistent naming conventions and grammar when referring to objects or instructions across screens. Use a meaningful word to begin the title of any menu, and utilise font size, boldface, underline, shading, or colour to indicate relativity.

- User interface and visual standards - use only two levels of brightness intensity, between four to seven colours in the visible spectrum, and no more than twenty icon types. Apply colour or brightness contrast to distinguish objects from background. Use brighter and more saturated colour to highlight or duller and less saturated colour to de-emphasise the learning content. Arrange buttons such as "home", "help", "instruction", and "exit" at consistent locations throughout the application.

\section{Provide error prevention}

Provide notifications when an input error has occurred and allow learners to correct any unintentional mistakes. For example, indicate the number of allowed characters in a data entry screen. 


\section{Design for recognition rather than recall}

Learners should not need to use high level of concentration when they are learning, nor remember any information from one screen to the others. For example, using strong typographical conventions such as ample white space, contrast, and other visual cues in conjunction with controlling text density helps ensure recognition and limit a user's reliance on memory recall.

\section{Provide flexibility and efficiency of use}

The design should accommodate both inexperienced and experienced users. Customisation options for frequently used functions should be made available to learners when necessary to reduce navigation steps.

\section{Use aesthetic and minimalist design}

Ensure only succinct, relevant and meaningful content are included in the design. Employ visual design principles such as hierarchy, harmony, balance, and contrast to help deliver the content.

9. Help users recognise, diagnose, and recover from errors

Provide error messages in accessible language that explain a problem accurately and offer an appropriate solution.

Continue to the next page 


\section{Offer help and documentation}

The design should match the learner's competency so that they can progress with their learning and perform learning tasks without any help or documentation. However, supplementary help documentation should be made available if appropriate. When help documentation is provided, it should be easy to understand, succinct, list relevant steps, and be accessible from any part of the application.

\section{Provide interactivity}

Activities that encourage learners to learn should be reinforced by interaction design, use additional modalities (including multimedia) and go beyond textual content alone to add greater dimensions of meaning to the content.

\section{Grounding learning design on learning theory}

The interactions of the M-learning application should be designed based on principles of learning theory to ensure that the design could engage learners and help them achieve learning objectives.

\section{Ensure appropriate media integration}

Media should be employed appropriately in order to support pedagogical process, motivate learners, and enrich learning content.

\section{Provide instructional assessment}

The assessment should be a high level self-assessment (e.g., analysis or evaluation) in alignment with learning objectives. 


\section{Provide external resources}

The resource should be up-to-date, reliable, able to help learners with their creation of knowledge, and improve learning effectiveness.

\section{Provide feedback}

Feedback should be consistent to the learners' achievement level, and application should enable them to seek additional feedback from experts, peers, and instructors through Internet communication channels.

\subsection{Applicability of the M-learning Heuristics}

To demonstrate the new heuristics' actual applicability, the first prototype was evaluated against these heuristics. As the new heuristics were developed to help predict potential usability issues with the prototype, the applicability of the new set of heuristics would be achieved if the heuristics evaluation using the new set of heuristics could predict the same usability issues that were genuinely identified in qualitative findings of the first iteration evaluation.

\subsubsection{Methodology}

Seven experts who were either working within the Information Technology sector or had prior experiences in user experience and product designs, were invited to take on the role as a learner by using the primary persona "Clara" created in chapter 3 and evaluate the first prototype. To assist the experts in their adoption of the persona during the evaluation process, the persona profile was recreated in a storytelling 
format (see figure 6.2) and paired with the following set of learning goals:

- Engage with the learning process, be entertained while learning, and be encouraged to learn

- Use all the provided media, perform all the given learning activities, and learn all the provided learning content

- Remember some of the learning content, and gain a better understanding towards the learning topic

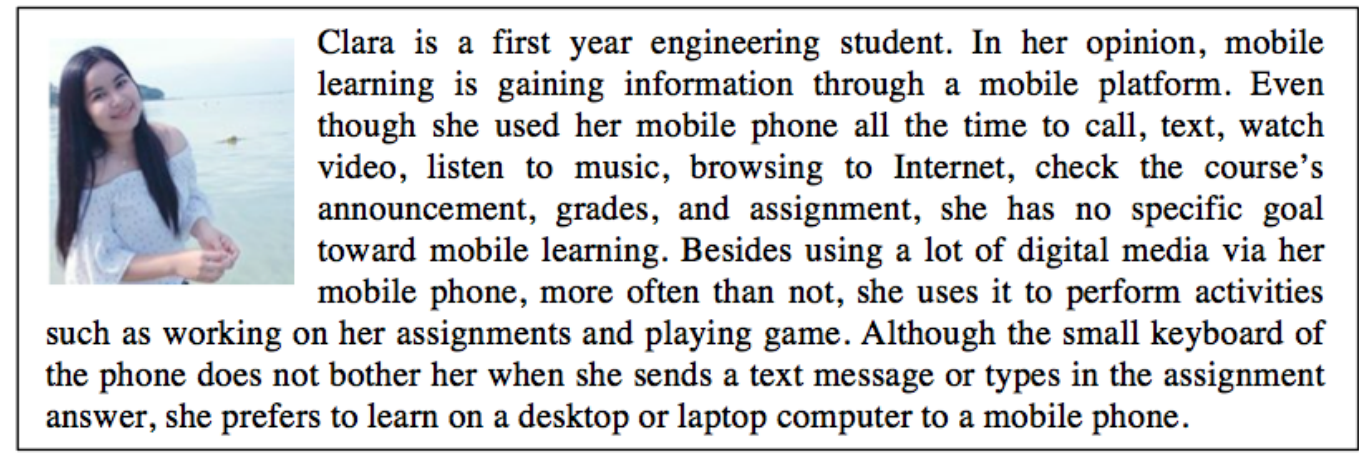

Figure 6.2: Storytelling format of the persona profile adapted from the primary persona, Clara, presented in chapter 3

To further support the experts in this evaluation process, a key path scenario for the persona was specified. The scenario explained how the persona would use the m-learning application to achieve the learning goals and how she interacted with the mobile devices' interface. Background context was also added to aid the flow of the scenario description and encourage the experts to complete the activities required in the evaluation. The scenario was:

1. While waiting for the next class to start, Clara opens a new learning application that she downloaded last night. This is the first time she uses the application. 
2. She skims through the types of available media and activities, and listens to the audio recording available in the first screen of the application.

3. Then she watches the introduction video provided in the lesson.

4. She starts to learn by reading the learning content in order and listens to all the available audio recordings on the first screen of each learning section. However, in the midst of this activity, her class starts, so she exits from the application.

5. After her class has ended, she re-opens the application and starts to study the rest of the learning content. However, during this process, she has a query about the content, so she contacts a teacher who teaches the lesson presented in the application. After she received a response, she still wants to obtain extra information from the Internet.

6. Upon learning all the course content, she starts to play the provided game. In the middle of playing the game, Clara wants to check her answer so she exits from the game to check the learning content.

7. After she played the game a couple of times, she feels confident that she can recognise and understand the content. Therefore, she goes to the assignment screen, types in some short answers and submits the assignment to the teacher.

The experts were then asked to evaluate the prototype based on the new set of m-learning heuristics presented in section 6.1. They captured their evaluation findings either within an electronic document or handwritten on paper. Their findings were listed against each heuristics. 


\subsubsection{Heuristic evaluation findings}

The following list summarises the findings collected from the experts' responses.

1. Provide visible application progress and status through appropriate and timely notification

The application received a mixture of positive and negative comments for this guideline. The comments suggested that there was still room for improvement in terms of increasing the visibility of application progress. For example, an expert who was satisfied with the visibility of the learning progress claimed that

"It's good at visual feedback and I could check my progress easily"

The other expert who was partially satisfied with the visibility commented that

"It is partially there - I can see it when the audio recording was playing.

However I find it difficult to see where I am up to within sections."

On the other hand, there was an expert who thought the application failed to provide sufficient visibility

"Progress through lessons was not clear. I was not sure where I was in the lesson or content."

\section{Match the system design with real world convention}

Many of the comments proved that the application accomplished this guideline. The experts noted that there was consistent use of home, backward, and forward icons. They were satisfied with how the learning content were divided into sections and were properly titled. In addition, they found that most words and phrases matched real world convention and were easy to read. 


\section{Allow user to take control of the system and provide them with navigational freedom}

The experts found major defects within the chat function. They reported that they were unable to leave the chat function and return to the home screen, and instead they had to reset the application and restart the testing process.

The experts also noted that navigation such as "forward" and "backward" buttons were provided so that the learners could navigate themselves through the application. However, many of them encountered problems and provided some suggestions. For example, experts stated that

"I can easily use the back arrows and home buttons and menus etc. to navigate around the application and go back and skip ahead, although the hierarchy and placement of menu needs to be more uniformed"

"User control is good. I understand how I should work with it. Just a minor suggestion - all pages looked similar to each other and this was a little confusing."

The experts also provided many suggestions on how the icon should be rearranged so that the learners could navigate through the learning content smoothly. For example, an expert suggested removing all unrelated icons from the chat page. Another expert suggested using text plus icon (only icon was provided in the application) to help the learners navigate accurately.

It has been shown that the experts acknowledged user control options provided throughout the application. However, the current interface design (of the icons, titles, colours, and buttons) and defective performance (of the chat function) affected the experts' satisfaction and should be corrected. 
4. Use consistent language and maintain software interaction standards Many criticisms were received when experts evaluated the prototype against this guideline. The following list contains the interface design issues noted by them:

- The location of the "back" and "forward" buttons were not consistent.

- The icons shown in the main menu and the other navigation screens were not consistent (i.e. missing the icons).

- The "back" button was meant to navigate the learners to the previous page, but it brought them to another navigation page and caused confusion.

- The background of many screens were distracting, including the cartoon character used in the application when it should be dimmer or faded out, and the text area with the lesson text should be wider.

- Text should be justified either left, right, or center consistently.

- Every part of the learning content should be presented in the same template.

- Many learning screens did not have title.

The comments and suggestions indicated that the application failed to provide consistency or adhere to the design standard.

\section{Provide error prevention}

No error prevention mechanism was provided in the application hence the experts were unable to comment on this heuristic.

\section{Design for recognition rather than recall}

Majority of the experts were satisfied with the application design when 
evaluating against this guideline. They did not need to remember any information from screen to screen. However, an expert pointed out that the application did not provide title for one of the learning section and this might require the learners to remember what they were learning.

Another expert suggested adding the original assignment question in the e-mail for learners, so that they would not need to remember the question or go back and forth between two screens when they are typing in their answers.

\section{Provide flexibility and efficiency of use}

The experts were considered as experienced users (They adopted the role of the persona Clara who had experience in using a mobile phone to perform many learning related activities). They found the application accommodated them well. Only one expert encountered issues when $\mathrm{s} /$ he was learning using the application. $\mathrm{S} /$ he commented that

"I think the design is good but it included so many similar pages, which made me a little confusing. So I have to click back to home screen to figure out the content in relation to the overall content structure."

The m-learning prototype did not include any customisation functionality, therefore the experts were unable to provide any comment related to that element of the guideline.

\section{Use aesthetic and minimalist design}

Experts' comments about this aspect of the application were varied. An expert stated that $\mathrm{s} /$ he was satisfied with the application design.

Another expert who was partly satisfied with the application design commented that

"I like the front page and the attractive first page - I think the app can be 
a bit bigger in terms of the area of text displayed, and background image should be more faded to make the text a bit more prominent. Icons and buttons are sufficient and as needed so those are succinct enough."

and s/he further suggested that the combination of text and icons were more meaningful compared to only an icon.

\section{Help users recognise, diagnose, and recover from errors}

Many experts did not encounter any errors while they were using the application; therefore they were unable to comment on this guideline.

\section{Offer help and documentation}

No help and/or support documentation was provided. Nevertheless, most of the experts were able to learn using the mobile application without any assistance.

\section{Provide interactivity}

Many experts were satisfied with the interactive features provided in the application. For example they stated that

"So interactive, I like playing with it",

"The combination of media and content felt good",

"Audio, video and games content are available."

Aside from the positive responses, some suggestions to improve the interactivity of the application was also received. For example, an expert suggested improving the pop-up design interface stated that

"Clicking on the text should also bring up the pop up as well as the exclamation marks icons." 
The positive responses indicated that the interactive features provided in the application were appealing.

\title{
12. Grounding learning design on learning theory
}

This heuristic was not possible to be observed through a heuristic evaluation unless the invited experts were also proficient in distance learning theories. Despite its abstract nature and being difficult to measure, this item was still deemed to be valuable to this research.

\section{Ensure appropriate media integration}

Many comments from the experts on the media integration were positive. For example, the experts claimed that

\author{
"Had media integration", \\ "Media was instructional and useful", \\ "Agree that media are integrated correctly where needed."
}

The various media provided within the application (i.e., recorded voice, text, video) were therefore deemed to be acceptable by the experts.

\section{Provide instructional assessment}

Unfortunately, few qualitative comments were received even though an assignment related to this guideline was provided to seek feedback from the experts (i.e., an analysis question asking the experts to express their opinions).

\section{Provide external resources}

As no link to external resources was provided, the experts were unable to comment on the application when evaluating against this guideline.

\section{Provide feedback}


The experts found that the application provided some feedback. For example, an expert stated that the application was

"Successful in providing feedback since it let the users contact the supervisor."

However, many experts expressed that the feedback was insufficient and suggested providing more feedback via audio media and using e-mail as another communication medium. The responses were:

"Very little feedback in the quiz game, some audio feedback would be nice." "I noted that games gave out scoring, Chat function is also available to chat with peers and instructor. I don't see ability to email instructor directly though?"

\subsubsection{Analysis}

Comparing to the qualitative findings based on the video recording from chapter 5, the heuristic evaluation enabled the experts to provide more insights and feedback related to usability issues.

The experts expressed satisfaction with five heuristic guidelines during their evaluation:

- 2 - Match the system design with real world conversion

- 6 - Design for recognition than recall

- 7 - Provide flexibility and efficiency of use

- 11 - Provide interactivity

- 13 - Ensure appropriate media integration 
Some of the positive responses received from the experts were considered to be the result of utilising TDT's based design guidelines in the prototype design. For example, the prototype provided flexible learning structure, a variety of media formats, and learning-support features that encouraged and motivated learners and increased the prototype's interactivity. Additionally, the eight golden rules of interface design incorporated into the design guidelines also helped group related learning content together via a menu interface design.

Contrarily, the experts heavily criticised the application when evaluating against the following heuristic guidelines:

- 3 - Allow users to take control of the system and provide them with navigational freedom

- 4 - Use consistent language and maintain software interaction standards

The negative responses could be attributed to the aforementioned technical problem with the chat function and incorrect navigational path. The inconsistent software interaction standard could be another contributing factor to the negative responses. This might be due in part to the intense focus on developing the application and its functionality needed to meet the TDT guidelines, and as a result, essential interface design principles were neglected.

The three heuristics guidelines with mixed responses were:

- 1 - Provide visible application progress and status through appropriate and timely notification

- 8 - Provide aesthetic and minimalist design

- 16 - Provide feedback

The comments from experts indicated that the first prototype design might have partially met the heuristics, and therefore the prototype could be improve in these areas. 
There were some heuristics the expert were unable to comment on, such as number 5 (i.e., provide error prevention) and number 9. (i.e., help users recognized, diagnose, and recover from errors) as the prototype did not provide features related to them.

Based on this analysis, the first design guidelines which underpinned the first prototype had been proven to engage the participants positively. As the first design guidelines were primarily developed based on the principles of TDT while incorporating the eight golden rules of interface design, it could be concluded then that TDT was applicable to m-learning mobile application.

Some of the negative responses in this heuristic evaluation could be attributed to technical problems with the learning-support feature, interface design inconsistencies, and lack of aesthetics and usability features. They could be predicted with heuristic evaluations and would allow developers to improve the design prior to the actual use.

Notably, some of the experts' responses coincided with the qualitative results collected from the laboratory evaluation session in the previous chapter. The chat function fault which both the experts and the learners encountered during their evaluation process; the lack of software interaction standard in the prototype as pointed out by the experts was reflected in the evaluation participants' behaviour when they became disoriented while navigating through menus as recorded in the video observation.

This provided some confidence that the new set of heuristics could be used to predict the effectiveness of the second iteration design guidelines and the second prototype design.

As mentioned, compared to the eight golden rules of interface design, the newly developed heuristics for m-learning provided more insightful instructions such as detailed software instruction standards which would be advantageous to the application's usability design and would bring more benefits to interface design usability. 


\subsection{Summary}

Due to some usability issues observed in the first iteration evaluation, this chapter sought to improve the usability of the first design guidelines by experimentally adopting usability heuristics. Firstly, it proposed a new set of heuristics specifically for m-learning by combining the heuristic evaluation from other contexts. The new set of m-learning heuristics were then used by experts as criteria to evaluate the first prototype.

Based on the experts' responses, the first prototype satisfied many heuristics, particularly in regards to its functionality. These positive responses were analysed and were found to be effected by the principles of TDT and the eight golden rules of interface design incorporated in the first design guidelines and utilised by the first prototype. On the other hand, the prototype design received negative responses which could be mostly mitigated with heuristic evaluation prior to its release to the target learners. Therefore, the heuristic evaluation was deemed to be useful in the application's usability design process.

Additionally, the similarities between the heuristic evaluation findings in this chapter and the qualitative evaluation from chapter 5 gave some confidence that the new set of heuristics proposed in this research was effective in predicting and highlighting usability issues. Moreover, it could provide more detailed insights and guidance when compared to the eight golden rules of interface design.

In summary, to improve the first design guidelines, the second design guideline development would remain primarily focused on the TDT's principles to guide the functional m-learning design. However, the eight golden rules of interface design used in the first iteration to guide the usability aspect of the m-learning application design (i.e., the first design guidelines number 6) would be replaced by the new set of heuristics. 



\section{Chapter 7}

\section{Second Design Guidelines \& Prototype Development}

In previous chapter, new heuristics for m-learning application were used to evaluate the first prototype. The similarities found in the heuristic evaluation and the actual participants' evaluation findings indicated that the new heuristics had applicability to predict usability issues that were not foreseen by the first design guidelines. In this chapter, the second iteration design guidelines and prototype are developed. Although the proposed second iteration design guidelines are still using the principles of TDT to guide the functional design of m-learning application, the usability aspect of the guidelines is developed based on the amalgamation of various heuristic evaluation. Ultimately, the second m-learning prototype is developed based on the second iteration design guidelines to illustrate the second design guidelines' applicability. 


\subsection{Second M-learning Design Guidelines}

The qualitative findings collected from the first iteration evaluation suggested that the first prototype had some usability issues. The heuristic evaluation presented in chapter 6 was found to be able to predict the usability issues and allowed the application's developers to perform some interface re-design and improve usability before launching the prototype to target learners. Therefore, the first step in developing this second iteration design guidelines was to incorporate the new heuristics into the first iteration design guidelines.

Due to some overlap between elements of the first design guidelines and the heuristics, only 9 items of the total 16 from the new heuristics for $\mathrm{m}$-learning presented in section 6.1 were kept as is. The remaining items were either adjusted, merged with the first iteration design guidelines, or eliminated. The following list and figure 7.1 present how the heuristics were adjusted and incorporated into the first iteration design guidelines.

- Heuristics number 1., 2., 4., 5., 6., 8., 9., 10. and 15. were kept and remained unchanged. Heuristics number 3. and 7. were kept but adjusted to remove the parts pertaining to course structure and overlapped with first iteration design guideline number 2 . These heuristics items (11 in total) completely replaced the first iteration design guideline number 6 . due to the overlap between the heuristics and the eight golden rules of interface design.

- Heuristics number 11. was merged into the first iteration design guidelines number 4 . and heuristics number 14., and 16. were merged into the first iteration design guidelines number 5 . These mergers provided further explanations to help improve the first iteration design guidelines rather than introduce any significant change to the guidelines.

- Heuristics number 12. and 13. were completely eliminated as the 
first design guidelines were already developed based on a learning theory, and the first design guidelines number 3 already provided guidance on how to choose appropriate media presentation formats.

Overall in the second iteration design guidelines, only guidelines number 1., 2. and the TDT-related portion of guideline number 3 from the original first iteration design guidelines were kept. The remaining first iteration design guidelines were merged or completely replaced as outlined above.

Table 7.1 presents the second iteration design guidelines. Note that similar to the first iteration design guidelines, developers should first observe learner autonomy prior to using the second iteration design guidelines. Additionally, the developers should arrange at least one round of heuristic evaluation prior to releasing the m-learning application to learners. The evaluation could be completed using the same process as outlined in section 6.2 (i.e., inviting some expert evaluators, providing them with the heuristics, a learner persona and scenario for role playing, collecting the evaluation findings, and improving the prototype). 


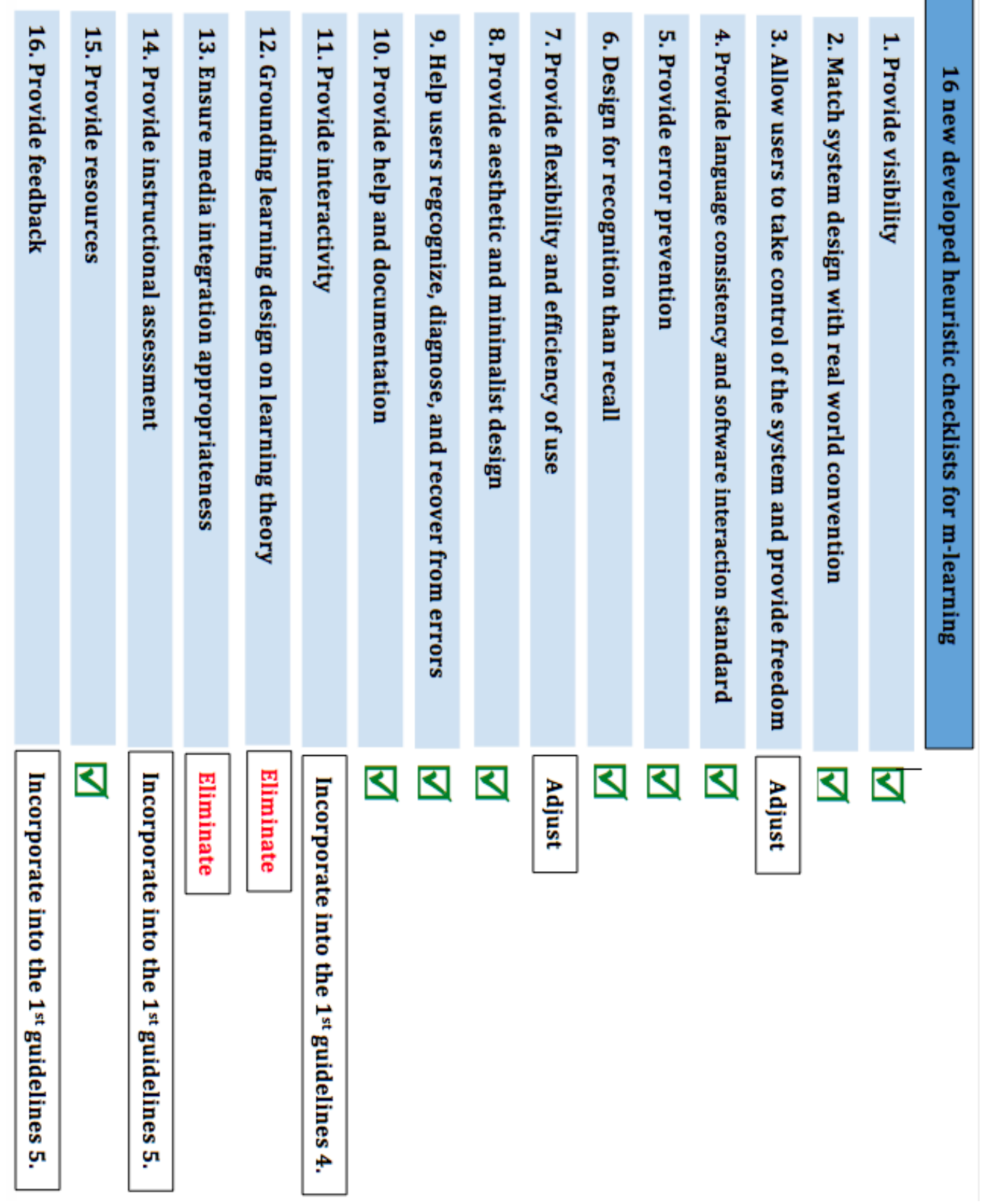

Figure 7.1: Adjustment and incorporation of the 16 developed heuristics into the first design guidelines 
Table 7.1: The second m-learning design guidelines

1. Despite learner autonomy, it is essential to provide positive quality dialogue opportunities among learners and teachers, and ensure that the resulting dialogues are constructive, encourage learners to collaborate, and promote learners' understanding of course content

2. Provide flexible course structure that caters to learner autonomy

2.1 Autonomous learners - Learners should receive a flexible course structure where they can take part in setting their own learning goals, manage their own learning schedule and learn at their own pace, set their own evaluation criteria to evaluate their knowledge. Teachers take on the role of facilitators to provide feedback, consultations, advice, and other learning support as required by the learners.

2.2 Non autonomous learners - provide an inflexible course structure. Teacher should set learning goals, track learning progress, provide constructive encouragement and feedback, arrange advice and consultation schedule, and provide constructive learning material and evaluate learners' knowledge to ensure learning quality.

3. Choose appropriate presentation media suitable for learners' capability and learning content - rich multimedia should only be used to deliver abstract or ambiguous content to avoid introducing distraction to learners' learning process 
4. Motivate Learners by providing learning tasks that are challenging and trigger learners' curiosity and competitiveness. The activities should be interactive and be reinforced by interaction design. If learners lacked motivation towards learning topics or learning tasks, use rewarding techniques to increase their participation

5. Allow learners to practice what they have learned. Developers should consider using high-level self-assessments (e.g., analysis or evaluation) that are aligned with learning objectives and ensure that they receive feedback on their performance. The feedback should be consistent with learners' achievement level and developer should consider allowing learners to seek additional feedback from experts, peers, and instructors through Internet communication channels

6. Perform heuristic evaluation against the following heuristics

6.1 Provide visible application progress and status through appropriate and timely notification

For example, use a status bar to indicate downloading progress; provide visual feedback for every task that requires learners' action; sort learning content hierarchically; and use visual feedback on buttons and menu items to inform learners which item is selectable and when it has been selected

6.2 Match the system design with real world convention

Use words and phrases that are familiar to the learners and 
appropriate to their knowledge level, and arrange the learning content in a natural and logical order.

For example, use icons and colours that suitably represent the learning content; categorise menus, ensure their titles are parallel grammatically, and their navigation are controlled to avoid memory overloading

\subsection{Ensure the interface is "forgiving"}

Enable learners to exit from the application and return to the closest point of their learning process after a mistake has been made with minimum penalty and seek their confirmation when their actions can lead to drastic consequences. For example, use "undo", "redo", "forward", "backward", and "exit" buttons when appropriate

6.4 Use consistent language and maintain software interaction standards

- Typographical standards - avoid heavy use of upper-case fonts, present the available menu vertically and its title should be positioned either in center or left-justified, and use the same heading for multiple learning screens that belong to the same category

- Language and tone of voice - use a soft vocal tone when giving learners positive feedback and adjust it to a harsher tone when the feedback is increasingly negative. Apply consistent naming conventions and grammar when referring to objects or instructions across screens. Use a meaningful word to begin the title of any menu, and utilise font size, boldface, underline, shading, or colour to indicate relativity 
- User interface and visual standards - use only two levels of brightness intensity, between four to seven colours in the visible spectrum, and no more than twenty icon types. Apply colour or brightness contrast to distinguish objects from background. Use brighter and more saturated colour to highlight or duller and less saturated colour to deemphasize the learning content. Arrange buttons such as "home", "help", "instruction", and "exit" at consistent locations throughout the application

6.5 Provide error prevention

Provide notifications when an input error has occurred and allow learners to correct any unintentional mistakes. For example, indicate the number of allowed characters in a data entry screen.

6.6 Design for recognition rather than recall

Learners should not need to use high level of concentration when they are learning, nor remember any information from one screen to the others. For example, using strong typographical conventions such as ample white space, contrast, and other visual cues in conjunction with controlling text density helps ensure recognition and limit a user's reliance upon memory recall

6.7 Provide efficiency of use

Customization options for frequently used functions should be made available to learners when necessary to reduce navigation steps 
6.8 Use aesthetic and minimalist design

Ensure only succinct, relevant, and meaningful content are included in the design. Employ visual design principles such as hierarchy, harmony, balance, and contrast to help deliver the content

6.9 Help users recognise, diagnose, and recover from errors

Provide error messages in accessible language that explain a problem accurately and offer an appropriate solution

6.10 Offer help and documentation

The design should match the learner's competency so that they can process their learning and perform learning tasks without any help or documentation. However, supplementary help documentation should be made available if appropriate. When help documentation is provided, it should be easy to understand, succinct, list relevant steps, and be accessible from any part of the application

\subsection{Provide external resources}

The resource should be up-to-date, reliable, able to help learners with their creation of knowledge, and improve learning effectiveness 


\subsection{Second Prototype Design}

Similar to the first iteration, a second iteration prototype design was developed to illustrate and evaluate the actual applicability of the second iteration design guidelines. Additionally, some changes were made to the second prototype design to observe the applicability of the second design guidelines when the learning topic was changed and the quantity of learning was increased.

The learning topic for the second prototype design was changed from "Engineering ethics" to "The internet" and "The internet security". These new learning topics were chosen based on future topics within the target participants' course curriculum. Therefore learning content based on these topics would benefit the participants' future learning.

As the learning topics increased from one to two, the second prototype included two quiz games and two compulsory assignments (i.e., one for each learning topic). Additionally, the prototype also provided more audio recordings and two animation videos. Figure 7.2 illustrates the overall learning content presentation within the prototype. The two learning topics were presented in the main menu whilst their sub-learning topics were presented in the sub-menus; each sub-menu was linked to a learning screen with multimedia presentation (i.e., figure, text, animation video, recording audio); every screen presented a navigation panel at the bottom; and some of the learning screens contained an audio-recording control panel, a "play" button for the animation videos, and a button linked to an in-app browser to allow easy access to further learning resources.

Apart from introducing some differences in the learning content and learning supported features in the second iteration prototype, the technical fault discovered in the chat function of the first prototype design was also remediated. Furthermore, the second prototype design was evaluated by the same seven experts against the heuristics (second 
iteration guideline $6^{\text {th }}$ ). Feedback received from the experts were used to make minor re-design adjustments to ensure the prototype's usability prior to being evaluated by target learners. 


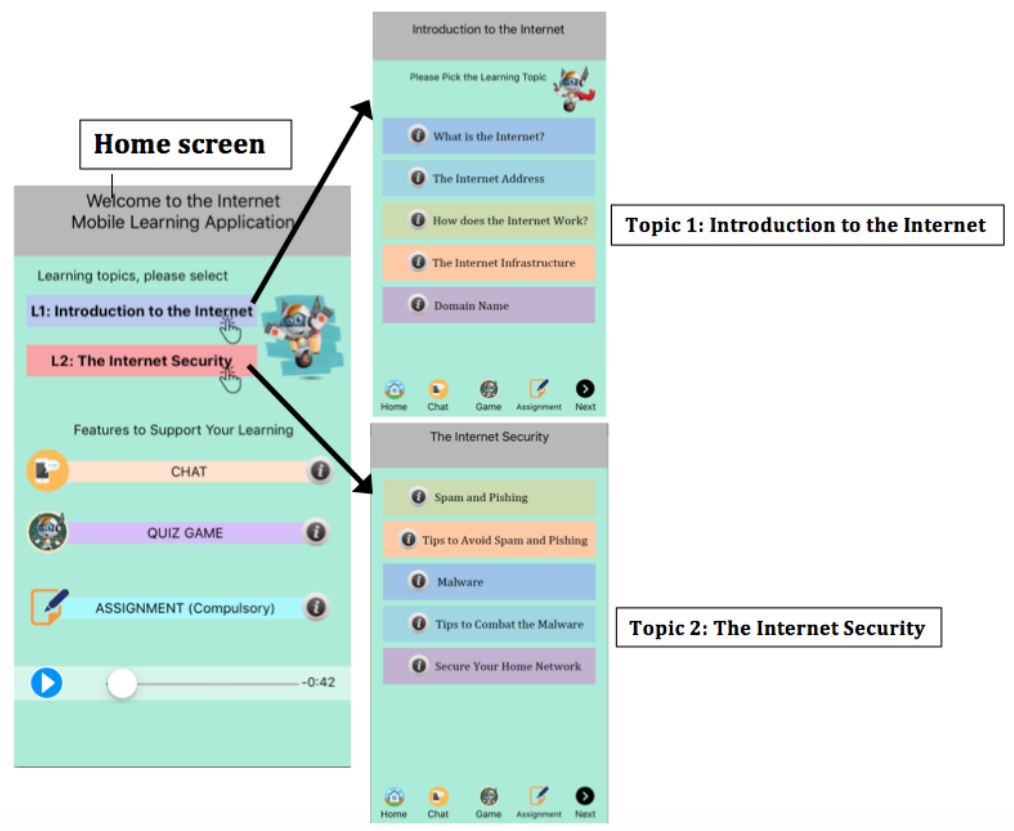

(a) Home screen and navigation to the learning topics
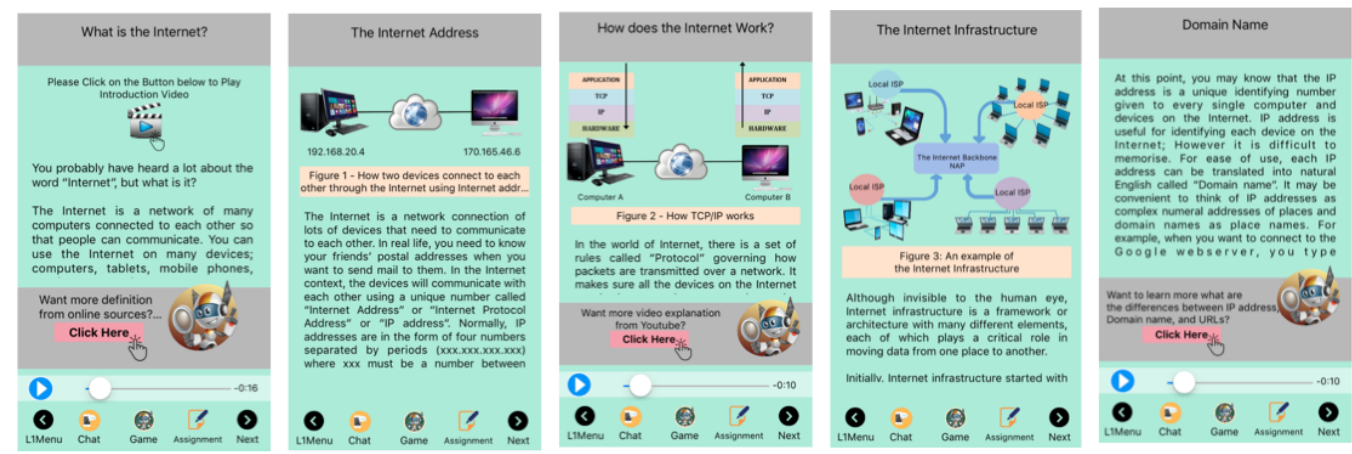

(b) Learning topic 1: Introduction to the Internet
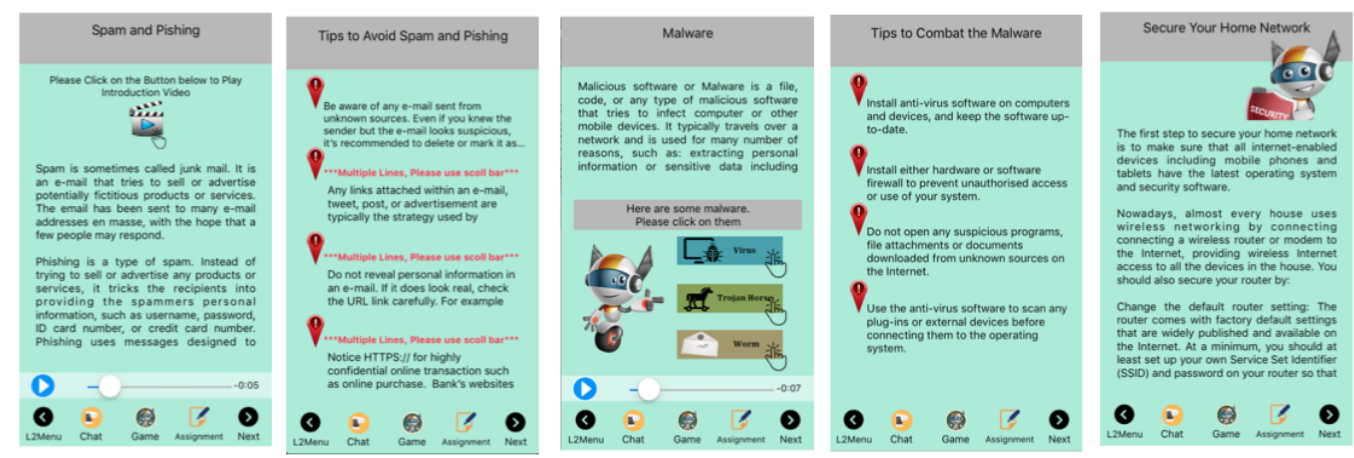

(c) Learning topic 2: The Internet security

Figure 7.2: Learning content presentation of the second prototype 
The following list demonstrates how the second iteration design guidelines were implemented by the second prototype design, lists improvements incorporated into the second prototype based on experts' feedback and enhancement when compared against the first iteration prototype.

As noted in the previous section, learners autonomy should be observed prior to using the developed guidelines. The second prototype was grounded on the learner autonomy findings from the first prototype evaluation, where participants were found to be autonomous learner.

According to the second design guidelines:

1. Dialogue opportunities were provided via a many-to-many chat feature. The interface design of the chat feature in the second prototype was the same as the first prototype. Figure 7.3 presents this interface design. Additionally, the chat functionality of the second prototype was expected to be used in the same manner as the first prototype:

- Learners would have the ability to initiate the chat when they chose to do so

- Learners could access the chat feature at any point of their learning process using the chat icon available throughout the second prototype

- Learners were expected to use the chat feature without any specific encouragement from teachers

Although the interface design remained the same, the heuristic evaluation helped improve the chat functionality in the second prototype. The following list and Figure 7.4 present the interface design improvements.

- Some experts tested the chat feature to ensure the functional failure found in the first iteration evaluation was resolved 
- As suggested in the second iteration design guideline number 6.5 (i.e., provide error prevention), the chat now provided notification for the number of allowed characters in the data input screen (See figure 7.4a).

- As suggested in the second iteration design guidelines number 6.9 (i.e., help users recognise, diagnose, and recover from errors), an error notification was provided in the chat (See figure $7.4 b)$.

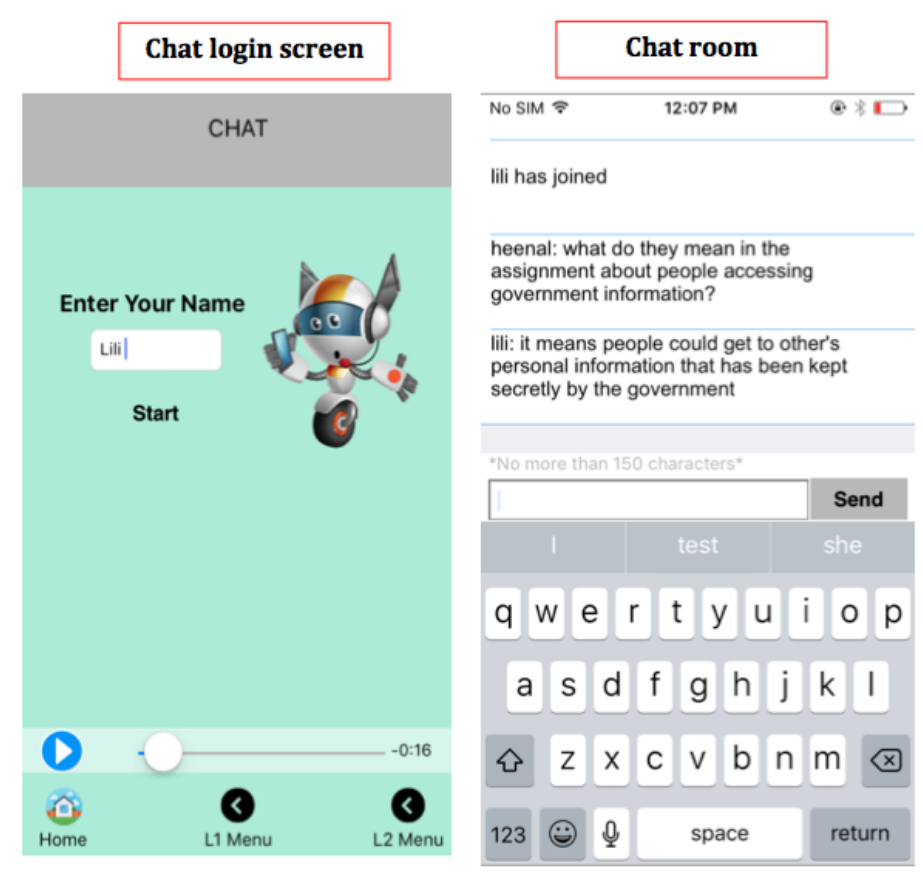

Figure 7.3: The second prototype chat room design 


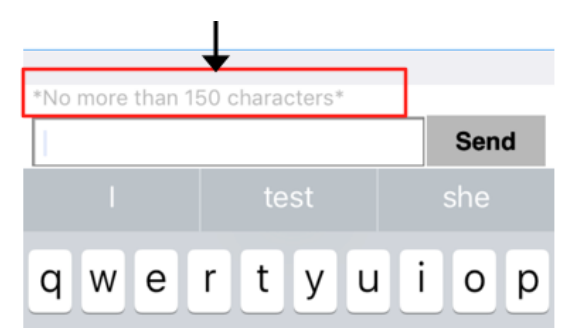

(a) Error prevention

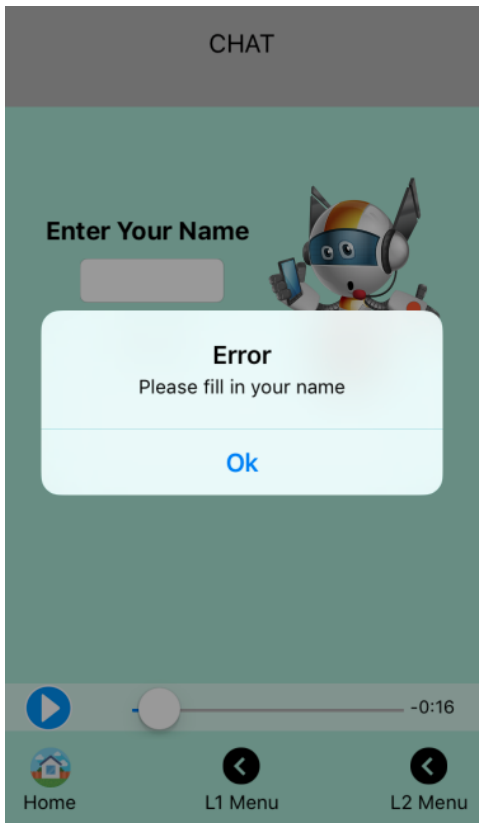

(b) Feedback

Figure 7.4: Chat feature interface design improvements

2. The second iteration prototype learners were assumed to be autonomous learners and matched the Clara persona used in the first prototype. Hence, the first and the second prototype were both designed to provide the same flexible course structure to match learners autonomy:

- Pre-learning guidance was provided to assist the learners in setting their learning goal by defining what they would gain from the selected learning topics.

- The learners would be allowed to control their own learning. Teachers would act as facilitators and provide assistance via the chat feature upon learners' request.

- During the evaluation process, self evaluation game-based learning activity along with compulsory assignments were 
used to gage the learners' understanding of the learning topics. The interface design of the second prototype quiz games were exactly the same as the one provided in the first prototype (See figure 7.5).

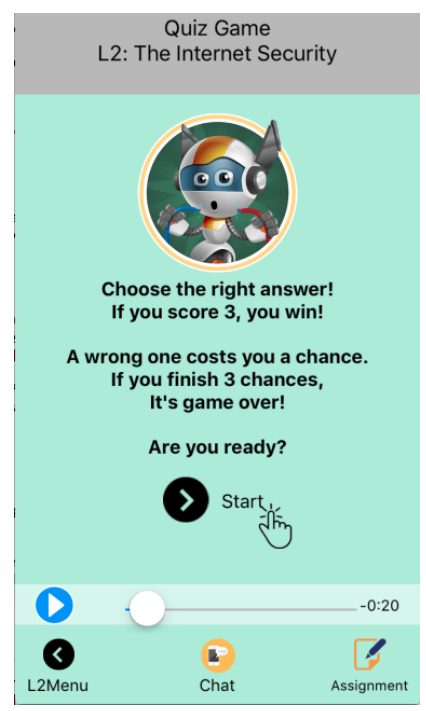

(a) Introduction

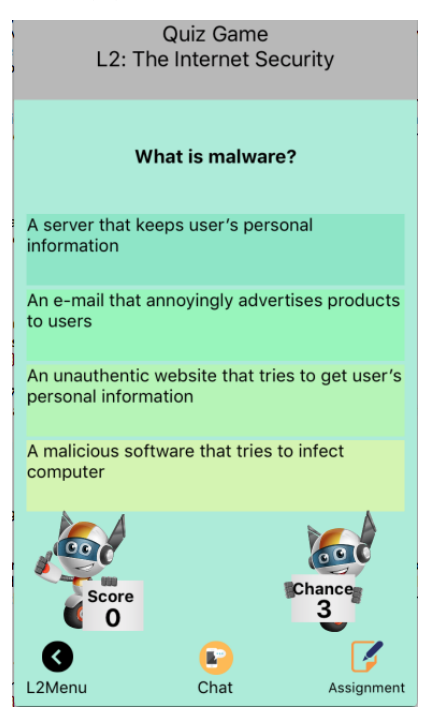

(c) Answer/Score

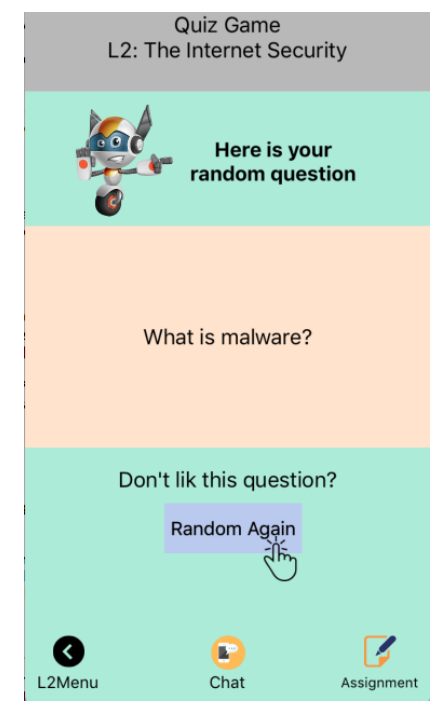

(b) Question

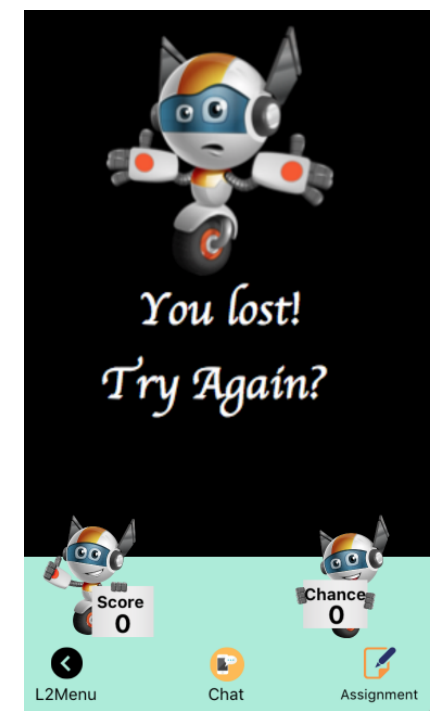

(d) Feedback

Figure 7.5: The second prototype game design 
However, there were some improvements to the assignments of the second prototype:

- As mentioned in the second iteration design guideline number 4. (i.e., motivate learners by providing learning tasks that are challenging and trigger their curiosity), the second iteration prototype provided a "hint button" to trigger the learners' curiosity and motivate them to go back to check particular parts of learning content (See figure 7.6a).

- The second iteration prototype's assignment was an analysis task and a button was provided to allow learners to open an in-app browser and access some reference websites (See figure 7.6b). This feature was an implementation of the second iteration design guideline number 5 (i.e., developers should consider using high-level self-assessments (e.g., analysis or evaluation) that are aligned with learning objectives and allow learners to seek additional feedback from experts, peers, and instructors through Internet communication channels).

- To apply the second design guidelines number 6.6 (i.e, design for recognition rather than recall), the assignment questions were provided for the learners in their response emails to the instructor, so they would not need to memorise the questions or navigate back and forth between the two screens (See figure 7.6). 


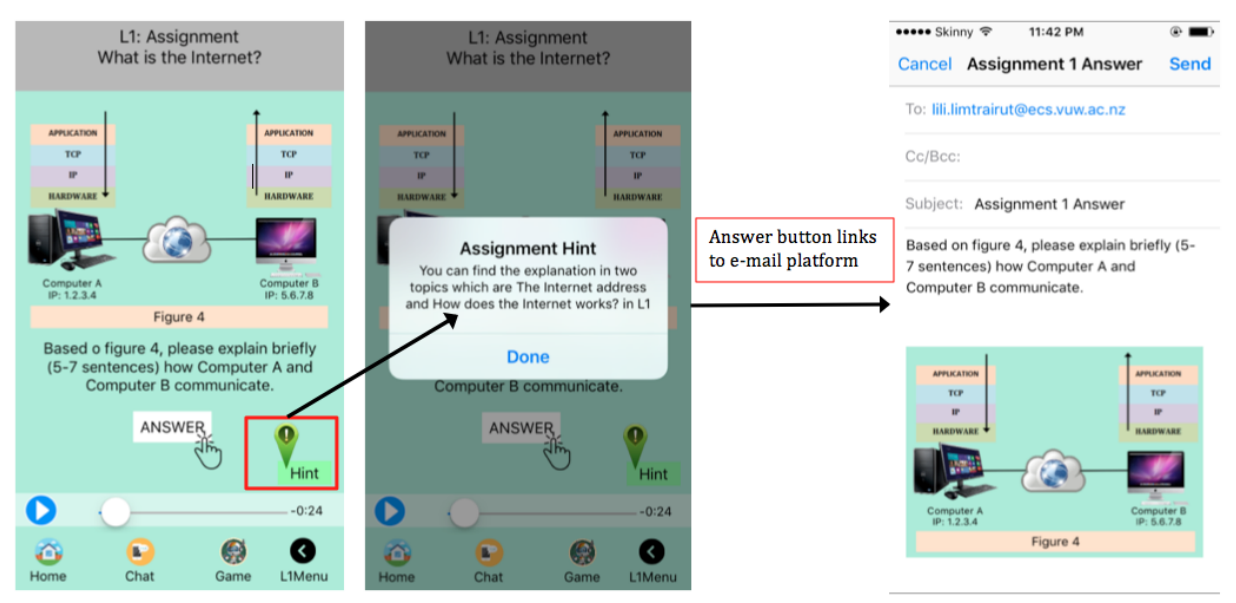

(a) Basic level assignment design

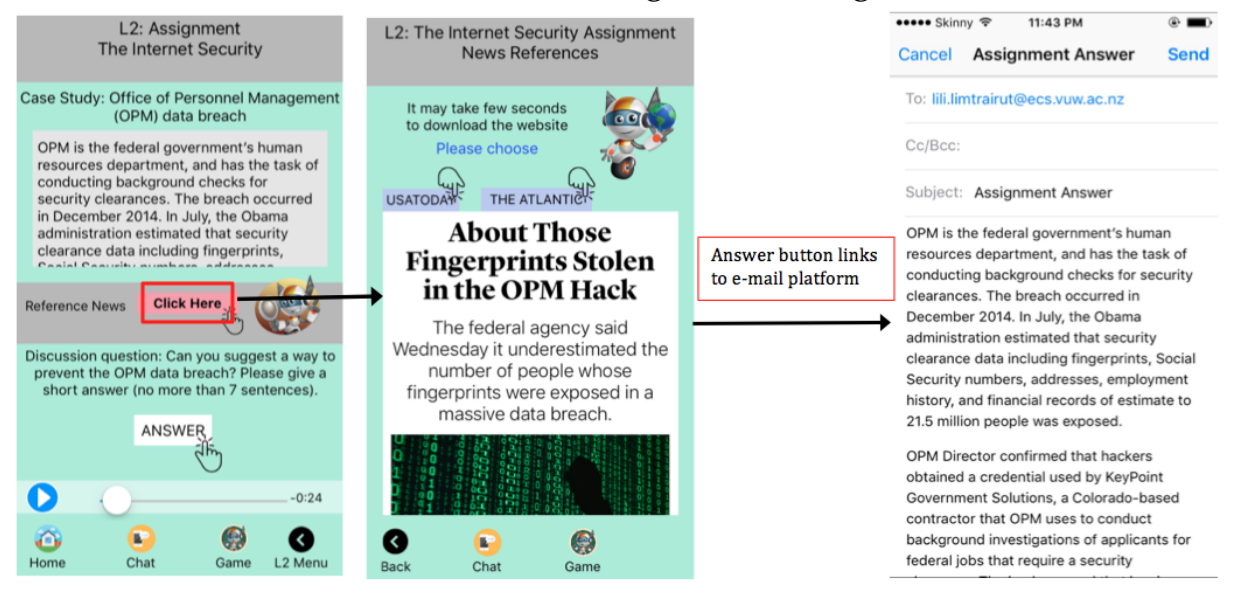

(b) Analytical level assignment design

Figure 7.6: Compulsory assignments in the second prototype 
3. Once again, text media, audio recordings and animation videos (See figure 7.7) were used to enrich participants' learning experience, motivate and engage them with their learning process.

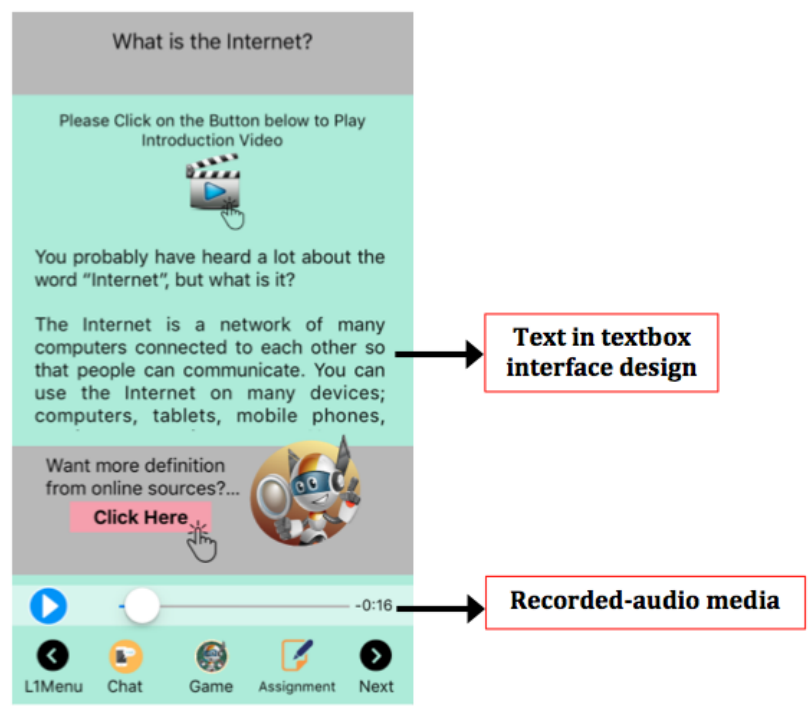

(a) Text and audio recording media

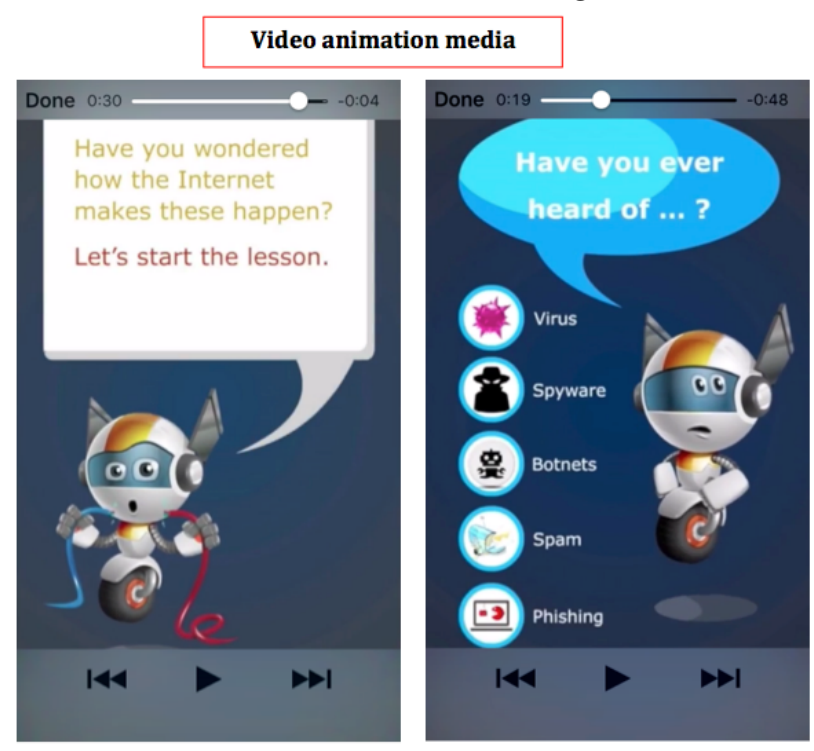

(b) Screenshots of animation videos

Figure 7.7: The second prototype's media presentation 
4. Two animation videos were provided with the aim to stimulate learners' curiosity and motivate them to learn right at the start of their learning process. The quiz games were designed to be challenging and might trigger their competitiveness.

5. The quiz games and the basic and analytic compulsory assignments were provided for the learners to evaluate their knowledge at different levels

6. The same seven experts who evaluated the first prototype design in section 6.2 carried out the same heuristic evaluation on the second prototype design. Based on their responses and comments, a minor interface re-design was carried out to ensure the second prototype design had acceptable usability

6.1 Provide visible application progress and status through appropriate and timely notification - In the second iteration prototype, learning content was arranged hierarchically inside menu buttons which would be greyed out once they had been tapped on to inform the participants which learning content they had already learned versus the ones which they hadn't (See figure 7.8a). Additionally, a self-check progress screen for both learning topics was provided to help learners track their progress and ensure they complete their learning (See figure $7.8 b)$.

6.2 Match the system design with real world convention - All learning content was arranged hierarchically and orderly within menu buttons. The title of the buttons were made easy to understand, suitable to learners' knowledge, and were grammatically parallel. Navigation controls were also provided at the bottom of every learning screens (See figure 7.9). 


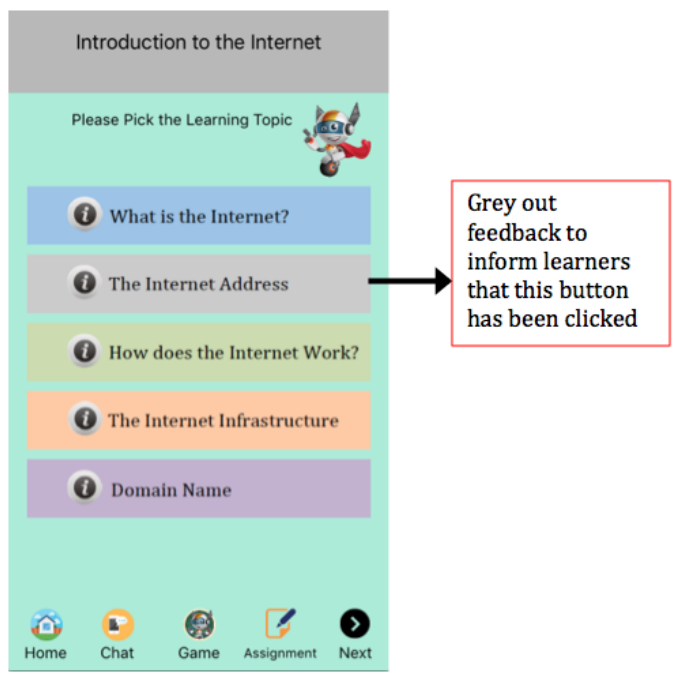

(a) Visual feedback

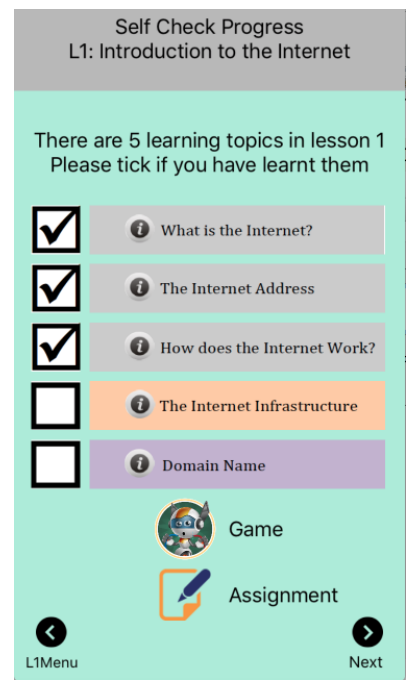

(b) Self-check progress

Figure 7.8: The second prototype visual design

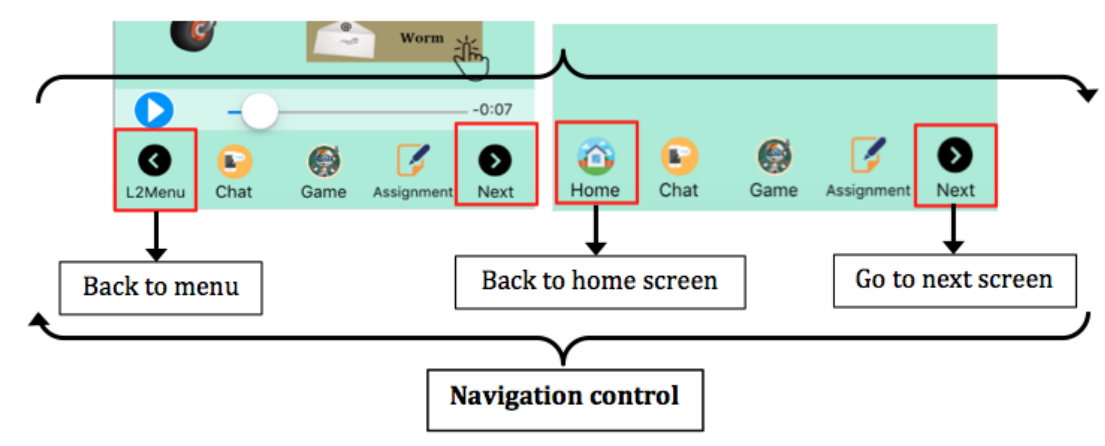

Figure 7.9: Navigation control

6.3 Ensure the interface is "forgiving" - There were "Back", "Next", and "Home" buttons available for learners to easily navigate through the application (See figure 7.9).

6.4 Use consistent language and maintain software interaction standards - The second prototype used typical and common design. It used the correct language standard, and the tone of 
voice (for the audio recordings), user interface and visual presentation elements all adhered to the heuristic design guidelines.

However, the second prototype received some negative feedback for its inconsistent use of icons during the heuristic evaluation by the experts. An expert commented that:

"In the lesson menu there are an " $i$ " icons for each learning topic - but that same icon is used in the home menu where if you click on it there is a pop up message. Perhaps some consistencies are required when it comes to the use of the ' $i$ ' icons."

"The home button should always be a 'Home' icon - even if other pages that location becomes other menu item - then that should be the scenario when the app displays " $<$ " instead."

Another expert commented that the buttons provided in the home screen were too small and would need its size increased. Based on these feedback, minor adjustments were made to the second prototype design to ensure the reported usability inconsistencies were rectified.

6.5 Provide error prevention - Most of the experts were satisfied that the chat feature had now been improved with error messages notifying learners that they should input their name before logging into the chat area (See figure 7.4). Furthermore, an expert suggested using visual notification to inform learners:

"When there is no text in the text box, the send button should be greyed out and not allow user to press send." 
The suggestion was later incorporated into the final second iteration prototype design.

6.6 Design for recognition rather than recall - The second prototype implementation of this guideline received mixed feedback from the experts during their heuristic evaluation. For example an expert who was satisfied with this item commented that:

"Users seem to be able to always go back to the lesson menu, which is good for not needing to recall anything related to the lesson."

On the other hand, an expert suggested an improvement to the assignment feature of the prototype, which involved the prototype including the original assignment questions as part of the application response email since the questions were quite long and the learner would not be able to recall them from their memory, in particular for the analysis question. This improvement to the assignment feature was included in the final second iteration prototype (See figure 7.6).

6.7 Provide efficiency of use - Although the prototype did not include any customisation option for frequently used functions, the prototype provided shortcut menus allowing the participants to navigate directly to the learning screen they required.

6.8 Use aesthetic and minimalist design - Developers had prior knowledge of the given learning topics, and therefore had ensured that only succinct, relevant, and meaningful content were included in the prototype design. The learning content 
was also hierarchically presented in menu buttons, using contrasting colours for text and background to ensure readability. The background colour for every learning screen were also consistently applied.

6.9 Help users recognise, diagnose, and recover from errors As previously stated, this had been accomplished in the chat feature of the second iteration prototype (See figure 7.4).

6.10 Offer help and documentation - Although there were no manual or online help document based on the assumption that participants had the necessary ability to use all provided media and learning-supported functions without any further assistance, the second prototype design had the chat function that the participants could use to seek help if required.

6.11 Provide external resources - A link to relevant external resource was provided (See figure 7.10). 

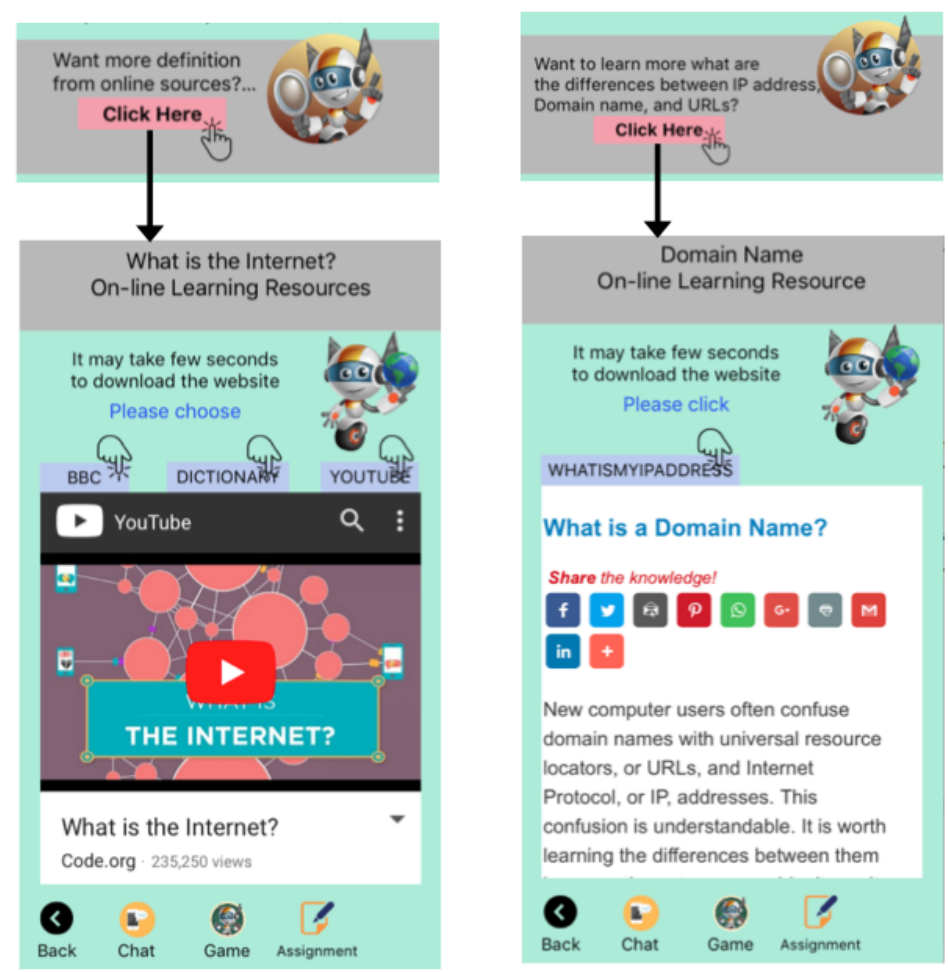

Figure 7.10: Provided links to resources from inside the prototype

Note that, among the 11 heuristics in the second design guideline (heuristics 6.1-6.11), 10 heuristics were overlapped with the eight golden rules that guided the interface design of the first design guidelines and only 1 heuristic was added (i.e., heuristic 6.11).

The added heuristic helped the developer of this study improve the second prototype by providing links to resources from inside the prototype (See figure 7.10). On the other hand, the other improvements to the second prototype were able to be incorporated as there were more detail explanations provided in the heuristics of the second design guidelines compared to the eight golden rules of interface design from the first design guidelines. As a result, the developer was able to predict the usability issue more accurately. Additionally, the heuristics that were not noticed by the developer were predicted by the experts in the 
heuristic evaluation. This was a double-checking process that helped improve the usability of the second prototype.

\subsection{Summary}

In order to improve the interface design usability, the new set of heuristics were added, adjusted and merged into the first design guidelines to form the second design guidelines. As discussed in chapter 6, the heuristic evaluation was found to be more helpful in guiding usability design for the m-learning application, therefore all of the eight golden rules of interface design that originally underpinned the interface design usability aspect of the first design guidelines were totally replaced by heuristics in the second iteration design guidelines.

Using the learner autonomy findings from the first prototype evaluation results and the second iteration m-learning design guidelines, the second prototype design was developed. The prototype was evaluated against the heuristics by experts to provide some degree of confidence in its interface usability. Overall, the prototype did not receive any critical comments against any of the heuristics. Feedback from the experts were used to improve and finalise the second iteration prototype design, ready for evaluation by target learners.

In the next chapter, the second prototype design will be evaluated to determine the relationship between prototype design and student engagement, investigate potential correlation between learner autonomy and student engagement, and to further investigate the applicability of the heuristic evaluation that had been newly merged into the guidelines. 


\section{Chapter 8}

\section{Second Prototype Evaluation}

In chapter 7, an m-learning application prototype was developed based on the second iteration design guidelines. In this chapter, the evaluation process used in the first iteration prototype evaluation (see chapter 5) is utilised again for the second iteration prototype. The quantitative results and qualitative findings are analysed to determine whether the second iteration design guidelines that were enhanced based on the first iteration evaluation results and findings can improve learning quality with regards to student engagement. This will once again verify TDT's validity and its ability to guide the design of modern education platforms such as m-learning applications. Additionally, by using the same statistical calculation methods for analysing the first iteration evaluation results, this chapter also seeks to highlight any potential correlation between learner autonomy and student engagement, thus verifying the conclusion from the first iteration's results that there was a weak correlation between these two variables. Finally, the results and qualitative findings from this second iteration prototype evaluation are compared to the first iteration prototype evaluation. The comparison outcome is used identify if the heuristics that were incorporated into the first design guidelines can enhance the overall usability of the prototype. 


\subsection{Hypotheses}

To verify whether the prototype developed based on the second iteration design guidelines could engage learners with their learning process despite an increase in the learning content quantity and changing learning topic, three hypotheses would be tested. The first hypothesis was:

1. An m-learning prototype designed to decrease transactional distance can engage autonomous learners better than a prototype providing the same learning flexibility but has no other mechanisms to decrease transactional distance

To test this hypothesis, the participants' autonomy must be observed. Additionally, to validate the first iteration evaluation findings that there was a weak correlation between learner autonomy and student engagement, the second hypothesis to be tested was:

2. There is no correlation between learner autonomy and student engagement

Finally, to observe if the heuristic evaluation checklist incorporated into the first iteration design guidelines and the new hierarchical menu interface design could enhance usability, the third hypothesis to be tested was:

3. The m-learning prototype designed based on the second iteration design guidelines can enhance usability better than the first iteration prototype designed based on the first iteration design guidelines 


\subsection{Evaluation Process}

The second m-learning application prototype evaluation was conducted using almost exactly the same process as the first iteration prototype evaluation (See section 5.2). However, some adjustments were made to improve the evaluation process. This section summarised the process and identified the adjustments.

\subsubsection{Participant recruitment}

For the second iteration prototype evaluation, the target learners were selected from the same group of students (i.e., first year engineering students enrolled in either the ENGR101 or COMP102 course at the school of Engineering and Computer Science from the Victoria University of Wellington). Moreover, students who were enrolled in the course "Introduction to Computer Science" (COMP112) were added to the pool of target learners.

The participants for the second iteration evaluation were also recruited via the same process (i.e., an invitation e-mail was sent to all students who enrolled in the three courses during the first trimester in 2017). The participants from first iteration evaluation process were automatically excluded from the participant selection pool for the second iteration evaluation. Additionally, the grocery voucher reward was still offered to each participant upon their completion of the prototype evaluation.

From a pool of approximately 749 students, 24 of them expressed interest in participating in the second iteration prototype evaluation. Of the 24 participants who took part in this study, 15 were male and 9 were female, aged between 18 to 25 years old.

The prototype evaluation was conducted between April $4^{\text {th }}$ to $13^{\text {th }} 2017$, week $14^{\text {th }}$ to $15^{\text {th }}$ of the first trimester. This second evaluation iteration was carried out in the same laboratory settings. Participants spent between 4 
to 74 minutes in the laboratory to complete this evaluation.

\subsubsection{Participant Observation and Data Collection}

The second stage of the prototype evaluation was also divided into the same four steps from the second stage of the first iteration prototype evaluation (See section 5.2.2). Moreover, the same material such as information sheet, consent form, pre- and post-questionnaire, and the eight m-learning tasks list from the first iteration evaluation were reused in this second iteration evaluation.

In the first and second steps, each participant was asked to complete the pre-questionnaire. They were provided with a smart phone and were observed individually while they performed the eight tasks (See the task list in Appendix) deemed to be relevant to m-learning using the given mobile phone. In the third step, the second iteration prototype developed in chapter 7 was loaded onto the mobile phone using two different design versions. Figure 8.1 provides some examples of the difference between the two versions.

- P2_1 - The prototype designed to decrease transactional distance. It included a chat room feature that allowed learners to have dialogues with their teachers. It also included various multimedia presentation (i.e., text, recorded audio, and animation videos) and learning-support features (i.e., quiz games, compulsory assignments, self-check progress, and internal links to external learning resources).

In the second iteration, some improvements were made to the prototype design:

1. Prototype P2_1 was evaluated by some experts to ensure its usability. 


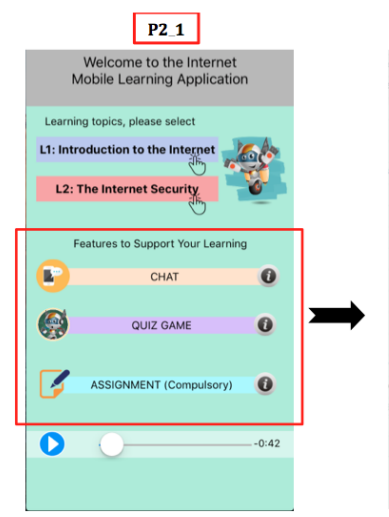

(a) Home Screen

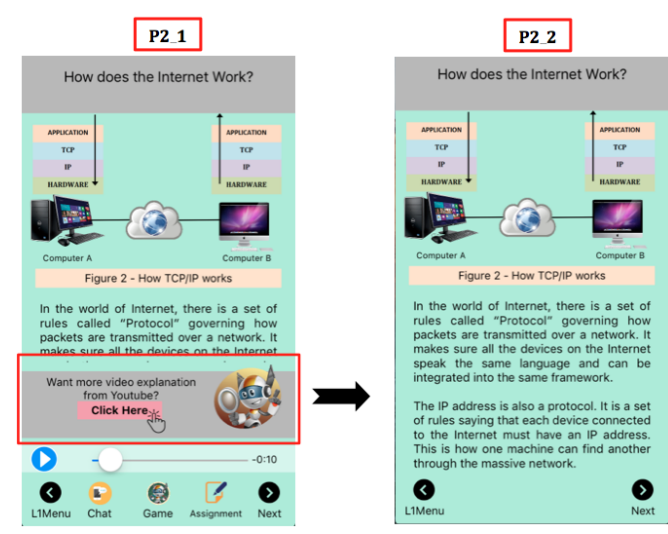

(c) Learning-supported functions

Figure 8.1: Comparison of P2_1 and P2_2 prototypes

2. Based on the heuristics, prototype P2_1 included two new learning-support features: self-check progress and internal links to external learning resources.

3. The chat room feature of prototype P2_1 now included error prevention and error notification mechanisms. It informed participants how many words were allowed in the chat box message and provided an pop-up window to inform participants of an error if they did not fill in their name before they entered the chat room. Note that the participants were 
informed that a researcher, who role played as a teacher, would answer their chat in real time.

4. The assignment feature of prototype $\mathrm{P} 2{ }_{-} 1$ had a hint button that identified which part of the learning content could help participants answer the relevant assignment questions. Additionally, in order to help them remember the assignment question rather than recalling it from their memory, the assignment questions of prototype P2_1 were also inserted into the e-mail answer platform. Therefore, participants who could not remember the questions did not need to navigate back and forth between screens.

- P2_2 - The prototype version designed to provide the same learning flexibility as prototype P2_1 but had no other mechanisms to decrease transactional distance.

It had almost none of the media presentation and learning-support features implemented. It lacked the chat function, so participants had no dialogue opportunity with their teachers or peers. Learning content was presented using text media only, with no recorded audio or animation video to motivate and encourage participants to learn. Furthermore, it contained no learning-support mechanism such as game-based learning, compulsory assignment, and self-check progress for participants to evaluate their own learning, nor receive any feedback from teachers or check their own learning progress.

Identical to the first iteration evaluation, both prototype versions had similar flexible course structure:

- Learning content was arranged in menu and sub-menus

- There was a navigation bar at the bottom of every screen 
- There were some visual feedback to inform participants which learning topic had been selected (i.e., the button that was just selected would be greyed out)

- The prototypes allowed participants to access all learning content and set their own learning goals, implement their own learning process and learn at their own pace

Equal numbers of participants were randomly selected to use each prototype design, i.e., twelve of them used prototype P2_1 and the remaining twelve used prototype P2_2.

\subsection{Quantitative Results}

\subsubsection{Learner Autonomy}

As mentioned in section 8.1, in order to test the first hypothesis, the participants must be autonomous learners. Similar to the first iteration prototype evaluation, the pre-questionnaire was used to verify learner autonomy and participants ranked their responses using the five point Likert scale with values ranging from -2 to 2 . The results collected showed that every participant had average motivation and average confident level values more than 0 (i.e., positive level value) (See table 8.1).

- The highest motivation level was 2.00 and the lowest was 0.55 .

- The highest confidence level was 1.78 and the lowest was 0.11 .

- The average motivation level was 1.23 and the average confidence level was 1.03 . 
Table 8.1: Average level of motivation and confidence for each participant

\begin{tabular}{|c|c|c|c|}
\hline Participant (P) & Prototype & Motivation Level & Confident Level \\
\hline $\mathrm{P} 1$ & P2_1 & 1.18 & 0.78 \\
\hline $\mathrm{P} 2$ & P2_2 & 1.00 & 1.00 \\
\hline P3 & P2_1 & 1.27 & 1.11 \\
\hline $\mathrm{P} 4$ & P2_2 & 0.64 & 1.67 \\
\hline P5 & P2_1 & 1.45 & 1.78 \\
\hline P6 & P2_2 & 1.09 & 0.56 \\
\hline P7 & P2_1 & 1.73 & 0.89 \\
\hline P8 & P2_2 & 1.64 & 1.44 \\
\hline P9 & P2_1 & 0.73 & 0.67 \\
\hline P10 & P2_1 & 1.18 & 1.22 \\
\hline $\mathrm{P} 11$ & P2_1 & 1.55 & 1.00 \\
\hline P12 & P2_1 & 1.18 & 1.22 \\
\hline P13 & P2_2 & 2.00 & 0.11 \\
\hline $\mathrm{P} 14$ & P2_1 & 1.09 & 0.89 \\
\hline P15 & P2_2 & 1.00 & 1.44 \\
\hline P16 & P2_1 & 1.00 & 0.89 \\
\hline P17 & P2_2 & 1.64 & 0.89 \\
\hline P18 & P2_1 & 0.91 & 1.00 \\
\hline P19 & P2_2 & 1.09 & 0.78 \\
\hline $\mathrm{P} 20$ & P2_2 & 1.55 & 1.56 \\
\hline $\mathrm{P} 21$ & P2_1 & 0.55 & 0.33 \\
\hline $\mathrm{P} 22$ & P2_2 & 1.36 & 0.89 \\
\hline $\mathrm{P} 23$ & P2_2 & 1.27 & 0.78 \\
\hline P24 & $\mathrm{P} 2{ }^{2}$ & 1.45 & 1.56 \\
\hline Average & & 1.23 (SD 0.35) & 1.03 (SD 0.42) \\
\hline
\end{tabular}

After completing the pre-questionnaire, participants' knowledge and skills were observed using the same observation methods as the first 
iteration prototype evaluation. The results indicated that all 24 participants could complete all eight tasks on their first attempt. None of them requested for further assistance from the researcher. Consequently, it could be concluded that

"All of the participants were autonomous learners"

\subsubsection{Student engagement}

In order to observe the student engagement aspect of the first hypothesis, the average engagement level values of prototype P2_1 and P2_2 were gathered using the same method identical to that used in the first iteration evaluation process. Table 8.2 and Figure 8.2 present the comparison between the average engagement values for the two prototypes.

During the evaluation process, all participants using either prototype P2_1 or P2_2 could choose to study, skim, or skip any or all of the learning content. Similarly, the participants who were assigned to use prototype $\mathrm{P} 2 \_1$ where learning content was presented using various multimedia and all the learning support features were included, could choose to use all, some or none of the media and features, with the exception of the compulsory assignments.

Table 8.2: Average engagement level and standard deviation of prototypes P2_1 and P2_2

\begin{tabular}{|c|c|c|}
\hline Prototype & Avg. Engagement & SD \\
\hline P2_1 & 0.63 & 0.58 \\
\hline P2_2 & 0.78 & 0.46 \\
\hline
\end{tabular}




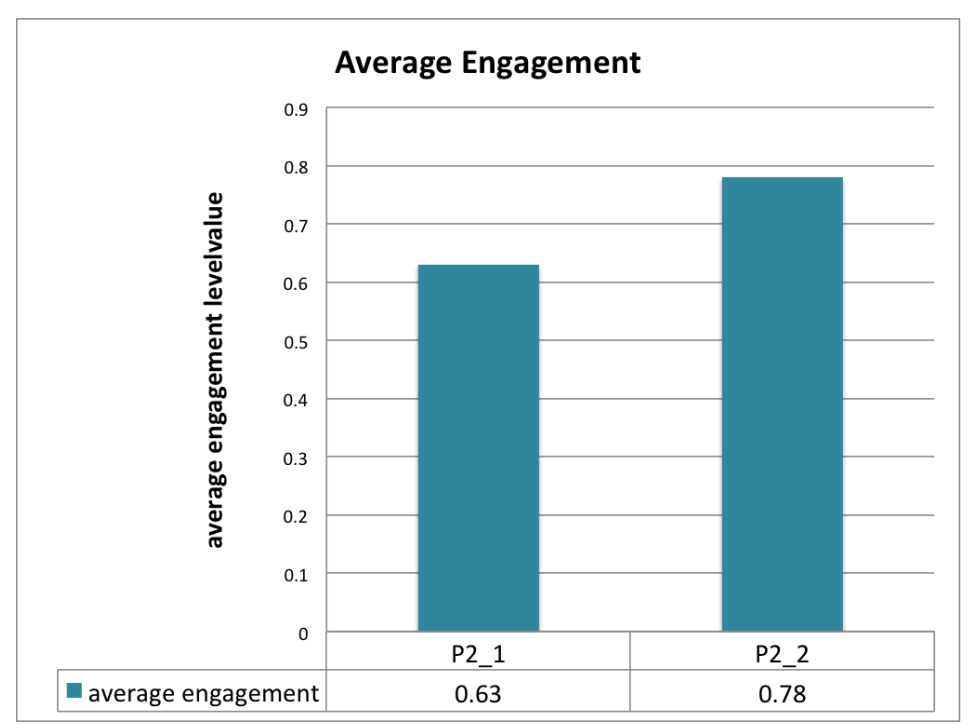

Figure 8.2: Average engagement levels of prototypes P2_1 and P2_2

Based on the comparison, the average engagement level value of prototype $\mathrm{P} 2 \_2$ was higher than the value of prototype $\mathrm{P} 2 \_1$. In order to verify if this comparison result was statistically significant, a hypotheses testing was performed using the identical hypotheses testing process from the first iteration evaluation (See section 5.3.2).

\section{Hypothesis testing: average engagement level value}

- Hypotheses:

$$
\begin{aligned}
& H_{1} \text { : average student engagement level value of } P 2 \_2>P 2 \_1 \\
& H_{0} \text { : average student engagement level value of } P 2 \_2 \leq P 2 \_1
\end{aligned}
$$

- Analysis plan: This research chose a significant level equal to 0.05. When the degree of freedom equal to 22 (i.e., number of participant 2 ), the critical value of $t$ found in the $t$-table (See foot note 9 in section 5.3.2) was 1.717. Therefore, 


$$
H_{0} \text { is rejected if } t>1.717
$$

- Data analysis: The test statistic for examining a hypothesis of two population means:

$$
t=\frac{\bar{x}_{1}-\bar{x}_{2}}{\sqrt{\frac{S_{1}^{2}}{n_{1}}+\frac{S_{2}^{2}}{n_{2}}}}
$$

where $\bar{x}_{1}$ and $\bar{x}_{2}$ are the average value of samples 1 and 2

$S_{1}$ and $S_{2}$ are standard deviation of samples 1 and 2

and $n_{1}$ and $n_{2}$ are the number of data points in samples 1 and 2

$t=0.702$

- Result interpretation:

Because the calculated $t$ - value $0.702 \leq$ the critical $t$ - value 1.717

It fail to reject $H_{0}$

- Calculate $\mathrm{p}$-value form the $\mathrm{t}$-value

$$
p-\text { value }=0.244
$$

The result is not statistical significant when $p<0.05$

This hypothesis test indicated that even though the average student engagement level value of prototype P2_2 was higher than the value of prototype $\mathrm{P} 2$ - 1 , this result was not statistically significant.

At this stage the first hypothesis had been tested and it seemed that the m-learning prototype designed to decrease transactional distance could not engage autonomous learners better than a prototype providing the same learning flexibility but had no other mechanisms to decrease transactional distance. 
Furthermore, this result implied that elements introduced to decrease transactional distance within the second iteration design guidelines which were developed based upon improvements on the first iteration design guidelines could not better engage participants. This implication was in conflict with the results gathered from the first iteration evaluation, as well as with the principles of TDT. Therefore, further investigation was needed to observe what could have influenced this result.

The first part of this investigation involved clustering the responses of participants from each prototype based on the six student engagement concepts to see if there were combination of values that might explain overall engagement level value suggested by its high standard deviation.

Secondly, the average learner autonomy of participants for each prototype was calculated. According to TDT, learner autonomy was an element that varied transactional distance. Although the participants had been verified to be autonomous learners, the difference in the participants' learner autonomy from each prototype might affect the result.

\section{Clustering}

The K-means clustering technique used in chapter 3 was utilised to cluster the participants based on their responses to the six student engagement concepts. Participants who were placed within the same cluster responded to the six student engagement concepts in a similar pattern.

In order to find an appropriate number of cluster $(\mathrm{K})$ for prototype P2_1 and P2_2, MATLAB was used to draw silhouette plots and calculate average silhouette value. Figures 8.3 and 8.4 present the Silhouette plots when $K=2,3$, and 4 for the prototypes P2_1 and P2_2 respectively. 


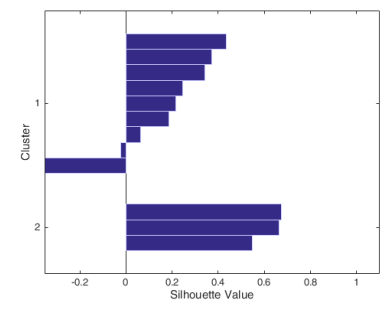

(a) $\mathrm{K}=2$

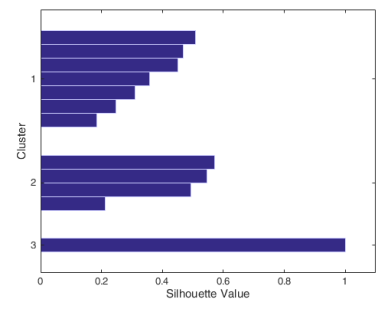

(b) $\mathrm{K}=3$

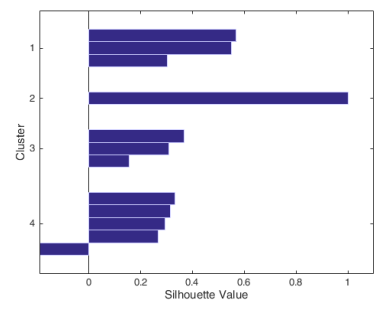

(c) $\mathrm{K}=4$

Figure 8.3: Silhouette plots to find the appropriate number of cluster $(\mathrm{K})$ for prototype P2_1

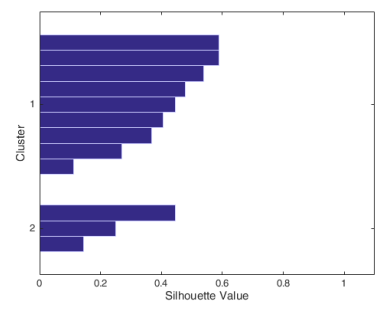

(a) $\mathrm{K}=2$

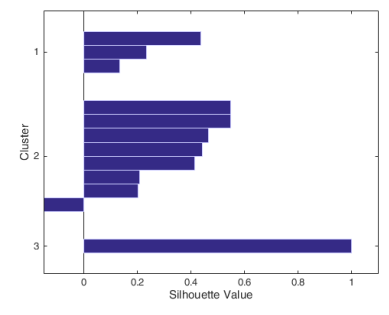

(b) $K=3$

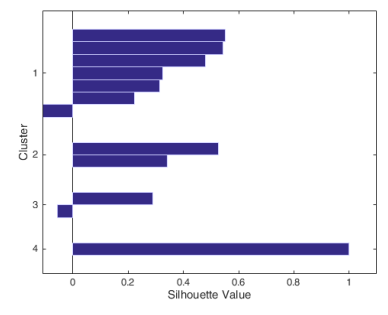

(c) $\mathrm{K}=4$

Figure 8.4: Silhouette plots to find the appropriate number of cluster $(\mathrm{K})$ for prototype P2_2

These plots and the average silhouette value calculation identified that the most appropriate number of cluster (K) for P2_1 and P2_2 was 3 and 2 respectively. To be exact, the participants who used prototype $\mathrm{P} 2$ _ 1 would be clustered into 3 clusters whilst the participants who used prototype P2_2 would be clustered into 2 clusters. Table 8.3 and 8.4 present the average engagement level values for each cluster of the two prototypes P2_1 and P2_2.

Based on the results, there were some variants in the average student engagement for both prototypes. For prototype P2_1, its cluster 1, 2, and 3 had almost neutral, high, and low average student engagement level values respectively. For prototype P2_2, its cluster 1 that had a major 
Table 8.3: Average engagement level value for the 3 clusters of prototype P2_1

\begin{tabular}{|c|c|c|}
\hline Cluster & Number of participants & Avg. Engagement \\
\hline 1 & 7 & 0.42 \\
\hline 2 & 4 & 1.27 \\
\hline 3 & 1 & -0.41 \\
\hline
\end{tabular}

Table 8.4: Average engagement level value for the 2 clusters of prototype P2_2

\begin{tabular}{|c|c|c|}
\hline Cluster & Number of participants & Avg. Engagement \\
\hline 1 & 9 & 1.01 \\
\hline 2 & 3 & 0.11 \\
\hline
\end{tabular}

number of participants with high average engagement value whilst cluster 2 had almost neutral average student engagement level value.

Clusters 1 and 2 of prototype P2_ 1 and both clusters of prototype P2_2 had a reasonable number of participants and were deemed able to provide results that would be meaningful. On the other hand, cluster 3 of prototype P2_1 only contained one participant who had a very different average student engagement level value when compared to the majority of the participants. This might reduce the average engagement level value of prototype P2_1. Re-calculating the average engagement level value for P2_1 after eliminating this participant from the calculation still yielded an average result lower than the value for prototype P2_2. Therefore statistically, the variant did not have significant effect on the overall result.

However, a further observation by reviewing the video recording of this specific participant from cluster 3 of prototype P2_ 1 found that the compulsory assignments might be the cause of the negative result and could imply the cause of the lower average engagement level value for 
prototype P2_1 (See further explanations in Section 8.4.4).

\section{Average leaner autonomy}

In order to determine the average learner autonomy level value, only the quantitative results of the participants' motivation and confidence level values were used. Table 8.5 and figure 8.5 present the comparison between average learner autonomy of participants who used prototype P2_1 and the value for participants who used prototype P2_2.

Table 8.5: Average learner autonomy level value and standard deviation of prototypes P2_1 and P2_2

\begin{tabular}{|c|c|c|}
\hline Prototype & Avg. Engagement & SD \\
\hline P2_1 & 1.08 & 0.31 \\
\hline P2_2 & 1.18 & 0.24 \\
\hline
\end{tabular}

In order to observe if the difference of the two average autonomy level values present in table 8.5 was statistical significant, we calculated $\mathrm{p}$-value. The $\mathrm{p}$-value was 0.386 which indicated that the difference was not statistical significant at $\mathrm{p}<0.05$. 


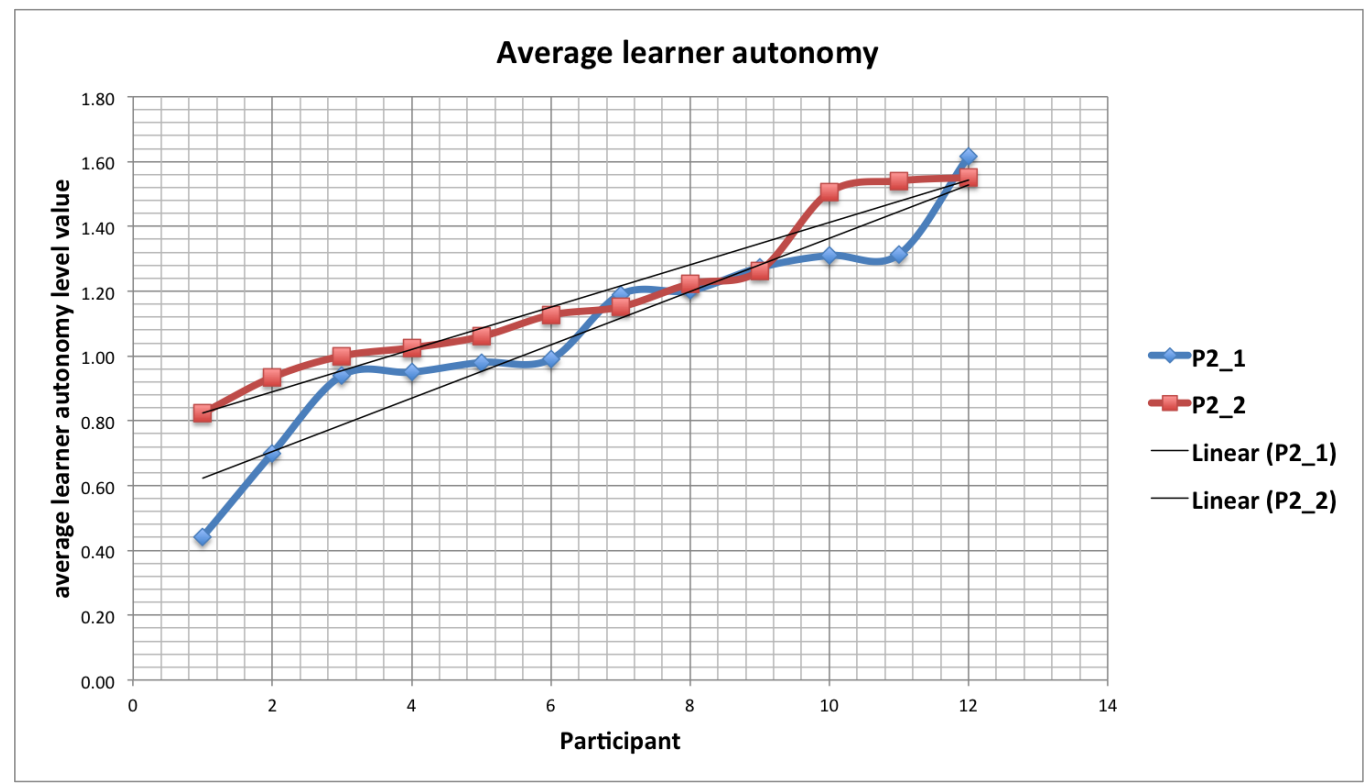

Figure 8.5: Average learner autonomy level values of prototypes P2_1 and P2_2

Based on table 8.5 and figure 8.5, the average learner autonomy level value of prototype P2_1 was less than the value of prototype P2_2. Even though the difference was not statistically significant, varying levels of learner autonomy among participants might have influenced the average student engagement level value, particularly when this result was considered in conjunction with the average student engagement level results from the previous section. The multimedia and learning-support features introduced in prototype $\mathrm{P} 2{ }_{-} 1$ to reduce transactional distance might have engaged the less autonomous participants in learning almost as much as the more autonomous learners feeling engaged using prototype $\mathrm{P} 2 \_2$ which did not have those features.

\subsubsection{Six concepts of student engagements}

To closely analyse the factors behind the overall student engagement level value captured in section 8.3.2, the results were further divided into 
each of the six concepts of student engagement. Table 8.6 and Figure 8.6 present the engagement levels for each engagement concept measured against prototypes P2_1 and P2_2.

Table 8.6: Average engagement level value and standard deviation for each engagement concept measured against prototypes P2_1 and P2_2

\begin{tabular}{|c|c|c|c|}
\hline Engagement Concept & P2_1 & P2_2 & p-value \\
\hline Focus Attention & 0.52 (SD 0.62) & 0.30 (SD 0.70) & 0.212 \\
\hline Usability & 1.00 (SD 0.96) & 1.10 (SD 0.56) & 0.379 \\
\hline Aesthetics & 0.28 (SD1.08) & 0.32 (SD 1.02) & 0.463 \\
\hline Edurability & 0.88 (SD 0.88) & 0.82 (SD 0.58) & 0.423 \\
\hline Novelty & 0.53 (SD 1.05) & 1.25 (SD 0.45) & 0.02 \\
\hline Involvement & 0.58 (SD 0.62) & 0.92 (SD 0.74) & 0.118 \\
\hline
\end{tabular}

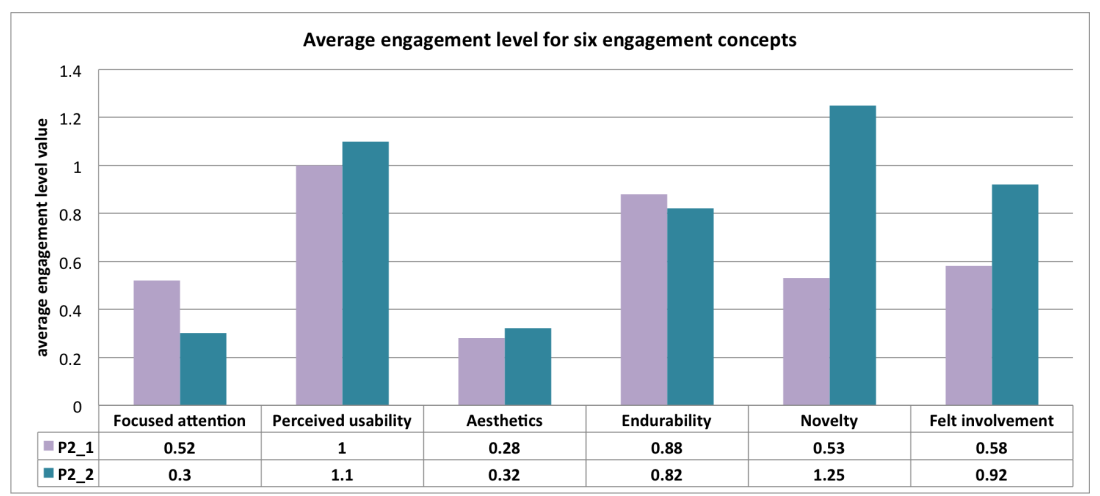

Figure 8.6: Average engagement level for each engagement concept measured against prototypes P2_1 and P2_2

The p-values presented in table 8.6 indicated that novelty was the engagement concepts that had statistical significance in the different average engagement levels (when $p<0.05$ ) between the two prototypes. On the other hand, the difference in average engagement of the other five engagement concepts (i.e., focus attention, usability, aesthetics, edurability, and involvement) was not statistically confirmed. 
Based on the results, perceived usability and novelty were the student engagement concepts that received the best response among the participants who used prototypes $\mathrm{P} 2{ }_{1} 1$ and $\mathrm{P} 2{ }_{2} 2$ respectively. On the other hand, aesthetic and focused attention were the student engagement concepts that received the worst response among the participants who used prototypes P2_1 and P2_2 respectively.

Furthermore, perceived usability, aesthetics, and endurability were the engagement concepts that prototypes $\mathrm{P} 2{ }_{1} 1$ and $\mathrm{P} 2{ }_{2} 2$ received almost equal average engagement level values. Hence, these three engagement concepts had no critical influence on the differences found in the student engagement level value, and therefore they were not the factors behind the lesser student engagement level value for prototype P2_1. Instead, the engagement concepts that most critically influenced this value for prototype P2_1 were novelty and felt involvement.

\subsubsection{Correlation between Learner Autonomy and Student Engagement}

In order to test the second hypothesis and better illustrate the correlation between learner autonomy and student engagement, the second iteration prototype results were arranged based on the average learner autonomy level values from low to high. These results were then plotted into scatter plots. Table 8.7, 8.8 show the average autonomy and engagement level for each participant who used prototype P2_1 and P 2_2 respectively and figure 8.7 illustrates correlation between learner autonomy and student engagement of the two prototypes.

To statistically determine whether there was correlation between these two factors, the same equation used in the first iteration evaluation (See section 5.3.4) was utilised again to calculate the correlation coefficient. The calculation indicated that there was a slight correlation between the two variables: 
The correlation coefficient between learner autonomy and student engagement of prototype P2_1 and P2_2 were 0.29 and 0.24 respectively

Table 8.7: Average autonomy and average engagement level for each participant who used prototype P2_1

\begin{tabular}{|c|c|c|}
\hline Participant & Avg. Autonomy & Avg. Engagement \\
\hline P21 & 0.44 & 0.73 \\
\hline P9 & 0.70 & 0.50 \\
\hline P16 & 0.94 & 0.70 \\
\hline P18 & 0.95 & 0.55 \\
\hline P1 & 0.98 & 0.30 \\
\hline P14 & 0.99 & 0.08 \\
\hline P3 & 1.19 & 0.07 \\
\hline P12 & 1.20 & 1.30 \\
\hline P11 & 1.27 & 1.19 \\
\hline P7 & 1.31 & -0.41 \\
\hline P10 & 1.31 & 0.91 \\
\hline P5 & 1.62 & 1.67 \\
\hline
\end{tabular}


Table 8.8: Average autonomy and average engagement level for each participant who used prototype P2_2

\begin{tabular}{|c|c|c|}
\hline Participant & Avg. Autonomy & Avg. Engagement \\
\hline P6 & 0.82 & 0.07 \\
\hline P19 & 0.93 & 0.86 \\
\hline P2 & 1.00 & 1.07 \\
\hline P23 & 1.03 & 0.91 \\
\hline P13 & 1.06 & 0.76 \\
\hline P22 & 1.13 & 0.68 \\
\hline P4 & 1.15 & 1.01 \\
\hline P15 & 1.22 & 0.12 \\
\hline P17 & 1.26 & 1.12 \\
\hline P24 & 1.51 & 1.51 \\
\hline P8 & 1.54 & 1.13 \\
\hline P20 & 1.55 & 0.15 \\
\hline
\end{tabular}

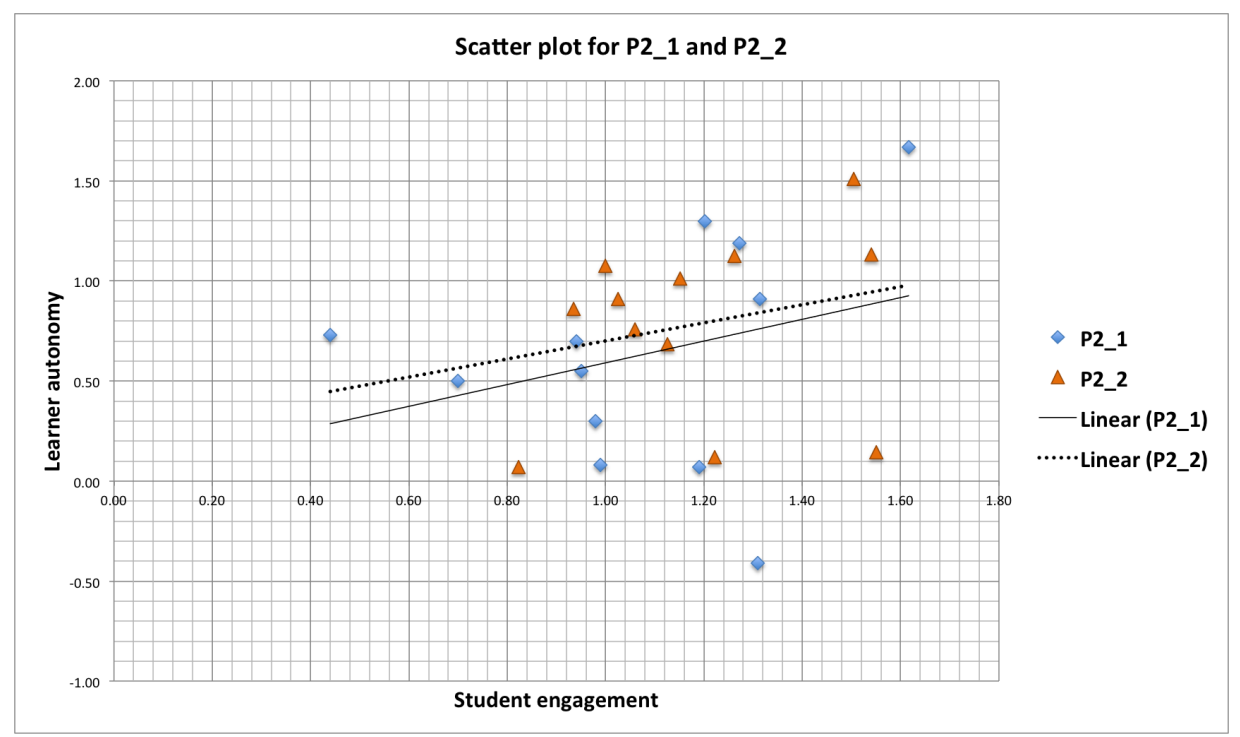

Figure 8.7: Graphical illustration of learner autonomy and student engagement for participants who used prototype P2_1 and P2_2 


\subsubsection{Average usability}

In order to test the third hypothesis, the average usability level values (i.e., measured by questions number 8 . through to 15 . in the post-questionnaire) of the first and second iteration evaluation were compared.

Due to the similarity of the provided learning-support features, the average usability level value of prototype P2_1 would be compared to the value for prototype P1_1, whilst this value for prototype P2_2 would be compared to that of prototype P1_2.

Despite similarities in the provided learning-support features between the first and second iteration prototypes (i.e., chat, quiz game, and assignment), there were some design differences that might affect this comparison:

- The two iterations' prototype designs presented different learning topics. The first iteration prototype presented "engineering ethics" whilst the second iteration prototypes presented two learning topics: "The Internet" and "The Internet security". Even though the topics presented in both iteration prototypes were selected using the same criteria (i.e., the learning topics were chosen based on learners' future course curriculum), the change in learning topics might affect the usability due to some potential biases such as the participants' personal preference and background knowledge on a particular learning topic.

- Since the second iteration presented two learning topics, it provided two quiz games and assignments whilst the first iteration provided only one of each of these features.

- Besides the TDT-theoretical learning-support features (i.e., chat, quiz game, and assignment), the second iteration prototypes added two features: self-check learning progress and links to external learning resources. 
- The first iteration presented learning content in using slide-out and dropdown hierarchical menus, whilst the second iteration prototype presented the learning content in using hierarchical menu and submenu interface design.

Table 8.9 and figure 8.8 present the comparison of the usability level values for prototypes $\mathrm{P} 2{ }_{1} 1$ and $\mathrm{P}{ }_{1}{ }^{1}$. Table 8.10 and figure 8.9 present the comparison of the same values for prototypes P2_2 and P1_2. 
Table 8.9: Average usability level and standard deviation of prototypes P2_1 and P1_1

\begin{tabular}{|c|c|c|}
\hline Prototype & Avg. Usability & Number of participant \\
\hline P2_1 & 1.00 (SD 0.96) & 12 \\
\hline P1_1 & 0.84 (SD 0.52) & 11 \\
\hline
\end{tabular}

In order to observe if the difference in average usability of the two prototypes presented in table 8.9 was statistical significant, we calculated the $\mathrm{p}$-value. The $\mathrm{p}$-value was 0.31 which indicated that the difference was not statistical significant at $\mathrm{p}<0.05$.

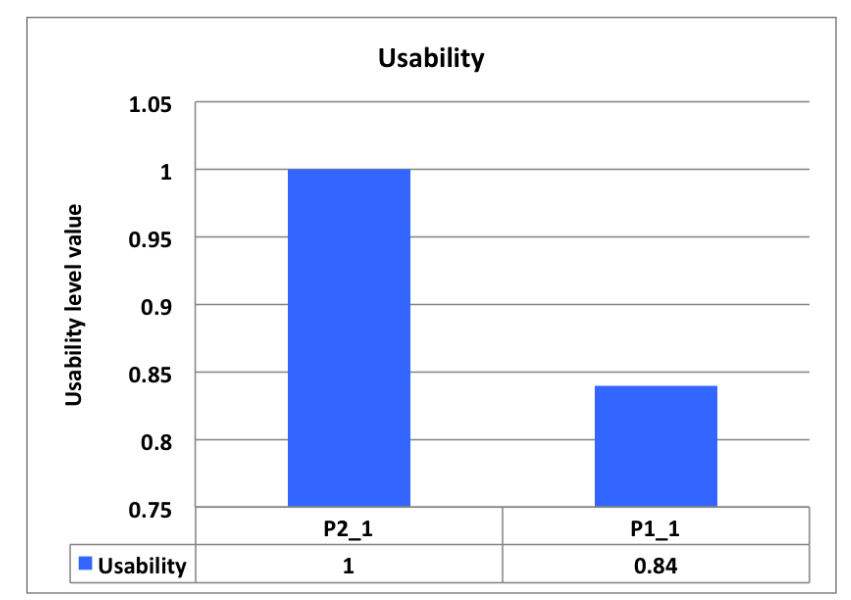

Figure 8.8: Average usability level of prototypes P2_1 and P1_1 
Table 8.10: Average usability level and standard deviation of prototypes P2_2 and P1_2

\begin{tabular}{|c|c|c|}
\hline Prototype & Avg. Usability & Number of participant \\
\hline P $2 \_2$ & 1.10 (SD 0.56) & 12 \\
\hline P1_2 & 0.64 (SD 0.79) & 10 \\
\hline
\end{tabular}

In order to observe if the difference in average usability of the two prototypes presented in table 8.10 was statistical significant, we calculated the $\mathrm{p}$-value. The $\mathrm{p}$-value was 0.069 which indicated that the difference was not statistical significant at $\mathrm{p}<0.05$.

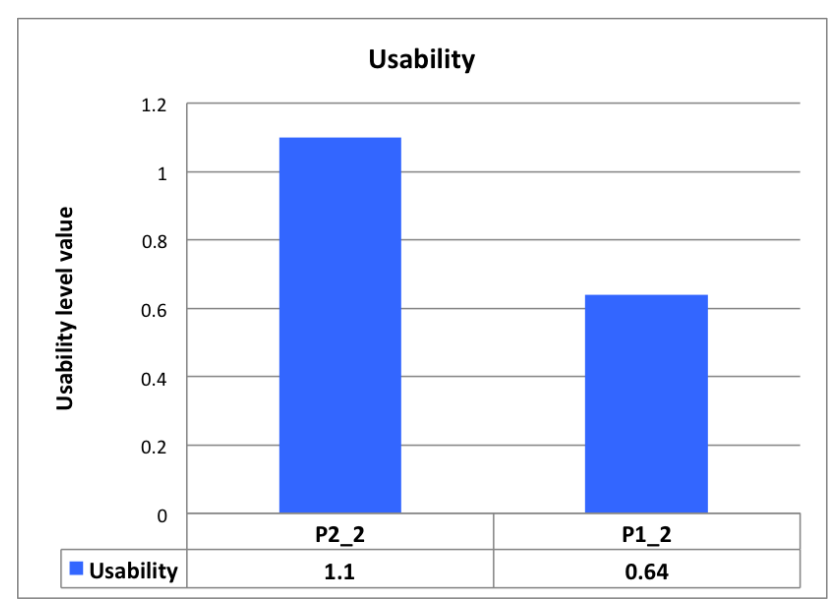

Figure 8.9: Average usability level of prototypes P2_2 and P1_2

Although it was not statistically confirmed, the second iteration design guidelines which incorporated the heuristics were deemed to have improved the prototype's usability based on these comparison results. 


\subsection{Qualitative Findings}

The qualitative findings from the second iteration prototype evaluation were gathered based on the video-recordings of participants using the prototypes. It focused on how the participants interacted with the learning content designed within the application and how they used the provided multimedia and learning-support features.

These findings would identify any usability improvements in this second iteration prototype compared to that from the first iteration, and could pinpoint potential factors behind the lower average student engagement level value of prototype $\mathrm{P} 2{ }_{-} 1$ from the results recorded in section 8.3.2.

\subsubsection{Menus and learning content interface design}

Hierarchical learning content design was available in both P 2_1 and P2_2 prototypes. As a result, qualitative findings from all 24 participants were considered.

\section{Sub-menus interface design}

Unlike the first prototype design where learning content was arranged hierarchically using slide-out and dropped down interface menus, learning content in the second iteration prototype was arranged hierarchically using sub-menus (See figure 8.10a). Additionally, following the heuristics, these sub-menus included visual feedbacks (i.e., the background colour of the selected button would be greyed out) to help learners identify which menu they had previously accessed.

From the total of 24 participants, 23 of them visited every learning screen and only 1 participant skipped some learning screens.

- Among the 12 participants who used prototype P2_1: 
- Nine participants studied learning content in the order they were presented. That is to say, they accessed the first learning topic (i.e., the Internet) by visiting each of the given sub-menu in an orderly fashion before repeating the same behaviour for the second learning topic (i.e., the Internet security).

- Two participants did not learn according to the order that the learning content was presented. At first, they skipped some learning screens. However eventually they visited every learning screen they previously skipped once they started using some of the learning-support features (i.e., quiz games and assignments).

- One participants skipped some learning screens and did not return to study them.

- Among the 12 participants who used prototype P2_2:

- Eight of them learned the content in order.

- Four participants, despite visiting every learning screen, navigated back and forth between screens.

Compared to the first iteration prototype's hierarchical interface design (i.e., slide-out and dropdown menu), this sub-menu interface design proved to provide a better navigation experience. Most of the participants learned the content in an orderly fashion. As this sub-menu design allowed the learning topics to be easily visible and discoverable to participants and provided visual progress feedback, almost every participants visited all the learning screens. These results showed that this particular menu interface design could increase the possibility of learning content being consumed by the learners. 


\section{Pop-up interface design}

The pop-up interface design had already been observed in the first iteration evaluation. Based on the first iteration findings, some participants could not find the pop-up buttons, tapped on other incorrect areas multiple times, and these led them to skip some of the learning content hidden under the pop-up menu buttons.

In this second iteration evaluation, the pop-up interface design had been improved. There were pointer signs (See figure 8.10c) to encourage learners to click on the pop-up buttons. Additionally, the prototype designs eliminated all other interface design elements (such as redundant labels) that could confuse the participants.

As a result, from the total of 24 participants, 23 of them successfully opened every information window on the screen with the pop-up menu and studied all the learning content.

\section{Learning content interface design}

The assignments and quiz games seemed to be able to encourage participants to return and check the learning content they had previously skipped.

Despite showing some positive effects on participants' learning process and improving the usability of the first iteration interface design, the exclamation marks (i.e., !) provided within a learning screen (See figure $8.10 \mathrm{~b}$ ) seemed to confuse the participants. The signs were purposefully used to alert the participants that there were text boxes with multiple lines of text and scrolling would be required to read the entire passage. However the participants misunderstood and took that as signs that some actions were required and therefore they tapped on the signs multiple times. This raised a design awareness that the choice of signs and icons used in the application might lead to misunderstanding and should probably be replaced with some more direct messaging. 
Although the second iteration prototype had been evaluated by the experts, this usability issue was not uncovered. Therefore, based on this particular case, multiple rounds of heuristic evaluation might be required to ensure optimal usability design. 


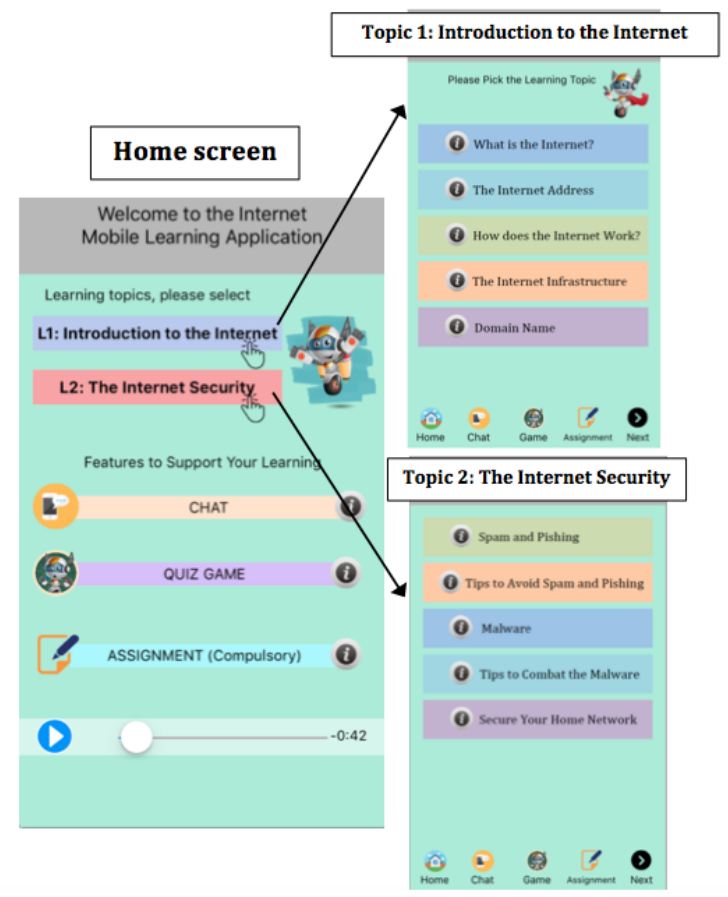

(a) Sub-menus interface design

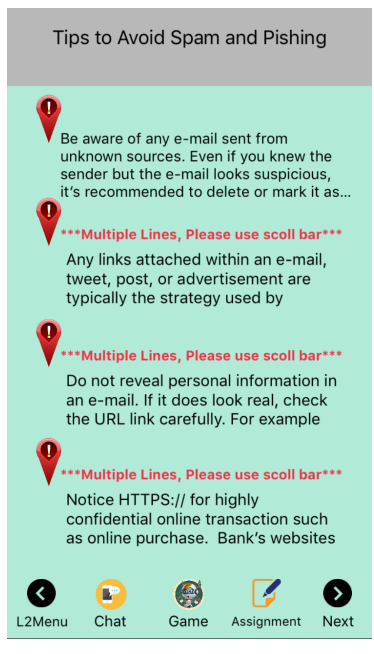

(b) Exclamation

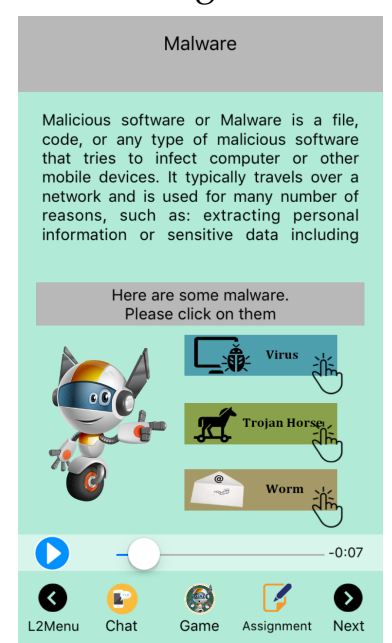

(c) Pop up

Figure 8.10: Learning content presentation 


\subsubsection{Media Presentation}

Audio recordings and animation videos were only available in the prototype P2_1. As a result, the qualitative findings related to these media were collected from the prototype evaluation results of the 12 participants assigned to use this prototype.

\section{Text media}

Text media was used in either pop-up information window or in text boxes. The font size of all text media was standardised throughout the application and was consistent with the size of text media used in the first iteration prototypes.

During the evaluation process, non of the participants made zooming gesture to view or highlight the text. 1 participant, who used prototype P2_1, copied some text from a learning screen and pasted them into the assignment answer. Overall, the participants were deemed to have encountered no difficulties in reading the provided text as it was without guidance. Additionally, all participants were able to scroll up and down each learning content screen and read all the text content.

\section{Animation video}

The second prototype provided two animation videos. Besides these videos, the participants could watch YouTube videos provided via external links from the in-app browser. The animation and YouTube videos introduced the learning topics and briefly explained the learning content.

The animation videos were purposefully included to engage and motivate learners at the beginning of the course. Hence, it was expected that the participants would watch the videos before they began studying the learning content. The YouTube videos were added to supplement the learning content with external learning resources. 
From a total of 12 participants who used prototype P2_1, every participants watched either the animation videos or the YouTube videos at least once:

- Three participants watched both animation videos in their entirety. However, none of them watched the videos before they started the learning process.

- Six participants watched only one animation video. Among these participants, three of them watched the video before they started their learning process. The audio recordings which accompanied these videos seemed to have encouraged these participants to watch the video.

- Three participants did not watch any of the provided animation videos. Instead, they watched the YouTube videos.

In the first iteration prototype, the participants rarely played the animation videos as they seemed unable to locate the play button for the videos. In this second iteration prototype design, this issue was addressed and the visibility of the play buttons was improved. However, the videos were still not watched by many participants at the beginning of the learning process.

Therefore, the videos should be considered as a secondary media to deliver learning content or information that were less material to the overall learning goals. Additionally, due to its nature of being a type of rich media, videos could be used to encourage and motivate learners but more persuasion might be required. Ultimately, when the course structure was flexible and learners could access any part of learning as they desired, it was a challenging task to design relevant videos for use at the beginning of the learning process. 


\section{Audio recordings}

There were eleven audio recordings available in the P2_1 prototype design. The recordings were used to guide the participants in using learning-support functions, encourage them to watch the animation videos, and suggest using the provided external resources if they needed more information. Therefore, audio control panels were available only on some of learning screens with these multimedia or features, whereas the learning screens with only text media did not have the control panel available.

From a total of 12 participants who used prototype P 2_1, only six of them listened to the audio recordings. These participants only listen to either one or two of the 11 provided audio recording files. Among these participants, two of them listen to the audio recording which encouraged them to play the animation video before they played it.

Based on these findings, similar to the video media, the audio recordings media should only be used as a secondary media to present non-critical learning content or information.

Compared to the first iteration prototype, the usage of this media seemed to have decreased. In this second iteration evaluation, the media was hardly the first media participants used prior to starting their learning process. This might be the result of several media and features being added and available from only one single learning screen (e.g, a learning screen presented text, an animation video, audio control panel, navigation bar, and some figures). As a result, participants' attention to each provided media and feature was divided and therefore reduced. 


\subsubsection{Learning-support features}

All learning-support functions proposed in chapter 6 were only made available in the $\mathrm{P} 2 \_1$ prototype. As a result, qualitative findings related to learning-support functions were collected from the prototype evaluation results of the 12 participants assigned to use this prototype.

\section{Chat}

The technical issue found in the first iteration evaluation was fixed in the second iteration prototype. Participants who used the chat function could now exit from the chat, continue their learning process, and no longer need to reset the application.

In this second iteration evaluation, this thesis' researcher took on the role of an instructor who replied to the chat. From a total of 12 participants, three of them used the chat function. Figure 8.11 shows all the chat conversations between the participants and the instructor. Among these participants, one of them used the chat to asked about the evaluation process (See figure 8.11a). One of the other participant asked for further clarification on the assignment (See figure 8.11b), while the remaining participant asked when $\mathrm{s} /$ he would receive the assignments' feedback (See figure 8.11c).

Additionally, it was observed that two participants had some positive dialogue quality as they showed positive acknowledgement. However, the participant who initiated dialogue about the assignment did not provide any further response to verify the quality of the dialogue. Based on these findings, the chat function in the second iteration prototype had some positive quality, which was similar to the first iteration prototype. 
From a total of 12 participants, all of them played the quiz game at least once. Among these participants, eight of them played both of the quiz games (one for each learning topic) while four of them played the quiz game for only one of the learning topic. Many participants played the game several times. It was also noted that they would play the game until they won. Additionally, in order to find the find the quiz games' answer, many participants went back to the learning content screen and re-check the learning content that they previously skipped.

\section{Assignment}

The assignments were compulsory. Every participants successfully submitted the assignments to the instructor via e-mail. Figure 8.12 and 8.13 present the questions and examples of answers for each of the assignment. Judging by the researcher's teaching background, all of the submitted answers were presented at an acceptable level, particularly as the second assignment was an analysis task. The participants were able to adequately explain their opinions and proved that they understood the given case study.

In addition to the observation on assignment submissions, there were three interesting findings on participants' interactions with the prototype:

1. The assignment questions presented in the assignment section of the prototype were also included as part of the answer e-mail template. This, as recommended in the heuristic design guidelines, helped participants recognised the assignment questions rather than recalling them from memory. Based on the observations, every participants scrolled up and down the screen to view the questions and case study when they were answering the assignments.

Compared to the first iteration evaluation when the participants had to exit from the e-mail template in order to check the question 


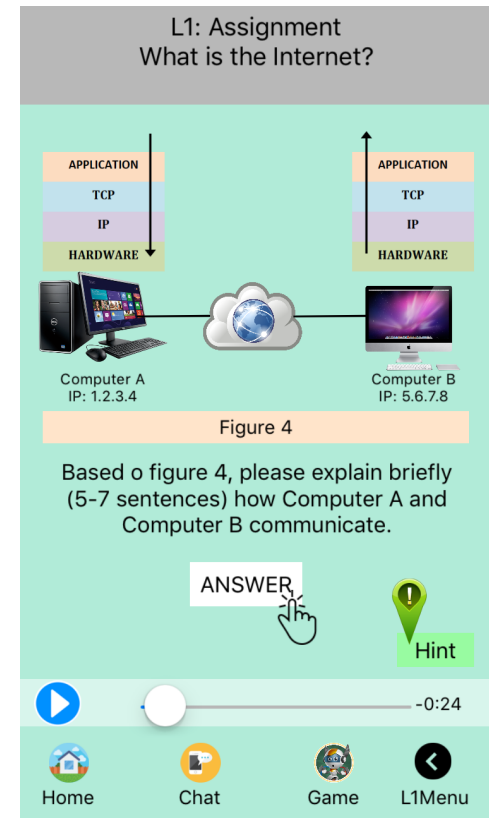

(a) Assignment 1

\begin{abstract}
The computer each have an ip adress. They then connect to a network. So that share the same language. They find each others IP address and transmit files. These files are divided into pieces called packets. The TCP and IP work together to send the file.
\end{abstract}

(c) Example answer 2

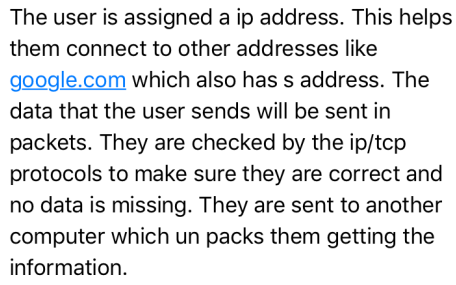
them connect to other addresses like google.com which also has s address. The data that the user sends will be sent in packets. They are checked by the ip/tcp protocols to make sure they are correct and no data is missing. They are sent to another computer which un packs them getting the information.

(b) Example answer 1

\begin{abstract}
When data from computer A reaches the IP zone, it gets converted into packets of information/data. TCP and IP ensure that there is little to no delay in sending these packets to computer B. This also "stamps" each packet with an IP address. Computer B then receives it and the packets are put back together in its original order.
\end{abstract}

(d) Example answer 3

Figure 8.12: Assignment 1 and some example answers

from the assignment screen, the second iteration assignment design provided more convenience.

2. There was a hint button available on the assignment question screen (See figure 8.12a and 8.13a). Almost every participants tapped on the hint button and followed the instructions given in the hint message. Therefore, this mechanism was deemed to be able to encourage and motivate participants to learn. 


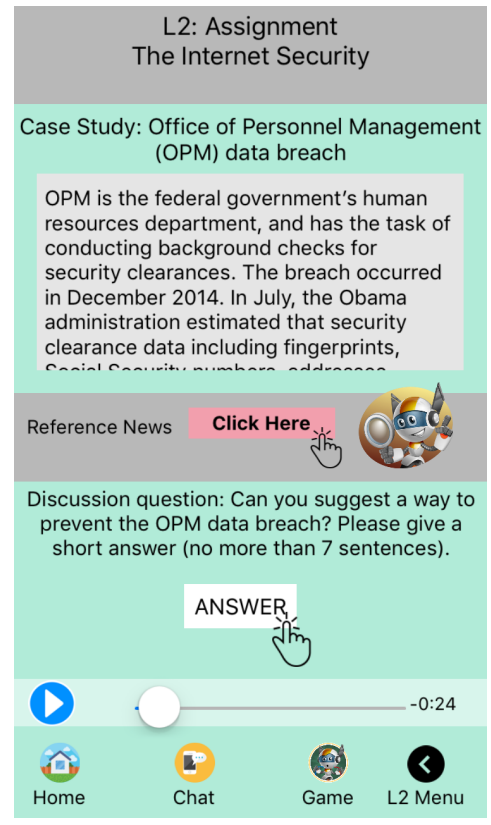

(a) Assignment 2

\begin{abstract}
The data could have been encrypted so that it would be harder to view. A 2 step sign in method could be used to make it harder to sign into an account. Firewalls could have been used to block harmful activity.
\end{abstract}

(c) Example answer 2
There could be separate credentials needed to access the personal information

Perhaps not use an outside contractor to do background investigations

And not give this contractor a log-in that has access to the personal information (if there was some way for them only to have the ability to add information, so that it can be handled directly by OPM, but not allow access to download or view existing data without extra clearance) The contractor will also need to have more secure ways of storing log in details with maybe a firewall

(b) Example answer 1

\begin{abstract}
To prevent the government being able to access your account is by not opening the emails. You could address the money taken from account with a government service. You could change the settings on router for your service set identifier and password. Logging out is essential as well, because it is important not to interrupt the routers firmware. That way it stays functional.
\end{abstract}

(d) Example answer 3

Figure 8.13: assignment 2 and some example answers

3. Participants seemed to have no problem typing on the virtual keyboard available on the provided smart phone. There was no significant typing error found.

\section{Self-check learning progress}

Of the total 12 participants, nine of them used this feature. Among these participants, six of them used this feature for both learning topics and the remaining three of them only used this for one learning topic. The final 
three participants did not visit this self-check screen.

This feature seemed to be able to help participants check their own learning progress for completeness. However, despite using this feature and discovering that they skipped some learning content, a few participants did not navigate back to learn what they skipped. Therefore, this feature had limited positive effects on learning encouragement.

\section{In-app browser}

Nine of the total 12 participants visited the in-app browser at least once to either learn by reading from the provided reference websites or by watching YouTube video. Most of the participants who used this feature used it to seek further information to answer the assignment questions. Therefore, this feature could be considered as an appropriate tool to accompany the assignment learning-support feature.

\subsubsection{Variants in the average engagement level value}

In section 8.3.2, the quantitative results indicated that there were some variants in the average student engagement level value, particularly for prototype P2_1 which had been divided into three clusters and one of the clusters (i.e., cluster 3) had a very different student engagement level value from the others. This section focused on observing the factors behind the emergence of the variants. Additionally, it sought aspects of usability design that could result in the lesser average student engagement level value for prototype P2_1.

For prototype P2_1, participant P7 belonged to cluster 3. P7 provided negative response with regards to average student engagement level value. Based on the video observation:

- Compared to other participants, P7 spent the longest time in the laboratory (i.e., 1 hour and 14 minutes) and most of the time was spent on completing the assignments. 
- P7 had used all provided media (i.e., read text, listen to some audio recordings, and watched an animation video), used chat to ask about the assignment, played both quiz games more than once.

- P7 did not use the self-check learning progress nor the in-app browser features.

- P7 seemed to be able to navigate through the prototype smoothly as $\mathrm{s} /$ he did not appear to exhibit actions indicating confusion when using the prototype, with the exceptions of some back-and-forth navigation between the assignment e-mail answer template and some learning screens.

Based on these findings, the assignments might be the cause behind participant P7's lower overall engagement level value.

For the remaining two clusters of prototype $\mathrm{P} 2{ }_{-} 1$ and the two clusters of prototype P2_2, all the participants exhibited similar behaviour when using the prototypes. Therefore there was no specific learning pattern found for each cluster.

\subsection{Limitations}

Although various technical and usability issues identified in the first iteration evaluation were resolved in the second iteration prototype, the second iteration evaluation still had some similar limitations found in the first iteration evaluation. The following list presents the issues resolved by the second iteration prototype and outlines the limitations of the second iteration evaluation.

1. Even though one academic course had been added to the recruitment list to increase the number of potential participants, as per the first iteration evaluation process, all participants from the second iteration evaluation were autonomous learners. Therefore 
the results and findings from this second evaluation process could not prove the part of TDT related to non-autonomous learning and that aspect remains unsolved by this thesis.

2. From a total 24 participants, 15 were male and 9 were female. The inequality in the number of male and female participants might be a factor that influenced the results and findings of this research. Additionally, the difference in the number of participants between the first and the second iteration (i.e., the first iteration evaluation had a total 21 participants: 18 were male and 3 were female) might also affect the usability results presented in section 8.3.5.

3. The second iteration evaluation was still conducted in a laboratory setting. Although the participants were verbally informed that they could spend as much time as they desired to use the prototype, the environment setting might still introduce a sense of time pressure to the participants. Additionally, identical to the limitation presented in the first iteration analysis, this setting would be different from an actual m-learning scenario where the learning would normally happen in a mobile and dynamic environment.

4. Despite providing many learning-support features, many of these features were not made compulsory in order to maximise the flexibility of the course structure (with the exception of the compulsory assignments). As a result, some participants only used some of the features and skipped some of the learning screens. Based on that result, this evaluation could only claim that participants who used prototype P2_1, which was developed according to the second iteration design guidelines and improved according to heuristic evaluation process, had used more than one type of media and had either direct (i.e., through chat room) or indirect (i.e., through quiz game feedback) dialogues with the instructor. 
5. Similar to the first iteration evaluation, there was no face-to-face debriefing to elucidate the results from the post-questionnaire. The engagement level results were based entirely upon the participants' self evaluation. Hence, there was likelihood of participants providing inaccurate results due to misunderstanding one or more questions within the post-questionnaire or selecting an incorrect ranking on the measurement scale.

6. Observation issues uncovered in the first iteration evaluation process whereby participants' movement had blocked the recording view was slightly improved during the second iteration evaluation. Less instances of such issue were found within the video recordings. However, there was a missing video recording file and the observation findings for this participant was instead collated from the statistical information gathered using Google Analytics.

7. In order to observe the third hypothesis presented in section 8.1, quantitative results collected from the first and second iteration evaluations were compared. However, the prototype designs from both iterations were quite different (e.g., learning topic, quantity of learning content, theme colour, quantity of learning-support features). These might affect the overall usability level value found in section 8.3.5.

\subsection{Results and Findings Analysis}

Results from the post-questionnaire indicated that a m-learning prototype designed to decrease transactional distance could not engage autonomous learners better than a prototype providing the same learning flexibility but had no other mechanisms to decrease transactional distance. These results implied that elements introduced to decrease transactional distance in the second iteration design guidelines, which contained improvements made 
to the first iteration design guidelines, could not better engage participants in this study.

However, this result was found to be statistically insignificant. Further investigations introduced the possibility that some variants in the average student engagement level value and the different learner autonomy levels of participants assigned to each prototype design could have affected and lowered the average student engagement level value for prototype P2_1.

1. For the variants in the average student engagement level value, the analysis highlighted a participant cluster for prototype P2_1 who responded very differently than other participants. However, his/her negative response was found to insignificantly decrease the overall average student engagement level value of prototype P2_1.

Qualitative findings indicated that this participant experienced no other usability problems when using the prototype, with the exception that $\mathrm{s} /$ he spent most of the time completing both assignments and went back and forth between the assignment screen, the e-mail answer template, and some learning screens. Additionally, S/he used the chat feature to ask for and received explanations regarding the assignments. However, s/he didn't provide any further affirmation to indicate the dialogue had sufficient positive quality to improve his/her understanding of the assignments. Based on the results and findings, the assignments were deemed to be a possible cause in the lower average student engagement level value for P2_1.

2. For the variance in the learner autonomy, the results indicated that the average learner autonomy of participants who used prototype P2_1 was lower than that for the participants who used prototype P2_2 although the difference in the average learner autonomy level value was not statistical significant.

As evident in the results and findings, prototype P2_1 which 
presented multimedia and several learning-supported features aiming to decrease transactional distance, helped the participants who were less autonomous to engage with prototype P2_1 as much as highly autonomous learners engaged with prototype 2_2 (even though P2_2 had no multimedia presentation neither learning-supported features).

When student engagement was further divided into six concepts. Results indicated that:

1. Prototype P2_1 received the best responses in terms of usability. Therefore, the heuristics incorporated into the second iteration design guidelines was deemed to have helped improve student engagement with regards to the usability.

2. Aesthetic was the engagement concept that received the worst response, particularly for prototype P2_1. However, in the first iteration evaluation results, that was not the case for the first iteration prototypes. This might be the effect of presenting multimedia and several learning-support features all on a single smart phone screen. For example, within a learning screen, there were figures, text media, navigation bar which included many icons at the bottom of the screen, a link button to an in-app browser, an audio control panel, and a button to play an animation video.

3. Novelty and felt involvement were the concepts that potentially lowered the average student engagement level value for prototype P2_1. This result was the direct opposite of the first iteration evaluation results. Additionally, the prototype provided many features allowing the participants to be involved with the learning process (i.e., quiz games and assignments), and therefore the participants were expected to feel a higher sense of involvement with the prototype design. 
When the post-questionnaires used to collect these engagement concept results were examined, the questions were mainly related to the learning tasks. Therefore the assignments were considered to have caused the negative response to the novelty and felt involvement concepts, as well as reducing the overall student engagement level value for prototype P2_1.

\subsection{Summary}

The second iteration prototype evaluation used an identical evaluation process as the first iteration prototype evaluation.

Results indicated that the m-learning prototype designed to decrease transactional distance could not engage autonomous learners better than a prototype providing the same learning flexibility but had no other mechanisms to decrease transactional distance. However, further investigation discovered that this result might have been affected by numerous variants, such as the assignment learning-support feature and the difference in learner autonomy among participants assigned to each of the prototype. These variants could have reduced the average student engagement level value. As a result, the principles of TDT were still deemed to be applicable to guide the design of m-learning in this study.

Correlation analysis was again used to observe the second hypothesis. The results were consistent with the first iteration evaluation results and verified that there was weak correlation between learner autonomy and student engagement.

Additionally, the usability concept, one of the six concepts of student engagement measured in the post-questionnaire, was used to observe the third hypothesis. Although the quantitative results relating to this concept was found to be statistically insignificant, the second iteration prototypes had a higher usability level value compared to the first iteration prototypes. 
Ultimately, the qualitative findings confirmed that the multimedia and learning-support features were functionally effective. These indicated that the heuristic evaluation help improve the usability of the m-learning prototype. 



\section{Chapter 9}

\section{Conclusion}

This chapter summarises the thesis, answers the three research questions posed in chapter 1 , and describes the thesis' three major contributions to the field of m-learning. By placing these contributions into the context of related works discussed in chapter 2, this chapter briefly reviews how the design guidelines developed in this thesis fit within the software engineering taxonomy. Ultimately, this thesis presents considerations and possible future approaches for m-learning application design guidelines.

\subsection{Contributions}

This thesis makes three contributions to m-learning:

1. Draws on TDT to contribute new design knowledge with emphasis on the concept of dialogue, course structure, and learner autonomy, which can be incorporated into the design and evaluation process of m-learning applications.

2. Develops new proof-of-concept prototypes for m-learning application based on learning principles and empirical studies to ensure learning engagement. 
3. Presents a critique towards the appropriateness, ability, and possibility of TDT in guiding the design of modern education platform such as m-learning.

\subsubsection{Critique towards TDT}

The principles of TDT proposed in its original distance education context can be applied to develop the design guidelines of the modern education platform such as m-learning applications. Additionally the prototypes developed using such guidelines have been observed to assist student engagement.

However, there are many challenges to develop such design guidelines. Firstly, TDT is originally proposed within the field of distance learning. As a result, it needs some modifications for the theory to be applicable to the modern m-learning environment. On the other hand, there is insufficient literature to fully guide such modifications. Secondly, the theory provides only high-level guidelines. In order to furnish the guidelines with sufficient details for use in application design, TDT has to be complemented by other learning theories and interface design guidelines, particularly to address the lack of usability guidance. Ultimately, the elements of the theory are explained using only two level of intensities (e.g., autonomous versus non-autonomous learners and flexible versus inflexible course structure). However, these elements can be defined in multiple levels. For example in chapter 5 and 8, the autonomous target learners were found to have varying levels of autonomy.

\subsubsection{M-learning design guidelines}

Drawing on TDT, this thesis presents a new proposed set of m-learning design guidelines. 


\section{First Iteration}

TDT is a distance learning theory. It introduces transactional distance as a learner's perception of isolation due to communication barriers and learning difficulties that arise when the learners are physically separated from their teachers and need to control their own learning process. Furthermore, it points out that as transactional distance increases, learning quality will decrease. TDT also identifies three elements that vary the transactional distance: dialogue, course structure and learner autonomy. The course with the least transactional distance is one which provides dialogue opportunities and has a flexible course structure. On the other hand, the course with the highest transactional distance is one that has no dialogue opportunities and has an inflexible course structure.

In order to address the learner autonomy element, learners are first assessed and categorised in a spectrum of autonomy based on their ability to set their own learning goals, implement their learning process, and evaluate learning outcomes and acquired knowledge. TDT suggests that autonomous learners have the ability to learn through having less dialogues with their teachers and they prefer flexible course structure to maximize their autonomy. On the other hand, non-autonomous learners requires more dialogues with their teachers and they prefer appointed course structure to help them progress their learning.

Based on these principles to minimise the transactional distance, a set of proposed m-learning application design guidelines were drawn to provide dialogue opportunities to learners using a course structure that suited their learner autonomy.

Next, in order to furnish the guidelines with more concrete details, they were supplemented by the 6 instructional processes:

- Presentation

- Motivation

- Stimulation of analysis and criticism 
- Advice and consolation

- Practice and evaluation

- Creation of knowledge

As well as other learning theories:

- Media richness theory

- Self-determination theory

- Cognitive load theory

- Learning theory of andragogy

- Activity theory and cultural-historical activity theory

To ensure the application design's usability, the eight golden rules of interface design were added into the guidelines.

The resulting design guidelines were used to develop a m-learning prototype, which was then evaluated for its ability to engage learners. The observation findings were then used to guide the improvements to, and re-development of the guidelines and prototype for a second iteration.

\section{Second Iteration}

In the second iteration of guidelines development, this thesis added new set of heuristics for m-learning developed from the combination of heuristics for general interactive systems, e-learning, and mobile devices.

To test the applicability of the new set of heuristics, they were used to evaluate against the first iteration prototype. As the heuristics were able to isolate the same usability issues found during the first iteration evaluation, they were deemed applicable in predicting potential usability issues in m-learning application. The heuristic evaluation and heuristics 
were then incorporated into the guidelines. This formed the second design guidelines.

The second design guidelines were used to develop the second version of m-learning application prototype, which was then evaluated for its applicability to engage learners.

\subsubsection{Proof-of-concept prototype design}

The second contribution of this thesis is a set of proof-of-concept prototypes and empirical studies to measure learning engagement.

\section{The first prototype development and evaluation}

The first prototype design was developed from the first iteration design guidelines and was evaluated for its ability to engage target learners.

At the initial stage of the prototype development, this thesis presents a user study which observes target learners (i.e., first year engineering and computer science student learners from the Victoria University of Wellington) using an online-based questionnaire to collect their motivation and experience on m-learning, presentation media and learning tasks that are often found on mobile devices. To define the scope of this study, presentation media and learning tasks were chosen based on the developed guidelines.

The gathered quantitative results were manipulated using two-separate and independent statistical analysis techniques. One was the statistical technique K-means clustering, which was a common practice used to cluster participants. On the other hand, this thesis proposed a new clustering technique named graphical clustering as a trial technique. After the clustering, qualitative findings gathered from the questionnaire were used to form the persona's profile. The persona development process presented in this thesis and the clustering techniques in particular, can be used as a model for carrying out further 
user studies.

Despite having some similarities in the profiles of personas created using both techniques, there were some concerns towards the graphical clustering technique as it neglected many of the participants. As a result, a primary persona created using the K-means clustering technique was chosen as a persona to represent the target learners. Based on the persona's profile, the target learners were assumed to be autonomous learners.

The first prototype was developed for these autonomous learners using a variety of multimedia to present learning content (i.e, text, recording-audio, and an animation video) and providing many learning-support features (i.e., chat, quiz game, and compulsory assignment). The learning content was presented hierarchically in various dropdown and side-slide menus as well as through pop-ups design interface.

The evaluation process began by measuring these target learners' autonomy. Based on the results and observation findings, all participants were observed to be autonomous learners.

Participants were then randomly selected to use either prototype P1_1 or P1_2. The prototype P1_1 was designed based on the design guidelines whilst the prototype P1_2 lacked most of the presentation media (i.e., recording audio and animation video) and did not have any learning-support features (i.e., chat, quiz game, and compulsory assignment).

Furthermore, each participant had full control over the prototype (i.e., a flexible course structure is provided). Therefore, all media and features were used according to each target learner's demand. Their evaluations were captured on video. Finally, student engagement was measured using a post-questionnaire (i.e., developed in this thesis from past literature).

Additionally, the video recordings of each participant's interaction with the prototype were reviewed. Observation findings indicated that 
all of the provided media and learning-support features were applicable and useful for the m-learning prototype. However, there were some usability issues. For example, some participants missed some of the learning content because they could not find the menu buttons. Some of them did not get to watch the video because they could not find the play button for the video player. If participants used the chat feature, they would need to reset the application to exit from the chat and restart the application to continue with their learning process.

Despite these usability issues, it had been statistical confirmed that participants engaged with the prototype P1_1 more than the prototype design P1_2. These results implies that the developed guidelines has the ability to engage participants.

\section{The second prototype development and evaluation}

Due to identified usability issues, the first iteration design guidelines were analysed. The analysis found that these usability issues would have been predicted if the guidelines provided more details to guide the interface design. Therefore, further improvements were made on the interface design to improve the prototype's usability.

In the second iteration, the second design guidelines were used to develop the second prototype. As the presentation media and learning-support features provided in the previous prototypes were found to be feasible and applicable for evaluating the effectiveness of TDT, they were re-used again in the second prototype design. Furthermore, to improve the application's usability, two extra features were added to the prototype: the self-check progress and in-app browser with links to external reference resources. Finally, the learning content was also presented in a more obvious menu-based format and the number of learning topic was increased from one to two. As the quantity of learning content increases, the number of learning-support features were also increased accordingly (i.e., providing two quiz games and two 
compulsory assignments). Additionally, the second prototype had undergone heuristic evaluation to observe its usability before being released for use by the target learners.

The same evaluation process from the first iteration was utilised for the second iteration evaluation. Once again, the recruited participants were observed to be autonomous learners. However, both versions of the second prototype were found to be able to engage participants almost equally due to some variants.

Other than the overall student engagement, the second iteration evaluation also collected usability results from the post-questionnaire (i.e., usability is one of the six concepts of engagement measured in the questionnaire). Compared to the first iteration, the usability of the prototype had improved. Additionally, the video observation findings also supported the quantitative results as no obvious usability issue was found. Such results imply that the heuristic evaluation incorporated into the design guidelines had contributed to usability improvement.

The gathered quantitative results of learner autonomy and student engagement were used to calculate correlation coefficient. Both iterations' coefficient results indicate that there was a weak correlation between learner autonomy and student engagement.

\subsection{Response to research questions}

M-learning design guidelines developed based on the principles of TDT and the proof-of-concept design guidelines helped answer all three thesis questions proposed in chapter 1 .

1. Can TDT principles be used to construct design guidelines that will affect student engagement on m-learning education application?

TDT principles can be used to construct design guidelines of $\mathrm{m}$-learning education application and they were observed to assist 
with student engagement.

2. Can m-learning heuristics usability be used to complement TDT-based design guidelines and affect student engagement?

Heuristic evaluation and the m-learning heuristics can be used to complemented TDT-based design guidelines and they are observed to assist student engagement with regards to usability.

3. Is there any correlation between learner autonomy and student engagement?"

There is a weak correlation between learner autonomy and student engagement.

\subsection{Comparison with related works}

This thesis proposes new design guidelines for m-learning applications grounded on the principles of a learning theory. The guidelines have shown that m-learning applications designed based on the guidelines have the potential to engage learners. However, this thesis does not solve the hardware and software limitations of mobile applications discussed in chapter 2. On the other hand, the guidelines can help institutions and developers design effective m-learning applications within the boundaries of such limitations.

M-learning faces further design challenges due to the lack of design guidelines and best practices available for researchers to draw upon. The design guidelines developed in this thesis can be used for that purpose and the proof-of-concept prototypes can be the evidential bases for future development of m-learning application design best practice.

Undeniably, as m-learning is a subset of e-learning and e-learning is a sub-set of distance education, some parts of the newly developed design guidelines overlapped with existing e-learning and distance learning 
design guidelines. However, the proposed design guidelines are unique in the sense that they are well grounded on a learning theory to ensure learning effectiveness. Additionally, compared to existing e-learning and distance education design guidelines, these new guidelines are able to address specifically the mobility characteristics of m-learning. Ultimately, comparing to existing design guidelines for mobile learning, the new guidelines have also encompassed the pedagogical aspect of learning.

The combination of heuristics proposed in this thesis is new to m-learning and has catered for both the pedagogical and mobility aspects of m-learning, which differentiates it from other exiting heuristic for e-learning and general mobile devices. The new heuristic for m-learning can also be used as an interface design guidelines for developers to ensure their applications' usability or as an inspection checklist for evaluators during heuristic evaluations.

\subsection{Future Work}

This section proposes some possible future works in areas that have remained unproven and unresolved by this thesis.

\subsubsection{M-learning design guidelines}

In this thesis, the developed m-learning design guidelines from two iterations had been evaluated on their effectiveness to enhance student engagement of autonomous learners. In contrast, the principles of TDT where non-autonomous learners may benefit from using an m-learning application with dialogue opportunities and an inflexible course remain unproven by this thesis as all participants from this research were autonomous learners. To recruit non-autonomous learners, researchers can either invite student learners from other faculties or from a different education level (i.e., this study recruited participants from the School of 
Engineering and Computer Science and they were first year tertiary students).

To observe the developed guidelines for non-autonomous learners in the future, the dialogue-support features of the prototype can be designed in a similar fashion as this thesis. However, the course structure of the prototype must be inflexible. To design an inflexible course structure, researchers can either restrict access to some learning screens based on learners' progress through the course content (e.g, design a prototype that does not allow participants to access the assignment screen if they have not yet played the quiz game at least once) or schedule the learning process for the participants (e.g, schedule them to spend 10 minutes on each learning screen before enabling their access to the next learning screen).

The hypothesis to observe the applicability of the guidelines for non-autonomous learners can be:

A m-learning prototype designed to decrease transactional distance can engage non-autonomous learners better than a prototype providing the same inflexible course structure but has no other mechanism in place to decrease transaction distance

Additionally, non-autonomous participants should be observed for their use of the dialogue feature to verify if they frequently contact their teachers and therefore align with the principle of TDT where non-autonomous learners are found to rely on dialogue to progress their learning.

Ultimately, the range of learners autonomy in this study was narrow (i.e., the participants had similar average autonomy level value). If future research studies can recruit participants with a wider range of autonomy levels, the correlation between learners autonomy and student engagement should be re-considered. 


\subsubsection{Mobility}

This research study conducted the two evaluation iterations in a laboratory setting which allowed the participants to learn in a stable environment. This differs from a real-life scenario when an m-learning application would actually be used in a dynamic environment and learners would be disturbed by the surroundings. Additionally, the laboratory environment might inadvertently introduce the feeling of time pressure to participants and they might feel conscious of being video-recorded. These factors might affect the overall engagement results and influence the observation findings. Therefore, future research studies can consider conducting the evaluation using field study to maximise the mobility aspect of m-learning. This can be achieved by lending the smart phone to participants and allowing them to learn using the prototype whenever and wherever they want for a set duration. Additionally, researchers can ask participants to write diary entries to collect qualitative results.

\subsubsection{Guidelines improvement}

The newly developed design guidelines presented in this thesis can be improved by adding further information to help direct developers. For example, the guidelines suggest providing "a variety of presentation media to learners" and the media richness theory has proved that high richness media is not appropriate for learning content that are simple and concrete in nature. It also points out that the use of too much media can be detrimental and can distract learning. Future research study can help enhance these guidelines by, for example, including best practice guidelines on the optimal amount of text media to be presented on the screen of mobile devices to avoid learners feeling worn out from reading or the ideal duration for an animation video to sustain learners' attention focus and maintain their engagement. 


\subsection{Summary}

In summary, this thesis has contributed: new design knowledge and heuristics with emphasis on the principles of TDT which can be incorporated into the design and evaluation process of m-learning applications; new proof-of-concept prototypes for m-learning applications based on learning principles and empirical studies to ensure learning engagement; a critique towards the appropriateness, ability, and possibility of TDT in guiding the design of modern education platform such as m-learning. These newly proposed knowledge are still in their infancy but can provide opportunities for future improvement and further studies to more firmly establish their possibility, applicability, and effectiveness. Ultimately, all of the above contributions will help institutions and developers design effective m-learning courses and applications for learners. 


\section{Appendix}

Approved HEC Applications

and Data Collection Documents 
MEMORANDUM

Phone 0-4-463 5676

Fax 0-4-463 5209

Email_Allison.kirkman@vuw.ac.nz

\begin{tabular}{l|l}
\hline TO & Pakapan Limtrairut \\
\hline COPY TO & $\begin{array}{l}\text { Stuart Marshall } \\
\text { Peter Andreae }\end{array}$ \\
\hline FROM & Dr Allison Kirkman, Convener, Human Ethics Committee \\
\hline
\end{tabular}

\begin{tabular}{l|l}
\hline DATE & 28 March 2015 \\
\hline PAGES & 1 \\
\hline
\end{tabular}

\begin{tabular}{l|l}
\hline SUBJECT & $\begin{array}{l}\text { Ethics Approval: } \mathbf{2 1 6 1 5} \\
\text { Mobile Learning for Computer Engineering Students: A } \\
\text { Transactional Distance Perspective }\end{array}$ \\
\hline
\end{tabular}

Thank you for your application for ethical approval, which has now been considered by the Standing Committee of the Human Ethics Committee.

Your application has been approved from the above date and this approval continues until 31 March 2017. If your data collection is not completed by this date you should apply to the Human Ethics Committee for an extension to this approval.

Best wishes with the research.

Allison Kirkman

Human Ethics Committee 


\section{MEMORANDUM \\ Phone 0-4-463 5480 \\ Email susan.corbett@vuw.ac.nz}

\begin{tabular}{l|l}
\hline TO & Pakapan Limtrairut \\
\hline COPY TO & Dr Stuart Marshall \\
\hline FROM & AProf Susan Corbett, Convener, Human Ethics Committee \\
\hline DATE & 24 March 2017 \\
\hline PAGES & 1 \\
\hline & $\begin{array}{l}\text { Ethics Approval: } 21615 \\
\text { Mobile Learning for Computer Engineering Students: A } \\
\text { Transactional Distance Perspective }\end{array}$ \\
\hline
\end{tabular}

Thank you for your request to extend your ethics approval. This has now been considered and the request granted. Your application approval has been extended until 30 September 2017.

If your data collection is not completed by this date you should apply to the Human Ethics Committee for an extension to this approval.

Best wishes with the research.

Kind regards

Susan Corbett

Convener, Victoria University Human Ethics Committee 


\section{Participant Information Sheet}

As part of completing a $\mathrm{PhD}$ into mobile learning, we are conducting a study to gather users' demographic data, goals, behavior, and attitude toward distance learning on mobile devices. You will be asked to answer a questionnaire. We have approval from the Human Ethics Committee of Victoria University of Wellington.

I am inviting the 1st year students from School of Engineering and Computer Science to participate in this research. Participation is voluntary, your name will be kept confidential. We will use a pseudonym for you in any written report produced as a result of this research, including possible publication in academic conferences and journals. This thesis will be submitted for examination and subsequently deposited in the University Library.

All written material will be kept in a locked file, all electronic information will be password-protected, and will be viewed only by myself and my supervisors Dr. Stuart Marshall, and Dr. Peter Andreae. All questionnaires will be destroyed within a year after the completion of the project.

We will draw five names out of a hat, and give a voucher to each winning participant.

If you have any questions or would like to receive further information about the project, please contact me at lili.limtrairut@ecs.vuw.ac.nz.

Thank you for participating in this survey

I have read and understand the research the research information supplied above

Y Yes

Please give us your e-mail address for a chance to win a voucher

What is your gender?

Male

Female

Age 
About how often have you done each of the following?

$\begin{array}{lccccc}\text { Using your mobile } & \text { Never } & \text { Rarely } & \text { Sometimes } & \text { Often } & \text { All of the Time } \\ \begin{array}{l}\text { phone daily for things } \\ \text { other than calls and texts }\end{array} & 0 & 0 & 0 & 0 & \bigcirc \\ \begin{array}{l}\text { Using your mobile } \\ \text { phone for education } \\ \text { purpose }\end{array} & 0 & 0 & 0 & 0 & 0\end{array}$

Please list, and briefly explain the activities that you perform on your mobile phone other than calling and texting.

How would you describe mobile learning?

What is your goal of learning on mobile phone?

Please briefly explain how you use your mobile phone to support your learning.

In your experience using a mobile phone, about how often have you done each of the following?

$\begin{array}{lccccc}\begin{array}{l}\text { Reading long text such as an on- } \\ \text { line article from the screen of } \\ \text { mobile phone }\end{array} & \text { Never } & \text { Rarely } & \text { Sometimes } & \text { Often } & \begin{array}{c}\text { All of the } \\ \text { time }\end{array} \\ \begin{array}{l}\text { Using a scroll-up and scroll-down } \\ \text { bar to go through text }\end{array} & 0 & 0 & 0 & 0 & 0 \\ \begin{array}{l}\text { Using zoom-in and zoom-out to } \\ \text { read text }\end{array} & 0 & 0 & 0 & 0 & 0 \\ \begin{array}{l}\text { Playing video on mobile phone } \\ \text { Pld }\end{array} & 0 & 0 & 0 & 0 & 0\end{array}$


Using play, pause, rewind, fast forward, or repeat functions of video player

Listening to recorded voice or music on mobile phone

Using play, pause, rewind, fast forward, or repeat functions of music player

Playing game on mobile phone

Sending/Receiving e-mail on mobile phone

Text chatting on mobile phone

Doing homework/assignment on mobile phone

$\begin{array}{ccccc}\text { Never } & \text { Rarely } & \text { Sometimes } & \text { Often } & \begin{array}{c}\text { All of the } \\ \text { time }\end{array} \\ 0 & 0 & 0 & 0 & 0 \\ 0 & 0 & 0 & 0 & 0 \\ 0 & 0 & 0 & 0 & 0 \\ 0 & 0 & 0 & 0 & 0 \\ 0 & 0 & 0 & 0 & 0 \\ 0 & 0 & 0 & 0 & 0\end{array}$

Please indicate how strongly agree or disagree with the following statements

$\begin{array}{ccccc}\begin{array}{c}\text { Strongly } \\ \text { Disagree }\end{array} & \text { Disagree } & \text { Neutral } & \text { Agree } & \begin{array}{c}\text { Strongly } \\ \text { Agree }\end{array} \\ 0 & 0 & 0 & 0 & 0 \\ 0 & 0 & 0 & 0 & 0 \\ 0 & 0 & 0 & 0 & 0 \\ 0 & 0 & 0 & 0 & 0 \\ 0 & 0 & 0 & 0 & 0 \\ 0 & 0 & 0 & 0 & 0 \\ 0 & 0 & 0 & 0 & 0 \\ 0 & 0 & 0 & 0 & 0 \\ 0 & 0 & 0 & 0 & 0 \\ 0 & 0 & 0 & 0 & 0 \\ 0 & 0 & 0 & 0 & 0\end{array}$

Mobile phone has helped me in my learning process

I prefer learning on a mobile phone rather than learning on a laptop or a desktop computer

I prefer learning by watching a video on a mobile phone rather than reading text on a mobile phone

I prefer learning by listening to a recorded voice on a mobile phone rather than reading text on a mobile phone

I like game based learning activities

I feel frustrated typing on small key board of a mobile phone

Assignments help me to improve my learning

I prefer doing an assignment on a computer rather than writing on actual paper

Keeping in touch with my instructor can encourage me to learn

I prefer sending an e-mail or a message to my instructor rather than having a face-to-face conversation

I prefer having synchronous rather than asynchronous communication with instructor 


\section{Participant Information Sheet}

Pakapan Limtrairut

PhD Student

Lili.limtrairut@ecs.vuw.ac.nz

Dr. Peter Andreae

Senior Lecturer

peter.andreae@ecs.vuw.ac.nz
Dr. Stuart Marshall

Senior Lecturer

stuart@ecs.vuw.ac.nz

School of Engineering and Computer Science

Victoria university of Wellington

\section{Research Project Title: Mobile Learning for Computer Engineering Students: A Transaction Distance Perspective}

As part of completing my $\mathrm{PhD}$, this study is designed to explore distance education context, with a particular focus on the observation of mobile learning designed to potentially enhance student engagement. We have developed a mobile learning application on a smartphone. Participants will be asked to perform several learning activities. The activities may include reading through learning content (Engineering Ethics), playing games, contacting an instructor, and working on an assignment. Your performance will be analyzed. Victoria University requires, and has granted, approval from the Human Ethics Committee.

Participants will be asked to take part in a 60 minute evaluation. The valuation will be conducted within VUW laboratory setting. The evaluation methods are answering paper-based questionnaires, recording a video only on the smart phone screen (Your face will not be shown), Google analytic service offered by Google that informs statistic information, and chat conversation may be kept in a server running on VUW system. Permission will be asked to record the performance, and the recorded video will be sent to participants upon request. Participants will be notified that the performance is being tracked on Google analytic and chat conversation may be kept in a server. All written material will be kept in a locked file, all electronic information will be password-protected, and will be viewed only by myself and my supervisors Dr. Stuart Marshall, and Dr. Peter Andreae.

I am inviting the $1^{\text {st }}$ year engineering students from School of Engineering and Computer Science to participate in this research. You will learn about Engineering Ethic. We will draw names out of a hat, and give a voucher to each winning participant in a manner similar to spot prizes at a sporting event. We will also develop a metric for achievement, and provide a voucher to the highest achieving participant, to encourage serious participation. 
Participation is voluntary, your name will be kept confidential. We will use a pseudonym for you in written report produced as a result of this research, including possible publication in academic conferences and journals. A soft-copy of any publish work based on this study will be sent to participants upon request.

The thesis will be submitted for marking to the School of Engineering and Computer Science and subsequently deposited in the University Library. Should any participant wish to withdraw from the project, they may do so before $1^{\text {st }}$ June 2016, and the data collected up to that point will be destroyed. All questionnaires will be destroyed and all video recording will be electronically deleted within a year after the completion of the project.

If you have any questions or would like to receive further information about the project, please contact me, my supervisors Dr. Stuart Marshall, or Dr. Peter Andreae at the details supplied above. 


\section{Participant Consent Form}

Pakapan Limtrairut

PhD Student

lili.limtrairut@ecs.vuw.ac.nz

Dr. Peter Andreae

Senior Lecturer

peter.andreae@ecs.vuw.ac.nz
Dr. Stuart Marshall

Senior Lecturer

stuart@ecs.vuw.ac.nz

School of Engineering and Computer Science

Victoria university of Wellington

\section{Research Project Title: Mobile Learning for Computer Engineering Students: A Transaction Distance Perspective}

I have been given and have understood an explanation of this research project. I have had an opportunity to ask questions and have them answered to my satisfaction. I understand that I may withdraw myself (or any information I have provided) from this project within a month after this evaluation without having to give reasons.

I understand that any information I provide will be kept confidential to the researcher, and the supervisors. I understand the published results will not use my name, and that no opinions will be attributed to me in any way that will identify me. I understand that the video recording of my performance on m-learning application will be wiped out within a year after the completion of the project.

\section{Please tick and sign}

I consent to information or opinions that I have given being presented in publicly available material

I consent to my interaction with the device being video recorded

I consent to my interaction with the device being tracked with Google analytic

I consent to my chat conversation on the application being kept in a server running on VUW system

I would like to be e-mailed a soft-copy of the video recording of my performance

I would like to be e-mailed a soft-copy of any published work based on this study

Signed:

Name of participant:

e-mail address (optional):

Date: 
Pre-Questionnaire

This pre-questionnaire measures your motivation and confidence of using mobile learning application and its features. Please fill up you answer in the given space or $\checkmark$ in the given box that indicates how much you agree with the given statements.

Section 1: Participant Information

Age:

Gender:

Male Female Other

Section 2: Motivation

Please choose how much you agree with the given statement

\begin{tabular}{|c|c|c|c|c|c|}
\hline Item & $\begin{array}{l}\text { Strongly } \\
\text { Disagree } \\
\end{array}$ & Disagree & $\begin{array}{l}\text { No } \\
\text { Opinion }\end{array}$ & Agree & $\begin{array}{l}\text { Strongly } \\
\text { Agree }\end{array}$ \\
\hline \multicolumn{6}{|l|}{ 1. When I learn new things, I attempt to understand them } \\
\hline \multicolumn{6}{|l|}{$\begin{array}{l}\text { 2. When I learn new things, I connect them to my previous } \\
\text { experience }\end{array}$} \\
\hline \multicolumn{6}{|l|}{$\begin{array}{l}\text { 3. When I do not understand the lesson, I find relevant } \\
\text { resources that will help me }\end{array}$} \\
\hline \multicolumn{6}{|l|}{$\begin{array}{l}\text { 4. When I do not understand the lesson, I would discuss } \\
\text { with the instructor, or other students to clarify my } \\
\text { understanding }\end{array}$} \\
\hline \multicolumn{6}{|l|}{$\begin{array}{l}\text { 5. During the learning process, I attempt to make } \\
\text { connections between the concepts that I learn. }\end{array}$} \\
\hline \multicolumn{6}{|l|}{ 6. When I make a mistake, I try to find out why } \\
\hline \multicolumn{6}{|l|}{$\begin{array}{l}\text { 7. When I find something that I do not understand, I still } \\
\text { try to learn them }\end{array}$} \\
\hline \multicolumn{6}{|l|}{$\begin{array}{l}\text { 8. When new lesson that I have learned conflict with my } \\
\text { previous understanding, I try to understand why }\end{array}$} \\
\hline \multicolumn{6}{|l|}{$\begin{array}{l}\text { 9. I think learning engineering ethic is important because I } \\
\text { can use it in my future professional life }\end{array}$} \\
\hline \multicolumn{6}{|l|}{$\begin{array}{l}\text { 10. I am willing to learn on a mobile phone because it } \\
\text { allows me to learn anywhere remotely }\end{array}$} \\
\hline $\begin{array}{l}\text { 11. I am willing to use mobile learning application because } \\
\text { it allows me to manage my own learning schedule }\end{array}$ & & & & & \\
\hline
\end{tabular}


Section 3: Confidence

Please choose how much you agree with the given statement

\begin{tabular}{|c|c|c|c|c|c|}
\hline Item & $\begin{array}{l}\text { Strongly } \\
\text { Disagree }\end{array}$ & Disagree & $\begin{array}{l}\text { No } \\
\text { Opinion }\end{array}$ & Agree & $\begin{array}{l}\text { Strongly } \\
\text { Agree }\end{array}$ \\
\hline $\begin{array}{l}\text { 1. I could complete m-learning if there was no one } \\
\text { around to tell me what to do as I go }\end{array}$ & & & & & \\
\hline $\begin{array}{l}\text { 2. I could complete m-learning if I had never used it } \\
\text { before }\end{array}$ & & & & & \\
\hline $\begin{array}{l}\text { 3. I could complete m-learning if I had only the } \\
\text { manual for reference }\end{array}$ & & & & & \\
\hline $\begin{array}{l}\text { 4. I feel confident that I can learn by reading a long } \\
\text { text on a mobile phone }\end{array}$ & & & & & \\
\hline $\begin{array}{l}\text { 5. I feel confident that I can learn by listening a pre- } \\
\text { recorded voice on a mobile phone }\end{array}$ & & & & & \\
\hline $\begin{array}{l}\text { 6. I feel confident that I can learn by watching a } \\
\text { learning video on a mobile phone }\end{array}$ & & & & & \\
\hline $\begin{array}{l}\text { 7. I feel confident that I can play a learning game on a } \\
\text { mobile phone }\end{array}$ & & & & & \\
\hline $\begin{array}{l}\text { 8. 7. I feel confident that I can chat with someone on } \\
\text { a mobile phone }\end{array}$ & & & & & \\
\hline $\begin{array}{l}\text { 9. I feel confident that send and receive an e-mail } \\
\text { using a mobile phone }\end{array}$ & & & & & \\
\hline
\end{tabular}


Section 4: Knowledge and Skills

\begin{tabular}{|c|c|c|c|}
\hline Tasks & Supported Learning & Instruction & Observation Note \\
\hline $\begin{array}{l}\text { 1. Connecting a } \\
\text { mobile phone } \\
\text { to an available } \\
\text { Wi-Fi }\end{array}$ & $\begin{array}{l}\text { Learners can contact } \\
\text { their supervisor using a } \\
\text { chat feature, submit an } \\
\text { assignment, and receive } \\
\text { feedbacks through an e- } \\
\text { mail. }\end{array}$ & $\begin{array}{l}\text { Please connect the given mobile } \\
\text { phone to an available Wi-Fi name } \\
\text { "victoria" }\end{array}$ & \\
\hline $\begin{array}{l}\text { 2. Opening a } \\
\text { web browser }\end{array}$ & $\begin{array}{l}\text { Learners can seek for } \\
\text { more information } \\
\text { available online. }\end{array}$ & $\begin{array}{l}\text { Please open a web browser } \\
\text { (safari) and open } \\
\text { www.google.co.nz }\end{array}$ & \\
\hline $\begin{array}{l}\text { 3. Sending an } \\
\text { e-mail }\end{array}$ & $\begin{array}{l}\text { Learners can } \\
\text { communicate with their } \\
\text { instructors and other } \\
\text { learners using via an e- } \\
\text { mail }\end{array}$ & $\begin{array}{l}\text { Please open a web browser go to } \\
\text { your e-mail platform (e.g., Gmail, } \\
\text { Hotmail, ecs e-mail) and send an } \\
\text { e-mail with topic "test" to } \\
\text { lili.limtrairut@ecs.vue.ac.nz } \\
\text { You do not need to type any e- } \\
\text { mail content. }\end{array}$ & \\
\hline $\begin{array}{l}\text { 4. Sending a } \\
\text { short message }\end{array}$ & $\begin{array}{l}\text { Learners can } \\
\text { communicate with their } \\
\text { instructors and other } \\
\text { learners via a short } \\
\text { message }\end{array}$ & $\begin{array}{l}\text { Please send a text "test" to } \\
0279589872\end{array}$ & \\
\hline $\begin{array}{l}\text { 5. Playing a } \\
\text { recorded voice }\end{array}$ & $\begin{array}{l}\text { Learners can listen to a } \\
\text { prerecorded voice } \\
\text { which is a type of media } \\
\text { provided in the } \\
\text { application }\end{array}$ & $\begin{array}{l}\text { Please look for a "Music" icon and } \\
\text { show that you can play the sound } \\
\text { file inside }\end{array}$ & \\
\hline $\begin{array}{l}\text { 6. Playing a } \\
\text { learning video }\end{array}$ & $\begin{array}{l}\text { Learners can watch a } \\
\text { learning video which is a } \\
\text { type of media provided } \\
\text { in the application }\end{array}$ & $\begin{array}{l}\text { Please look for an icon "Videos" } \\
\text { and play a video named } \\
\text { "engineer.mov" }\end{array}$ & \\
\hline $\begin{array}{l}\text { 7. Capturing a } \\
\text { photo }\end{array}$ & $\begin{array}{l}\text { Learners can capture of } \\
\text { learning materials (e.g., } \\
\text { lecture note) for a future } \\
\text { use. }\end{array}$ & $\begin{array}{l}\text { Please capture a photo of this } \\
\text { instruction sheet and show that } \\
\text { the photo has been stored inside } \\
\text { icon "photo" }\end{array}$ & \\
\hline $\begin{array}{l}\text { 8. Managing } \\
\text { Calendar }\end{array}$ & $\begin{array}{l}\text { Learners can manage } \\
\text { their learning time, set } \\
\text { an assignment due date } \\
\text { reminder, or make a } \\
\text { notification. }\end{array}$ & $\begin{array}{l}\text { Please look for a "Calendar" icon } \\
\text { and create an event name "test" } \\
\text { on today date. }\end{array}$ & \\
\hline
\end{tabular}




\section{Post-Questionnaire}

This post-questionnaire measures your engagement toward the mobile learning application. Please $\checkmark$ in the given box that indicates how much you agree with the given statements.

\begin{tabular}{|c|c|c|c|c|c|}
\hline Questions & $\begin{array}{l}\text { Strongly } \\
\text { Disagree }\end{array}$ & Disagree & $\begin{array}{c}\text { No } \\
\text { Opinion } \\
\end{array}$ & Agree & $\begin{array}{c}\text { Strongly } \\
\text { Agree }\end{array}$ \\
\hline 1. I lost myself in this m-learning application & & & & & \\
\hline 2. I was involved in my learning tasks that I lost track of time & & & & & \\
\hline $\begin{array}{l}\text { 3. I blocked out things around me when I was learning on this m- } \\
\text { learning application }\end{array}$ & & & & & \\
\hline $\begin{array}{l}\text { 4. When I was learning in this m-learning application, I lost track } \\
\text { of the world around me }\end{array}$ & & & & & \\
\hline 5. The time I spent learning just slipped away & & & & & \\
\hline 6. I was absorbed in my learning task & & & & & \\
\hline 7. During this learning experience I let myself go & & & & & \\
\hline 8. I felt frustrated while learning this m-learning application & & & & & \\
\hline 9. I found this m-learning application confusing to use & & & & & \\
\hline 10. I felt annoyed while learning this m-learning application & & & & & \\
\hline 11. I felt discourage while learning in this m-learning application & & & & & \\
\hline 12. Using this m-learning application was mentally taxing & & & & & \\
\hline 13. This learning experience was demanding & & & & & \\
\hline 14. I felt in control of my learning experience & & & & & \\
\hline $\begin{array}{l}\text { 15. I could not do some of the things I needed to do on this m- } \\
\text { learning application }\end{array}$ & & & & & \\
\hline 16. This m-learning application is attractive & & & & & \\
\hline 17. This m-learning application was aesthetically appealing & & & & & \\
\hline $\begin{array}{l}\text { 18. I like the graphics and image used on this m-learning } \\
\text { application }\end{array}$ & & & & & \\
\hline 19.The m-learning application appealed to my visual sense & & & & & \\
\hline $\begin{array}{l}\text { 20. The screen layout of this m-learning application was visually } \\
\text { pleasing }\end{array}$ & & & & & \\
\hline 21. Learning on this m-learning application was worthwhile & & & & & \\
\hline 22. I consider my learning experience a success & & & & & \\
\hline $\begin{array}{l}\text { 23. This learning experience did not work out the way I had } \\
\text { planed }\end{array}$ & & & & & \\
\hline 24. My learning experience was rewarding & & & & & \\
\hline $\begin{array}{l}25 . \text { I would recommended learning on this m-learning application } \\
\text { to my friends }\end{array}$ & & & & & \\
\hline $\begin{array}{l}\text { 26. I continue to learn on this m-learning application out of } \\
\text { curiosity }\end{array}$ & & & & & \\
\hline 27. The content of the m-learning application incited my curiosity & & & & & \\
\hline 28. I felt interested in my learning tasks & & & & & \\
\hline 29. I was really drawn in my learning tasks & & & & & \\
\hline 30. I felt involved in these learning tasks & & & & & \\
\hline 31. This learning experience was fun & & & & & \\
\hline
\end{tabular}




\section{Bibliography}

[1] AdKINS, S. The 2012-2017 worldwide mobile learning market. "http: / /www . ambientinsight. com", 2013 (accessed August 14 2017).

[2] ALDRICH, C. Simulations and the future of learning: An innovative (and perhaps revolutionary) approach to e-learning. John Wiley \& Sons, 2003.

[3] Alessi, S. M., AND Trollip, S. R. Multimedia for learning: Methods and development. Allyn \& Bacon, Inc., 2000.

[4] Alexander, B. Teaching in the wireless cloud, 2003.

[5] Alghamdi, E., Yunus, F., And Househ, M. S. The impact of mobile phone screen size on user comprehension of health information. In ICIMTH (2013), pp. 154-156.

[6] ALLY, M. Foundations of educational theory for online learning. Theory and practice of online learning 2 (2004), 15-44.

[7] Alonso, F., López, G., Manrique, D., And Viñes, J. M. An instructional model for web-based e-learning education with a blended learning process approach. British Journal of educational technology 36, 2 (2005), 217-235.

[8] Astin, A. W. Student involvement: A developmental theory for higher education. Journal of college student personnel 25, 4 (1984), 297308. 
[9] Attewell, J. From research and development to mobile learning: Tools for education and training providers and their learners. In 4 th World Conference on mLearning (2005), pp. 1-6.

[10] Attewell, J., AND Webster, T. Engaging and supporting mobile learners. Mobile learning anytime everywhere: A book of papers from mLearn 2004 (2005), 15-19.

[11] Attfield, S., Kazai, G., Lalmas, M., And Piwowarski, B. Towards a science of user engagement (position paper). In WSDM Workshop on User Modelling for Web Applications (2011).

[12] BANDURA, A. Social-learning theory of identificatory processes. Handbook of socialization theory and research 213 (1969), 262.

[13] BARKI, H., AND HARTWICK, J. Rethinking the concept of user involvement. MIS quarterly (1989), 53-63.

[14] Benson, R., and Samarawickrema, G. Addressing the context of e-learning: using transactional distance theory to inform design. Distance Education 30, 1 (2009), 5-21.

[15] Berge, Z. L., AND MuilenburG, L. Handbook of mobile learning. Routledge, 2013.

[16] Bischoff, W. R., BisCONER, S. W., KOOKER, B. M., AND WOOdS, L. C. Transactional distance and interactive television in the distance education of health professionals. American Journal of Distance Education 10, 3 (1996), 4-19.

[17] BROWN, T. H. The role of m-learning in the future of e-learning in africa. In 21st ICDE World Conference (2003), vol. 110, pp. 122-137.

[18] Bulger, M. E., Mayer, R. E., Almeroth, K. C., And Blau, $\mathrm{S}$. D. Measuring learner engagement in computer-equipped college 
classrooms. Journal of Educational Multimedia and Hypermedia 17, 2 (2008), 129-143.

[19] Bunker, E., Gayol, Y., NTI, N., AND Reidell, P. A study of transactional distance in an international audioconferencing course. Technology and Teacher Education Annual (1996), 40-44.

[20] Calvo, R., Iglesias, A., And Moreno, L. User-centered requirement engineering for accessible chats in m-learning. $j$-jucs 20, 6 (2014), 964-985.

[21] Carini, R. M., Kuh, G. D., AND KLein, S. P. Student engagement and student learning: Testing the linkages*. Research in Higher Education 47, 1 (2006), 1-32.

[22] Cercone, K. Characteristics of adult learners with implications for online learning design. AACE journal 16, 2 (2008), 137-159.

[23] Chae, M., AND KIM, J. Do size and structure matter to mobile users? an empirical study of the effects of screen size, information structure, and task complexity on user activities with standard web phones. Behaviour \& information technology 23, 3 (2004), 165-181.

[24] CHEN, Y.-J. Dimensions of transactional distance in the world wide web learning environment: a factor analysis. British Journal of Educational Technology 32, 4 (2001), 459-470.

[25] CHEN, Y.-J. Transactional distance in world wide web learning environments. Innovations in Education and Teaching International 38, 4 (2001), 327-338.

[26] Chen, Y.-J., AND Willits, F. K. A path analysis of the concepts in moore's theory of transactional distance in a videoconferencing learning environment. International Journal of E-Learning $\mathcal{E}$ Distance Education 13, 2 (2007), 51-65. 
[27] Chittaro, L. Visualizing information on mobile devices. Computer 39,3 (2006), 40-45.

[28] Clark, R. C., AND MAYer, R. E. E-learning and the science of instruction: Proven guidelines for consumers and designers of multimedia learning. John Wiley \& Sons, 2016.

[29] Clarke, T., Ayres, P., AND Sweller, J. The impact of sequencing and prior knowledge on learning mathematics through spreadsheet applications. Educational Technology Research and Development 53, 3 (2005), 15-24.

[30] Cochrane, T., And BAteman, R. Smartphones give you wings: Pedagogical affordances of mobile web 2.0. Australasian Journal of Educational Technology 26, 1 (2010).

[31] Compeau, D. R., And Higgins, C. A. Computer self-efficacy: Development of a measure and initial test. MIS quarterly (1995), 189211.

[32] COOPER, A., ET AL. The inmates are running the asylum:[why hightech products drive us crazy and how to restore the sanity](vol. 261). Sams Indianapolis (1999).

[33] Corbeil, J. R., And VAldes-Corbeil, M. E. Are you ready for mobile learning? Educause Quarterly 30, 2 (2007), 51.

[34] CROMPTON, H. A historical overview of mobile learning: Toward learner-centered education. Handbook of mobile learning (2013), 3-14.

[35] DAFT, R. L., AND LENGEL, R. H. Information richness. a new approach to managerial behavior and organization design. Tech. rep., Texas A and M Univ College Station Coll of Business Administration, 1983. 
[36] Dermitzaki, I., Stavroussi, P., Vavougios, D., And Kotsis, K. T. Adaptation of the students' motivation towards science learning (smtsl) questionnaire in the greek language. European journal of psychology of education 28, 3 (2013), 747-766.

[37] Dix, A. Human-computer interaction. In Encyclopedia of database systems. Springer, 2009, pp. 1327-1331.

[38] Ellis, R. A., Ginns, P., And Piggott, L. E-learning in higher education: some key aspects and their relationship to approaches to study. Higher Education Research \& Development 28, 3 (2009), 303-318.

[39] Engeström, Y., Miettinen, R., And PunamäKI, R.-L. Perspectives on activity theory. Cambridge University Press, 1999.

[40] Ertl, B., Winkler, K., And Mandle, H. E'learing: Trends and future development. In Advances in computer-supported learning. IGI Global, 2007, pp. 122-144.

[41] Evans, C. The effectiveness of m-learning in the form of podcast revision lectures in higher education. Computers $\mathcal{E}$ education 50, 2 (2008), 491-498.

[42] FernáNdez-LóPez, Á., RodríGuez-FóRtiz, M. J., RodríGuez-Almendros, M. L., AND MartíNez-SEgura, M. J. Mobile learning technology based on ios devices to support students with special education needs. Computers $\mathcal{E}$ Education 61 (2013), 77-90.

[43] Florida International University. 5 apps to help you through the semester. "https://news.fiu.edu/2013/01/ 5-apps-to-help-you-through-the-semester/50363", 2013 (accessed December 13 2017). 
[44] FOOT, K. A. Cultural-historical activity theory: Exploring a theory to inform practice and research. Journal of Human Behavior in the Social Environment 24, 3 (2014), 329-347.

[45] FOWLER, J., AND NOyEs, J. Are there health risks for teenagers using mobile phones? a study of phone use amongst 14-18 year olds. In Occupational Safety and Hygiene V: Proceedings of the International Symposium on Occupational Safety and Hygiene (SHO 2017), April 10-11, 2017, Guimarães, Portugal (2017), CRC Press, p. 59.

[46] Georgiev, T., Georgieva, E., And Smrikarov, A. M-learninga new stage of ĐTु-learning. In International conference on computer systems and technologies-CompSysTech (2004), vol. 4, pp. 1-4.

[47] GOdWIN-JONES, R. Emerging technologies: Mobile apps for language learning. Language Learning $\mathcal{E}$ Technology 15, 2 (2011), 211.

[48] Gong, J., AND TARASEWICH, P. Guidelines for handheld mobile device interface design. In Proceedings of DSI 2004 Annual Meeting (2004), pp. 3751-3756.

[49] GORSKY, P., AND CASPI, A. A critical analysis of transactional distance theory. The Quarterly Review of Distance Education 6, 1 (2005), 1-11.

[50] Guri-Rosenblit, S. Distance education and e-learning: Not the same thing. Higher education 49, 4 (2005), 467-493.

[51] HaRASIM, L. A history of e-learning: Shift happened. In The international handbook of virtual learning environments. Springer, 2006, pp. 59-94.

[52] Hinze, A., Vanderschantz, N., Timpany, C., Cunningham, S. J., SARAVANI, S.-J., AND WILKINSON, C. Use of mobile apps for teaching and research. 
[53] Holec, H. Autonomy and Foreign Language Learning. ERIC, 1979.

[54] Hoppe, H. U., Joiner, R., Milrad, M., and Sharples, M. Guest editorial: Wireless and mobile technologies in education. Journal of computer assisted Learning 19, 3 (2003), 255-259.

[55] HoY, M. B. Moocs 101: an introduction to massive open online courses. Medical reference services quarterly 33, 1 (2014), 85-91.

[56] Hsu, M.-H., AND CHIU, C.-M. Internet self-efficacy and electronic service acceptance. Decision support systems 38, 3 (2004), 369-381.

[57] Humphry, J. Homeless and Connected: Mobile phones and the Internet in the lives of homeless Australians. 2014.

[58] HwanG, M. I., AND ThorN, R. G. The effect of user engagement on system success: a meta-analytical integration of research findings. Information \& Management 35, 4 (1999), 229-236.

[59] IDOUghI, D., SEFFAH, A., AND KOLSKI, C. Adding user experience into the interactive service design loop: a persona-based approach. Behaviour \& Information Technology 31, 3 (2012), 287-303.

[60] JACOB, S. M., AND ISSAC, B. The mobile devices and its mobile learning usage analysis. arXiv preprint arXiv:1410.4375 (2014).

[61] Jones, M., AND MARSDEN, G. Mobile interaction design.

[62] Kaitali, M., OzKaya, A., Altun, H., Haddad, H., And Alier, M. Designing a secure exam management system (sems) for mlearning environments. IEEE Transactions on Learning Technologies 9, 3 (2016), 258-271.

[63] KANG, H., AND GYORKE, A. S. Rethinking distance learning activities: A comparison of transactional distance theory and activity theory. Open Learning 23, 3 (2008), 203-214. 
[64] KAUR, R., AND SIDHU, G. Learner autonomy via asynchronous online interactions: a malaysian perspective. International Journal of Education and Development using ICT 6, 3 (2010), 88-100.

[65] Klopfer, E., Squire, K., And Jenkins, H. Environmental detectives: Pdas as a window into a virtual simulated world. In Wireless and Mobile Technologies in Education, 2002. Proceedings. IEEE International Workshop on (2002), IEEE, pp. 95-98.

[66] KNOWLES, M. S., ET AL. The modern practice of adult education, vol. 41. New York Association Press New York, 1970.

[67] Kop, R. The challenges to connectivist learning on open online networks: Learning experiences during a massive open online course. The International Review Of Research In Open And Distributed Learning 12, 3 (2011), 19-38.

[68] KRAUSE, K. Understanding and promoting student engagement in university learning communities. Paper presented as keynote address: Engaged, Inert or Otherwise Occupied (2005).

[69] KuH, G. D. The national survey of student engagement: Conceptual framework and overview of psychometric properties. Bloomington, IN: Indiana University Center for Postsecondary Research (2001), 1-26.

[70] KuUtTI, K. Activity theory as a potential framework for humancomputer interaction research. Context and consciousness: Activity theory and human-computer interaction 1744 (1996).

[71] Lehmann, J., Lalmas, M., Yom-Tov, E., And Dupret, G. Models of user engagement. In User Modeling, Adaptation, and Personalization. Springer, 2012, pp. 164-175. 
[72] Lehner, F., And Nosekabel, H. The role of mobile devices in elearning first experiences with a wireless e-learning environment. In Wireless and Mobile Technologies in Education, 2002. Proceedings. IEEE International Workshop on (2002), IEEE, pp. 103-106.

[73] Liaw, S.-S., Hatala, M., AND HuANG, H.-M. Investigating acceptance toward mobile learning to assist individual knowledge management: Based on activity theory approach. Computers $\mathcal{E}$ Education 54, 2 (2010), 446-454.

[74] LiAW, S.-S., AND HuANG, H.-M. A case of study of investigating users' acceptance toward mobile learning. In Recent progress in data engineering and internet technology. Springer, 2012, pp. 299-305.

[75] Limtrairut, P., Marshall, S., And Andreae, P. Know the mobile learning application users-transactional distance perspective. In CSEDU (2) (2016), pp. 378-387.

[76] Limtrairut, P., Marshall, S., And Andreae, P. Mobile learning application for computer science students: A transactional distance perspective. In Proceedings of the 2016 ACM Conference on International Computing Education Research (2016), ACM, pp. 285-286.

[77] LitTLE, D. Learner autonomy and second/foreign language learning. Guide to Good Practice (2003).

[78] LitTlewood, W. âĂIJautonomyâĂ İ: An anatomy and a framework. System 24, 4 (1996), 427-435.

[79] LiU, H., XIE, X., MA, W.-Y., AND ZhANG, H.-J. Automatic browsing of large pictures on mobile devices. In Proceedings of the eleventh ACM international conference on Multimedia (2003), ACM, pp. 148-155. 
[80] LIU, Y., HAN, S., AND LI, H. Understanding the factors driving m-learning adoption: a literature review. Campus-Wide Information Systems 27, 4 (2010), 210-226.

[81] LOHNARI, T. Mobile learning: Revolutionizing education. International Journal of Engineering Research and General Science 4, 3 (2016).

[82] Lönn, S., Ahlbom, A., Hall, P., And Feychting, M. Mobile phone use and the risk of acoustic neuroma. Epidemiology 15, 6 (2004), 653-659.

[83] LOW, L., AND OÂĂŹCONNELL, M. Learner-centric design of digital mobile learning. In Proceedings of the OLT Conference (2006), pp. 71-82.

[84] LOWRY, C. M. Supporting and facilitating self-directed learning. eric digest no. 93 .

[85] Malone, T. W., AND Lepper, M. R. Making learning fun: A taxonomy of intrinsic motivations for learning. Aptitude, learning, and instruction 3, 1987 (1987), 223-253.

[86] Manuguerra, M., And Petocz, P. Promoting student engagement by integrating new technology into tertiary education: The role of the ipad. Asian Social Science 7, 11 (2011), 61.

[87] Merriam, S. Caffarella (1991, 1998) learning in adulthood. a comprehensive guide.

[88] Mezirow, J. Transformative learning: Theory to practice. New directions for adult and continuing education 1997, 74 (1997), 5-12.

[89] Moore, M. The individual adult learner. Education for adults, Adult learning and education 1 (1983), 153-168. 
[90] MoOre, M. G. Learner autonomy: The second dimension of independent learning. Convergence 5, 2 (1972), 76.

[91] Moore, M. G. Toward a theory of independent learning and teaching. The Journal of Higher Education 44, 9 (1973), 661-679.

[92] MoOre, M. G. Independent study. Redefining the discipline of adult education 5 (1980), 16-31.

[93] MoOre, M. G. Theory of transactional distance. Theoretical principles of distance education 1 (1993), 22-38.

[94] Moore, M. G. Handbook of distance education. Routledge, 2013.

[95] Moore, M. G., And Kearsley, G. Distance education: A systems view of online learning. Cengage Learning, 2011.

[96] Muntean, C. I. Raising engagement in e-learning through gamification. In Proc. 6th International Conference on Virtual Learning ICVL (2011), no. 42, pp. 323-329.

[97] NiELSEN, J. 10 usability heuristics for user interface design. Fremont: Nielsen Norman Group.[Consult. 20 maio 2014]. Disponível na Internet (1995).

[98] Nielsen, J., AND MOlich, R. Heuristic evaluation of user interfaces. In Proceedings of the SIGCHI conference on Human factors in computing systems (1990), ACM, pp. 249-256.

[99] Norman, D. The Psychology of Everyday Things. Basic Books, 1988.

[100] O'BRIEN, H. L., AND TOMS, E. G. What is user engagement? a conceptual framework for defining user engagement with technology. Journal of the American Society for Information Science and Technology 59, 6 (2008), 938-955. 
[101] O'BRIEN, H. L., AND TOMS, E. G. The development and evaluation of a survey to measure user engagement. Journal of the American Society for Information Science and Technology 61, 1 (2010), 50-69.

[102] O’Malley, C., Vavoula, G., Glew, J., Taylor, J., Sharples, M., AND LEFRERE, P. Guidelines for learning/teaching/tutoring in a mobile environment. mobilearn project deliverable. Retrieved March 24 (2003), 2013.

[103] PARK, Y. A pedagogical framework for mobile learning: Categorizing educational applications of mobile technologies into four types. The International Review of Research in Open and Distributed Learning 12, 2 (2011), 78-102.

[104] Parsons, D., RYu, H., and Cranshaw, M. A study of design requirements for mobile learning environments. In Advanced Learning Technologies, 2006. Sixth International Conference on (2006), IEEE, pp. 96-100.

[105] PERKINS, D. Smart schools: From training memories to educating minds. Simon and Schuster, 2008.

[106] PERRY, D. Handheld computers in schools.

[107] Peters, K. Learning on the move: Mobile technologies in business and education. Flexible Learning Advisory Group, 2005.

[108] Petrova, K. Mobile learning using sms: A mobile business application. In Proceedings for the 18th Annual Conference of the National Advisory Committee on Computing Qualifications. July (2005), pp. 10-13.

[109] Pontius, J. L., AND Harper, S. R. Principles for good practice in graduate and professional student engagement. New Directions for Student Services 2006, 115 (2006), 47-58. 
[110] PozzI, F. The impact of m-learning in school contexts: An âĂIJinclusiveâĂİ perspective. Universal access in human-computer interaction. applications and services (2007), 748-755.

[111] PRUITT, J., AND AdLIN, T. The persona lifecycle: keeping people in mind throughout product design. Morgan Kaufmann, 2010.

[112] RAHIM, W. A., ISA, W. M., LOKMAN, A. M., TAHARIM, N. F., AND WAHID, N. D. Engineering m-learning using agile user-centered design. In Next Generation Mobile Apps, Services and Technologies (NGMAST), 2014 Eighth International Conference on (2014), IEEE, pp. 60-65.

[113] Reeves, T. C., Benson, L., Elliott, D., Grant, M., Holschuh, D., KIM, B., KIM, H., LAUber, E., AND LOH, S. Usability and instructional design heuristics for e-learning evaluation.

[114] Reimagine Education. It's pedagogy go with location-based mobile learning at the university of south australia. "http:// www.reimagine-education.com/", 2017 (accessed December 13 2017).

[115] Repacholi, M. H. Health risks from the use of mobile phones. Toxicology letters 120, 1 (2001), 323-331.

[116] Research New Zealand. A report on a survey of new zealanders' use of smartphones and other mobile communication devices 2015. "http://www.researchnz.com/pdf/SpecialReports/ ResearchNewZealandSpecialReport-UseofSmartphones. pdf", 2015 (accessed June 30 2017).

[117] Rice, E., LeE, A., AND TAITT, S. Cell phone use among homeless youth: potential for new health interventions and research. Journal of Urban Health 88, 6 (2011), 1175-1182. 
[118] RocA, J. C., CHIU, C.-M., And Martínez, F. J. Understanding e-learning continuance intention: An extension of the technology acceptance model. International Journal of human-computer studies 64 , 8 (2006), 683-696.

[119] Rosenfield, D., Folger, R., AND Adelman, H. F. When rewards reflect competence: A qualification of the overjustification effect. Journal of Personality and Social Psychology 39, 3 (1980), 368.

[120] RYAN, R. M., AND DECI, E. L. Intrinsic and extrinsic motivations: Classic definitions and new directions. Contemporary educational psychology 25, 1 (2000), 54-67.

[121] SABA, F., AND SHEARER, R. L. Verifying key theoretical concepts in a dynamic model of distance education. American Journal of Distance Education 8, 1 (1994), 36-59.

[122] SCHNOTZ, W., AND RASCH, T. Enabling, facilitating, and inhibiting effects of animations in multimedia learning: Why reduction of cognitive load can have negative results on learning. Educational Technology Research and Development 53, 3 (2005), 47-58.

[123] SchwABE, G., AND GÖTH, C. Mobile learning with a mobile game: design and motivational effects. Journal of computer assisted learning 21, 3 (2005), 204-216.

[124] Sharples, M., AND SPIKOL, D. Mobile learning. In Technology enhanced learning. Springer, 2017, pp. 89-96.

[125] Sharples, M., TAYlor, J., AND VAVOula, G. Towards a theory of mobile learning. In Proceedings of mLearn (2005), vol. 1, pp. 1-9.

[126] SHNEIDERMAN, B. Designing the user interface: strategies for effective human-computer interaction. Pearson Education India, 2010. 
[127] Shudong, W., AND Higgins, M. Limitations of mobile phone learning. In Wireless and Mobile Technologies in Education, 2005. WMTE 2005. IEEE International Workshop on (2005), IEEE, pp. 3-pp.

[128] SKiadA, R., Soroniati, E., GArdeli, A., AND Zissis, D. Easylexia: A mobile application for children with learning difficulties. Procedia Computer Science 27 (2014), 218-228.

[129] SMITH, T. Personal digital assistants (pdas) in further and higher education. TechLearn Briefing (2003).

[130] SMURA, T., KIVI, A., AND TÖYLI, J. A framework for analysing the usage of mobile services. info 11, 4 (2009), 53-67.

[131] StANFORd Universit. Stanford mobile. "https://ucomm. stanford.edu/mobi leapp/", 2017 (accessed December 13 2017).

[132] Suhag, A., LARIK, R., MAngi, G., Khan, M., Abbasi, S., et Al. Impact of excessive mobile phone usage on human. J Comput Sci Syst Biol 9 (2016), 173-177.

[133] Sun, P.-C., AND CHENG, H. K. The design of instructional multimedia in e-learning: A media richness theory-based approach. Computers $\mathcal{E}$ education 49, 3 (2007), 662-676.

[134] Sweller, J., VAn Merrienboer, J. J., And PaAs, F. G. Cognitive architecture and instructional design. Educational psychology review 10, 3 (1998), 251-296.

[135] ThoméE, S., HÄrenstam, A., And Hagberg, M. Mobile phone use and stress, sleep disturbances, and symptoms of depression among young adults-a prospective cohort study. BMC public health 11, 1 (2011), 66. 
[136] TRaXLER, J. Defining, discussing and evaluating mobile learning: The moving finger writes and having writ.... The International Review of Research in Open and Distributed Learning 8, 2 (2007).

[137] TuAN*, H.-L., ChIN, C.-C., AND SHIEH, S.-H. The development of a questionnaire to measure students' motivation towards science learning. International Journal of Science Education 27, 6 (2005), 639654 .

[138] United NATIONS. The millennium development goals report 2015. "http: / /www .un.org/millenniumgoals/2015MDGReport/

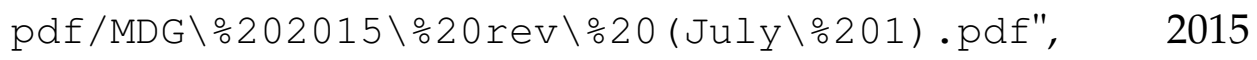
(accessed June 30 2017).

[139] Vavoula, G. N., AND Sharples, M. Kleos: A personal, mobile, knowledge and learning organisation system. In Wireless and Mobile Technologies in Education, 2002. Proceedings. IEEE International Workshop on (2002), IEEE, pp. 152-156.

[140] WaycotT, J., Jones, A., AND Scanlon, E. Pdas as lifelong learning tools: an activity theory based analysis. Learning, Media and Technology 30, 2 (2005), 107-130.

[141] Webster, J., AND Ho, H. Audience engagement in multimedia presentations. ACM SIGMIS Database 28, 2 (1997), 63-77.

[142] WRIGHT, P. Editing: policies and processes. Designing usable texts (1985), 63-96.

[143] Yáñez Gómez, R., CASCAdo Caballero, D., AND Sevillano, J.-L. Heuristic evaluation on mobile interfaces: a new checklist. The Scientific World Journal 2014 (2014).

[144] ZHANG, A. M. Transactional distance in web-based college learning environments: Toward measurement and theory construction. Virginia Commonwealth University, 2003. 